MACIEL MANOEL DE QUEIROZ

A CADEIA DE PETRÓLEO NO BRASIL: O CASO DA INDÚSTRIA DE APOIO MARÍTIMO

São Paulo

2017 
ESCOLA POLITÉCNICA DA UNIVERSIDADE DE SÃO PAULO

MACIEL MANOEL DE QUEIROZ

A CADEIA DE PETRÓLEO NO BRASIL: O CASO DA INDÚSTRIA DE APOIO MARÍTIMO

São Paulo

2017 


\title{
A CADEIA DE PETRÓLEO NO BRASIL: O CASO DA INDÚSTRIA DE APOIO MARÍTIMO
}

\author{
Versão Corrigida \\ (Versão original encontra-se na unidade que aloja \\ o Programa de Pós-graduação)
}

Tese apresentada à Escola Politécnica da Universidade de São Paulo para obtenção do título de Doutor em Ciências.

Área de Concentração:

Engenharia Naval e Oceânica

Orientador:

Prof. Dr. André Bergsten Mendes

São Paulo

2017 
Este exemplar foi revisado e corrigido em relação à versão original, sob responsabilidade única do autor e com a anuência de seu orientador.

São Paulo, de de

Assinatura do autor:

Assinatura do orientador:

Catalogação-na-publicação

de Queiroz, Maciel Manoel

A cadeia de petróleo no Brasil: o caso da indústria de apoio marítimo / M.

M. de Queiroz -- versão corr. -- São Paulo, 2017.

$167 \mathrm{p}$.

Tese (Doutorado) - Escola Politécnica da Universidade de São Paulo.

Departamento de Engenharia Naval e Oceânica.

1.Indústria de Apoio Marítimo 2.Cadeia de petróleo 3.Fatores Críticos de Sucesso 4.Mapa Estratégico da Indústria I.Universidade de São Paulo.

Escola Politécnica. Departamento de Engenharia Naval e Oceânica II.t. 


\section{AGRADECIMENTOS}

Primeiramente gostaria de fazer um agradecimento especial ao meu orientador, conselheiro e amigo Prof. Dr. André Bergsten Mendes, por sempre acreditar no meu potencial e pela oportunidade, incentivo, condução e por tornar possível a concretização deste trabalho. Ao departamento PNV (Engenharia Naval e Oceânica) pela infraestrutura disponibilizada. Ao Prof. Dr. Marco Antonio Brinati pelos valiosos conhecimentos transmitidos em aula. Aos outros professores e departamentos da Poli que cursei disciplinas: Engenharia de Transportes (PTR), Engenharia de Computação e Sistemas Digitais (PCS) e Engenharia de Produção (PRO). A todos os funcionários da secretaria do $\mathrm{PNV}$, aos professores que contribuíram, direta e indiretamente para a realização desta pesquisa. Aos executivos e especialistas da indústria de apoio marítimo que se propuseram a participar da pesquisa. À Agencia Nacional do Petróleo ANP, por meio do programa PRH19-ANP (Programa de Formação de Recursos Humanos) e Petrobrás através do convênio \#6000.0079977.12.4. Aos coordenadores do PRH19-ANP. À minha família: mãe, pai, irmãos e irmãs; ao meu sogro e sogra; e à minha maravilhosa esposa Ana Catarina, pela compreensão e incentivo em todos os momentos. 
Querem que vos ensine o modo de chegar à ciência verdadeira? Aquilo que se sabe, saber que se sabe; aquilo que não se sabe, saber que não se sabe; na verdade é este o saber.

\section{Confúcio}




\section{RESUMO}

Esta pesquisa aborda a Indústria de Apoio Marítimo por meio de uma visão estratégica. Tratase de um problema relacionado à identificação e mapeamento dos Fatores Críticos de Sucesso (FCSs). A indústria de apoio marítimo é um importante segmento da cadeia de petróleo, pois, participa desde as fases iniciais, envolvendo a prospecção de um campo, até o fim da vida útil por meio da desativação dos poços de petróleo. A presente tese se propõe a analisar a indústria de apoio marítimo, caracterizando os aspectos mais importantes e impactantes, por meio da identificação dos FCSs, desenvolvimento de um framework a partir dos FCSs para a melhoria da tomada de decisão pelas empresas e também a modelagem do mapa estratégico da indústria. Por meio de entrevistas com armador, especialistas da área, dados dos sites das empresas e anuários do setor, o estudo identificou 68 FCSs. Os fatores críticos identificados foram submetidos a 28 empresas, por meio de um questionário estruturado (escala Likert de 5 pontos). As análises, por meio de estatística descritiva e testes de correlação, identificou os FCSs mais sensíveis à indústria. Além dessa contribuição, também foi proposto um framework (Matriz de Produtividade x Competitividade) para analisar a distribuição dos FCSs e o desdobramento em estratégias relacionadas a foco em melhorias urgentes, foco na inovação, foco na captação de projetos e foco na liderança do setor. Também foi modelada uma adaptação do Mapa Estratégico da Indústria da CNI para a indústria de apoio marítimo. Por fim, os principais resultados sinalizaram a sensibilidade do setor frente às variáveis relacionadas às Políticas (Industriais/Governamentais), Financiamentos e a necessidade do desenvolvimento de Inovação em toda a cadeia de suprimentos.

Palavras-chave: Fatores Críticos de Sucesso. Mapa Estratégico da Indústria. Petróleo. Transporte Marítimo. 


\begin{abstract}
This research addresses the Maritime Support Industry through a strategic vision. This is a problem related to the identification and mapping of Critical Success Factors (CSFs). The maritime support industry is an important segment of the oil chain since it participates from the early stages, involving the prospecting of a field, to the end of its useful life by deactivating the oil wells. The present thesis proposes to analyze the maritime support industry, characterizing the most important and impacting aspects, through the identification of the CSFs, development of a framework from the CSFs for the improvement of the decision making by the companies and also the modeling of the Strategic map of the industry. Through interviews with ship-owner, experts from the area, company website data and industry yearbooks, the study identified 68 CSFs. The identified critical factors were submitted to 28 companies, through a structured questionnaire (Likert scale of 5 points). The analyzes, through descriptive statistics and correlation tests, identified the most sensitive CSFs to the industry. In addition to the contribution, a framework was also proposed for the analysis of the distribution of CSFs and the focus on urgent improvements, focus on innovation, focus on project capture and focus on sector leadership. An analysis was also made of the CNI's Industry Strategic Map for the Maritime Support Industry. Finally, the main results showed a sensitivity of the sector to the variables related to policies (industrial / governmental), finance and the need to develop innovation throughout the supply chain.
\end{abstract}

Key-words: Critical Success Factors. Maritime Transportation. Petroleum. Strategic Industry Map. 


\section{LISTA DE FIGURAS}

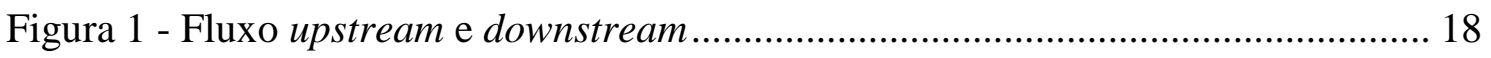

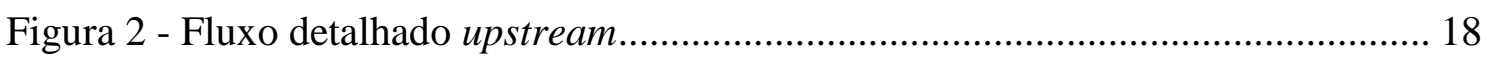

Figura 3 - Fluxo detalhado upstream, midstream e downstream................................. 19

Figura 4 - Oferta Interna de Energia no Brasil em 2015 ............................................ 25

Figura 5 - Dimensionamento de Produção pelo Pico ..................................................... 26

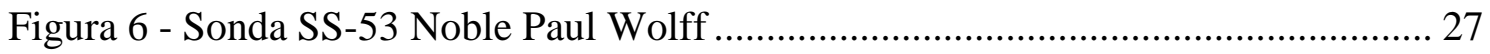

Figura 7 - Evolução dos Investimentos em PD\&I por Concessionário 2006-2015........ 30

Figura 8 - Produção de Derivados Energéticos x Não Energéticos................................ 32

Figura 9 - Terminal Aquaviário de Angra dos Reis (Tebig) ......................................... 33

Figura 10 - Evolução das Vendas no Brasil de Derivados de Petróleo 2006-2015 ........ 34

Figura 11 - Vendas dos Principais Players de Distribuição........................................... 35

Figura 12 - Preços Médios de Combustíveis ao Consumidor ......................................... 35

Figura 13 - Gráfico Preços Médios (US\$) no Mercado SPOT 2006-2015 .................... 39

Figura 14 - Principais serviços de apoio marítimo offshore …....................................... 40

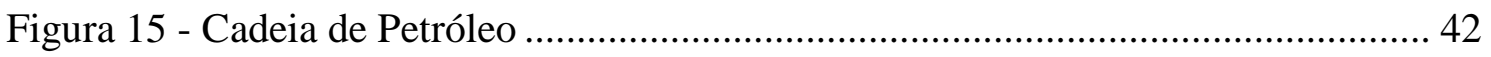

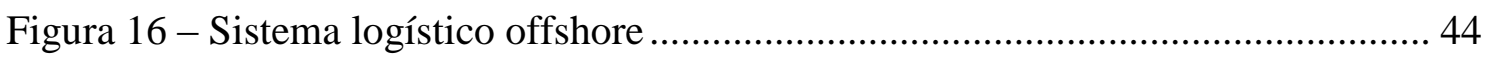

Figura 17 - Histórico do apoio marítimo no Brasil.................................................... 45

Figura 18 - Relação do preço do barril e sondas marítimas encomendadas. .................. 46

Figura 19 - Evolução da frota de apoio marítimo ......................................................... 47

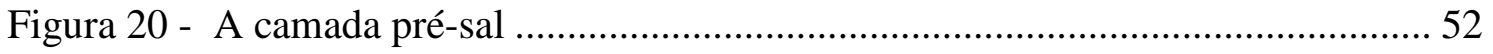

Figura 21 - Extensão potencial da camada pré-sal.................................................... 53

Figura 22 - Evolução da produção pré-sal x pós-sal (Mboe/d) ..................................... 54

Figura 23 - Mapa Estratégico da Indústria ................................................................... 56

Figura 24 - Investimento em P\&D como uma Proporção do PIB em 2010 ................... 57

Figura 25 - Investimento em P\&D como uma Proporção do PIB em 2015 .................... 58

Figura 26 - Taxa de Investimento 2003 - 2011, em \% do PIB ....................................... 60

Figura 27 - Desembolsos do BNDES em inovação 2010 - 2016 .................................. 66

Figura 28 - Exemplos de Fatores Críticos de Sucesso em diferentes indústrias ............. 67

Figura 29 - Modelo de Competitividade de Slack ........................................................... 69

Figura 30 - Variações do Estudo de Caso Único............................................................ 73

Figura 31 - Proposta para Condução do Estudo de Caso .............................................. 74

Figura 32 - Esquema dos Instrumentos de Pesquisa Utilizado...................................... 77 


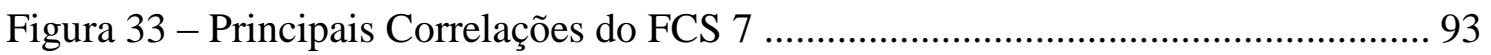

Figura 34 - Principais Correlações do FCS 47 ................................................................ 94

Figura 35 - Matriz de Produtividade x Competitividade ............................................... 96

Figura 36 - Resultado da Matriz de Produtividade x Competitividade ...................... 100

Figura 37 - Mapa Estratégico do Apoio Marítimo...................................................... 101

Figura 38 - Evolução das Rodadas de licitações 1999 - 2015 e o conteúdo local ...... 125

Figura 39 - Principais componentes para identificação do CL .................................... 126

Figura 40 - Exemplo de cálculo de CL para um bem ................................................. 127

Figura 41 - Exemplo de cálculo de CL para um sistema............................................. 127

Figura 42 - Conteúdo local não realizado ................................................................ 129 


\section{LISTA DE TABELAS}

Tabela 1 - Orçamento 2015 de Ministérios Selecionados ............................................. 21

Tabela 2 - Top 10 Produtores de Petróleo e Gás Natural em 2015 ............................... 29

Tabela 3 - Evolução da Participação Governamental e Terceiros de 2006-2015 ............ 30

Tabela 4 - Evolução da Capacidade de Refino 2006-2015 …....................................... 31

Tabela 5 - Evolução das Reservas Provadas de Petróleo 2006-2015 ............................. 36

Tabela 6 - Evolução da Produção de Petróleo 2006-2015 ................................................ 37

Tabela 7 - Consumo de Petróleo por Países Selecionados 2015 ..................................... 38

Tabela 8 - Preços Médios (US\$) no Mercado SPOT 2006-2015 .................................... 38

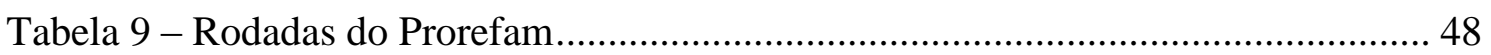

Tabela 10 - Composição da Frota de Apoio Marítimo do Brasil em 2016 ..................... 50

Tabela 11 - Classificação do Brasil no Doing Business 2017 ...................................... 62

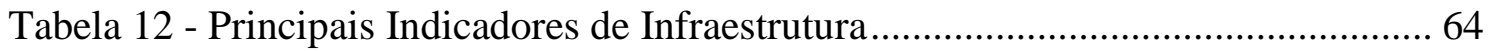

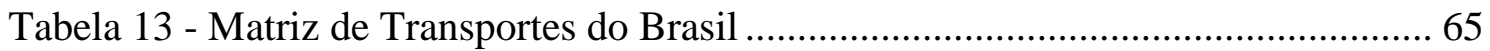

Tabela 14 - Consistência Interna de Alfa de Cronbach ................................................ 83

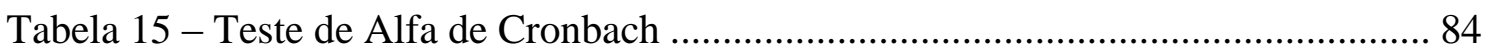

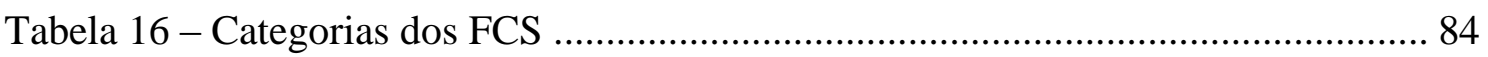

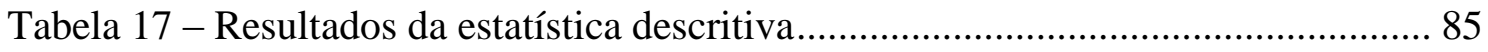

Tabela 18 - Ranking Top 20 FCS Baseado na Média................................................. 87

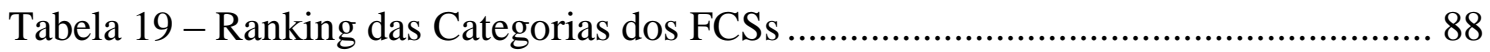

Tabela 20 - Maiores Correlações Positivas entre FCSs ................................................ 89

Tabela 21 - Mapa das Maiores Correlações Positivas entre FCSs por Dimensão .......... 90

Tabela 22 - Maiores Correlações Negativas entre FCSs ............................................. 91

Tabela 23 - Mapa das Maiores Correlações Negativas entre FCSs por Dimensão ....... 92

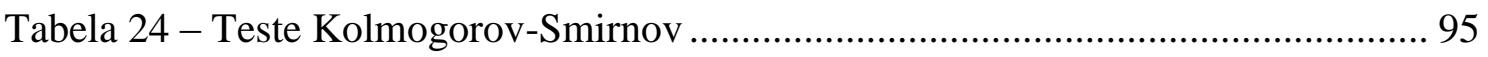

Tabela 25 - Rodadas de licitações 1999 - 2015 e o conteúdo local ............................ 125 


\section{LISTA DE QUADROS}

Quadro 1 - Tipos de Embarcações de Apoio Marítimo .................................................... 49

Quadro 2 - Exemplos de Fatores Críticos de Sucesso na Manufatura ............................ 68

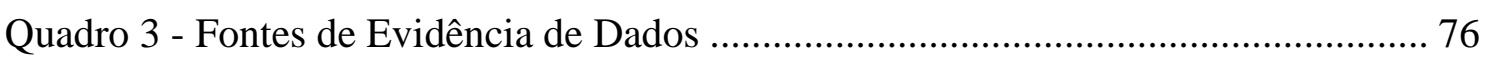

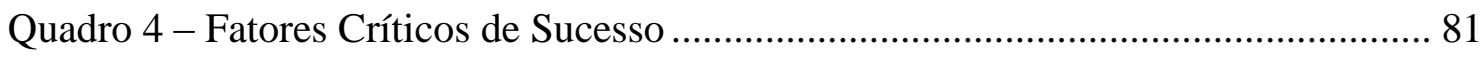

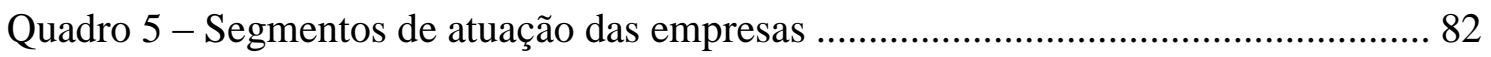

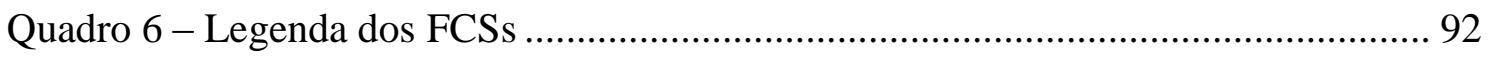

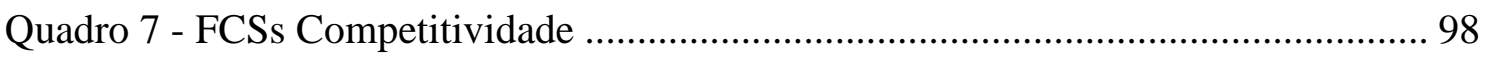

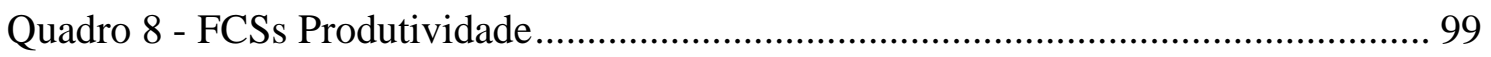

Quadro 9 - Temas e Objetivos Prioritários da Dimensão Inovação .............................. 102

Quadro 10 - Temas e Objetivos Prioritários da Dimensão Políticas (Industriais e

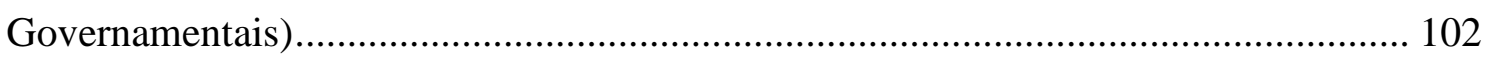

Quadro 11 - Temas e Objetivos Prioritários da Dimensão Competitividade ................ 102

Quadro 12 - Temas e Objetivos Prioritários da Dimensão Estratégias ......................... 103

Quadro 13 - Temas e Objetivos Prioritários da Dimensão Financiamentos.................. 103

Quadro 14 - Temas e Objetivos Prioritários da Dimensão Mão-de-Obra ...................... 103

Quadro 15 - Temas e Objetivos Prioritários da Dimensão Fornecedores ..................... 104

Quadro 16 - Temas e Objetivos Prioritários da Dimensão Produtividade .................... 104 


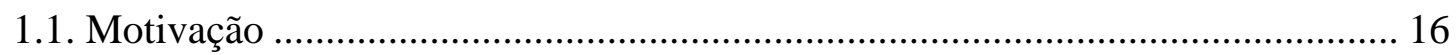

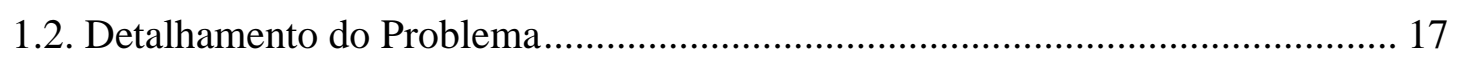

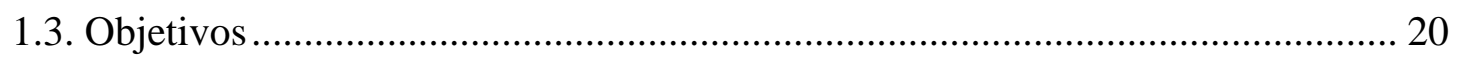

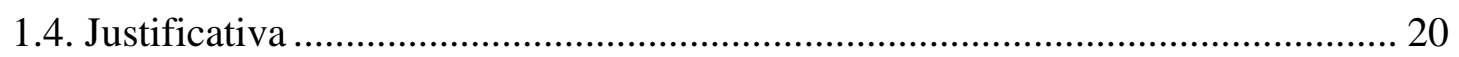

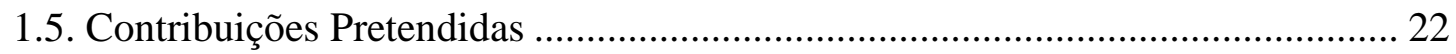

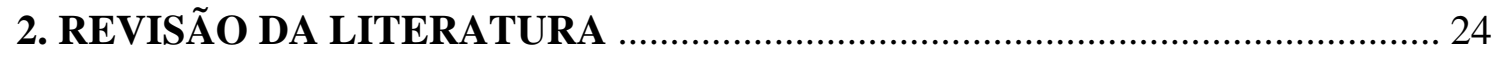

2.1. Indústria Nacional de Petróleo …………………………………………....... 24

2.1.1. Exploração e Produção (E\&P) ................................................................. 28

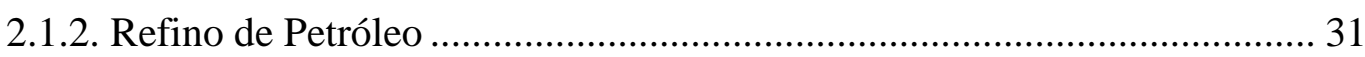

2.1.3. Comercialização e Distribuição................................................................... 33

2.2. Panorama Internacional de Petróleo .................................................................. 36

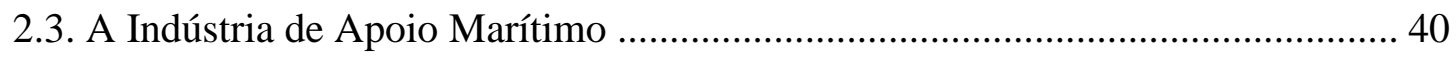

2.3.1. Complexidades da Previsão de Novos Blocos Exploratórios para o Apoio

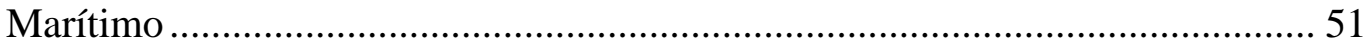

2.3.2. Os Desafios Logísticos da Exploração \& Produção do Pré-sal.................. 52

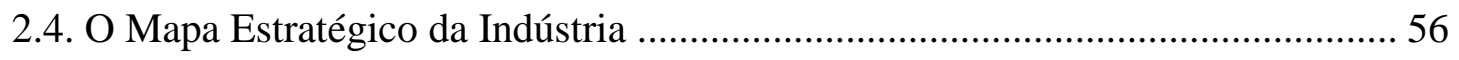

2.4.1. Dimensão Educação .............................................................................. 59

2.4.2. Dimensão Ambiente Macroeconômico ..................................................... 59

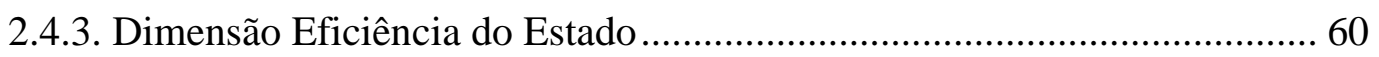

2.4.4. Dimensão Segurança Jurídica e Burocracia .............................................. 61

2.4.5. Dimensão Desenvolvimento de Mercados ............................................... 62

2.4.6. Dimensão Relações de Trabalho ............................................................... 63

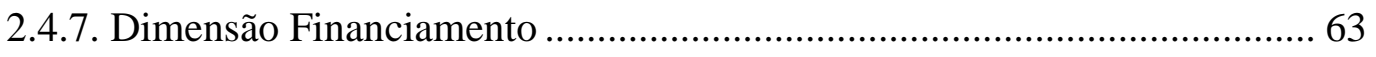

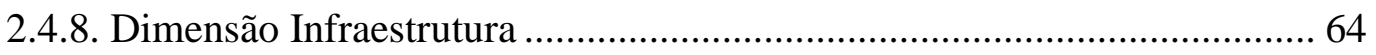

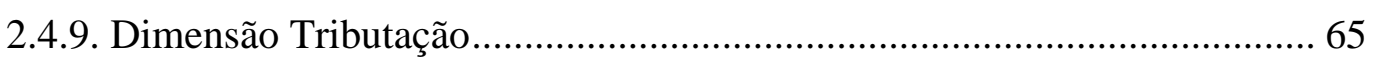

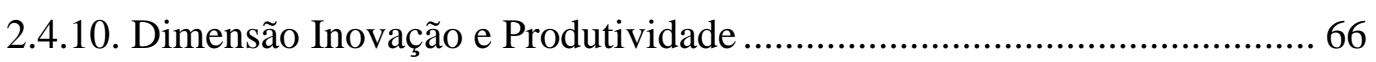

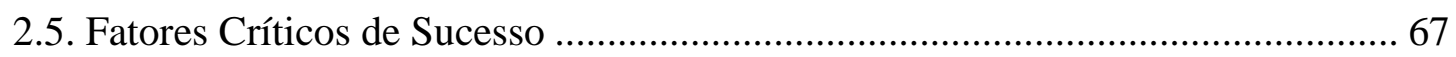

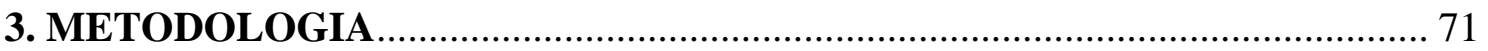

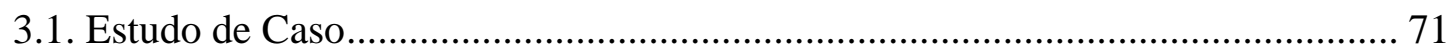

3.2. Definição da Estrutura Conceitual Teórica........................................................... 74

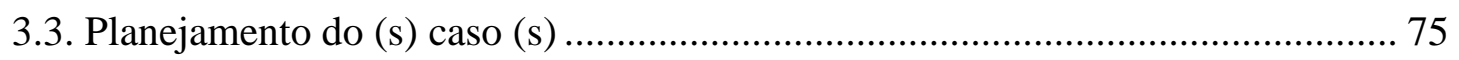

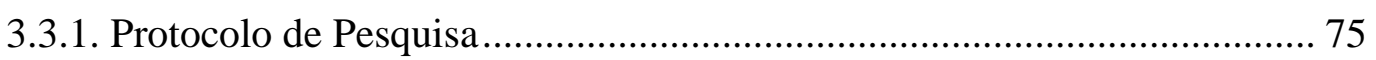

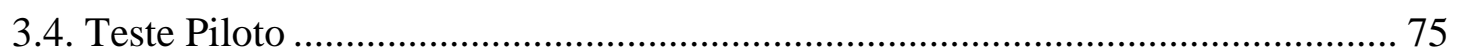

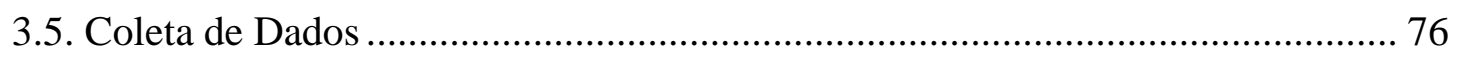

3.6. Seleção das Unidades Múltiplas de Análise …………………………………... 76 


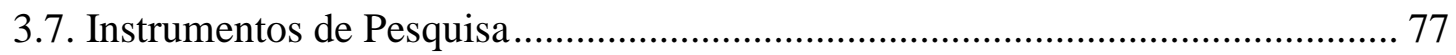

3.8. Fatores Críticos de Sucesso Identificados ............................................................ 78

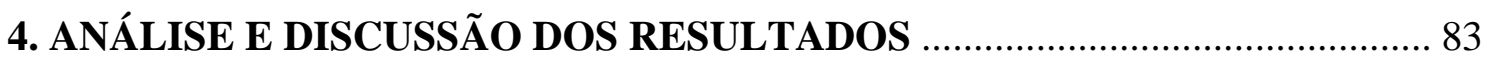

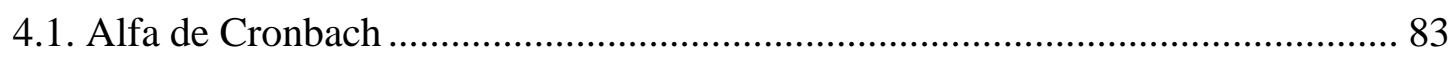

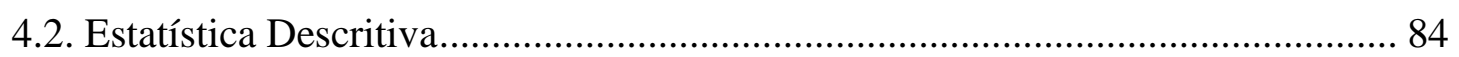

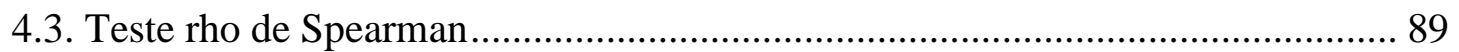

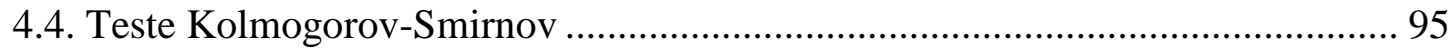

4.5. Matriz de Produtividade x Competitividade ....................................................... 96

4.6. Exemplo de Aplicação da Matriz Produtividade x Competitividade................... 97

4.7. Modelagem do Mapa Estratégico da Indústria de Apoio Marítimo ................... 101

5. CONCLUSÕES E RECOMENDAÇÕES ........................................................ 105

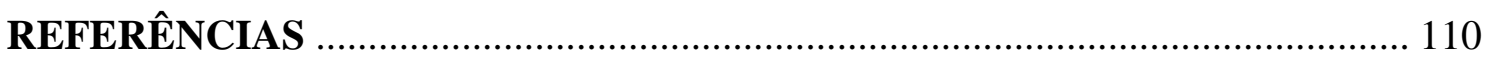

APÊNDICE A - POLÍTICA DE CONTEÚDO LOCAL ….................................... 124

APÊNDICE B - PROTOCOLO DE PESQUISA ................................................ 130

APÊNDICE C - RESULTADOS CORRELAÇÃO DE SPEARMAN (CCS) ....... 138

APÊNDICE D - PRINCIPAIS TIPOS DE EMBARCAÇÕES DE APOIO

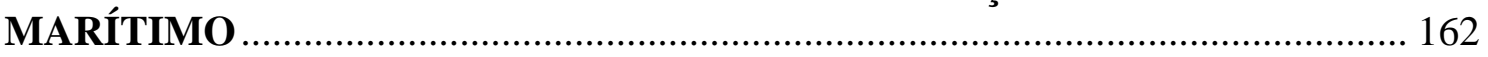




\section{INTRODUÇÃO}

Este capítulo tem por finalidade introduzir o problema abordado nesta pesquisa, intitulada A CADEIA DE PETRÓLEO NO BRASIL: O CASO DA INDÚSTRIA DE APOIO MARÍTIMO, definir os principais objetivos propostos, a relevância do tema e também as principais contribuições pretendidas, e o encaminhamento do trabalho.

A indústria de apoio marítimo consiste nas atividades de suporte à exploração de petróleo e gás, por meio de embarcações especializadas em diversos tipos de serviços (KAISER, 2015; CUESTA et al., 2017; BORCH; BATALDEN, 2014). Esta indústria é regulada pela LEI No 9.432, DE 8 DE JANEIRO DE 1997, que define em seu Art. $2^{\circ}$, Inciso VIII: "navegação de apoio marítimo: a realizada para o apoio logístico a embarcações e instalações em águas territoriais nacionais e na Zona Econômica, que atuem nas atividades de pesquisa e lavra de minerais e hidrocarbonetos". É uma área essencial em diversas fases da exploração de petróleo, o que faz com que o mercado possua diversos players, especializados em atividades como: reboque de plataformas, transporte de tripulantes, suprimentos, materiais, retirada de óleos, monitoramento ambiental, etc.

Pesquisas envolvendo a indústria de apoio marítimo não são muito comuns, porém, os estudos que já foram realizados, abordam mais na perspectiva da Pesquisa Operacional. Nestas abordagens, diversos algoritmos de otimização baseado em técnicas exatas e heurísticas são propostos, com objetivos que variam desde a programação de frota sujeita à requisição de múltiplas embarcações para uma mesma tarefa (MENDES, 2007) até minimização de penalidades pelo não atendimento das tarefas, roteirização, composição de frota etc.

Esta pesquisa aborda a Indústria de Apoio Marítimo numa perspectiva mais estratégica (PORTER, 2004), de modo que possa contribuir para a melhoria nos processos de tomada de decisão desse importante segmento do petróleo, assim como avançar no desenvolvimento da literatura que ainda é escassa.

Compreender a Indústria de Apoio Marítimo é fundamental para o desenvolvimento de políticas que impactem de forma positiva toda a cadeia de petróleo, tanto no nível operacional, quanto no estratégico. Entender também as principais variáveis que impactam a indústria de 
forma negativa, também se faz necessário. A utilização de fatores críticos de sucesso, justificase pela aderência em estudos exploratórios (ROCKART, 1979, JALONEN; LÖNNQVIST, 2011; MOURA, 2008; YEOH; POPOVIČ, 2016). Os fatores críticos de sucesso são atividades chaves de uma área, nas quais os resultados favoráveis são absolutamente necessários para atingir os objetivos de uma empresa (BULLEN; ROCKART, 1981).

Portanto, a presente pesquisa fornecerá uma compreensão holística da Indústria de Apoio Marítimo, identificando e mapeando os fatores mais impactantes e fornecendo ferramentas que aumentem a qualidade das decisões, e também otimize os processos relacionados à tomada de decisão.

\subsection{Motivação}

A Exploração e Produção de petróleo (E\&P) e gás natural em águas profundas e ultra profundas tem contribuído para que o Brasil ganhe destaque no cenário mundial. Nestes ambientes, são de fundamental importância o suporte e a operação coordenada dos serviços de apoio, tanto na fase prospectiva, quanto na fase da implantação de novos sistemas produtivos e, posteriormente, na manutenção e no escoamento da produção (MENDES, 2007).

Um dos grandes desafios das empresas envolvidas nesta indústria, é a busca pela eficiência operacional, principalmente por empregar recursos escassos como as embarcações de apoio marítimo (existem mais tarefas para serem executadas, que o tamanho da frota suporta). A política brasileira para o petróleo, ao permitir contratos com empresas estrangeiras para a exploração de novos campos na plataforma continental, incentiva não só a expansão da área de atuação da Petrobras, como a instalação de outras companhias no Brasil, aumentando sensivelmente a demanda de embarcações e equipamentos de apoio marítimo (MENDES, 2007).

A indústria de apoio marítimo, cada vez mais ganha importância no contexto das atividades de Exploração \& Produção de petróleo (E\&P). É uma área que necessita de mão de obra especializada, devido à complexidade do mercado e também por questões operacionais, como a escassez dos recursos produtivos. Entender de forma sistêmica o comportamento desta indústria é fundamental para que os players envolvidos possam oferecer cada vez mais serviços de alta qualidade, e com custos operacionais baixos. 
Esta tese foi motivada pelo fato de não existirem trabalhos que discutissem a indústria de apoio marítimo por meio de uma visão mais gerencial, e nem o mapeamento dos fatores críticos de sucesso, que são importantíssimos para a tomada de decisão. Sejam decisões associadas a investimentos de novos equipamentos, mão de obra especializada, concorrência para captação de novos projetos etc. Um dos poucos trabalhos realizados nesta área, pode ser visto em Moura (2008), que identificou os fatores críticos de sucesso da indústria marítima brasileira, considerando os segmentos da construção náutica, construção naval, construção de plataforma e reparo naval.

Portanto, oferecer contribuições para um melhor entendimento desta indústria é a principal motivação deste trabalho.

\subsection{Detalhamento do Problema}

A cadeia produtiva de petróleo é dividida em dois grupos: i) upstream e ii) downstream. O fluxo upstream corresponde às atividades de Exploração \& Produção de petróleo. Estas atividades podem ser em terra (onshore) ou em mar (offshore). O fluxo downstream é composto por atividades de escoamento, refino, transporte, distribuição e comercialização.

O foco deste trabalho é na cadeia upstream (offshore), a qual a indústria de apoio marítimo exerce um papel essencial nas atividades de Exploração \& Produção de petróleo. Conseguir um desempenho otimizado nesta fase, é fundamental, pois também acaba impactando o fluxo downstream e, por consequência, o consumidor final. A Figura 1 a seguir, destaca numa mesma perspectiva os fluxos upstream e downstream. 


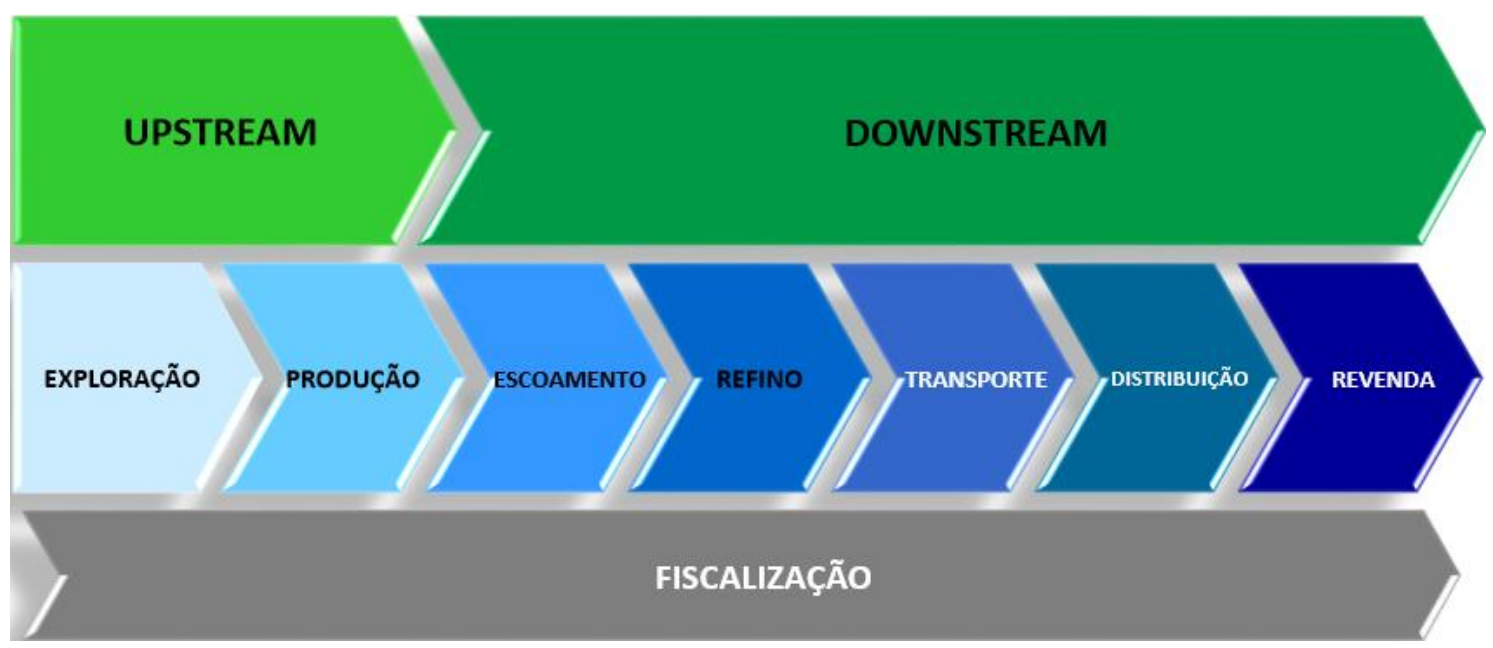

Figura 1 - Fluxo upstream e downstream

Fonte: SEBRAE RJ, 2014

As atividades de Exploração \& Produção possuem muitas complexidades, pois, demandam diversos recursos de apoio, desde as fases iniciais de prospecção de um campo potencial, até a efetiva produção. Neste contexto, existem centenas de empresas envolvidas, cada uma, especializada em um conjunto de atividades de apoio. Porém, dado que os recursos são escassos, qualquer variação no planejamento provoca consequências negativas para toda a cadeia. A Figura 2 a seguir, destaca as principais atividades do fluxo upstream.

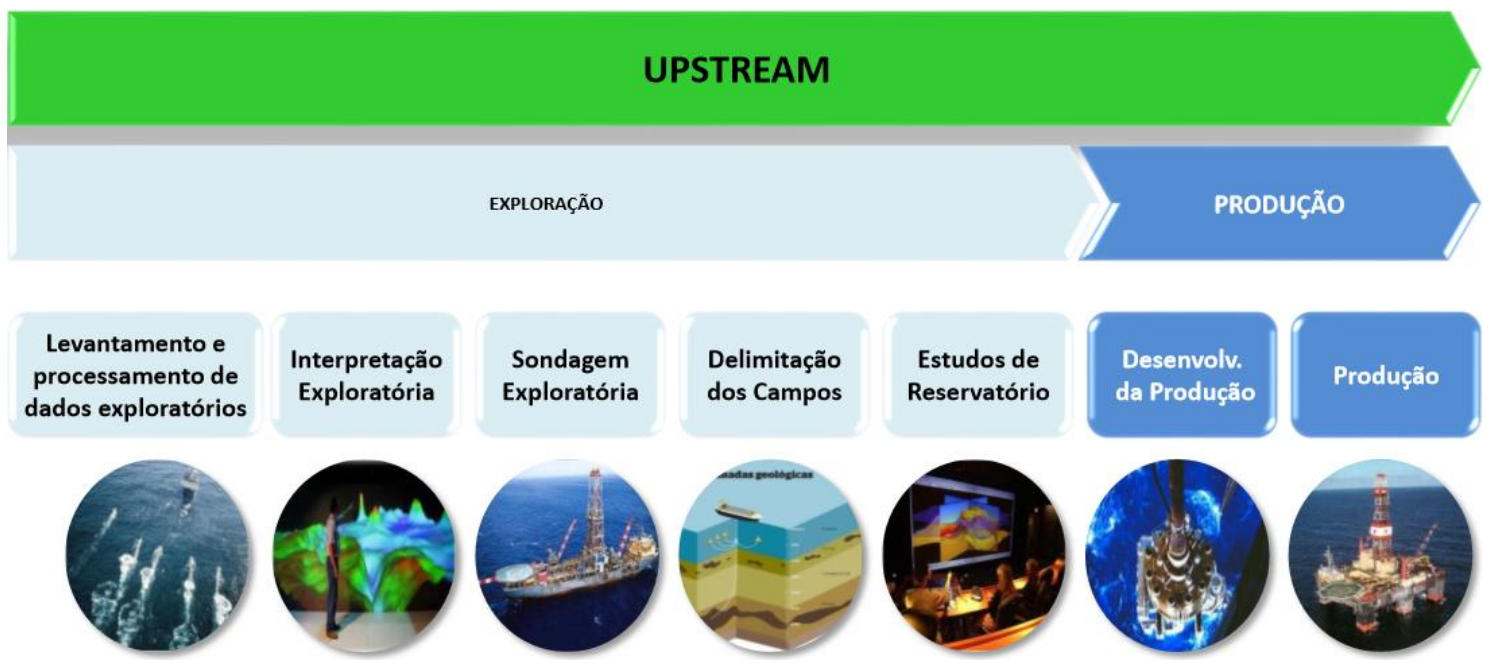

Figura 2 - Fluxo detalhado upstream Fonte: SEBRAE RJ, 2014.

Já a Figura 3 destaca os fluxos upstream e downstream, porém com a inserção do termo midstream, que segundo Ferreira Filho (2016), é um termo mais recente que é utilizado para caracterizar as atividades de compra e venda de petróleo, transporte e armazenamento. 


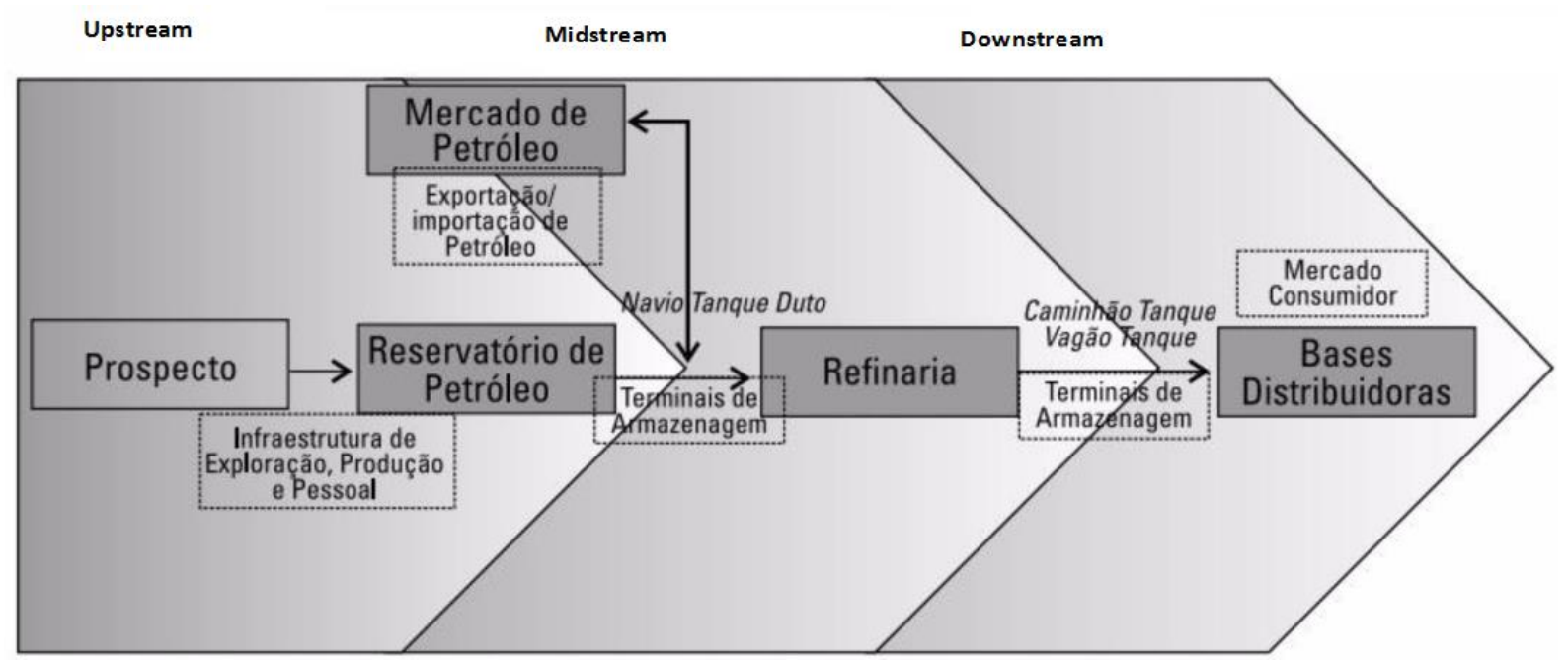

Figura 3 - Fluxo detalhado upstream, midstream e downstream

Fonte: Ferreira Filho (2016).

De acordo com Mathedi (2010) e Antaq (2012), as principais atividades de apoio marítimo são:

1. Reboque de plataformas, navios e balsas;

2. Manuseio de cabos e âncoras de plataformas;

3. Transporte de pessoal, peças, equipamentos, estruturas metálicas e contêineres;

4. Apoio a equipamentos de mergulho e atividades subaquáticas;

5. Apoio à pesquisa científica e consultoria ambiental;

6. Suporte as atividades de transporte de tripulantes, técnicos e vistoriadores via lancha;

7. Abastecimento de (cimento, tubos, lama, salmoura, água doce, óleo e granéis);

8. Implantação e reposicionamento de boias de sinalização;

9. Manutenção de boias de sinalização;

10. Levantamentos hidrográficos;

11. Retirada de óleos e resíduos nocivos;

12. Suprimento às unidades de exploração e produção de petróleo;

13. Combate ao derramamento de óleo;

14. Monitoramento ambiental;

15. Inspeção Naval;

16. Assessoria offshore;

17. (Mooring - amarração);

18. Manutenção de unidades de perfuração. 
Para que as empresas envolvidas nesta cadeia possam ser eficientes, elas dependem de outras organizações. Por exemplo, financiamento para renovação da frota, autorizações para operar, restrições de ordem jurídica etc. Somado a estes fatores, também tem-se a própria necessidade das empresas com compra de equipamentos, softwares, mão de obra qualificada, treinamentos etc. Dessa forma, a pergunta que se pretende responder nesta tese é: COMO A IDENTIFICAÇÃO DOS FATORES CRÍTICOS DE SUCESSO DA INDÚSTRIA DE APOIO MARÍTIMO PODE CONTRIBUIR PARA O SISTEMA DE TOMADA DE DECISÃO DAS EMPRESAS?

\subsection{Objetivos}

Este estudo tem como objetivo geral compreender a indústria de apoio marítimo, no contexto da cadeia de petróleo no Brasil, por meio da identificação e mapeamento dos Fatores Críticos de Sucesso (FCSs), contribuindo para o avanço da teoria da área e também melhorando as ferramentas de tomada de decisão deste setor.

Os objetivos específicos desta tese são:

1) Analisar a indústria de apoio marítimo no Brasil;

2) Identificar os fatores críticos de sucesso (FCS) e analisar as principais relações entre eles;

3) Desenvolver um framework a partir dos FCS para a melhoria da tomada de decisões;

4) Adaptar o Mapa Estratégico da Indústria para a Indústria de Apoio Marítimo.

\subsection{Justificativa}

A Exploração \& Produção de petróleo em alto mar, conhecida como exploração offshore, necessita de uma grande quantidade de atividades de apoio marítimo, requerendo a utilização dos mais variados tipos de embarcações e serviços de suporte. Para que as atividades de apoio aconteçam da melhor forma possível, é necessário que haja um planejamento otimizado de todos os recursos que serão empregados (humanos, financeiros e materiais). Além da necessidade de mão de obra especializada, as empresas envolvidas neste mercado tomam 
decisões todos os dias, de vários níveis de complexidade, por exemplo: como investir ou não em uma embarcação, sendo que a maioria pode ter preços superiores a US\$ 100 milhões.

Além disso, os gastos com afretamento anual representam valores superiores que muitos ministérios do país. Em 2015, os gastos foram da ordem de US\$ 5,3 bilhões (SINAVAL, 2015a). De acordo com o MPDG (2015), este valor é superior ao orçamento dos seguintes ministérios:

Tabela 1 - Orçamento 2015 de Ministérios Selecionados

\begin{tabular}{ll}
\hline \multicolumn{1}{c}{ Ministério } & Orçamento \\
\hline Fazenda & $\mathrm{R} \$ 3,9$ bilhões \\
Justiça & $\mathrm{R} \$ 3,2$ bilhões \\
Esportes & $\mathrm{R} \$ 2,4$ bilhões \\
Aviação Civil & $\mathrm{R} \$ 2,3$ bilhões \\
Agricultura & $\mathrm{R} \$ 2,3$ bilhões \\
Desenvolvimento Agrário & $\mathrm{R} \$ 1,9$ bilhões \\
Relações Exteriores & $\mathrm{R} \$ 1,2$ bilhões \\
Comunicações & $\mathrm{R} \$ 1,05$ bilhões \\
Desenvolvimento & $\mathrm{R} \$ 0,96$ bilhões \\
Cultura & $\mathrm{R} \$ 0,93$ bilhões \\
Portos & $\mathrm{R} \$ 0,82$ bilhões \\
Meio Ambiente & $\mathrm{R} \$ 0,81$ bilhões \\
Trabalho & $\mathrm{R} \$ 0,80$ bilhões \\
Planejamento & $\mathrm{R} \$ 0,80$ bilhões \\
Minas e Energia & $\mathrm{R} \$ 0,75$ bilhões \\
Turismo & $\mathrm{R} \$ 0,48$ bilhões \\
Pesca e Aquicultura & $\mathrm{R} \$ 0,16$ bilhões \\
Direitos Humanos & $\mathrm{R} \$ 0,15$ bilhões \\
Micro e Pequena Empresa & $\mathrm{R} \$ 0,05$ bilhões \\
\hline
\end{tabular}

Fonte: Adaptado de MPDG (2015) ${ }^{1}$

A falta de conhecimento mais sistematizado sobre a indústria de apoio marítimo por meio de uma perspectiva estratégica, apoiada pela identificação e análise dos fatores críticos de sucesso, fortalece a oportunidade para o desenvolvimento deste trabalho.

\footnotetext{
${ }^{1}$ Valores atualizados após o Ministério do Planejamento cortar R \$ 69,9 bilhões aprovados pelo Congresso Nacional.
} 


\subsection{Contribuições Pretendidas}

Esta tese é a primeira a abordar a modelagem da indústria de apoio marítimo do Brasil, por meio de uma visão mais estratégica. Também é o primeiro trabalho que utiliza o Mapa Estratégico da Indústria para analisar e modelar este importante setor, assim como a identificação dos Fatores Críticos de Sucesso (FCS).

Do ponto de vista acadêmico, contribuirá para o avanço da literatura sobre a indústria de apoio marítimo, por meio de uma visão estratégica e mapeamento dos fatores críticos que contribuem para o desempenho do segmento.

Do ponto de vista prático, contribuirá para que toda a cadeia logística de apoio marítimo possa entender o mapa estratégico da indústria, verificando onde ela está inserida e com isso, identificando os Fatores Críticos de Sucesso que são comuns ao mercado, e também os fatores específicos de suas atividades. Dessa forma, tornará mais eficiente o sistema de tomada de decisão, gerando uma utilização mais otimizada de todos os recursos.

O presente trabalho está organizado da seguinte forma:

Capítulo 2: aborda a revisão da literatura, onde é discutida a indústria nacional e internacional de petróleo, a indústria de apoio marítimo, os desafios logísticos da Exploração \& Produção no pré-sal, o mapa estratégico da indústria e os fatores críticos de sucesso.

Capítulo 3: o método estudo de caso é discutido, formalizando a estrutura a ser seguida, assim como as formas de coleta de dados.

Capítulo 4: é feita a análise e discussão dos resultados. Primeiramente é apresentada uma análise com estatística descritiva, seguido de um teste não paramétrico por meio da correlação de Spearman e do teste Kolmogorov-Smirnov. Na sequência um framework (matriz de produtividade x competitividade) é proposto e finalmente é modelado o Mapa Estratégico da Indústria de Apoio Marítimo. 
Capítulo 5: as conclusões e recomendações são discutidas, tendo em vista a proposta inicial e a análise dos resultados. Também é evidenciado sugestões para futuros trabalhos nesta linha de pesquisa. 


\section{REVISÃO DA LITERATURA}

Este capítulo apresenta a revisão da literatura, destacando inicialmente a indústria nacional de petróleo, em que é abordada a Exploração \& Produção (E\&P), o refino de petróleo, a comercialização e distribuição. Na sequência, o panorama internacional de petróleo, seguido da indústria de apoio marítimo, dos desafios logísticos da Exploração \& Produção no pré-sal, e por fim, os Fatores Críticos de Sucesso.

\subsection{Indústria Nacional de Petróleo}

O petróleo faz parte do grupo de energias não renováveis, formado por recursos minerais que levaram milhões de anos para se formar e que não pode ser renovado em um período de tempo adequado ao seu uso. A comercialização do petróleo é feita por contratos, que informam o tipo de óleo e origem. Os preços variam conforme sua qualidade e custos de refino e transportes. As transações ocorrem por meio de aplicação de ágio e deságio sobre os preços dos óleos de referência. A principal referência na Europa é o Brent, com preços cotados em Roterdã, e o WTI (West Texas Intermediate), com preços tomados em Oklahoma, (D’ALMEIDA, 2015).

A Figura 4 mostra a matriz de energia brasileira no ano de 2015. O petróleo é o tipo de energia que predomina, com 37,3\% de participação, seguido de derivados de cana, com 16,9\%. Na sequência, tem-se o gás natural com $13,7 \%$ de participação. A energia hidráulica possui 11,3\% de participação e a lenha/carvão vegetal são responsáveis por 8,2\%. Já o carvão mineral e coque correspondem a 5,9\%; o urânio possui uma pequena participação de 1,3\%. Outras energias renováveis compõem $4,7 \%$ e outras energias não renováveis chegam a $0,6 \%$. Se for considerado o petróleo e o gás natural juntos, estes são responsáveis por 51,0\% da matriz energética. 


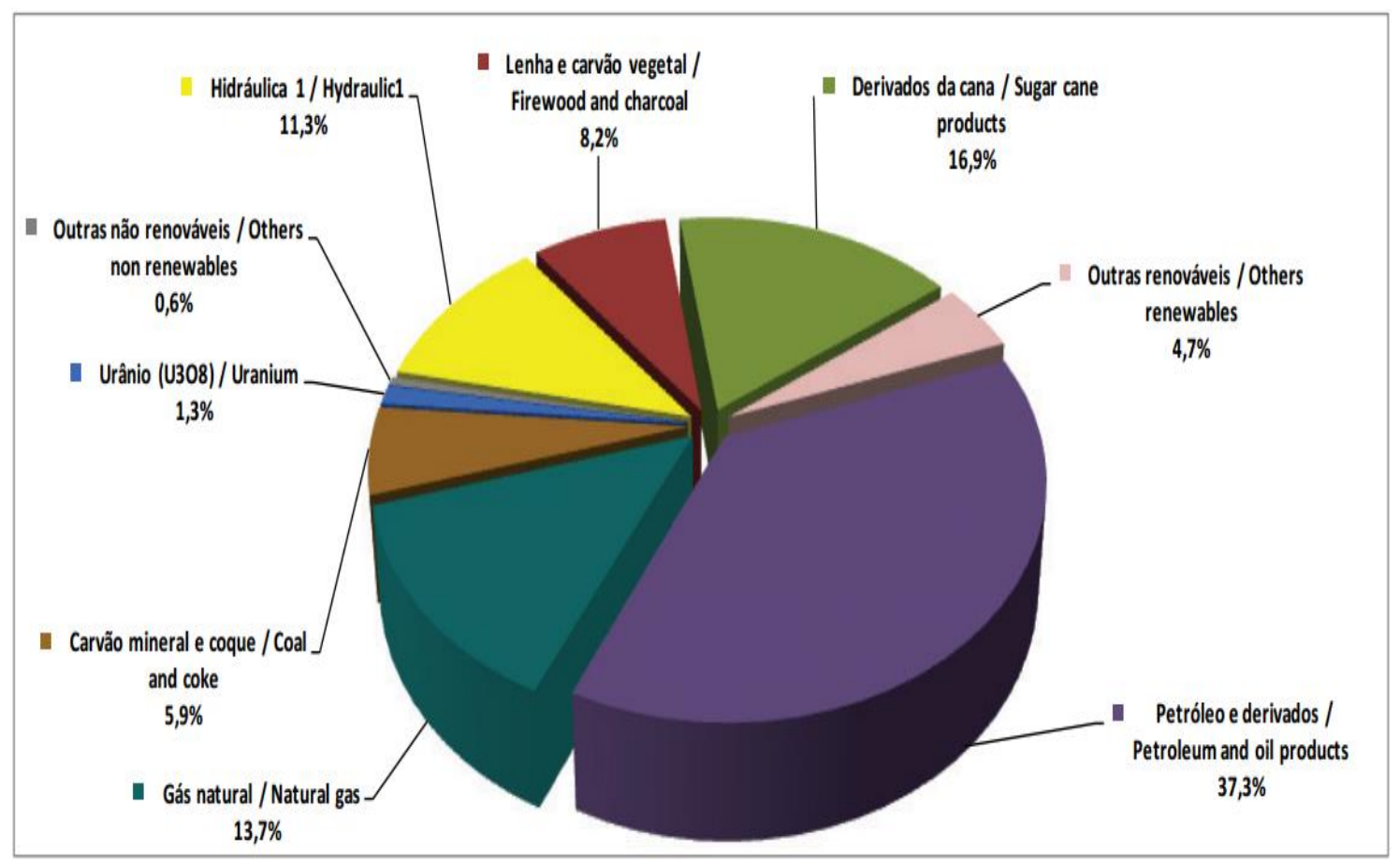

Figura 4 - Oferta Interna de Energia no Brasil em 2015 Fonte: BEN, 2016.

A fase de Exploração e Produção (E\&P) de petróleo é a etapa que envolve o maior risco financeiro, pois é necessário um grande aporte de capital, e o grau de incertezas é muito alto. Quando é confirmada a viabilidade econômica de uma reserva de petróleo, ainda existe um tempo grande de maturação para começar a gerar receita, podendo ser necessário um período de oito a nove anos após o investimento inicial (D'ALMEIDA, 2015). Nesta fase, é importante destacar que existem diversas empresas de apoio marítimo dando suporte e sendo fundamental para o sucesso do desenvolvimento de um campo marítimo.

Segundo Faria (2013), o pico de produção é o modelo de dimensionamento mais comum no Brasil, pois gera receita mais rapidamente. Porém, de acordo com gráfico indicado na Figura 5, existe um tradeoff, pois como os equipamentos foram superdimensionados no início da operação, gerando altos custos de investimentos, ocorre uma grande ociosidade das instalações e equipamentos, principalmente no decorrer da metade para o fim da vida útil. 


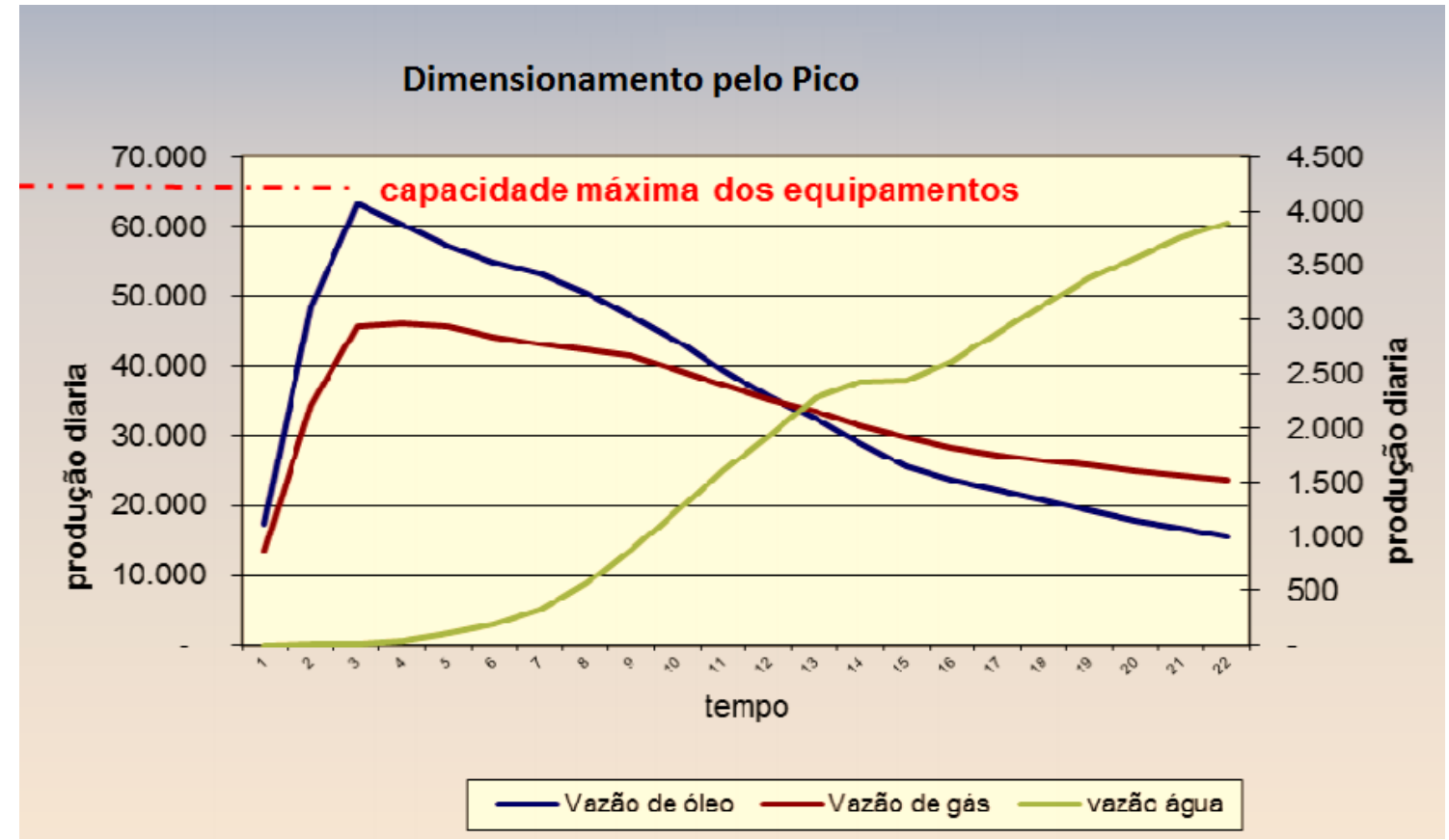

Figura 5 - Dimensionamento de Produção pelo Pico Fonte: Faria, 2013.

No caso do dimensionamento ser feito pela capacidade inferior ao pico de produção, diminui a ociosidade dos equipamentos ao longo do tempo, gerando uma produtividade melhor e também minimizando os investimentos em imobilizados na fase inicial. Mas, devido à vazão restringida, o tempo de retorno dos investimentos será maior que o dimensionamento pelo pico.

De acordo com D’Almeida (2015), os contratos de produção na modalidade concessão possuem duração de 27 anos, podendo ser prorrogados. A atividade de perfuração permeia todo o upstream, já que o seu produto é o poço. Devido a isso, a perfuração necessita de muitas atividades de apoio e pode representar mais de $50 \%$ dos custos de desenvolvimento de um campo de petróleo, já que as sondas marítimas mais modernas podem superar o valor de aluguel diário de US\$ 500 mil. A Figura 6 a seguir ilustra uma sonda. 


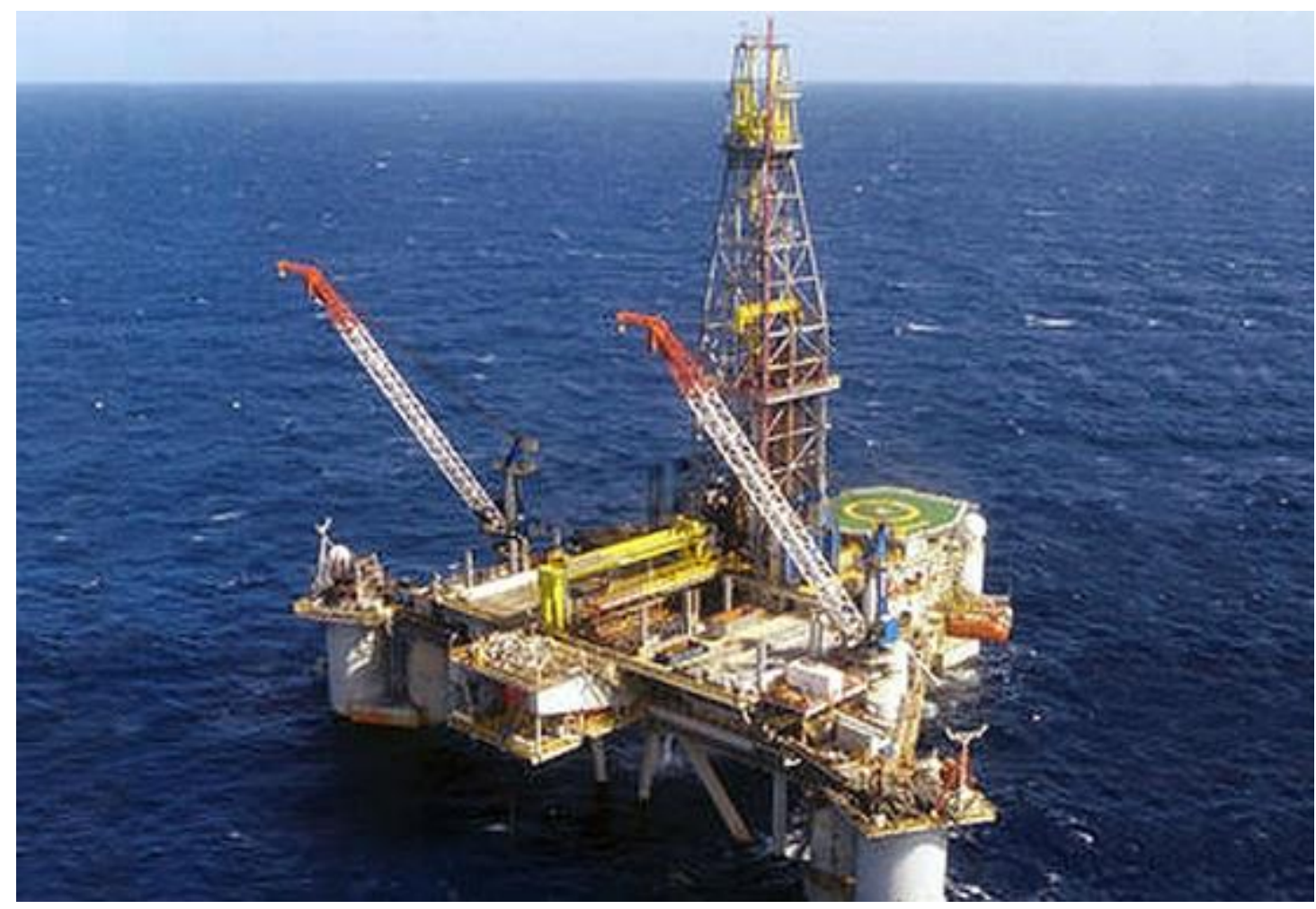

Figura 6 - Sonda SS-53 Noble Paul Wolff

Fonte: http://portalnaval.com.br/

A indústria de petróleo possui a necessidade de altos investimentos em pesquisa e desenvolvimento (P\&D), segundo D’Almeida (2015), a Exploração \& Produção (offshore) possuem diversos desafios tecnológicos, que necessita de áreas multidisciplinares como conhecimentos de engenharia, automação, materiais, química, logística etc. O autor destaca a importância na logística, devido à grande quantidade de restrições que existem na E\&P, como armazenamento nas instalações marítimas, pesos das cargas (ex: sondas), impossibilidade de paradas devido o fornecimento de insumos e reparos etc. As inovações geralmente custam caro, e conforme apresentado anteriormente, os projetos possuem um tempo alto de maturação. A área de Exploração e Produção (E\&P) da Petrobras consome $70 \%$ dos investimentos da empresa.

A indústria de petróleo brasileira operou por meio de uma estrutura de monopólio até 1997, ano em que foi criada a Lei 9.478, que revoga a Lei 2004, que havia instituído o monopólio. O objetivo básico era atrair novos operadores e com isso, reduzir o fluxo de petróleo importado e também aumentar as receitas. O modelo utilizado é o de concessão, que estabelece um processo concorrencial entre as empresas que demonstrarem capacidade técnica/financeira 
para a execução dos projetos. O órgão responsável pelas licitações é a Agência Nacional do Petróleo, Gás Natural e Biocombustíveis (ANP).

Nas atividades de Exploração e Produção (E\&P), existem compensações financeiras, conhecidas como participações governamentais. Segundo D’Almeida (2015), as participações governamentais são uma forma de compensar a degradação ambiental e os custos sociais gerados. As participações governamentais, de acordo com Gutman (2007), são:

i) Bônus de assinatura: é o pagamento do vencedor da licitação, que ressarce os custos administrativos do processo de licitação da ANP;

ii) Royalties: é uma compensação financeira ao Estado pela exploração do recurso não renovável. O pagamento é mensal, e varia entre 5\% e $10 \%$ da receita bruta do campo;

iii) Participação Especial (PE): utilizada para os campos de alta produção ou lucratividade. A alíquota pode chegar até $40 \%$ da receita bruta de produção após dedução de royalties, bônus de assinatura, taxa de ocupação de área, pagamento ao proprietário de terra, investimentos de exploração, custos operacionais, depreciações e tributos;

iv) Ocupação ou retenção de área: pagamento anual destinado à ANP, em função da área ocupada ( $\left.\mathrm{R} \$ / \mathrm{Km}^{2} / \mathrm{ano}\right)$.

\subsubsection{Exploração e Produção (E\&P)}

A cadeia de fornecedores da indústria de petróleo é fundamental para o sucesso do setor. As duas principais dificuldades existentes são o desenvolvimento técnico e financeiro dos fornecedores para atender às demandas de bens e serviços. Segundo D’Almeida (2015) a indústria nacional pleiteia programas de incentivo à inovação, desoneração na produção, melhorias na comercialização e financiamentos, baseado no modelo asiático, em que deveria haver clusters tecnológicos, formados por centros de pesquisa e desenvolvimento (P\&D), maior cooperação com universidades e também incentivos para atrair empresas estrangeiras. 
Segundo a ANP (2016), em 2015 havia 790 áreas sob contratos, sendo que 348 blocos estavam na fase de exploração, 71 em desenvolvimento e 371 em produção. Dos que estavam em exploração, a Petrobras tinha participação em 142, dos quais 58 eram concessões exclusivas e 84 em parceria com outras empresas. O volume de reservas provadas de Petróleo foi de 13 bilhões de barris, em que $81,2 \%$ estavam no Rio de Janeiro.

A produção offshore no ano de 2015 foi responsável por 93,4\% do total de petróleo produzido. A média de processamento de barris por dia foi de 2,4 milhões, totalizando 889,7 milhões de barris. A relação reserva/produção (R/P) de petróleo reduziu de 19,6 anos em 2014, para 14,6 anos em 2015, devido à queda das reservas provadas. A empresa que mais produziu foi a Petrobras, sendo responsável por $83,5 \%$ do total produzido de petróleo e gás natural. $\mathrm{O}$ Brasil ficou na $12^{\mathrm{a}}$ posição no ranking mundial de produtores de petróleo (ANP, 2016). A Tabela 2 a seguir mostra o ranking com os dez concessionários que mais produziram petróleo e gás natural em 2015.

Tabela 2 - Top 10 Produtores de Petróleo e Gás Natural em 2015

\begin{tabular}{clcc}
\hline Ranking & \multicolumn{1}{c}{ Concessionário } & Petróleo (Barris) & Gás Natural em $\left(\mathbf{M i l ~ M}^{\mathbf{3}}\right)$ \\
\hline $1^{\text {o }}$ & Petrobras & $742.975 .318,9$ & $28.523 .872,7$ \\
$2^{\circ}$ & BG Brasil & $49.797 .132,8$ & $2.052 .409,5$ \\
$3^{\circ}$ & Repsol Sinopec & $18.763 .274,9$ & $621.006,1$ \\
$4^{\circ}$ & Statoil Brasil & $15.875 .576,0$ & $22.063,9$ \\
$5^{\circ}$ & Petrogal Brasil & $12.000 .469,7$ & $571.675,9$ \\
$6^{\circ}$ & Shell Brasil & $13.491 .035,7$ & $159.100,8$ \\
$7^{\circ}$ & Sinochem Petróleo & $10.583 .717,4$ & $14.709,2$ \\
$8^{\circ}$ & Parnaíba Gás Natural & $3.136,8$ & $1.095 .723,2$ \\
$9^{\circ}$ & Queiroz Galvão & $79.260,3$ & $919.567,0$ \\
$1^{\circ}$ & ONGC Campos & $4.749 .748,4$ & $48.098,4$ \\
\hline
\end{tabular}

Fonte: Adaptado de ANP, 2016.

As participações governamentais e de terceiros, instituída pela Lei ${ }^{\circ}$ 9.478/1997, teve a seguinte arrecadação: royalties $\mathrm{R}$ \$ 13,9 bilhões, participação especial $\mathrm{R}$ \$ 11,4 bilhões, pagamento pela ocupação ou retenção de área $\mathrm{R}$ \$221,7 milhões e obrigação de investimentos em pesquisa, desenvolvimento e inovação (PD\&I) totalizou R \$ 1 bilhão. A Tabela 3, elaborada a partir do Anuário Estatístico da ANP 2016, mostra a evolução de tais participações. 
Tabela 3 - Evolução da Participação Governamental e Terceiros de 2006-2015

\begin{tabular}{|c|c|c|c|c|c|c|c|c|c|c|}
\hline $\begin{array}{l}\text { Participação } \\
\text { Governamental/ } \\
\text { Terceiros } \\
\end{array}$ & 2006 & 2007 & 2008 & 2009 & 2010 & 2011 & 2012 & 2013 & 2014 & 2015 \\
\hline Royalties (Bilhões R\$) & 7,7 & 7,5 & 10,9 & 8,0 & 9,9 & 13,0 & 15,6 & 16,3 & 18,5 & 13,9 \\
\hline $\begin{array}{l}\text { Participação Especial (Bilhões } \\
\mathrm{R} \$ \text { ) }\end{array}$ & 8,8 & 7,2 & 11,7 & 8,5 & 11,7 & 12,6 & 15,9 & 15,5 & 16,9 & 11,4 \\
\hline $\begin{array}{l}\text { Pagamento pela Ocupação ou } \\
\text { Retenção de Área (Milhões } \\
\mathrm{R} \$ \text { ) }\end{array}$ & 134,6 & 142,5 & 146,6 & 174,2 & 170,4 & 196,5 & 206,6 & 219,1 & 218,8 & 221,7 \\
\hline $\begin{array}{l}\text { Pagamento aos Proprietários } \\
\text { de Terra (Milhões R\$) }\end{array}$ & 87,9 & 80,1 & 102,6 & 71,4 & 82,3 & 112,6 & 133,1 & 145,6 & 150,4 & 103,8 \\
\hline $\begin{array}{l}\text { Obrigação de Investimentos } \\
\text { em Pesquisa, } \\
\text { Desenvolvimento e Inovação } \\
\text { PD\&I (Milhões R\$) }\end{array}$ & 616,4 & 616,5 & 860,9 & 638,9 & 746,9 & $1.031,9$ & $1.226,7$ & $1.259,9$ & $1.407,6$ & $1.031,0$ \\
\hline
\end{tabular}

Fonte: Adaptado de ANP, 2016.

É importante destacar a atuação da ANP como órgão fomentador de pesquisas na exploração, produção, transporte, refino e processamento. Por meio do Programa de Recursos Humanos da ANP (PRH-ANP), implementado a partir de 1999, tem sido um dos mais relevantes para o desenvolvimento de mão de obra especializada para toda a cadeia de petróleo. A iniciativa consiste na concessão de bolsas de estudos de graduação, mestrado e doutorado, além de bolsas de coordenador e pesquisador visitante (PV). No período de 2006 a 2015, os investimentos na concessão de bolsas de estudos e taxas de bancada foram da ordem de R\$ 284,6 milhões, (ANP, 2016). A Figura 7 mostra a evolução da obrigação de investimentos em PD\&I pelos concessionários entre 2006 e 2015.

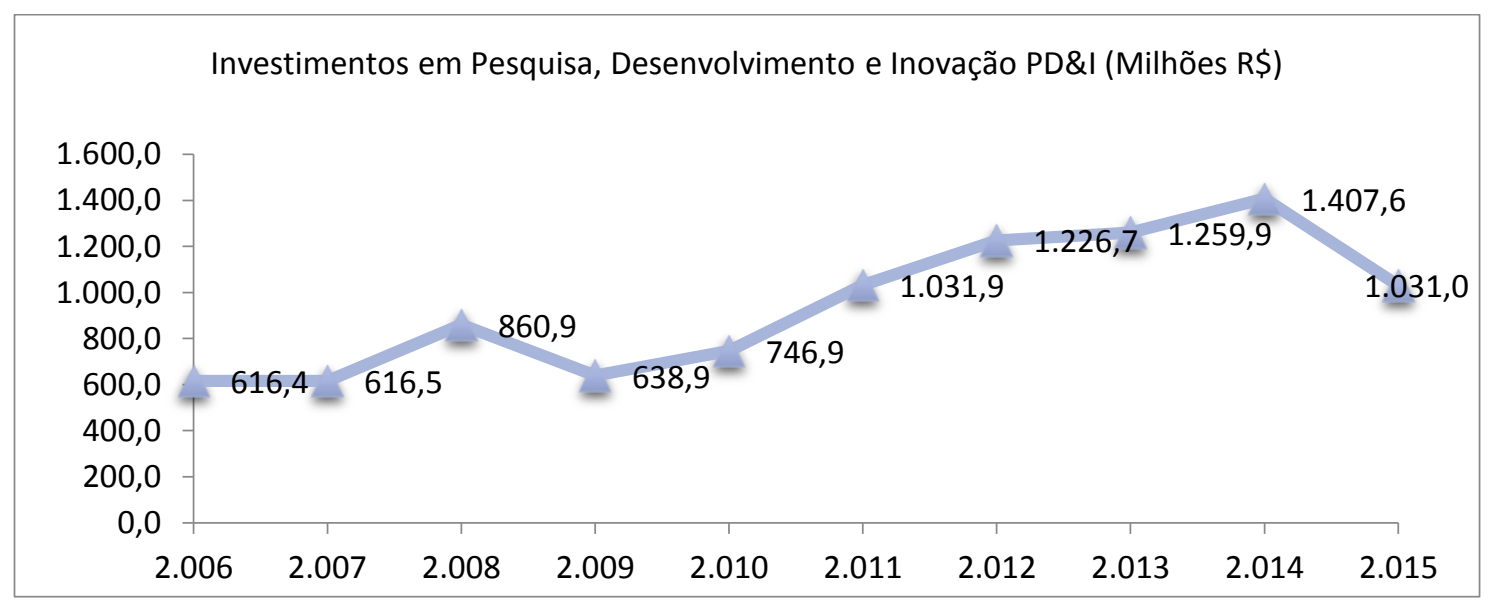

Figura 7 - Evolução dos Investimentos em PD\&I por Concessionário 2006-2015 Fonte: Adaptado de ANP, 2016. 
Entre 2006 e 2015, a somatória de investimentos ultrapassou os $\mathrm{R} \$ 9,4$ bilhões. No período de 2009 a 2014, houve crescimento nos investimentos, porém, comparando 2015/2014, o montante investido foi $26,8 \%$ menor. Os recursos são gerados a partir da cláusula de investimento em pesquisa, desenvolvimento e inovação nos contratos de concessão para exploração, desenvolvimento e produção de petróleo e gás natural.

\subsubsection{Refino de Petróleo}

De acordo com a ANP (2016), em 2015, o Brasil contava com 17 refinarias com capacidade de processamento diário de 2,4 milhões de barris, valor 1,9\% superior a 2014. Porém, o volume de processamento efetivo foi de 2 milhões de barris/dia. Em relação às importações, a África foi o principal parceiro do Brasil, fornecendo 167,3 mil barris/dia, que correspondem a 60,3\% das importações, já as exportações atingiram o valor de 268,9 milhões de barris, alta de $42 \%$. A Tabela 4 mostra a evolução da capacidade de refino da indústria brasileira no período de 2006 a 2015.

Tabela 4 - Evolução da Capacidade de Refino 2006-2015

\begin{tabular}{|c|c|c|c|c|c|c|c|c|c|c|}
\hline \multirow{2}{*}{ Refinarias } & \multicolumn{10}{|c|}{ Capacidade de Refino (Barril/dia) } \\
\hline & 2006 & 2007 & 2008 & 2009 & 2010 & 2011 & 2012 & 2013 & 2014 & 2015 \\
\hline Riograndense (RS) & 16.983 & 16.983 & 16.983 & 16.983 & 16.983 & 17.014 & 17.014 & 17.014 & 17.014 & 17.014 \\
\hline Lubnor (CE) & 6.919 & 6.919 & 8.177 & 8.177 & 8.177 & 8.177 & 8.177 & 8.177 & 8.177 & 9.435 \\
\hline Manguinhos (RJ) & 14.001 & 14.001 & 14.001 & 14.001 & 14.001 & 14.001 & 14.001 & 14.001 & 14.001 & 14.001 \\
\hline Recap (SP) & 53.463 & 53.463 & 53.463 & 53.463 & 53.463 & 53.463 & 53.463 & 53.463 & 53.463 & 62.898 \\
\hline Reduc (RJ) & 242.158 & 242.158 & 242.158 & 242.158 & 242.158 & 242.158 & 242.158 & 242.158 & 242.158 & 251.593 \\
\hline Refap (RS) & 8.695 & 188.695 & 188.695 & 188.695 & 188.695 & 201.274 & 201.274 & 201.274 & 201.274 & 220.144 \\
\hline Regap (MG) & 150.956 & 150.956 & 150.956 & 150.956 & 150.956 & 150.956 & 150.956 & 150.956 & 166.051 & 166.051 \\
\hline Reman (AM) & 45.916 & 45.916 & 45.916 & 45.916 & 45.916 & 45.916 & 45.916 & 45.916 & 45.916 & 45.916 \\
\hline Repar (PR) & 188.695 & 201.274 & 220.144 & 220.144 & 220.144 & 220.144 & 207.564 & 207.564 & 207.564 & 213.854 \\
\hline Replan (SP) & 364.810 & 364.810 & 383.679 & 415.128 & 415.128 & 415.128 & 415.128 & 415.128 & 433.998 & 433.998 \\
\hline Revap (SP) & 251.593 & 251.593 & 251.593 & 251.593 & 251.593 & 251.593 & 251.593 & 251.593 & 251.593 & 251.593 \\
\hline RLAM (BA) & 322.982 & 322.982 & 295.307 & 279.897 & 279.897 & 279.897 & 279.897 & 377.389 & 377.389 & 377.389 \\
\hline RPBC (SP) & 169.825 & 169.825 & 169.825 & 169.825 & 169.825 & 169.825 & 169.825 & 169.825 & 169.825 & 169.825 \\
\hline RPCC (RN) & 27.222 & 27.222 & 27.222 & 27.222 & 27.222 & 35.223 & 37.739 & 37.739 & 37.739 & 37.739 \\
\hline Rnest (PE) & - & - & - & - & - & - & - & - & 115.009 & 115.009 \\
\hline Univen (SP) & - & 6.919 & 6.919 & 6.919 & 6.919 & 9.158 & 9.158 & 9.158 & 9.158 & 9.158 \\
\hline Dax Oil (BA) & - & - & 1.730 & 1.730 & 1.730 & 2.095 & 2.095 & 2.095 & 2.095 & 2.095 \\
\hline
\end{tabular}

Fonte: ANP, 2016 
Em 2015, a capacidade de armazenamento das refinarias alcançou o valor de 6,3 milhões de $\mathrm{m}^{3}$ de petróleo, sendo que $39,7 \%$ se localizavam em refinarias do estado de São Paulo. A região, também possui uma grande representatividade no armazenamento de derivado de petróleo, intermediários e etanol, atingindo 45,8\% de um total nacional de 11,5 milhões de $\mathrm{m}^{3}$. Já a produção de derivados de petróleo ${ }^{2}$ foi de 122,1 milhões de $\mathrm{m}^{3}$, valor 6,2\% inferior a 2014. É importante destacar que estes valores não incluem a produção a partir do xisto betuminoso ${ }^{3}$. A figura a seguir, mostra a distribuição percentual da produção de derivados (energéticos x nãoenergéticos).
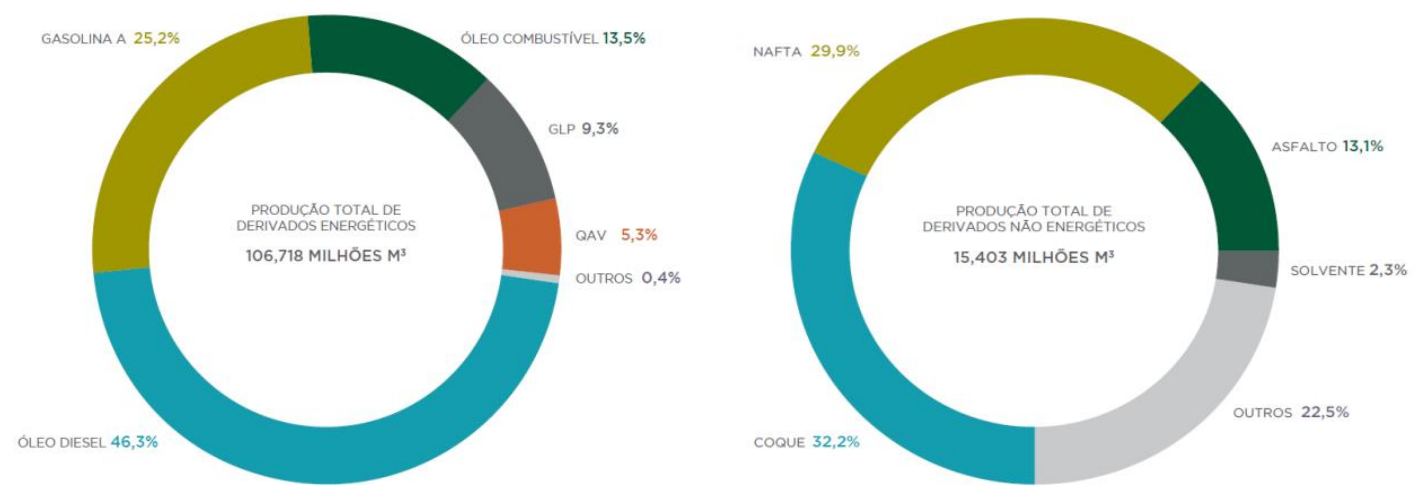

Figura 8 - Produção de Derivados Energéticos x Não Energéticos Fonte: ANP, 2016.

Um destaque na produção dos derivados energéticos, é o volume do óleo diesel, que representa $46,3 \%$ da produção total de 106,718 milhões de $\mathrm{m}^{3}$, seguido pela produção da gasolina A com 25,2\% de participação. No caso dos derivados não energéticos, a liderança foi do coque com $32,2 \%$ de participação na produção de um total de 15,403 milhões de $\mathrm{m}^{3}$, seguido pela nafta, com $29,9 \%$.

A movimentação do petróleo nos terminais é uma atividade complexa e que demanda um custo alto. De acordo com a ANP (2016), no final de 2015, o país tinha 108 terminais autorizados a operar, totalizando 13,5 milhões de $\mathrm{m}^{3}$ de capacidade nominal. Os terminais

\footnotetext{
${ }^{2}$ Os derivados de petróleo são divididos em energéticos e não energéticos. No grupo dos energéticos temos: gasolina A, gasolina de aviação, GLP, óleo combustível, QAV (querosene de aviação), querosene iluminante; não energéticos: asfalto, coque, nafta, óleo lubrificante, parafina e solventes.

${ }^{3}$ Xisto betuminoso: rocha sedimentar rica em querogênio, quando submetida a temperaturas altas, decompõe-se em óleo, água, gás e resíduo sólido contendo carbono. É possível obter uma série de subprodutos por meio de industrialização. No Brasil, a produção de xisto bruto tem dado origem aos seguintes produtos: gás de xisto, GLP, óleo combustível e nafta.
} 
aquaviários representam aproximadamente $70 \%$ desta capacidade. A Figura 9 a seguir mostra o terminal aquaviário de Angra dos Reis (Tebig).

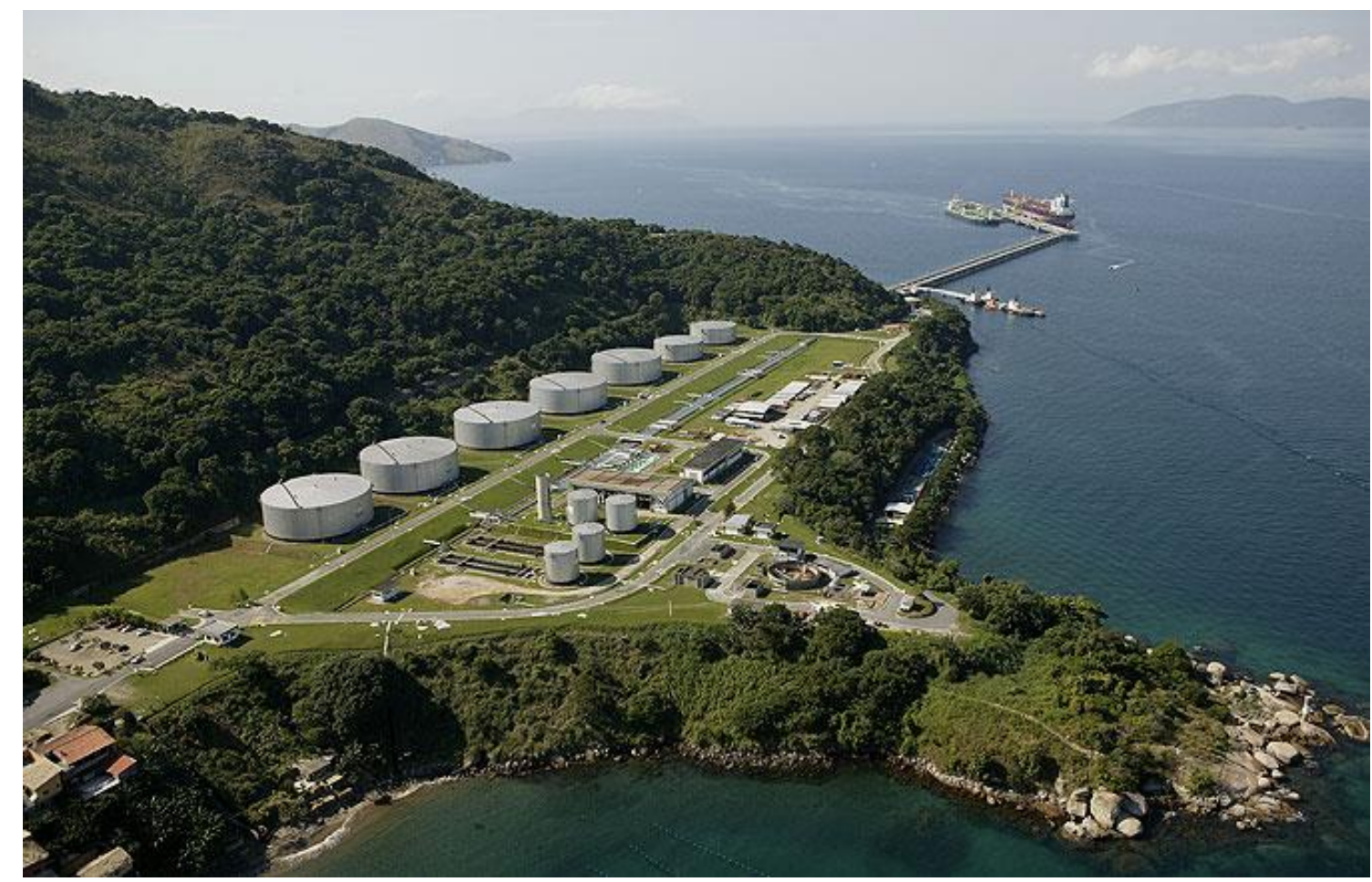

Figura 9 - Terminal Aquaviário de Angra dos Reis (Tebig)

Fonte: Transpetro

Os terminais aquaviários são operados pela Transpetro, subsidiária de transportes da Petrobras, ou por empresas parceiras. Além dos terminais aquaviários, a rede de transporte é composta por 45 terminais terrestres e 9 centros coletores de etanol. Já a rede de dutos é composta por $19,7 \mathrm{mil} \mathrm{km}$.

\subsubsection{Comercialização e Distribuição}

As fases de distribuição e comercialização são muito intensivas em atividades logísticas. Segundo a ANP (2016), no final de 2015, a rede de distribuição de combustíveis líquidos autorizados, chegou a 291 bases. São Paulo com 56 bases de distribuição e Paraná com 36 são os estados que mais possuem bases. Já Amapá e Piauí são os estados com menos bases de distribuição, com apenas uma. As vendas de derivados de petróleo das distribuidoras no mercado nacional totalizaram 124 milhões de $\mathrm{m}^{3}$, representando uma queda de 5,8\% em relação a 2014. A Figura 10 a seguir mostra a evolução do desempenho das distribuidoras no período de 2006 a 2015. 


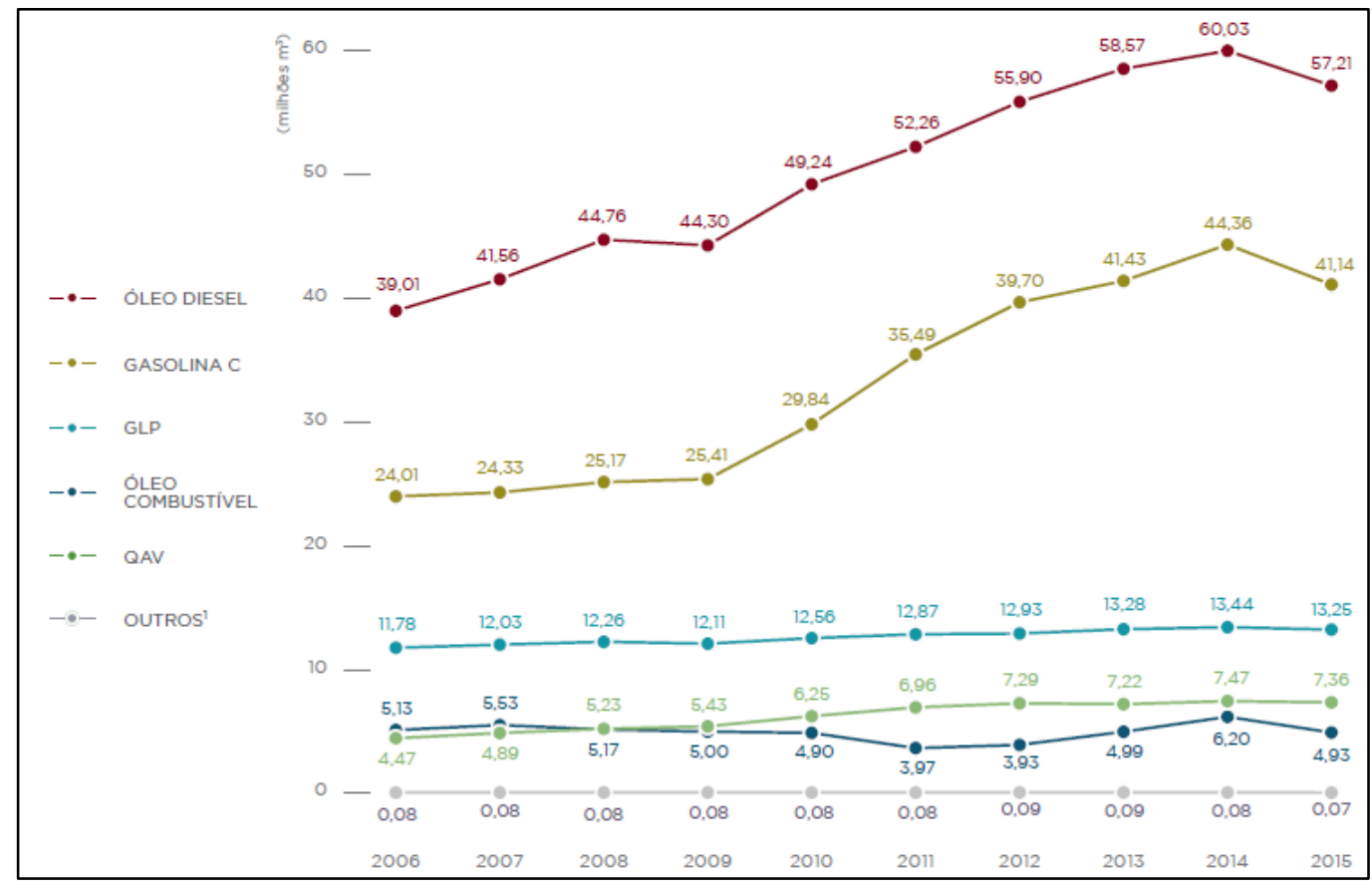

Figura 10 - Evolução das Vendas no Brasil de Derivados de Petróleo 2006-2015 Fonte: ANP, 2016.

linclui gasolina de aviação e querosene iluminante.

As vendas de óleo diesel lideram as comercializações das distribuidoras, seguida pela gasolina. Porém, tanto o óleo diesel quanto a gasolina tiveram queda em relação a 2014. As maiores baixas foram óleo combustível e querosene iluminante com 20,4\% e 20,7\% respectivamente. O mercado de óleo diesel foi suprido por 137 distribuidoras, porém aproximadamente $80 \%$ das vendas se concentraram em apenas quatro empresas: BR com 37,2\%, Ipiranga 22,9\%, Raízen 16,1\% e Alesat com 2,8\%. A Figura 11 a seguir, mostra a distribuição das vendas dos principais players. 


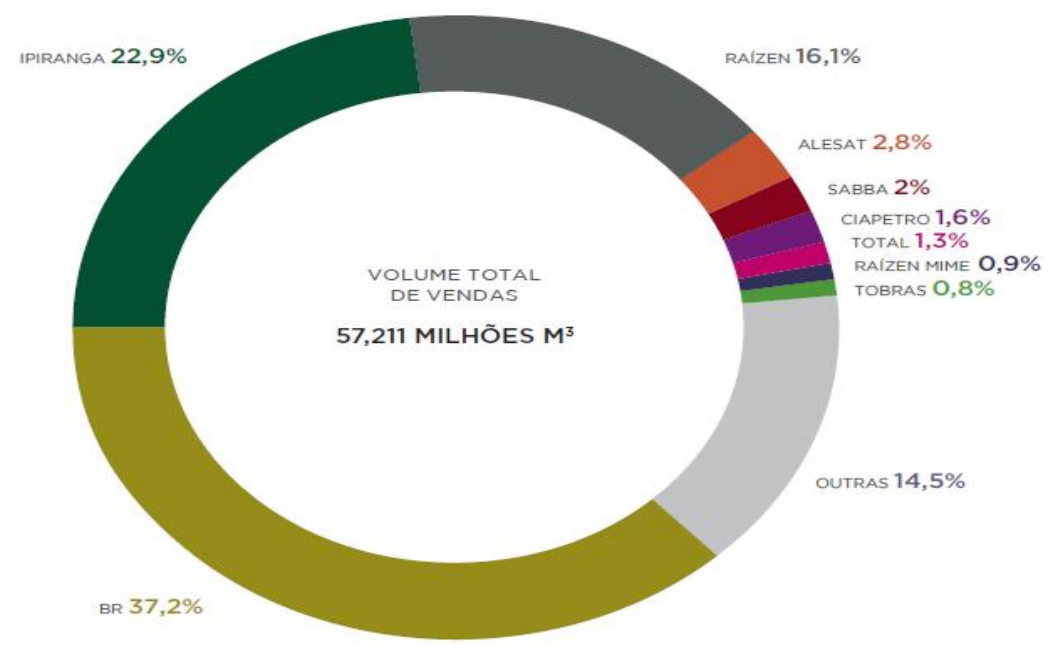

Figura 11 - Vendas dos Principais Players de Distribuição

Fonte: ANP, 2016.

Outras $=128$ distribuidoras

A Figura 12 destaca que, em relação aos preços médios praticados ao consumidor, a média nacional do óleo diesel foi de R \$2,83/litro, com o menor preço na Região Sul com R \$ 2,76/litro); já o maior preço foi na Região Norte, com R \$ 3,03. No caso da gasolina, a média nacional foi de $\mathrm{R} \$ 3,34$; novamente, a Região Norte foi a que praticou os maiores valores médios, com R \$3,57/litro. Em relação ao menor preço de comercialização da gasolina, a Região Sudeste foi a que obteve o menor valor médio, com $\mathrm{R} \$ 3,29 /$ litro.

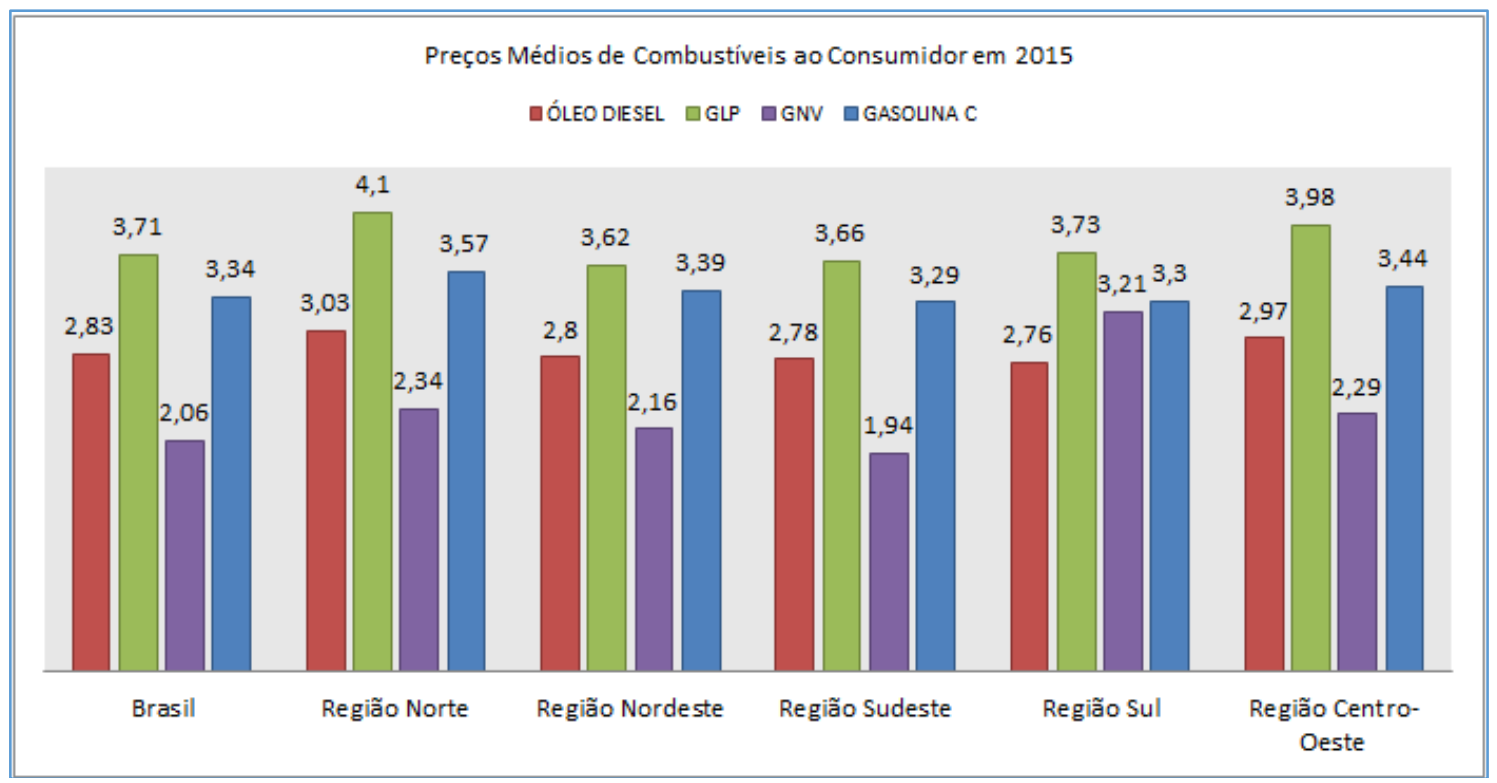

Figura 12 - Preços Médios de Combustíveis ao Consumidor Fonte: ANP, 2016. Gasolina C e óleo diesel expressos em litros, GLP em kg e GNV em m³ . 


\subsection{Panorama Internacional de Petróleo}

Segundo a ANP (2016), as reservas de petróleo atingiram o valor de 1,7 trilhões de barris no final de 2015. As reservas dos membros da $\mathrm{OPEP}^{4}$ somaram o valor de 1,2 trilhões de barris, ou $71,4 \%$ do total mundial. A Venezuela é o país com maior volume de reservas, com 17,7\% do total mundial, seguido pela Arábia Saudita com 15,7\% do total mundial. Já o Brasil, ficou na $15^{\mathrm{a}}$ posição do ranking. A Tabela 5 a seguir mostra a evolução das reservas mundiais provadas de petróleo no período de 2006 a 2015.

Tabela 5 - Evolução das Reservas Provadas de Petróleo 2006-2015

\begin{tabular}{lccccccccccc}
\hline \multirow{2}{*}{ Regiões Geográficas } & \multicolumn{8}{c}{ Reservas Provadas de Petróleo em Bilhões de Barris } \\
\cline { 2 - 11 } & $\mathbf{2 0 0 6}$ & $\mathbf{2 0 0 7}$ & $\mathbf{2 0 0 8}$ & $\mathbf{2 0 0 9}$ & $\mathbf{2 0 1 0}$ & $\mathbf{2 0 1 1}$ & $\mathbf{2 0 1 2}$ & $\mathbf{2 0 1 3}$ & $\mathbf{2 0 1 4}$ & $\mathbf{2 0 1 5}$ \\
\hline América do Norte & 221,7 & 221,5 & 216,6 & 217,8 & 221,5 & 225,3 & 229,3 & 232,6 & 238,0 & 238,0 \\
Américas Central e do & 110,8 & 122,9 & 198,3 & 237,0 & 324,2 & 326,9 & 328,8 & 329,8 & 331,7 & 329,2 \\
Sul & 137,6 & 160,4 & 159,0 & 158,0 & 157,9 & 158,0 & 158,2 & 157,2 & 154,6 & 155,2 \\
Europa e Eurásia & 755,9 & 754,9 & 753,7 & 753,1 & 765,9 & 797,9 & 799,3 & 803,0 & 803,8 & 803,5 \\
Oriente Médio & 116,9 & 119,2 & 119,9 & 122,6 & 125,0 & 125,2 & 130,6 & 130,1 & 129,3 & 129,1 \\
África & 40,9 & 40,0 & 42,4 & 40,8 & 42,0 & 41,9 & 42,2 & 42,9 & 42,6 & 42,6 \\
Ásia-Pacífico & $\mathbf{9 3 6 , 1}$ & $\mathbf{9 4 9 , 5}$ & $\mathbf{1 0 2 4 , 4}$ & $\mathbf{1 0 6 4 , 6}$ & $\mathbf{1 1 6 3 , 3}$ & $\mathbf{1 1 9 7 , 5}$ & $\mathbf{1 2 0 4 , 6}$ & $\mathbf{1 2 0 9 , 1}$ & $\mathbf{1 2 1 1 , 1}$ & $\mathbf{1 2 1 1 , 6}$ \\
Total OPEP & $\mathbf{4 4 7 , 6}$ & $\mathbf{4 6 9 , 5}$ & $\mathbf{4 6 5 , 6}$ & $\mathbf{4 6 4 , 6}$ & $\mathbf{4 7 3 , 2}$ & $\mathbf{4 7 7 , 8}$ & $\mathbf{4 8 3 , 7}$ & $\mathbf{4 8 6 , 5}$ & $\mathbf{4 8 8 , 9}$ & $\mathbf{4 8 6 , 0}$ \\
\hline Total não OPEP & \multicolumn{7}{c}{ Fonte: ANP, 2016.} & & & &
\end{tabular}

A região do Oriente Médio é a que detém a maior quantidade das reservas, com 803,5 bilhões de barris, seguida pela América do Sul e Central, com 329,2 bilhões de barris, sendo que 91,4\% ou 300,9 bilhões de barris são da Venezuela. O Brasil fechou 2015 com 13,0 bilhões de barris, representando uma queda de 19,68\% em relação a 2014, quando o valor das reservas provadas alcançou 16,2 bilhões de barris.

A produção de petróleo mundial em 2015 aumentou em 3,2\%, atingindo 91,7 milhões de barris/dia. A OPEP teve um aumento na produção de 4,3\%, enquanto que os países que não fazem parte da OPEP apresentaram uma alta de apenas 2,4\%. Dentre os países da OPEP, o Iraque registrou a maior alta (22,7\%); já a maior baixa foi da Líbia (-13,3\%). No caso dos países que não fazem parte da OPEP, o maior crescimento na produção foi do Reino Unido, com

\footnotetext{
${ }^{4}$ Opep - Organização dos Países Exportadores de Petróleo, criada em 1960, formada por grandes produtores que tem por objetivo estabelecer uma política petrolífera comum a todos os membros, definindo estratégias de produção, e controlando os preços no mercado mundial. Membros atuais (2016): Angola, Argélia, Líbia, Nigéria, Gabão, Venezuela, Equador, Arábia Saudita, Emirados Árabes Unidos, Irá, Iraque, Kuwait, Catar e Indonésia.
} 
12,9\%. O Brasil também obteve alta, registrando um crescimento de 7,7\%. Já o maior produtor mundial de petróleo foram os Estados Unidos com volume médio de 12,7 milhões de barris/dia, o Brasil, atingiu o volume de 2,5 milhões de barris/dia, assegurando a $12^{\mathrm{a}}$ posição.

A Tabela 6 a seguir, mostra a evolução da produção mundial segmentada por região/bloco econômico no período de 2006 a 2015. O Oriente Médio é a região com o maior índice de produção, atingindo a marca de 30 milhões de barris/dia, sendo que o seu maior produtor foi à Arábia Saudita com 12 milhões de barris/dia. Já a América do Sul + Central, chegaram a 7,7 milhões de barris/dia, sendo que o Brasil foi responsável pela produção de mais de um terço deste valor.

Tabela 6 - Evolução da Produção de Petróleo 2006-2015

\begin{tabular}{|c|c|c|c|c|c|c|c|c|c|c|}
\hline \multirow{2}{*}{ Regiões Geográficas } & \multicolumn{10}{|c|}{ Produção de Petróleo (Mil Barris/dia) } \\
\hline & 2006 & 2007 & 2008 & 2009 & 2010 & 2011 & 2012 & 2013 & 2014 & 2015 \\
\hline América do Norte & 13.726 & 13.631 & 13.159 & 13.447 & 13.843 & 14.310 & 15.535 & 16.934 & 18.786 & 19.676 \\
\hline $\begin{array}{l}\text { Américas Central e do } \\
\text { Sul }\end{array}$ & 7.463 & 7.295 & 7.376 & 7.322 & 7.348 & 7.401 & 7.322 & 7.344 & 7.605 & 7.712 \\
\hline Europa e Eurásia & 17.587 & 17.800 & 17.577 & 17.760 & 17.699 & 17.390 & 17.124 & 17.166 & 17.206 & 17.463 \\
\hline Oriente Médio & 25.764 & 25.322 & 26.372 & 24.723 & 25.827 & 28.160 & 28.532 & 28.181 & 28.557 & 30.098 \\
\hline África & 10.011 & 10.269 & 10.246 & 9.890 & 10.142 & 8.548 & 9.327 & 8.711 & 8.371 & 8.375 \\
\hline Ásia-Pacífico & 7.937 & 7.961 & 8.088 & 8.039 & 8.424 & 8.287 & 8.378 & 8.254 & 8.310 & 8.346 \\
\hline Total OPEP & 35.570 & 35.241 & 36.269 & 33.998 & 35.149 & 36.061 & 37.536 & 36.621 & 36.652 & 38.226 \\
\hline Total não OPEP & 46.918 & 47.036 & 46.549 & 47.184 & 48.134 & 48.035 & 48.682 & 49.970 & 52.182 & 53.445 \\
\hline
\end{tabular}
Fonte: ANP, 2016.

Segundo a ANP (2016), o consumo mundial de petróleo em 2015 foi de 95 milhões barris/dia, que representou uma alta de $2 \%$ em relação a 2014. O país que mais consumiram foram os Estados Unidos, com 19,4 milhões de barris/dia, que corresponde a 20,4\% do total mundial, seguido da China com 12 milhões de barris/dia. O Brasil ficou em quinto lugar no ranking dos países que mais consumiram petróleo, chegando a 3,2 milhões de barris/dia. 
Tabela 7 - Consumo de Petróleo por Países Selecionados 2015

\begin{tabular}{lc}
\hline \multicolumn{1}{c}{ País } & \% do Consumo Mundial \\
\hline Estados Unidos & $20,0 \%$ \\
China & $12,3 \%$ \\
Índia & $4,3 \%$ \\
Japão & $4,3 \%$ \\
Arábia Saudita & $4,0 \%$ \\
Brasil & $3,3 \%$ \\
Rússia & $3,2 \%$ \\
Coréia do Sul & $2,7 \%$ \\
Alemanha & $2,4 \%$ \\
Canadá & $2,4 \%$ \\
Irã & $2,0 \%$ \\
México & $2,0 \%$ \\
Outros & $37,1 \%$ \\
\hline
\end{tabular}

Fonte: BP Statistical Review of World Energy 2016; ANP, 2016.

A Tabela 8 e o gráfico indicado na Figura 13 mostram a evolução dos preços médios no Mercado Spot (mercado à vista), com as duas principais referências de preços, a Brent e a WTI. Comparando 2015 com 2014, houve uma forte redução, tanto na Brent, quanto na WTI, ambas com reduções na casa dos $47 \%$.

Tabela 8 - Preços Médios (US\$) no Mercado SPOT 2006-2015

\begin{tabular}{|c|c|c|c|c|c|c|c|c|c|c|c|}
\hline \multirow{2}{*}{ Petróleo } & \multicolumn{10}{|c|}{ Preços Médios (US\$) no Mercado SPOT 2006-2015 } & \multirow[b]{2}{*}{$\operatorname{Var} \% 15 / 14$} \\
\hline & 2006 & 2007 & 2008 & 2009 & 2010 & 2011 & 2012 & 2013 & 2014 & 2015 & \\
\hline Brent & 65 & 72 & 97 & 62 & 80 & 111 & 112 & 109 & 99 & 52 & $-47,05$ \\
\hline WTI & 66 & 72 & 100 & 62 & 79 & 95 & 94 & 98 & 93 & 49 & $-47,78$ \\
\hline
\end{tabular}

Fonte: BP Statistical Review of World Energy 2016; ANP, 2016.

Por meio Figura 13 é possível visualizar que entre 2006 e 2010 as variações do preço Brent e WTI foram pequenas. A partir de 2010, houve um distanciamento mais acentuado, atingindo seu pico em 2012, com uma diferença de US\$ 18 do Brent em relação ao WTI. Em 2014, os preços de ambos começaram a baixar, reduzindo a diferença para US\$ 6, e no final de 2015, eles atingiram os menores valores da década e também a diferença entre eles caiu para US\$ 3. 


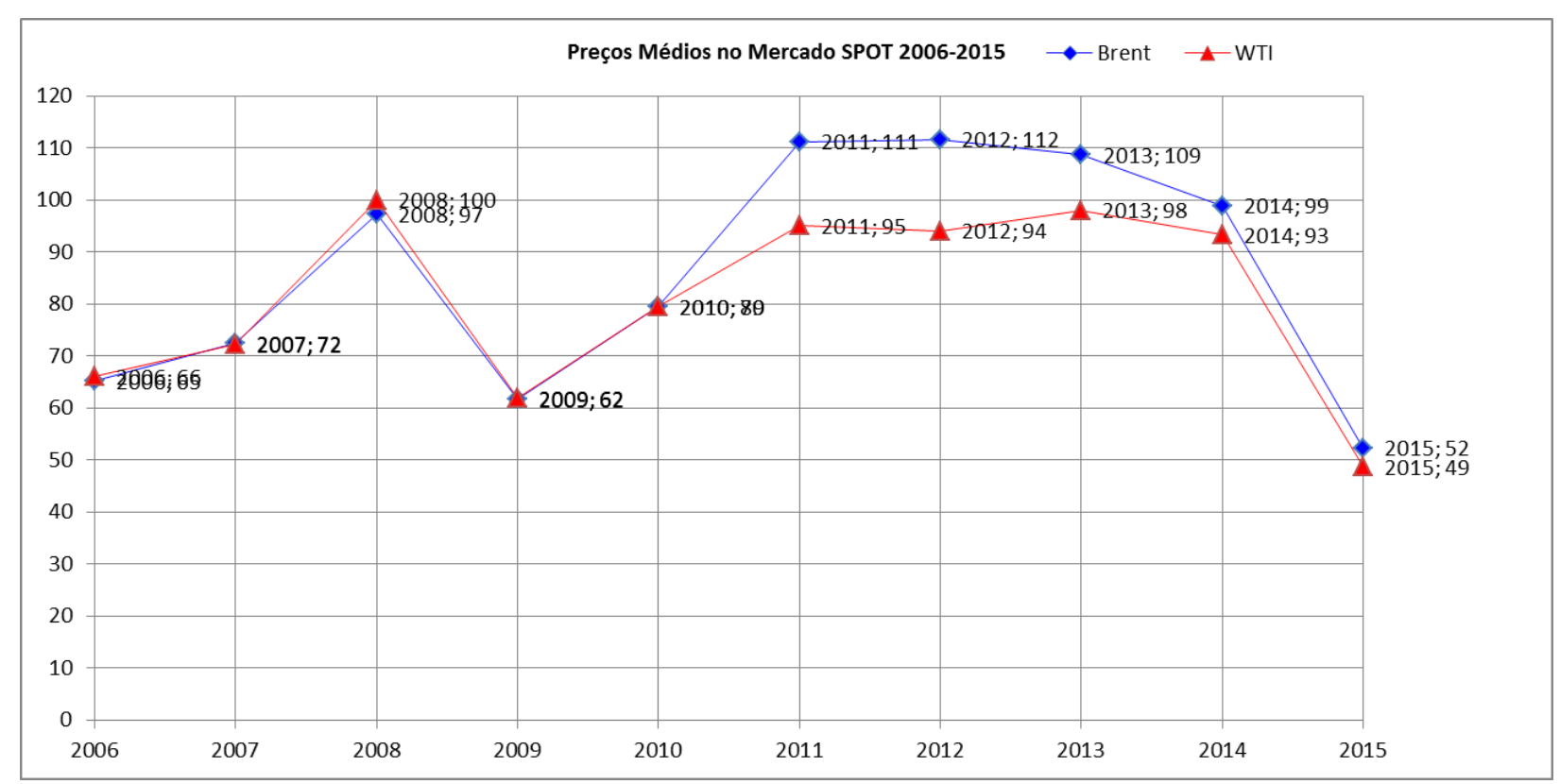

Figura 13 - Gráfico Preços Médios (US\$) no Mercado SPOT 2006-2015 Fonte: Adaptado de BP Statistical Review of World Energy 2016; ANP, 2016. 


\subsection{A Indústria de Apoio Marítimo}

Di Luccio e Dores (2016) destacam que os serviços de apoio marítimo offshore tem como objetivo o fornecimento de apoio logístico às unidades de Exploração \& Produção de petróleo. Diversos tipos de serviços são prestados, como o transporte de equipamentos, pessoas, manuseio de âncoras, manutenção de plataformas, combate à incêndios etc. A logística de apoio marítimo em instalações offshore é uma parte importantíssima da Exploração \& Produção de petróleo, porém, poucas pesquisas têm sido feitas nesta área (AAS et al., 2007). Já Ritchie (2008) afirma que a indústria de apoio marítimo é um setor variado, que opera com vários tipos de embarcações, realizando diferentes tipos de tarefas. As embarcações são construídas de acordo com o tipo de serviço especializado que irá realizar.

O apoio marítimo possui grande relevância na indústria de petróleo, pois funciona como uma área estratégica que integra diversos segmentos da Exploração \& Produção offshore. A Figura 14 a seguir, mostra os principais serviços de apoio marítimo offshore.

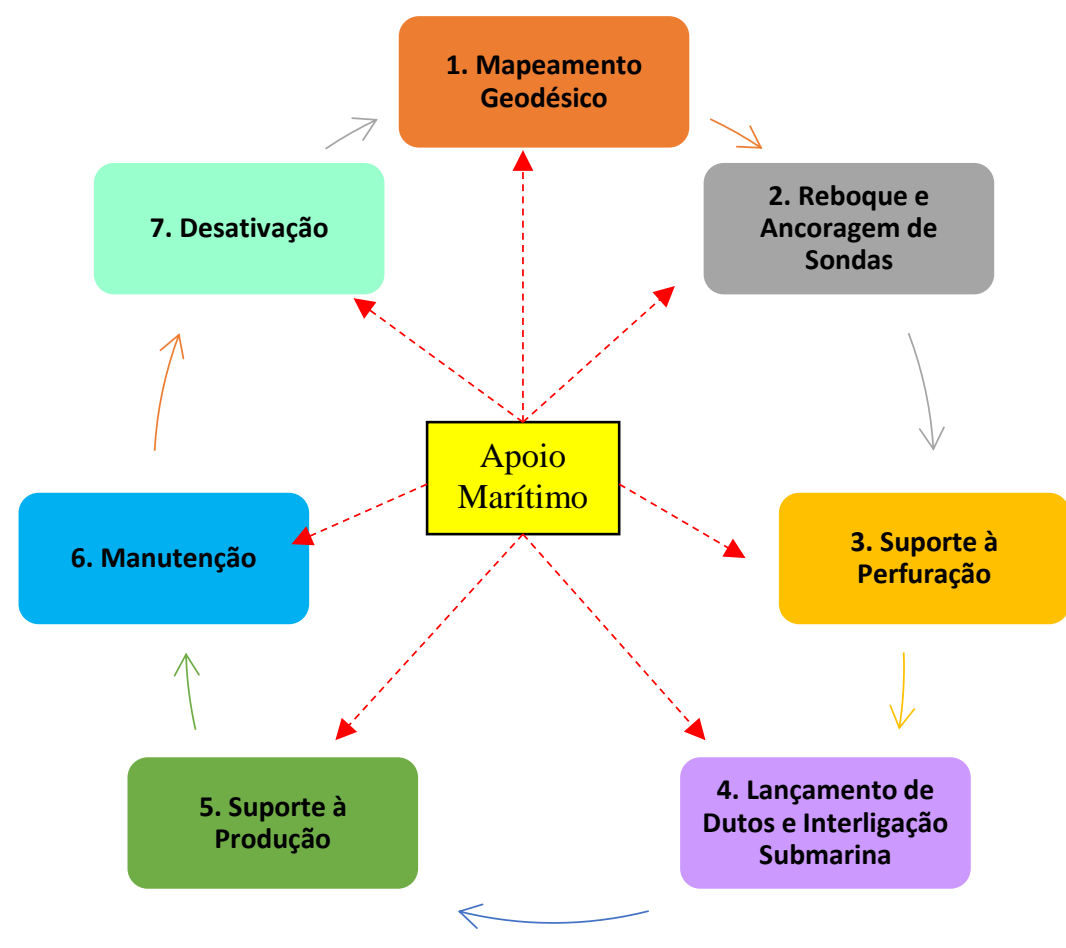

Figura 14 - Principais serviços de apoio marítimo offshore

Fonte: Adaptado de Mathedi (2010), Antaq (2012). 
De acordo com a Figura 14, os principais serviços de apoio marítimo são compostos por:

1. Mapeamento geodésico: consiste no levantamento geodésico visando determinar o potencial de presença de óleo em um campo ainda não explorado. Por meio da aquisição de dados geofísicos é possível analisar a estrutura do subsolo e determinar locais mais prováveis que haja acumulação de hidrocarbonetos (BACON et al., 2007).

2. Reboque e Ancoragem de Sondas: nos locais identificados com potencial de conter óleo é realizada a perfuração por uma sonda. Algumas sondas são navios adaptados e possuem sistemas de posicionamento dinâmico (hélices distribuídos ao longo do casco do navio que, quando acionados, permitem manter o sistema flutuante em uma posição fixa). Por outro lado, muitas sondas são unidades flutuantes (ex: plataforma semi-sub) desprovidas de sistemas de propulsão, que necessitam ser rebocadas e ancoradas em seus locais de operação (RITCHIE, 2004; MENDES, 2007; SHYSHOU et al., 2010).

3. Suporte à Perfuração: o processo de perfuração e preparação de um poço para a etapa produtiva consome diversos materiais, como tubos de diferentes diâmetros, cimento, lama para perfuração, entre outros itens. Estes materiais são supridos a partir de bases em terra por embarcações de apoio, que também fornecem água potável, água para uso industrial, alimentos e óleo diesel para os geradores elétricos a bordo (RITCHIE, 2004).

4. Lançamento de Dutos e Interligação Submarina: após a preparação do poço, um conjunto de equipamentos são instalados, inclusive com o objetivo de interligar a produção de outros poços que estejam próximos, centralizando a transferência do óleo produzido à unidade flutuante de produção, de onde o petróleo será transportado para terminais em terra. Assim, tanto o lançamento de dutos como a interligação destes aos manifolds (equipamento disposto no leito submarino composto de painéis de controle de válvulas que permitem controlar o fluxo de óleo dos poços a ele interligados) constituem serviços especiais de apoio marítimo. (QUEIROZ, 2011; BAI; BAI, 2012).

5. Suporte à Produção: de forma semelhante ao suporte à perfuração, as unidades flutuantes de produção necessitam de materiais, equipamentos, ferramentas, além de consumíveis como água potável, água para uso industrial, óleo diesel para os geradores e alimentos. Estes itens de suprimento são transportados de forma regular às unidades (FAGERHOLT; LINDSTAD, 2000; GRIBKOVSKAIA et al., 2008; HALVORSENWEARE et al., 2012) por embarcações de apoio marítimo.

6. Manutenção: a infraestrutura submarina passa por um processo permanente de manutenção, seja em caráter corretivo, ou preventivo e preditivo. Inspeções 
programadas também fazem parte desta classe de serviço. Tendo em vista que uma interrupção no sistema produtivo resulta em prejuízos para a empresa, a cobertura deve ser eficaz, no sentido de conferir uma rápida resposta na presença de uma intercorrência (BASSI et al., 2012; EL-REEDY, 2012). O apoio marítimo de manutenção realiza estes serviços, que são imprescindíveis para a produção do petróleo no mar, de forma contínua e sustentável.

7. Desativação: ocorre ao fim da vida útil de um poço. Este serviço tem uma dimensão crítica em relação ao meio ambiente, dado que não deve haver risco de qualquer tipo de vazamento ou contaminação com a desativação de um poço. Esta classe de serviço também envolve a desmobilização (retirada) dos equipamentos envolvidos (GERWICK Jr, 2007), e são realizados com o suporte das embarcações de apoio marítimo.

A figura 15 a seguir, mostra um panorama da cadeia de petróleo.

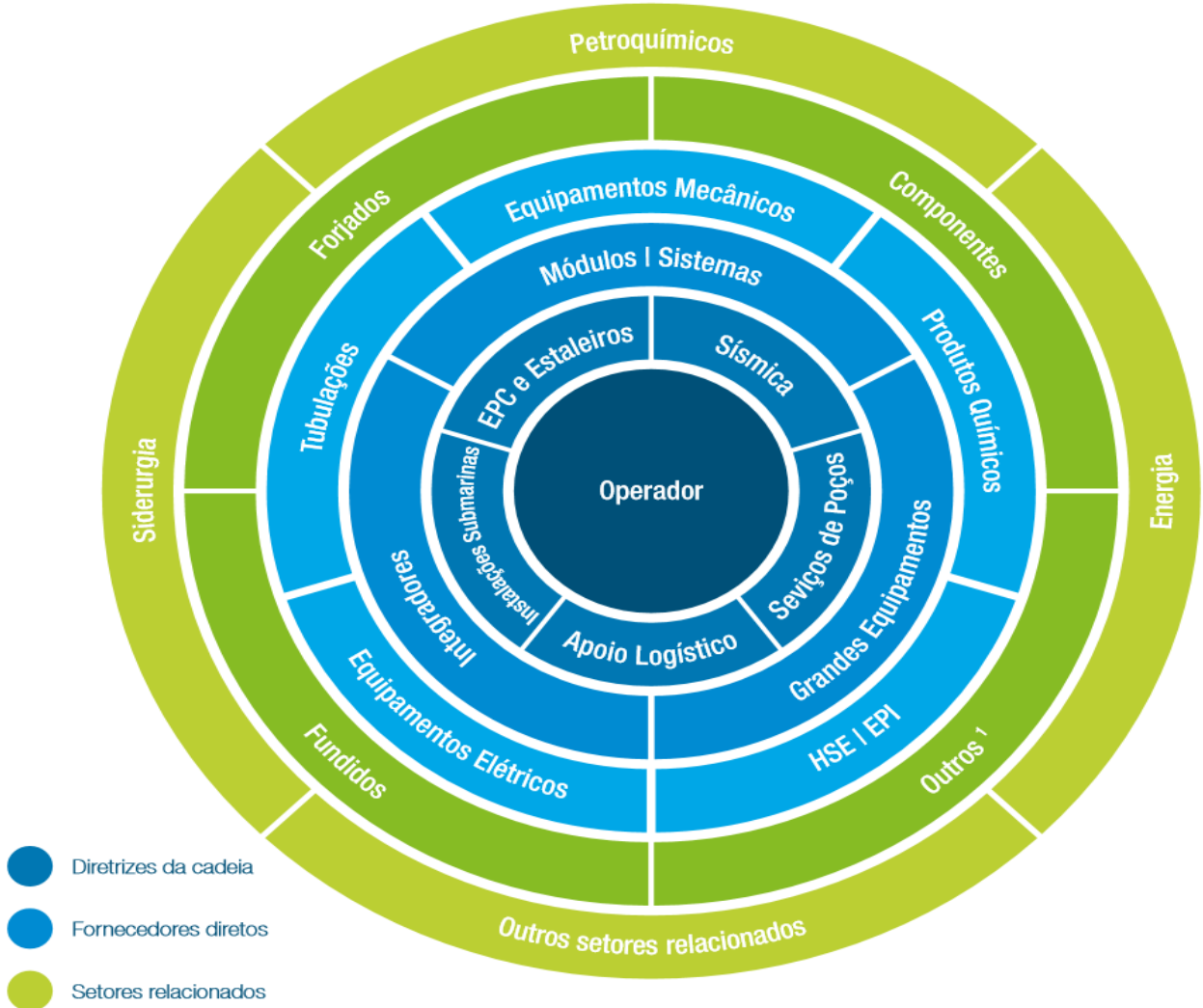

Figura 15 - Cadeia de Petróleo Fonte: Onip, 2010.

Conforme visto, o apoio marítimo desempenha muitas atividades logísticas. De acordo com o $\operatorname{CSCMP}^{5}$ (1998), a logística é o processo de planejamento, implementação e controle do

\footnotetext{
${ }^{5}$ Council of Supply Chain Management Professionals. Em 1998 era CLM (Council of Logistics Management)
} 
fluxo eficiente e eficaz de mercadorias, serviços e das informações relativas desde o ponto de origem até o ponto de consumo com o propósito de atender às exigências dos clientes. $\mathrm{O}$ conceito de cliente é muito amplo, já que na cadeia de petróleo, as interações são basicamente B2B (business to business). Esta cadeia demanda serviços logísticos dos mais variados tipos e complexidades.

Em ILOS (2013), a classificação proposta para os tipos de apoio marítimo são: i) logística de cargas (envolvendo todos os suprimentos anteriormente mencionados); ii) transporte de passageiros (que, no Brasil, é feito unicamente por helicópteros - MENEZES et al., 2010); iii) logística de serviços (demais serviços excluindo o transporte de suprimentos).

As embarcações que realizam os serviços de apoio marítimo são conhecidas como offshore support vessels (OSVs). As atividades das OSV geram uma conexão essencial entre as instalações offshore e a cadeia de suprimentos (KAISER, 2015). É importante destacar que poucos estudos abordaram as atividades operacionais e os impactos causados pelas OSVs nos portos, na área costeira e na qualidade do ar (KAISER, 2015). Em relação aos custos das embarcações, Aas et al., (2009) relatam que as instalações offshore necessitam de serviços de apoio regularmente, e que as embarcações responsáveis por transportar suprimentos (Supply Vessels) representam um dos maiores custos na cadeia de suprimentos upstream de uma instalação offshore.

O apoio marítimo ou apoio logístico offshore, faz parte de um sistema logístico offshore (KAISER; SNYDER, 2013). Este sistema pode ser dividido em três partes:

i) Parte terrestre;

ii) Parte portuária;

iii) Parte offshore.

A parte terrestre consiste em ferrovias, dutos, rodovias que são usadas para movimentar as mercadorias em terra para os portos, onde são separados, coletados e armazenados antes de serem transportados para o mar. Na parte portuária, o porto possui o papel de conectar as mercadorias que chegam pela parte terrestre às instalações offshore, por meio dos serviços de apoio marítimo. Os portos diferenciam-se em tamanhos, layout e capacidade de atendimento das embarcações, porém possuem objetivos comuns. 
Os portos servem como bases para as empresas de apoio marítimo, em que é possível executar uma série de serviços como: recebimento de mercadorias que chegam pelo fluxo terrestre, armazenagem, fabricação, reparo e manutenção de embarcações, e gestão dos resíduos. Já a parte offshore, consiste em diversos tipos de embarcações especializadas em diferentes serviços. Realizam o transporte de suprimentos, tripulantes e diversos materiais para as instalações offshore, e também executam a logística reversa. A Figura 16 a seguir, mostra a interação das três áreas.

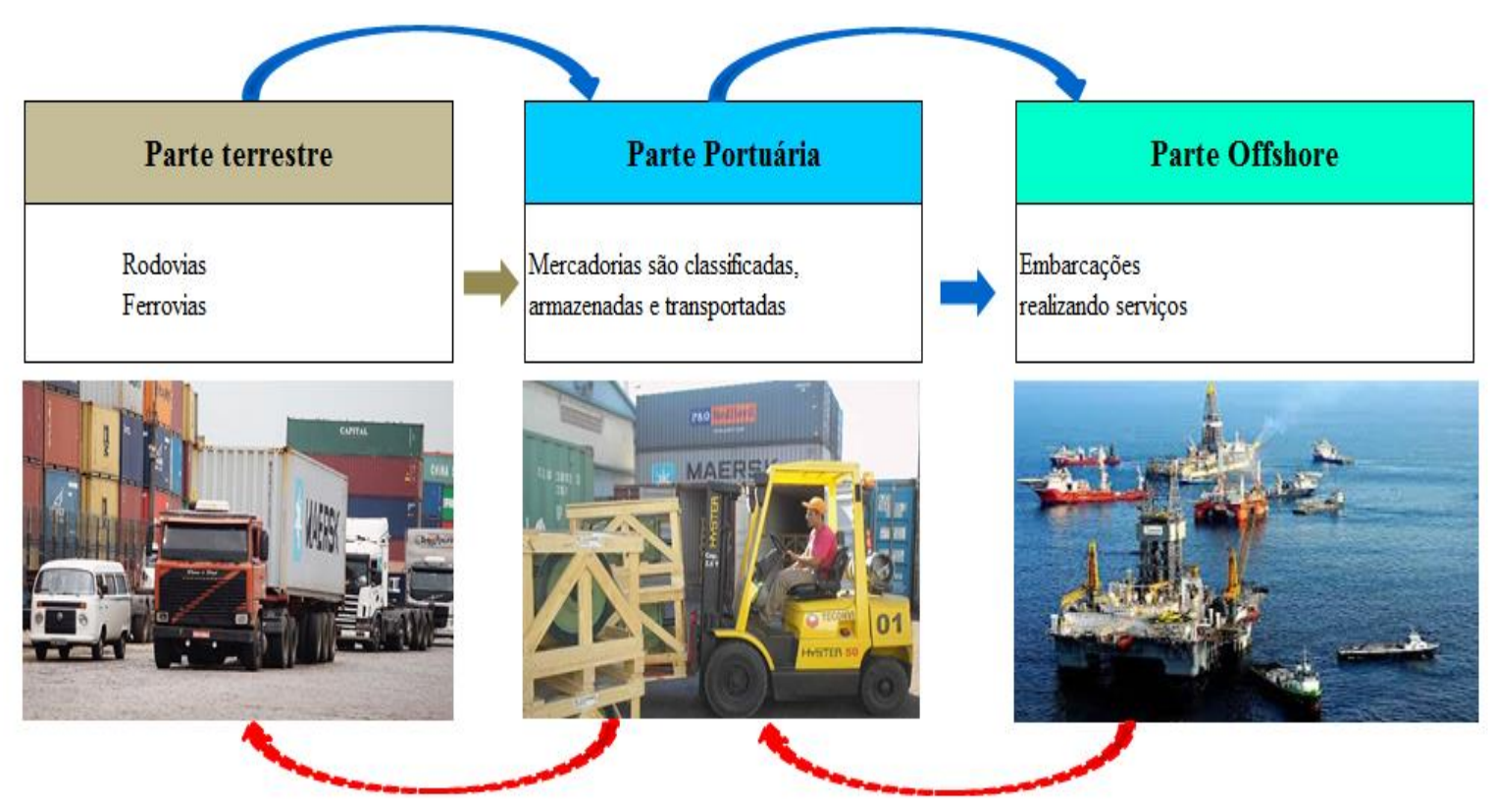

Figura 16 - Sistema logístico offshore

O fluxo em azul é o fluxo direto de abastecimento das unidades de Exploração \& Produção. As rodovias e as ferrovias trafegam os diversos materiais e mercadorias, que serão descarregados nos portos para uma triagem e depois armazenados, para posterior embarque e transporte para as unidades de E\&P, de acordo com a programação. Já o fluxo em vermelho, diz respeito à logística reversa, tanto de materiais, quanto de tripulantes que trabalham nas unidades marítimas.

De acordo com Mathedi (2010), as embarcações de apoio marítimo possuem características que vão além do atendimento às plataformas, como: i) convés para o transporte de carga geral como tubos de perfuração, equipamentos, dutos etc; ii) tanques para granéis líquidos, podendo ser óleo combustível, água para uso industrial, água potável, fluídos para perfuração etc; iii) silos e tanques para granéis sólidos, para cimentos, por exemplo e iv) 
câmaras frigoríficas para os alimentos. A Figura 17, elaborada a partir de Mathedi (2010) mostra a evolução do setor de apoio marítimo no Brasil.

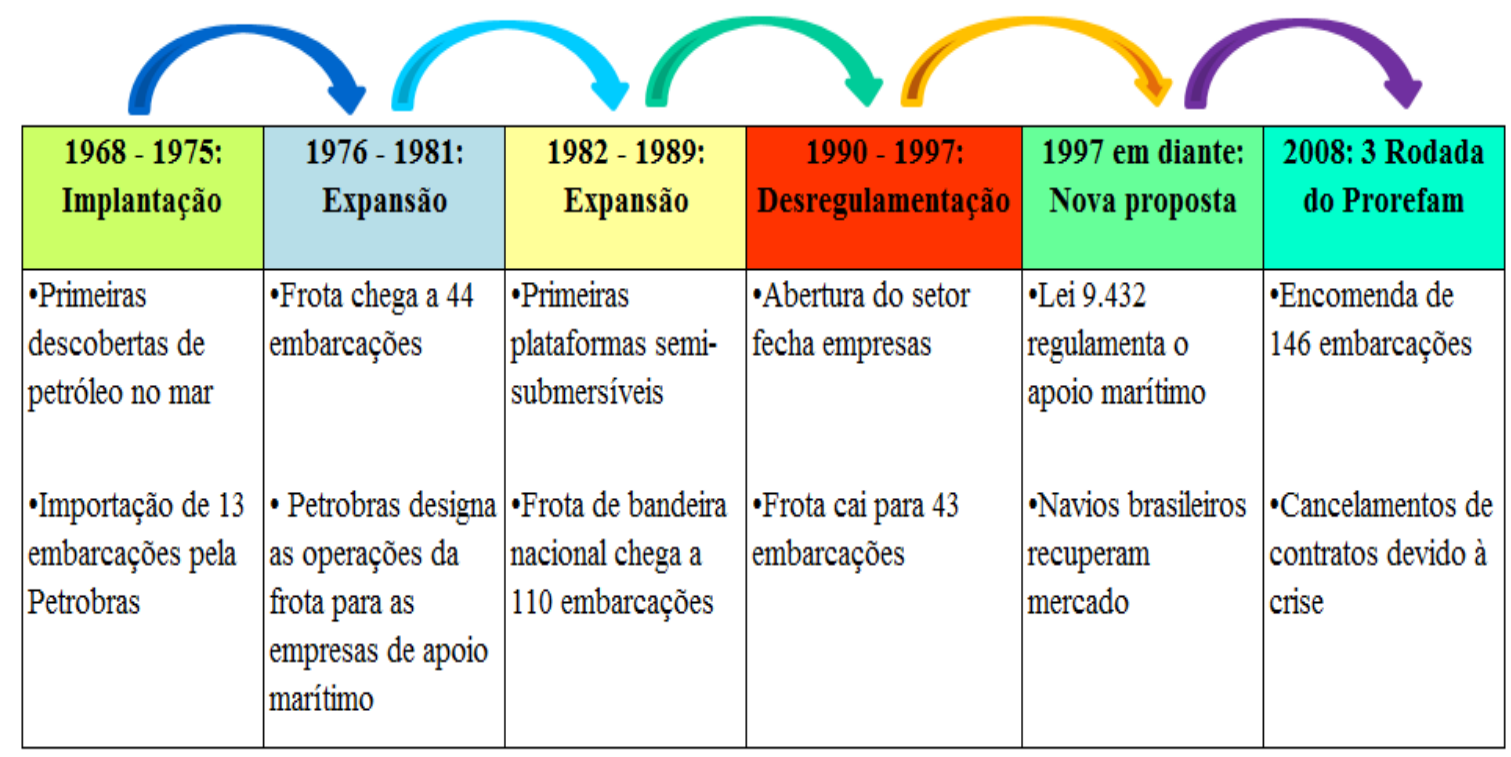

Figura 17 - Histórico do apoio marítimo no Brasil.

Fonte: Adaptado de Mathedi (2010).

No início dos anos 2000, com o aumento das cotações do barril de petróleo, o crescimento da produção offshore, e com o avanço da tecnologia possibilitando explorações em águas profundas e ultraprofundas, resultou em um aumento da demanda no mercado de apoio marítimo em escala global, gerando assim, uma busca por embarcações mais complexas e eficientes. E isto refletiu positivamente no mercado brasileiro.

Di Luccio e Dores (2016) mostram que existe uma forte correlação da indústria de apoio offshore com os preços do barril de petróleo, e com o número de unidades marítimas em atuação. Os autores mostram que a demanda por embarcações de apoio marítimo é proporcional à quantidade de unidades de perfuração e de produção em uma razão de dois a quatro embarcações por unidade, a depender da fase do ciclo do campo de petróleo, e das peculiaridades tecnológicas envolvidas. 


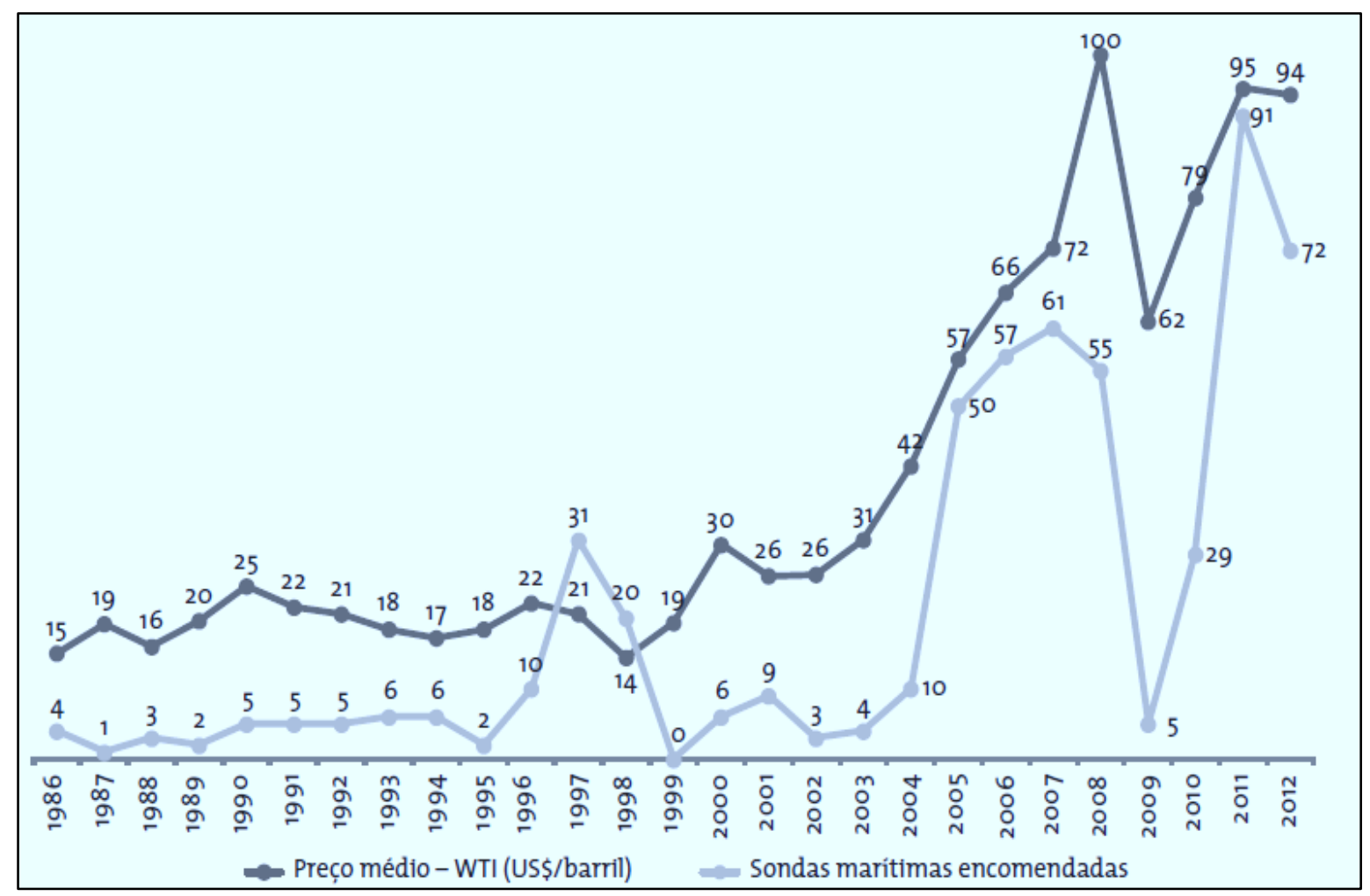

Figura 18 - Relação do preço do barril e sondas marítimas encomendadas. Fonte: Di Luccio e Dores (2016).

Um aspecto importante para o avanço e desenvolvimento da indústria de apoio marítimo, são as políticas industriais/governamentais desenvolvidas para o setor. Um programa de destaque nos últimos anos é o Programa de Renovação e Ampliação da Frota de Apoio Marítimo (PROREFAM). Foi desenvolvido para impulsionar o crescimento da indústria naval brasileira. Consiste basicamente na contratação de embarcações de apoio pela Petrobras por meio de contratos de longo prazo. Isto fez com que o setor de apoio marítimo ficasse bastante atrativo e também aumentou a demanda em estaleiros para a construção de embarcações de apoio (PETROBRAS, 2014). O PROREFAM é dividido em três pilares:

i. $\quad$ Construção de navios no Brasil;

ii. Obter índice de conteúdo local mínimo de $65 \%$ e $70 \%$ na primeira e segunda fase do programa;

iii. Atingir competitividade internacional. 
O PROREFAM teve início em 1999, mas somente em 2008 decolou com a previsão de construção de 146 embarcações até 2014, impulsionado, principalmente, pelas descobertas do pré-sal. A Figura 19 a seguir mostra a evolução da frota de apoio marítimo em um intervalo de tempo de 30 anos (1985-2015).

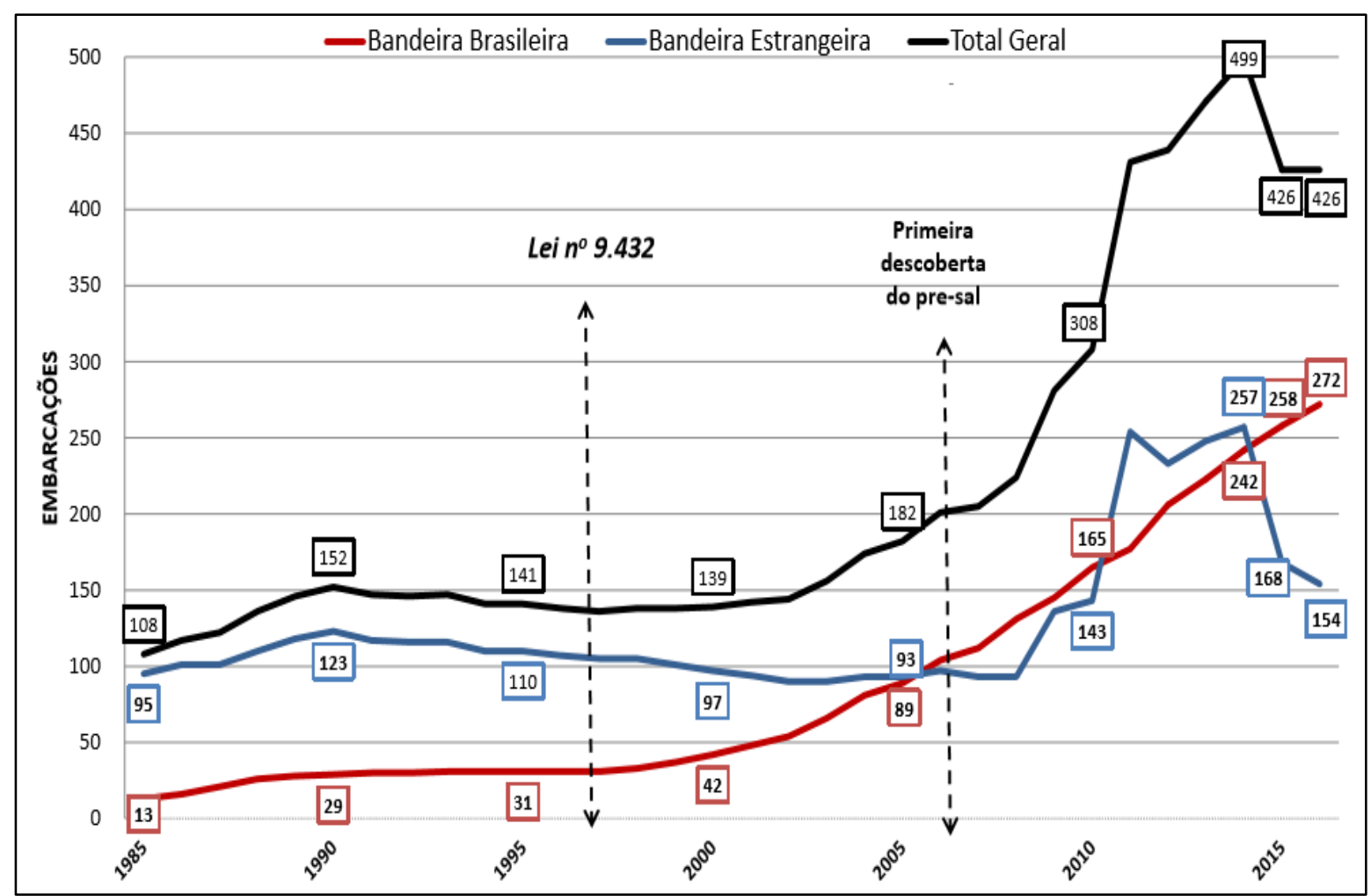

Figura 19 - Evolução da frota de apoio marítimo

Fonte: Abeam, 2017.

A Tabela 9 seguir mostra o histórico das rodadas do Prorefam. O primeiro Prorefam e o segundo, foram constituídos por somente uma rodada cada. Já o terceiro que teve início em 2008, com sua primeira rodada em 2009, pode ser considerado o mais relevante, já que previa a contratação de 146 embarcações, que acabou impactando de forma positiva toda a cadeia naval. 
Tabela 9 - Rodadas do Prorefam

\begin{tabular}{|c|c|c|c|c|c|c|}
\hline RODADA & ANO & AHTS & PSV & OSRV & LH & TOTAL \\
\hline $1^{\circ}$ PROREFAM & 2000 & 9 & 3 & - & 6 & 18 \\
\hline $2^{\circ}$ PROREFAM & 2004 & - & 20 & - & - & 20 \\
\hline \multicolumn{7}{|l|}{$3^{\circ}$ PROREFAM } \\
\hline $1^{\mathrm{a}}$ Rodada & 2009 & - & 8 & 5 & - & 13 \\
\hline $2^{\mathrm{a}}$ Rodada & 2010 & 6 & 20 & 1 & - & 27 \\
\hline $3^{\text {a }}$ Rodada & 2011 & - & 8 & 8 & - & 16 \\
\hline $4^{\mathrm{a}}$ Rodada & 2013 & - & 9 & 14 & - & 23 \\
\hline $5^{\text {a Rodada }}$ & 2013 & 5 & 3 & - & - & 8 \\
\hline $6^{\mathrm{a}}$ Rodada & 2014 & 4 & 19 & - & - & 23 \\
\hline $7^{\text {a }}$ Rodada & 2014 & - & 9 & 2 & & 11 \\
\hline Subtotal $3^{\circ}$ PROREFAM & & 15 & 76 & 30 & 0 & 121 \\
\hline Cancelamentos & & - & -4 & -4 & & -8 \\
\hline Total $3^{\circ}$ PROREFAM & & 15 & 72 & 26 & 0 & 113 \\
\hline $\begin{array}{l}\text { Previsão de Contratações } 3^{\circ} \\
\text { PROREFAM }\end{array}$ & & & & & & 146 \\
\hline
\end{tabular}

Fonte: Abeam, 2017.

Percebe-se que após as primeiras descobertas do pré-sal, a partir de 2007, houve uma "corrida" pela contratação de embarcações para dar suporte à grande demanda projetada. Em 2005, a frota total (bandeira brasileira mais bandeira estrangeira) era de 182 embarcações. Em 2015, este número já era praticamente de 500 embarcações. A partir da crise acentuada (econômica/política) que o país passou a vivenciar a partir de 2014, e também do baixo preço do barril de petróleo no mundo, de acordo com a Abeam (2017), a frota de apoio marítimo em janeiro de 2017 passa a ser de 390 embarcações, sendo 303 embarcações de bandeira brasileira e 87 de bandeira estrangeira.

Os tipos e características das embarcações de apoio marítimo podem ser classificados em três grandes grupos, conforme Pinto et al. (2006):

1) Embarcações Rebocadoras e Supridores: embarcações de porte médio, variando de 60 a 80 metros de comprimento. Possui capacidade de reboque, desenvolvendo tarefas variadas como: manuseio e transporte de âncoras e plataformas, suprimento às plataformas de perfuração e produção;

2) Embarcações Supridoras: embarcações de médio porte, cujo objetivo é abastecer com insumos e equipamentos as unidades de Exploração \& Produção. Esta classe de embarcações pode transportar cargas sólidas a granel e também em container, por 
exemplo, alimentos, peças de reposição, tubos etc. Também transportam cargas líquidas como combustíveis e lamas de perfuração;

3) Embarcações de Pequeno Porte e Utilitário: embarcações de pequeno porte, que possuem entre 20 e 40 metros de comprimento, utilizadas principalmente para o transporte de passageiros para as plataformas, cargas leves, suporte a manobras de amarração etc.

A seguir, o Quadro 1 destaca os principais tipos de embarcações utilizadas no apoio marítimo:

\begin{tabular}{|c|c|}
\hline Tipo de Embarcação & Descrição \\
\hline AHTS - Anchor Handling Tug Supply & $\begin{array}{l}\text { Atua como rebocador, manuseio de âncoras e transportes de } \\
\text { suprimentos (tubos, água doce, óleo, lama, salmoura, cimento, } \\
\text { peças etc.). }\end{array}$ \\
\hline CREWBOAT & $\begin{array}{l}\text { Utilizado no transporte rápido da tripulação e de outras equipes } \\
\text { que atuam nas plataformas. }\end{array}$ \\
\hline DSV - Diving Support Vessel & Suporte e apoio ao mergulho \\
\hline FSV - Fast Supply Vessel & $\begin{array}{l}\text { Utilizadas para levar de forma bastante ágil tripulantes para as } \\
\text { plataformas de petróleo, bem como equipamentos e itens de } \\
\text { consumo como água e alimentação. }\end{array}$ \\
\hline LH - Line Handling & Utilizada no manuseio de espias (cabos de amarração). \\
\hline MPSV - Multi-purpose Supply Vessel & $\begin{array}{l}\text { Navio multitarefa - transporte de suprimentos (cimento, tubos, } \\
\text { lama, salmoura, água doce, óleo e granéis) e manuseio de âncoras. }\end{array}$ \\
\hline OSRV - Oil Spill Recovery Vessel & Utilizado no combate ao derramamento de óleo. \\
\hline PLSV - Pipe Laying Support Vessel & Usadas na construção e lançamento de linhas. \\
\hline PSV - Platform Supply Vessel & $\begin{array}{l}\text { Utilizado no apoio às plataformas de petróleo, transportando } \\
\text { material de suprimento: cimento, tubos, lama, salmoura, água } \\
\text { doce, óleo, granéis. }\end{array}$ \\
\hline RSV - Research Supply Vessel & Barco de apoio à pesquisa e coleta de dados sísmicos \\
\hline SV - Supply Vessel & $\begin{array}{l}\text { Embarcação de apoio às plataformas de petróleo menor que um } \\
\text { PSV. }\end{array}$ \\
\hline UT - Utility & $\begin{array}{l}\text { Embarcação de pequeno porte e ligeira usada no transporte de } \\
\text { pessoal que trabalham a bordo das plataformas }\end{array}$ \\
\hline WSV - Well Stimulation Vessel & Embarcação utilizada para estimulação de poços \\
\hline
\end{tabular}

Quadro 1 - Tipos de Embarcações de Apoio Marítimo

Fonte: Antaq (2012a). 
Segundo Stopford (2009), as formas de contratação dos serviços de apoio marítimo são: i) Afretamento por tempo: o fretador disponibiliza a embarcação armada e tripulada por um período de tempo definido para o afretador; ii) Afretamento por viagem: o navio e sua tripulação são colocados à disposição do afretador para efetuar um número determinado de viagens e manobras; iii) Afretamento a casco nu: o fretador disponibiliza apenas a embarcação por um tempo determinado, sendo o afretador responsável pela designação da tripulação. No serviço de apoio marítimo predomina o afretamento por tempo (caso i), no qual a embarcação de apoio fica à disposição da contratante (ex: Petrobras), a qual paga ao armador a taxa diária de afretamento e os custos decorrentes de uso da navegação (combustível e taxas portuárias). A seguir, a Tabela 10 destaca a composição da frota de apoio marítimo do Brasil em 2016.

Tabela 10 - Composição da Frota de Apoio Marítimo do Brasil em 2016

\begin{tabular}{lcc}
\multicolumn{1}{c}{ Tipo de Embarcação } & Quantidade & \% do total \\
\hline $\begin{array}{l}\text { PSV - Platform Supply Vessel } \\
\text { AHTS - Anchor Handling Tug }\end{array}$ & 161 & 38,9 \\
Supply & 65 & 15,7 \\
LH - Line Handling & 62 & 15,0 \\
OSRV - Oil Spill Recovery Vessel & 43 & 10,4 \\
RSV - Research Supply Vessel & 16 & 3,9 \\
FSV - Fast Supply Vessel & 14 & 3,4 \\
PLSV - Pipe Laying Support Vessel & 14 & 3,4 \\
CREW - CREWBOAT & 12 & 2,9 \\
MPSV - Multi-purpose Supply & 10 & 2,4 \\
Vessel & 7 & 1,7 \\
SV - Supply Vessel & 5 & 1,2 \\
DSV - Diving Support Vessel & 5 & 1,2 \\
WSV - Well Stimulation Vessel & $\mathbf{4 1 4}$ & $\mathbf{1 0 0}$ \\
\hline$\quad$ Total da Frota & Singval, &
\end{tabular}




\subsubsection{Complexidades da Previsão de Novos Blocos Exploratórios para o Apoio Marítimo}

O apoio marítimo é um segmento dependente das demandas de Exploração \& Produção de petróleo. Nesse contexto, existe um conjunto de vários complicadores que as empresas estão sujeitas, e que torna as atividades de planejamento uma das mais difíceis. A necessidade de previsão e acompanhamento de novos blocos de exploração caracteriza uma das maiores complexidades, visto que existe uma lacuna de tempo considerável entre o processo de licitação do bloco, e a efetiva contratação das embarcações pelo grupo responsável pela exploração do bloco.

Por meio do site http://www.brasil-rounds.gov.br a ANP comunica todas as ações e processos referentes a licitações de petróleo e gás. Dessa forma, é possível estudar e entender o potencial dos blocos que estão sendo licitados, como também as rodadas em planejamento. Em 2017, o calendário aprovado para o biênio 2018-2019, de acordo com a ANP (2017), está previsto as seguintes rodadas de licitações de blocos:

$\checkmark \quad$ 15 $^{\text {a }}$ Rodada de Licitações de Blocos. (Previsão: primeiro semestre de 2018);

$\checkmark \quad$ 16 $^{\text {a }}$ Rodada de Licitações de Blocos. (Previsão: segundo semestre de 2019).

Assim, é fundamental para as empresas de apoio marítimo possuírem ferramentas de inteligência e previsão de demanda, pois, de acordo com o tamanho do bloco exploratório licitado, haverá a necessidade de contratação de várias embarcações, porém, em muitos casos, as empresas não possuem embarcações disponíveis para atender toda a demanda. Com isso, gera-se a necessidade para a encomenda de novas embarcações. Dependendo da embarcação, o tempo médio desde a contratação, construção até a entrega, pode ser superior a 40 meses (SINAVAL, 2015b). Este longo tempo é gerado por causa de diversas ineficiências como: i) problemas na contratação com o estaleiro; ii) qualificação da mão de obra na construção naval; iii) atendimento ao conteúdo local e iv) dificuldades para obtenção de financiamento (SINAVAL, 2015b). Esta demora, gera consequências negativas para as empresas, principalmente em relação aos financiamentos das embarcações.

Portanto, as empresas de apoio marítimo, além de lidar com a escassez de recursos diariamente, necessitam "planejar” as demandas, para: i) conseguir participar das concorrências atuais dos serviços de apoio marítimo; ii) obter os retornos financeiros necessários para quitar 
o financiamento das embarcações; iii) otimizar a produtividade; iv) minimizar custos; v) prospectar novos contratos (concorrências).

A necessidade de as empresas de apoio marítimo possuírem ferramentas de inteligência para fazer a previsão de novos blocos, torna-se importante, pois, analisar o fluxo de caixa atual, e projetá-lo em um horizonte de tempo médio/longo, fazendo o cruzamento com o potencial retorno dos possíveis contratos de afretamento, é de alta complexidade. Esta dinâmica, deveria ser levada em consideração ao decidir sobre a encomenda de novas embarcações. Porém, não são análises triviais, e que necessita de ferramentas, métodos e técnicas robustas.

\subsubsection{Os Desafios Logísticos da Exploração \& Produção do Pré-sal}

O pré-sal constitui-se de reservas de petróleo e gás no subsolo oceânico que antecede a densa camada de sal. O anúncio oficial da descoberta do pré-sal foi feito em outubro de 2007 pela Petrobras e isto colocaria o Brasil como um dos grandes players mundiais, tanto como produtor, quanto como exportador. Estima-se que haja mais de 100 bilhões de barris recuperáveis nesta camada, e até mesmo, que o número seja o triplo deste valor, colocando o Brasil como um dos maiores detentores do recurso ao lado da Venezuela e Arábia Saudita (SAUER; RODRIGUES, 2016). A seguir, a Figura 20, mostra a camada pré-sal.

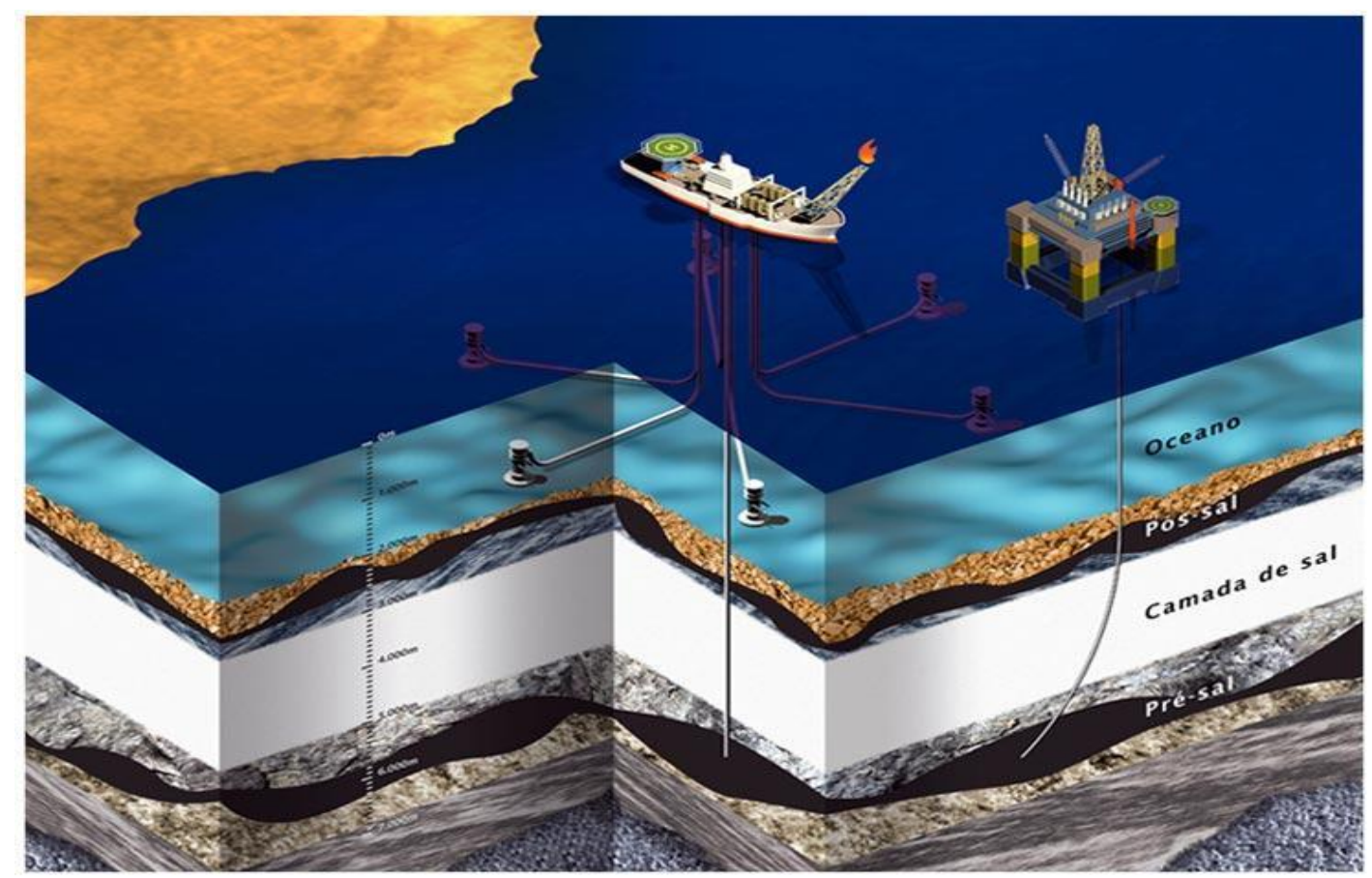

Figura 20 - A camada pré-sal

Fonte: http://www.estudopratico.com.br/a-camada-pre-sal/ 
O pré-sal encontra-se em águas ultraprofundas, com lâminas d'água superiores a 2.000 metros (BELTRÃO et al., 2009; FERRO; TEIXEIRA, 2009). Já os reservatórios estão localizados entre 5.300 e 7.000 metros de profundidade e a uma distância da costa de cerca de $300 \mathrm{~km}$ (BUCHEB, 2014). Estes fatores são muito complexos, o que acaba necessitando de serviços logísticos (apoio marítimo) especializados, tanto na Exploração \& Produção, quanto no escoamento da produção. A Figura 21 mostra o mapa da área de exploração do pré-sal. A área abrange aproximadamente $800 \mathrm{~km}$ de comprimento e em alguns locais até $200 \mathrm{~km}$ de largura, que vai desde o litoral do Espírito Santo até o litoral de Santa Catarina (FERRO; TEIXEIRA, 2009).

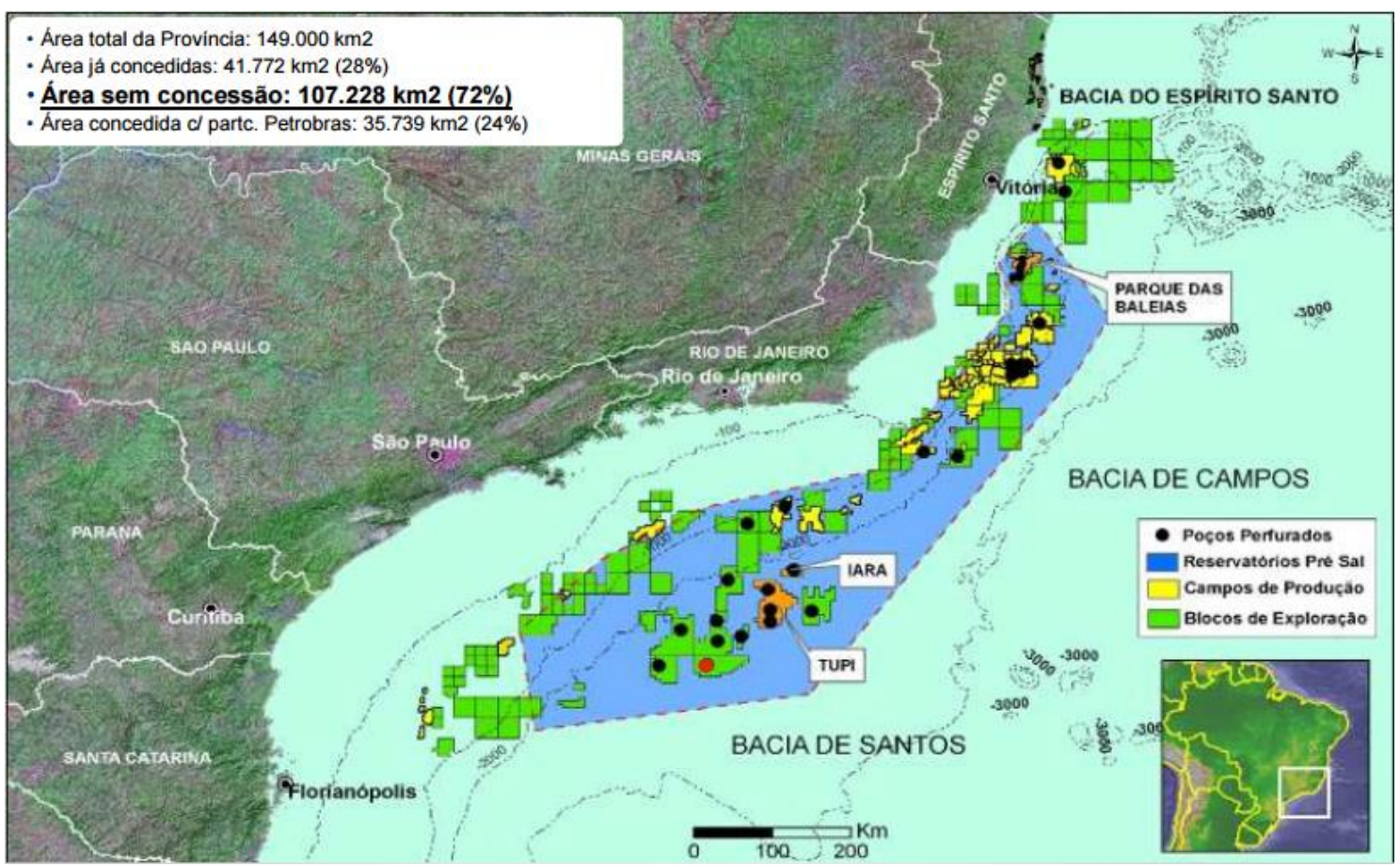

Figura 21 - Extensão potencial da camada pré-sal

Fonte: Estrella (2009)

Um dos principais desafios da Exploração \& Produção na região do pré-sal é o planejamento logístico. A distância de $300 \mathrm{~km}$ do continente associado ao fluxo de aproximadamente 60 mil profissionais por mês, tendo ainda estimativas para dobrar este valor, torna o processo complexo (TERRA; FERREIRA; NASCIMENTO, 2014). Os portos atuais não serão suficientes para atender o crescimento da produção do pré-sal. Por exemplo, o campo de Libra necessitará de 12 a 15 plataformas de produção, sendo cada plataforma atendida por 4 embarcações de apoio, o que demandaria mais 48 embarcações (GÓES; NOGUEIRA, 2013). 
Este cenário desafiador impacta diretamente no planejamento e operação das empresas de apoio marítimo, visto que terão que buscar estratégias e tecnologia para prover serviços de alta qualidade, alta produtividade, e ao mesmo tempo reduzindo os custos operacionais e sem esquecer da busca constante pela inovação. Caso isso não ocorra, toda a cadeia de suprimentos ficará prejudicada e com isso, o consumidor final arca com tais ineficiências e o país também perde em termos de competitividade mundial. Por exemplo, a produção do pré-sal em 2010 era de aproximadamente 41 mil barris/dia, já em 2016, a Petrobras alcançou a marca de 1 milhão de barris/dia (PETROBRAS, 2017). Dessa forma, os serviços de apoio marítimo deverão acompanhar este ritmo acelerado de crescimento, sem onerar os custos. A Figura 22 a seguir, compara a produção da camada pré-sal em relação a produção da camada pós-sal, durante um intervalo de um ano.

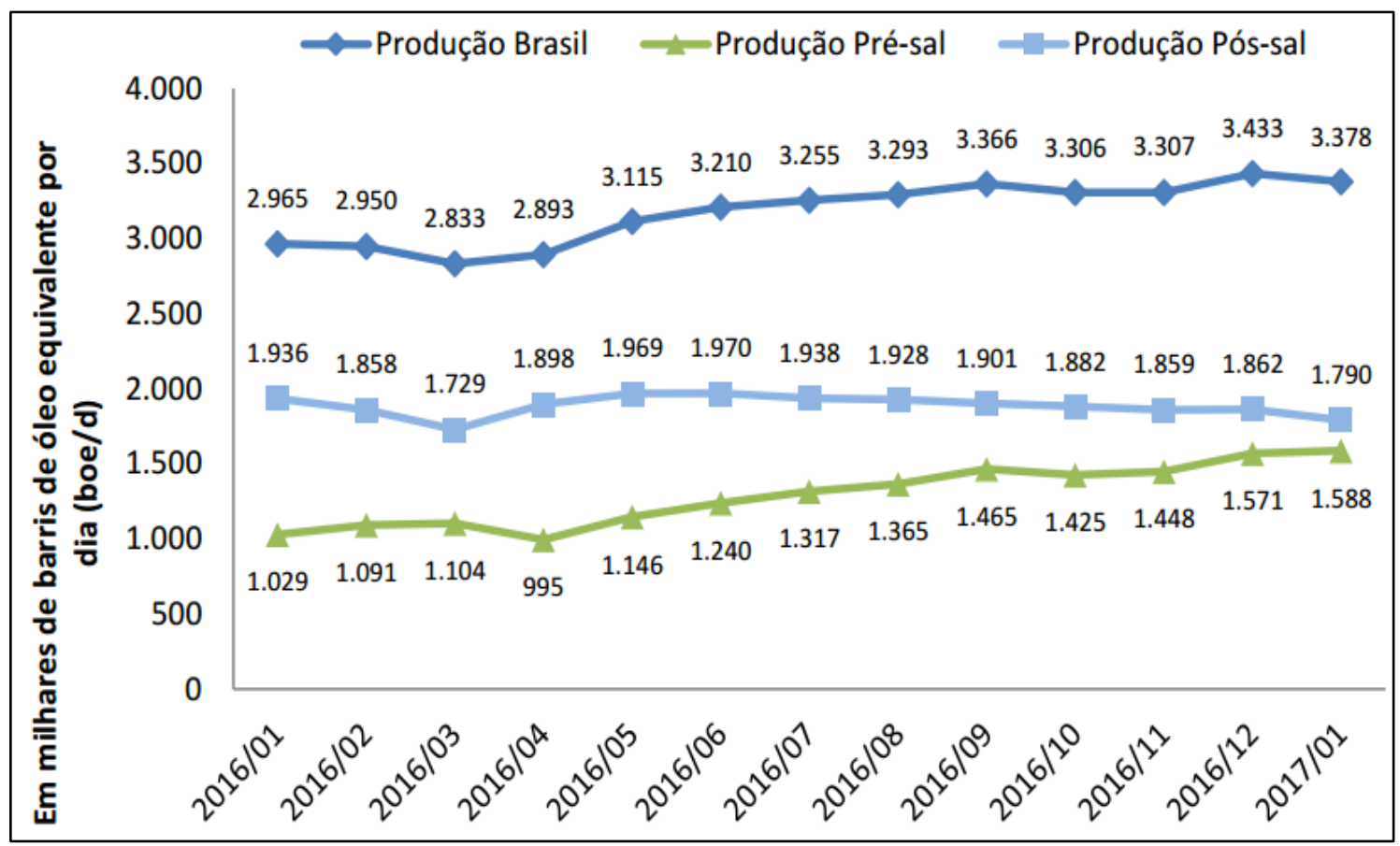

Figura 22 - Evolução da produção pré-sal x pós-sal (Mboe/d)

Fonte: http://www.anp.gov.br/wwwanp/images/publicacoes/boletins-anp/Boletim_de_janeiro2017.pdf

Por meio do gráfico, percebe-se que existe uma tendência de a produção do pré-sal ultrapassar a produção do pós-sal em um horizonte de tempo curto. Para que isto ocorra, há a necessidade cada vez mais de serviços de apoio marítimo de excelência mundial. 
Falcão et al. (2007) destaca alguns dos principais desafios na Exploração \& Produção do pré-sal:

i. Problemas logísticos para o transporte do petróleo e gás, devido ao alto custo do transporte, principalmente pela distância dos campos até o continente;

ii. Complexidade logística por causa da distância de $300 \mathrm{~km}$ da costa. Este fator gera grande dificuldade para o transporte de operários, materiais diversos e suprimentos;

iii. Condições oceânicas complexas, com ondas altas, que dificulta o sistema de ancoragem das plataformas;

iv. Escassez de mão de obra;

v. Dificuldade para atendimento das metas de conteúdo local, devido a maior parte das empresas serem de pequeno porte;

vi. Destinação adequada do $\mathrm{CO}_{2}$ produzido;

vii. Complexidade para a perfuração dos poços, por causa da baixa taxa de penetração e à instabilidade do sal. 


\subsection{O Mapa Estratégico da Indústria}

O Mapa Estratégico da Indústria desenvolvida pela CNI (2013) tem como objetivo identificar oportunidades, ameaças e fraquezas da indústria brasileira, e desenvolver estratégias para superar as adversidades com o propósito de crescer de forma sustentável. O Mapa Estratégico da Indústria está relacionado com um exercício de visão estratégica para a construção de uma indústria de classe mundial, acelerando o ritmo de crescimento.

O mapa identifica 10 prioridades para o aumento da competitividade da indústria brasileira. A Figura a seguir, destaca o mapa.

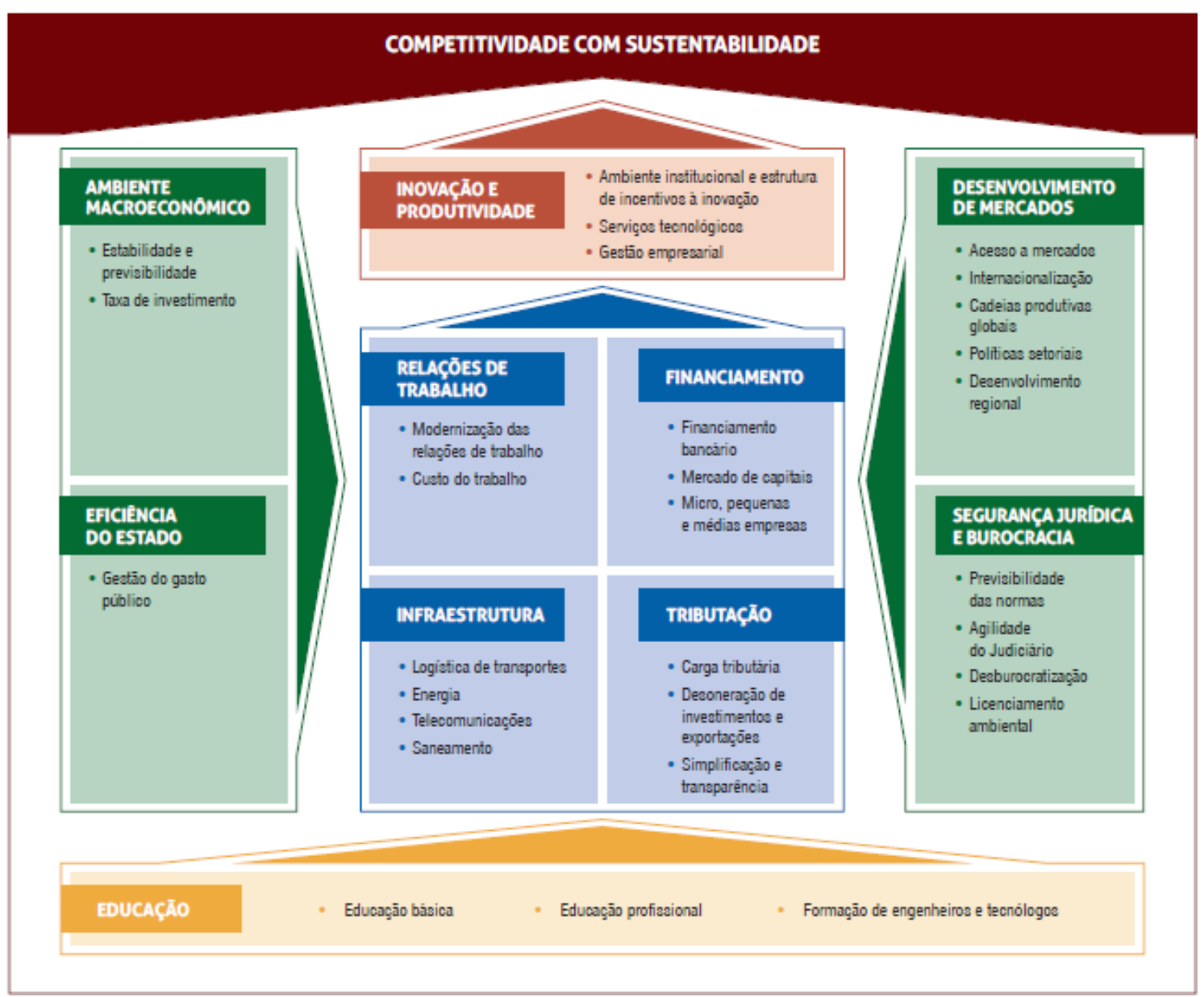

Figura 23 - Mapa Estratégico da Indústria

Fonte: CNI (2013)

A base do mapa é sustentada pela educação, que abrange todos os níveis educacionais (básico, profissional e superior). Assim, é fundamental para a geração de negócios e também para o desenvolvimento de inovação. Na sequência, tem-se os elementos que estão associados 
ao ambiente de atuação: ambiente macroeconômico, eficiência do Estado, desenvolvimento de mercados, e segurança jurídica e burocracia. O próximo grupo são os elementos associados aos investimentos e custos de produção, a saber: infraestrutura, financiamento, relações de trabalho e tributação. O último grupo contempla a inovação e a produtividade.

Conhecimento e Inovação são os principais motores para o aumento da produtividade e competitividade, visto que de acordo com a Organização para a Cooperação e Desenvolvimento Econômico - OCDE, mais da metade da riqueza mundial é gerada pelo conhecimento. O gráfico indicado na Figura 24 destaca esta importância, ao apontar os investimentos em Pesquisa \& Desenvolvimento como um percentual do PIB de alguns países, e também a relação de pesquisadores e engenheiros por milhão de pessoas.

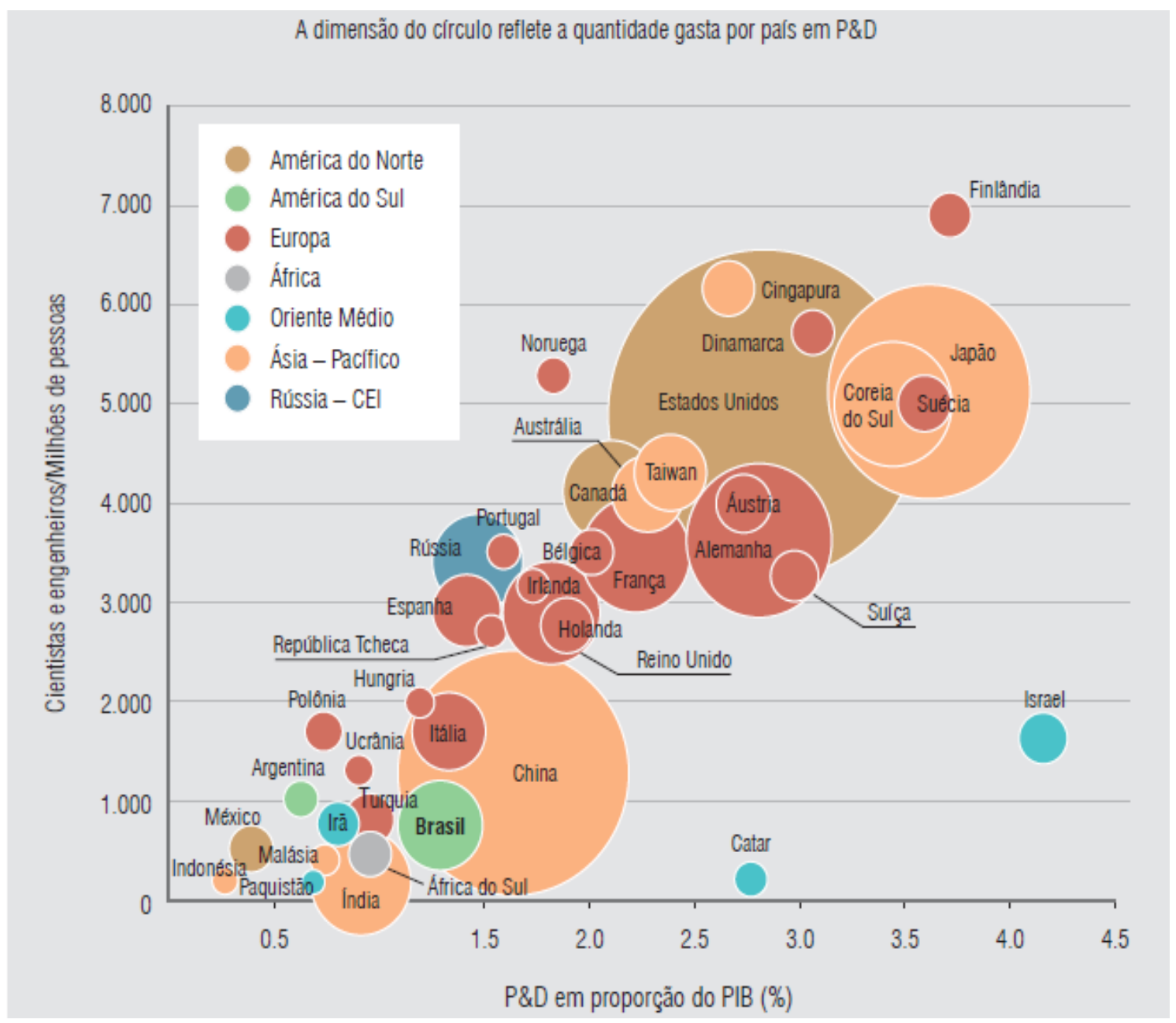

Figura 24 - Investimento em P\&D como uma Proporção do PIB em 2010

Fonte: CNI, 2013. 
A Figura 25 mostra a evolução de alguns países em um período de cinco anos. Porém, o Brasil, não conseguiu melhorar seu desempenho. Ocorreu na verdade, uma leve retração. Fato que pode ser explicado pela instabilidade política econômica, e os desinvestimentos em Ciência e Tecnologia.

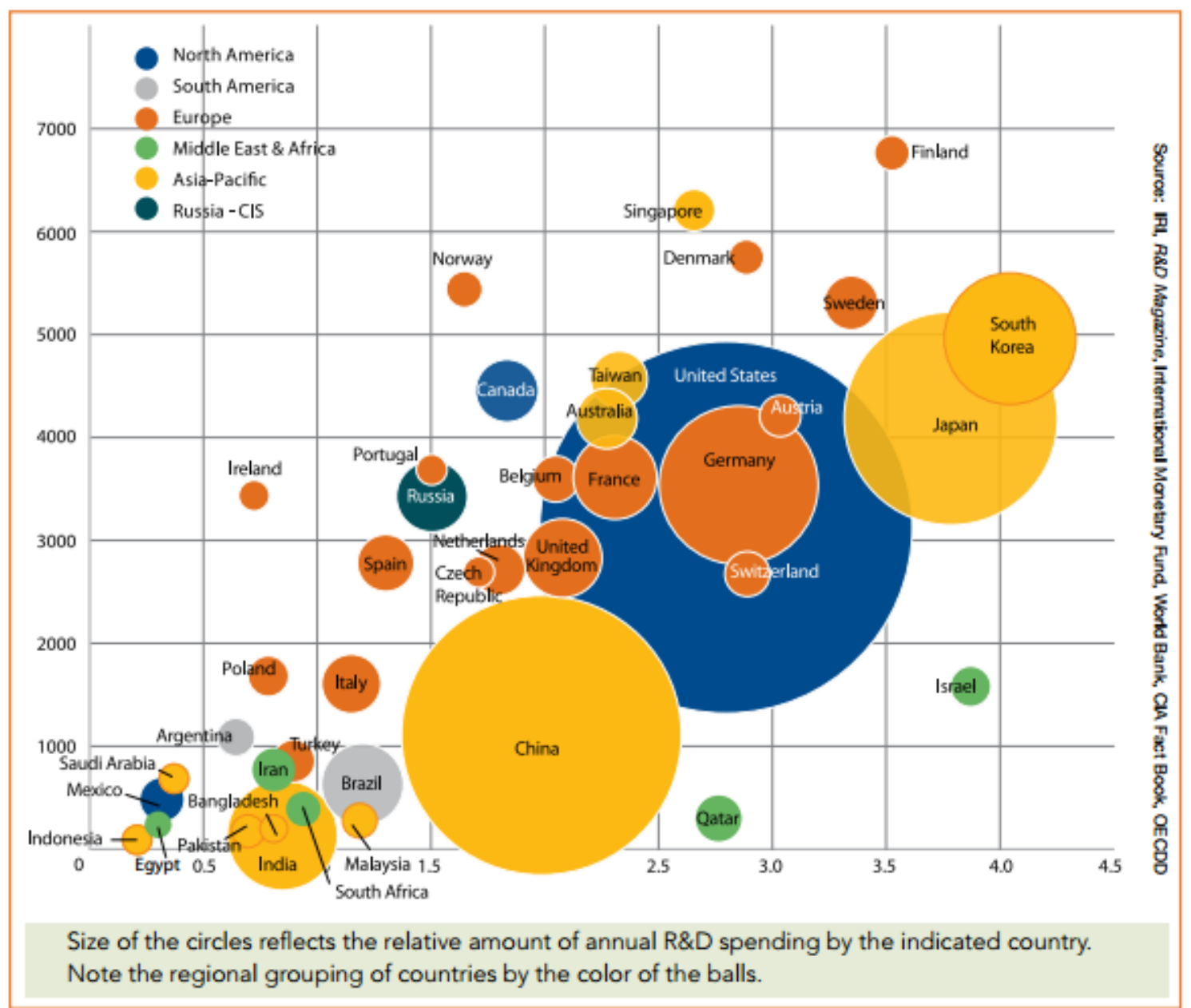

Figura 25 - Investimento em P\&D como uma Proporção do PIB em 2015 Fonte: R\&D Magazine.

A China é um dos países que mais tem investido em inovação. Em 2004, os seus centros de pesquisa e desenvolvimento depositaram 107 patentes, já em 2010, este número subiu para 1.100 (CNI, 2103). A seguir, são apresentadas as dimensões do Mapa Estratégico da Indústria. A estrutura aborda, para cada dimensão, uma visão de longo prazo, uma macrometa e um indicador. 


\subsubsection{Dimensão Educação}

A educação é a base para o desenvolvimento de qualquer país. De acordo com WEF (2016), em seu Relatório Global de Competitividade, o Brasil ocupa a posição 84 no ranking de educação, de um total de 138 países. A visão de longo prazo é elevar a educação básica, aumentar a oferta de mão de obra qualificada (tecnólogos e engenheiros), e também a formação profissional por meio de investimentos em treinamentos pelas empresas. A macrometa para o período é melhorar a qualidade da educação, e o indicador é a posição no ranking do Pisa ${ }^{6}$.

Um dos grandes gargalos para a inovação é a falta de profissionais graduados, de acordo com o IBGE (2007), já que apenas 0,03\% dos jovens entre 20 e 29 anos estavam matriculados em um curso da área de mineração. Enquanto no Brasil tem-se 2 graduados em engenharia para cada 10.000 habitantes, no Chile a proporção é de 4,1 para 10.000 habitantes, na Itália de 9,4, em Portugal 13,9 e na Coréia do Sul de 16,4, (IEDI, 2010).

\subsubsection{Dimensão Ambiente Macroeconômico}

Esta dimensão possui uma grande importância na composição do Mapa Estratégico, pois aborda os fatores essenciais relativos a investimentos. Reduzir as incertezas futuras é um dos fatores chaves para atrair investimentos para a indústria. $\mathrm{O}$ ambiente macroeconômico também é abordado pelo WEF (2016) em seu Relatório Global de Competitividade. Em 2016, o Brasil ocupou a posição $126^{\mathrm{a}}$, no ranking composto por 138 países.

A visão de longo prazo é crescer por meio das taxas de investimentos, juros competitivos, inflação baixa e redução da carga tributária. Estes são considerados fatores fundamentais para que o ambiente de negócios possa alavancar. A macrometa é elevar a taxa de investimento da economia e o indicador é a taxa de investimento. De acordo com a CNI (2013), o aumento da taxa de investimento é baseado no desempenho de 2012 de 18,1\% para $24 \%$ em 2022. Este valor referência deu-se pelo fato de a média mundial em 2012 ser de 23,6\%.

O gráfico da Figura 26 compara a evolução dos investimentos como um percentual do PIB do Brasil e seis países, no período de 2003 a 2011.

\footnotetext{
${ }^{6}$ PISA - Programa Internacional de Avaliação de Estudantes. É uma prova que aborda três áreas do conhecimento: matemática, leitura e ciências, que é aplicada pela Organização para Cooperação e Desenvolvimento Econômico (OCDE). O exame é realizado a cada três anos, para alunos na faixa etária de 15 anos.
} 


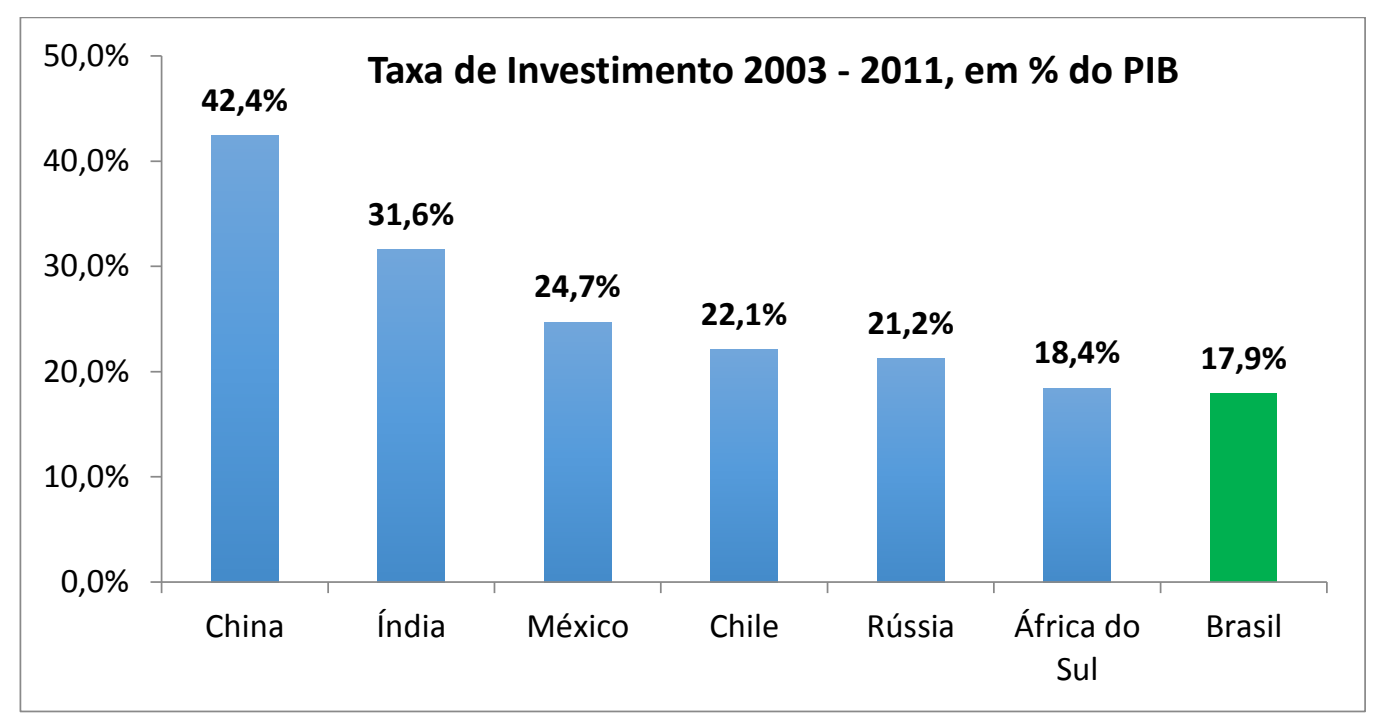

Figura 26 - Taxa de Investimento 2003 - 2011, em \% do PIB Fonte: Adaptado de CNI, 2013

Enquanto a taxa de investimento da China ultrapassa os $40 \%$, a do Brasil não chegou a 20\%. Países como o México e Chile, neste mesmo período, ultrapassaram a barreira dos $20 \%$. O fato é que estes países também estão à frente do Brasil no pilar educacional.

\subsubsection{Dimensão Eficiência do Estado}

Esta dimensão está atrelada aos gastos públicos (incluído investimentos). Impacta diretamente a educação e infraestrutura. Quando o Estado é eficiente, alocando de forma otimizada os investimentos, toda a cadeia industrial é beneficiada. Porém, quando existe ineficiência, impacta diretamente na indústria e, consequentemente, na competitividade do país. A ineficiência do Estado, gera externalidades negativas à indústria, ao fazer com que as empresas utilizem mais recursos que o necessário.

No Relatório Global de Competitividade 2016 do WEF, o Brasil ocupou a posição 120a em um ranking composto por 138 países. A meta de longo prazo é o Estado aprimorar a gestão, principalmente na execução do orçamento. Isto impactará significativamente na infraestrutura e serviços agregados, beneficiando toda a cadeia produtiva.

A macrometa para o horizonte de tempo considerado (2013-2022) é melhorar a composição do gasto público, e o indicador é a participação do investimento na despesa 
primária ${ }^{7}$ total do governo federal. A participação em 2012 foi de 5,8\%, e a meta é que se alcance $8 \%$ em 2022. A CNI (2013), destaca que neste mesmo período, a taxa do Chile foi de $12 \%$, enquanto a da Coréia do Sul atingiu $18 \%$.

\subsubsection{Dimensão Segurança Jurídica e Burocracia}

Segundo a CNI (2013), a falta de clareza e as constantes modificações nas legislações, assim como nos marcos regulatórios, prejudica de forma significativa a indústria nacional e consequentemente a competitividade do país. A complexidade das normas jurídicas e a burocracia estatal acabam dificultando a cadeia industrial, gerando um ambiente de negócios desfavorável, minimizando os investimentos internos e externos, e aumentando os custos de transação.

O Doing Business ${ }^{8}$ (2017), classificou o Brasil na Posição $123^{\mathrm{a}}$, em um ranking composto por 190 países. As dimensões analisadas estão na Tabela 11 a seguir.

\footnotetext{
${ }^{7}$ Despesa Primária: também conhecida como despesa não financeira, corresponde ao conjunto de gastos que possibilita a oferta de serviços públicos à sociedade, deduzidas às despesas financeiras. São exemplos os gastos com pessoal, custeio e investimento. Pode ser de natureza obrigatória ou discricionária.

${ }^{8}$ O Doing Business mensura, analisa e compara as regulamentações aplicáveis às empresas e o seu cumprimento em 190 economias e cidades selecionadas nos níveis subnacional e regional. Lançado em 2002, o projeto Doing Business examina as pequenas e médias empresas nacionais e analisa as regulamentações aplicadas a elas durante o seu ciclo de vida. Assim, este estudo serve de ferramenta para se medir o impacto das regulamentações sobre as atividades empresariais ao redor do mundo.
} 
Tabela 11 - Classificação do Brasil no Doing Business 2017

\begin{tabular}{lcc}
\hline \multicolumn{1}{c}{ Tópicos } & $\begin{array}{c}\text { Doing Business } \\
\mathbf{2 0 1 7}\end{array}$ & $\begin{array}{c}\text { Doing Business } \\
\mathbf{2 0 1 6}\end{array}$ \\
\hline Classificação Geral & $\mathbf{1 2 3}$ & $\mathbf{1 2 1}$ \\
Abertura de empresas & 175 & 174 \\
Obtenção de alvarás de construção & 172 & 170 \\
Obtenção de eletricidade & 47 & 39 \\
Registro de Propriedades & 128 & 130 \\
Obtenção de crédito & 101 & 97 \\
Proteção dos investidores minoritários & 32 & 30 \\
Pagamento de impostos & 181 & 181 \\
Comércio internacional & 149 & 150 \\
Execução de Contratos & 37 & 45 \\
Resolução de insolvência & 67 & 60 \\
\hline
\end{tabular}

Fonte: Doing Business 2017

Esta classificação é preocupante, já que a média dos países latino-americanos e caribenhos é $97^{a}$ posição. Analisando a tabela, percebe-se que os itens que estão com as piores classificações, são os referentes a segurança jurídica e burocracia. Na dimensão Abertura de empresas, o Brasil alcançou a posição 175 ; no tópico Obtenção de alvarás de construção, 172ª ; em Registro de propriedades, $128^{\mathrm{a}}$; em Obtenção de crédito, $101^{\mathrm{a}}$ posição; referente a pagamentos de impostos, $181^{\text {a }}$ posição; e em comércio internacional, obtivemos a posição $149^{\text {a }}$.

A visão para 2022 é que as leis e as normas sejam mais previsíveis, assim com a tramitação dos processos jurídicos seja mais rápida, e haja maior simplificação dos aspectos burocráticos. Essas mudanças farão com que o ambiente de negócios seja mais dinâmico, produtivo e inovador. Como macrometa, a CNI estabeleceu aumentar a segurança jurídica e reduzir a burocracia. O indicador é a posição no ranking Doing Business.

\subsubsection{Dimensão Desenvolvimento de Mercados}

O desenvolvimento de mercados é uma dimensão estratégica para o país, pois, com uma base industrial diversificada acaba impulsionando o país para competir em mercados internacionais e em cadeias globais de valor. Tudo isso só é possível por meio de altas taxas de produtividade e inovação. O Relatório Global de Competitividade do WEF (2016) destaca o Brasil na $8^{\mathrm{a}}$ posição, porém, no comércio internacional estamos em $27^{\mathrm{a}}$ posição, e em exportações como um percentual do PIB, a posição é a $128^{\mathrm{a}}$. 
O desafio para o país é integrar-se às cadeias globais de valor. Segundo a CNI (2013), a estrutura industrial do país tende a melhorar por meio de políticas setoriais específicas, e consequentemente, maximizando a participação no contexto do comércio internacional. Como macrometa, foi estabelecida a ampliação da participação do Brasil na produção mundial de manufaturados, e o indicador é participação da produção brasileira de manufaturados na produção mundial.

\subsubsection{Dimensão Relações de Trabalho}

Esta dimensão possui um grande impacto na competitividade das empresas, devido às leis que regulamentam as relações de trabalho estarem ultrapassadas. Segundo a CNI (2013), é necessário à criação e implantação de regras modernas e claras para gerar eficiência. No Relatório Global de Competitividade 2016 do WEF, o Brasil alcançou a posição 117 .

Com melhores relações entre empregado e empregador, a produtividade pode ter um aumento significativo. A CNI (2013), destaca como macrometa a modernização nas relações de trabalho. Um dos grandes impactos da falta de modernização das regulações do trabalho, é o custo do trabalho. De acordo com Souza et al. (2012), o custo de um trabalhador pode chegar a 2,83 vezes o salário da carteira, considerando um vínculo de 12 meses.

\subsubsection{Dimensão Financiamento}

Esta é uma dimensão chave para todas as cadeias produtivas, já que elas possuem uma grande dependência de disponibilidade de recursos para financiamento. E, por outro lado, o sistema financeiro deveria ofertar crédito a baixo custo para fomentar o desenvolvimento industrial. Segundo a CNI (2013), quando os recursos são insuficientes, com prazo inadequados e custos elevados, acabam inviabilizando uma grande quantidade de projetos.

O WEF (2016), em seu Relatório de Global de Competitividade, coloca o Brasil na posição (93 $)$. A CNI (2013) acredita que deveria haver uma menor dependência em relação aos 
bancos públicos, e isso seria conseguido mediante maior facilidade de concessão de crédito, com custos mais baixos, maior concorrência bancária e spreads ${ }^{9}$ mais baixos.

Isso possibilitaria uma maior participação de terceiros nos investimentos das empresas industriais, e, consequentemente, ampliando a oferta de longo prazo, assim, beneficiando o desenvolvimento da indústria. A macrometa estabelecida pela CNI é a ampliação da capacidade de investimento das empresas e o indicador e a participação de recursos de terceiros no financiamento de investimentos das empresas industriais.

\subsubsection{Dimensão Infraestrutura}

Não adianta as empresas maximizarem as suas produtividades, se a infraestrutura do país não avançar. A infraestrutura de transportes é considerada inadequada e ultrapassada. A Tabela 12 a seguir, elaborada a partir do Relatório Global de Competitividade 2016, retrata a situação da infraestrutura do Brasil.

Tabela 12 - Principais Indicadores de Infraestrutura

\begin{tabular}{lcc}
\hline \multicolumn{1}{c}{ Indicadores de Infraestrutura } \\
\hline \multicolumn{1}{c}{ Pilar } & Ranking \\
\hline Rodovias & 111 \\
Ferrovias & 93 \\
Portos & 114 \\
Aeroportos & 95 \\
Oferta de Eletricidade & 91 \\
\hline
\end{tabular}

Fonte: WEF, 2016

Este desempenho acontece pela falta de investimentos e também pela matriz de transportes que é desbalanceada. A Tabela 13, elaborada a partir de dados da CNT (2014), mostra a participação de cada modal na matriz. O domínio do modal rodoviário, faz com que a infraestrutura rodoviária se desgaste rapidamente e também acabe minimizando a competitividade entre os modais.

\footnotetext{
${ }^{9}$ Spread bancário é a diferença entre o que os bancos pagam na captação de recursos e o que eles cobram ao conceder um empréstimo para uma pessoa física ou jurídica.
} 
Tabela 13 - Matriz de Transportes do Brasil

\begin{tabular}{|c|c|c|}
\hline Modal & Milhões (TKU) ${ }^{10}$ & Participação \% \\
\hline Rodoviário & 485.625 & 61,1 \\
\hline Ferroviário & 164.809 & 20,7 \\
\hline Aquaviário & 108.000 & 13,6 \\
\hline Dutoviário & 33.300 & 4,2 \\
\hline Aéreo & 3.169 & 0,4 \\
\hline
\end{tabular}

Fonte: CNT, 2014

O Mapa Estratégico da Indústria reforça que é fundamental para o sistema logístico brasileiro que haja uma melhor distribuição dos modais. A macrometa é a melhoria da infraestrutura e o indicador é a participação do investimento em infraestrutura no PIB. Ao longo dos últimos anos, esta participação vem oscilando em torno de 2,0\%. A meta para 2022 é chegar em 5\%. Além da infraestrutura logística, o mapa também destaca a necessidade de melhorias na área de energia elétrica, telecomunicações e saneamento.

\subsubsection{Dimensão Tributação}

Quando o sistema tributário é complexo e oneroso, este impacta diretamente os investimentos e, consequentemente, reduz a competitividade. O Brasil possui uma das cargas tributárias mais altas do mundo, isto acaba elevando os custos de produção de bens e serviços, e o resultado é a perda de competitividade. O Doing Business (2017), classifica o Brasil na posição $\left(181^{\text {a }}\right)$, em um ranking composto por 190 países. Esta categoria, é a que o país obteve o menor desempenho. A alíquota total de impostos, representa aproximadamente $70 \%$ dos lucros das empresas, sendo que a média dos países latino americanos e caribenhos é de 46,3\%.

O Mapa Estratégico da Indústria, destaca a necessidade de uma estrutura tributária mais simples e transparente, com destaque para o fim das guerras fiscais. Como meta para o período, foi estabelecido a cumulatividade zero com redução da carga tributária, O indicador é a proporção da arrecadação gerada com incidências cumulativas na arrecadação tributária total. Além disso, como temas prioritários, existe a necessidade de desoneração de investimentos e exportações e simplificação da estrutura tributária.

\footnotetext{
${ }^{10}$ A produção em TKU é obtida multiplicando-se a tonelagem transportada pela distância percorrida.
} 


\subsubsection{Dimensão Inovação e Produtividade}

A inovação é uma das variáveis que mais impactam a produtividade, pois depende mais das próprias ações das empresas. De acordo com o Manual de Oslo (1997), uma inovação de produto é a introdução de um bem ou serviço novo ou significativamente melhorado. Estas melhorias significativas podem ser especificações técnicas, componentes e materiais, softwares incorporados, facilidade de uso etc. Segundo a CNI (2013), a produtividade da indústria manufatureira brasileira cresceu em média $0,6 \%$ no período de 2000 a 2010 . Esta taxa baixa de crescimento reflete no Relatório de Competitividade Global (2016), em que o Brasil ocupa a posição $\left(100^{a}\right)$ na dimensão inovação. A figura a seguir ilustra os desembolsos do BNDES para a inovação no período de 2010 a 2016.

\section{Desembolsos do BNDES para inovação, 2010-2016}

(em R\$ bilhões)

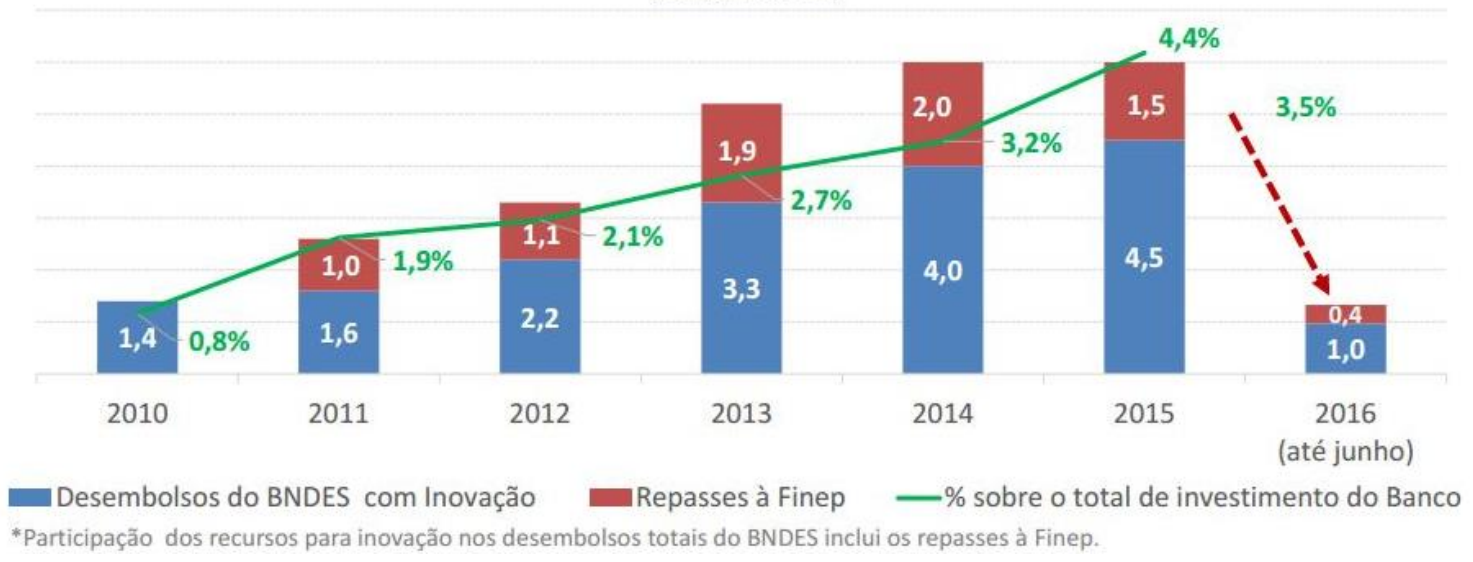

Figura 27 - Desembolsos do BNDES em inovação 2010 - 2016

Fonte: Portal da Indústria, 2016

O valor de 2016 foi quatro vezes inferior ao de 2015, em que foram investidos $R \$ 6$ bilhões para projetos e pesquisas. Para estimular os investimentos, a CNI destaca que é necessário um ambiente institucional favorável, com estruturas de financiamentos e incentivos à inovação. Como macrometa para o período, estabeleceu-se aumentar a produtividade da indústria, e o indicador é a taxa de crescimento da produtividade do trabalho na indústria. Além disso, faz parte dos temas prioritários o aumento da oferta de serviços tecnológicos para empresas e melhoria da qualidade da gestão empresarial. 


\subsection{Fatores Críticos de Sucesso}

A abordagem Fatores Críticos de Sucesso (FCS) foi introduzida por Daniel (1961), que discutiu os fatores críticos de sucesso que são relevantes para qualquer empresa em um segmento particular. Rockart (1979), define FCS como um método que determina precisamente quais são as informações mais vitais para um negócio. Bullen e Rockart (1981) caracterizam os Fatores Críticos de Sucesso como atividades chaves de uma área, nas quais os resultados favoráveis são absolutamente necessários para atingir os objetivos da empresa. A Figura 28, exemplifica alguns fatores críticos de sucesso em algumas indústrias.

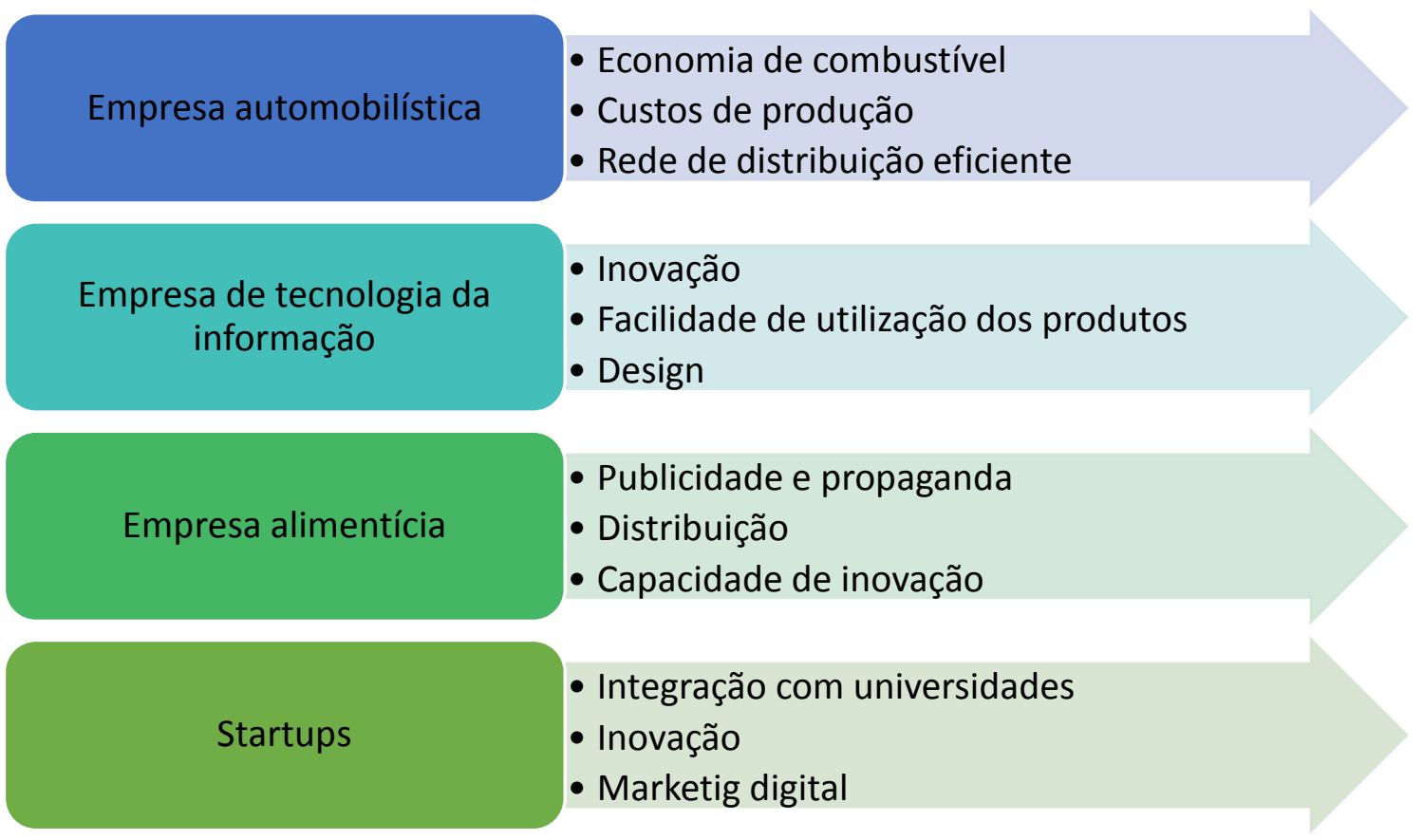

Figura 28 - Exemplos de Fatores Críticos de Sucesso em diferentes indústrias

A principal ideia dos Fatores Críticos de Sucesso é abordar poucos fatores que são críticos para o sucesso e performance competitiva de uma empresa. Isto representa as atividades que devem ser focadas e necessitam de muita atenção. Hofer e Schendel (1978) destacam que os Fatores Críticos de Sucesso podem ser influenciados pela gerência e que estes fatores variam geralmente de um segmento para outro. Já Leidecker e Bruno (1984) definem Fatores Críticos de Sucesso como as características, condições ou variáveis que, se corretamente seguidas, mantidas e geradas, podem ter um impacto significativo sobre o sucesso de uma firma de um determinado setor. 
Os Fatores Críticos de Sucesso não são imutáveis. Eles podem sofrer variações de acordo com as mudanças ocorridas no ambiente da indústria em que a organização está inserida. Os Fatores Críticos de Sucesso têm provado a sua aderência para o planejamento estratégico das organizações, fornecendo suporte para os gerentes focarem nos aspectos críticos do negócio (ROCKART, 1979, JALONEN; LÖNNQVIST, 2011, YEOH; POPOVIČ, 2016).

De Carli et al. (2010) afirmam que os Fatores Críticos de Sucesso atualmente são um conjunto de itens (atividades) que devem ser observados e gerenciados durante o planejamento, execução e controle de um projeto, dessa forma, contribuindo para que os resultados possam ser alcançados. Ainda de acordo com os autores, as empresas podem definir os FCS global (para toda a empresa), ou para diferentes funções da organização, como Fatores Críticos de marketing, manufatura, projeto etc.

Os Fatores Críticos de Sucesso influenciam de maneira significativa o desempenho de uma organização. De acordo com Slack (2002), os objetivos de desempenho de uma organização estão diretamente relacionados com o grau de competitividade dela, e os objetivos de desempenho também estão intrinsicamente relacionados com os fatores críticos de sucesso da empresa e os FCS correspondem às exigências estabelecidas pelos clientes e mercados.

\begin{tabular}{|l|l|}
\hline Fatores Críticos de Sucesso & Objetivos do Desempenho \\
\hline Serviços pós-venda & Qualidade \\
\hline Entrega no prazo correto & Confiabilidade \\
\hline Customização & Flexibilidade \\
\hline Economia de escala & Custo \\
\hline Tempo de entrega do produto final & Velocidade \\
\hline
\end{tabular}

Quadro 2 - Exemplos de Fatores Críticos de Sucesso na Manufatura Fonte: Slack, 2002.

Slack (2002) aborda os fatores críticos de sucesso do Quadro 2, por meio de uma adaptação do Modelo do Cone de Areia proposto por Ferdows; De Meyer (1990), para descrever o conceito de cumulatividade. A Figura 29 mostra o conceito de cumulatividade, que de uma maneira geral, podem ser Fatores Críticos de Sucesso para diversos tipos de indústrias, não somente a de manufatura. 
A ideia da cumulatividade baseia-se que para construir um cone de areia estável, é necessário primeiro um alicerce como base, essa base no modelo é representada pela melhoria de qualidade. Após a base estável ter sido construída, são acrescentadas outras camadas, como confiabilidade, velocidade, flexibilidade e custo. Somente por meio da expansão das partes mais baixas do cone é que se consegue atingir maiores alturas, por isso, é um processo de melhoria contínua (cumulativo) e não sequencial.

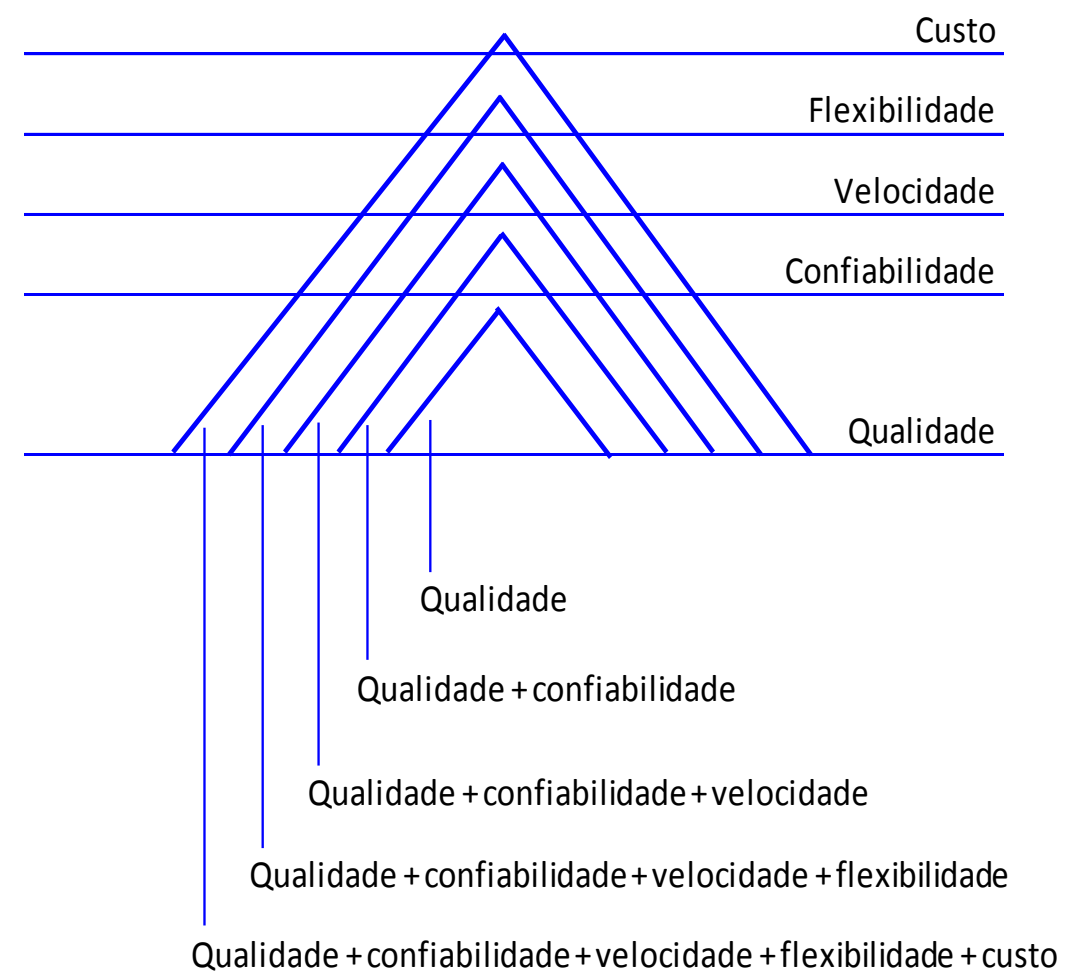

Figura 29 - Modelo de Competitividade de Slack

Fonte: Slack (2002)

Corrêa e Corrêa (2012) destacam o processo de priorização de critérios que os clientes realizam, introduzido por Hill (1985). Estes critérios são: ganhadores de pedidos e os qualificadores. Os critérios qualificadores diz que as empresas para competir em um determinado mercado, devem atingir um nível mínimo de desempenho. Já os critérios ganhadores de pedidos, estão relacionados com os critérios que levam os clientes a decidir sobre a escolha de um fornecedor, dentre um conjunto de fornecedores qualificados. Os autores também destacam uma terceira categoria de critérios, conhecido como "critérios menos importante". Nesta categoria, temos os critérios que não influenciam significativamente a 
decisão de compra dos clientes, porém é importante identifica-los, pois, influencia a alocação dos recursos e operações das organizações. Esta visão é fundamental, e reforça a importância da identificação dos fatores críticos de sucesso para qualquer segmento de mercado. 


\section{METODOLOGIA}

Este capítulo tem por objetivo apresentar o método utilizado na pesquisa, a fim de dar suporte e garantir a confiabilidade na identificação dos Fatores Críticos de Sucesso.

\subsection{Estudo de Caso}

O presente trabalho utilizou o método estudo de caso. Conforme Voss et al. (2002), o estudo de caso é um dos métodos mais poderosos em gerenciamento de operações (operations management ${ }^{11}$ ), principalmente, para o desenvolvimento de uma nova teoria. Os resultados gerados por este método possuem alto impacto, principalmente com os profissionais (mercado/segmento) que estão inseridos no contexto da pesquisa.

O estudo de caso é uma investigação empírica que tem por objetivo investigar um fenômeno contemporâneo com profundidade em seu contexto de mundo real, principalmente quando os limites entre o contexto e o fenômeno não puderem ser evidenciados claramente (YIN, 2015; MIGUEL, 2007, MIGUEL; SOUSA, 2012). Dessa forma, o estudo de caso é um dos métodos mais aderentes para investigar e mapear os Fatores Críticos de Sucesso da indústria de apoio marítimo.

Eisenhardt (1989) descreve um roadmap para utilização do estudo de caso para construção de novas teorias, podendo também ser utilizado para outros propósitos como, por exemplo, em pesquisas exploratórias. As pesquisas exploratórias, geralmente são utilizadas em áreas em que há pouco conhecimento sistematizado (VERGARA, 2003). Sampieri, Collado;

\footnotetext{
${ }^{11}$ De acordo com o MIT: A Gestão de Operações lida com a concepção e gestão de produtos, processos, serviços e cadeias de suprimentos. Envolve desde a aquisição, desenvolvimento e utilização de recursos que as empresas precisam para entregar os bens e serviços. A Gestão de Operações envolve desde questões estratégicas, até as operacionais. As decisões estratégicas envolvem a determinação do tamanho e da localização das fábricas, decisões sobre a estrutura das redes de transportes e o desenvolvimento de tecnologia para a cadeia de suprimentos. As decisões táticas incluem a modelagem de layout, métodos de gerenciamento de projetos e seleção e substituição de equipamentos. Já as decisões operacionais incluem programação e controle de produção, gerenciamento de estoque, controle de qualidade e inspeção, tráfego e manuseio de materiais e políticas de manutenção de equipamentos.
} 
Lucio (2006), também sinalizam a aderência dos estudos exploratórios para problemas ou áreas pouco estudadas.

Hair Jr et al. (2005) mostram que a pesquisa exploratória é muito útil quando há poucas informações a respeito do que está sendo pesquisado, ou seja, são orientadas para a descoberta. A pesquisa exploratória tem como objetivo gerar maior familiaridade com o problema, com vistas a torná-lo mais explícito ou a construir hipóteses. Estes tipos de pesquisas envolvem o levantamento bibliográfico e entrevistas com pessoas que tiveram experiências práticas com o problema pesquisado. Os estudos de casos são um dos tipos mais comuns empregados nas pesquisas exploratórias (GIL, 2007).

Para assegurar a aplicabilidade de um estudo de caso, Yin (2015) sugere quatro testes:

1) Validade do constructo: diz respeito à identificação de medidas operacionais para os conceitos que estão sendo estudados. Yin (2015) sugere a utilização de múltiplas fontes de evidência, encadeamento de evidências e informantes-chave (entrevistados) para a revisão do rascunho do relatório. O encadeamento de evidências consiste em explicitar as evidências obtidas para as questões iniciais e como elas foram relacionadas às conclusões do estudo, servindo de orientação para observadores externos ou para aqueles que farão uso dos resultados do estudo.

2) Validade interna: é utilizada apenas para estudos causais ou explicativos. Não se aplica nesta pesquisa, por ser exploratória;

3) Validade externa: definição do domínio em que os resultados/descobertas da pesquisa podem ser generalizados;

4) Confiabilidade: demonstração dos procedimentos para a coleta de dados, que se repetido, os mesmos resultados podem ser atingidos. Neste caso, Yin (2015) sugere a utilização de um protocolo do estudo de caso.

Segundo Yin (2015) existe cinco justificativas para a utilização de estudos de caso único: i) deve ser um caso crítico: o caso único pode ser utilizado para representar uma contribuição significativa para a formação do conhecimento e teoria. Assim, desafiando, 
confirmando ou ampliando a teoria; ii) peculiar: deve ser um caso extremo, em que há pouca teoria sobre ele; iii) comum: o caso deve captar as circunstâncias e condições de uma situação cotidiana; iv) revelador: oportunidade do pesquisador observar e analisar um fenômeno considerado inacessível até aquele momento e v) longitudinal: está associado ao estudo do caso ao longo de um intervalo de tempo.

Os estudos de caso único podem ser divididos em dois tipos. O primeiro é o holístico, em que é estudada somente uma unidade única de análise. O segundo tipo é o caso único integrado, com abordagem de unidades múltiplas de análise. Uma unidade única de análise (holístico) diz respeito a um único caso para ser estudado, por exemplo, poderia ser estudado o caso do grau de inovação em apenas uma empresa de apoio marítimo especializada no manuseio de âncoras. Já no caso integrado, poderia ser estudado o grau de inovação de várias empresas de apoio marítimo especializada no manuseio de âncoras. Esta pesquisa utiliza o estudo de caso único integrado (unidades múltiplas de análise). A Figura 30 compara o caso único holístico versus integrado.

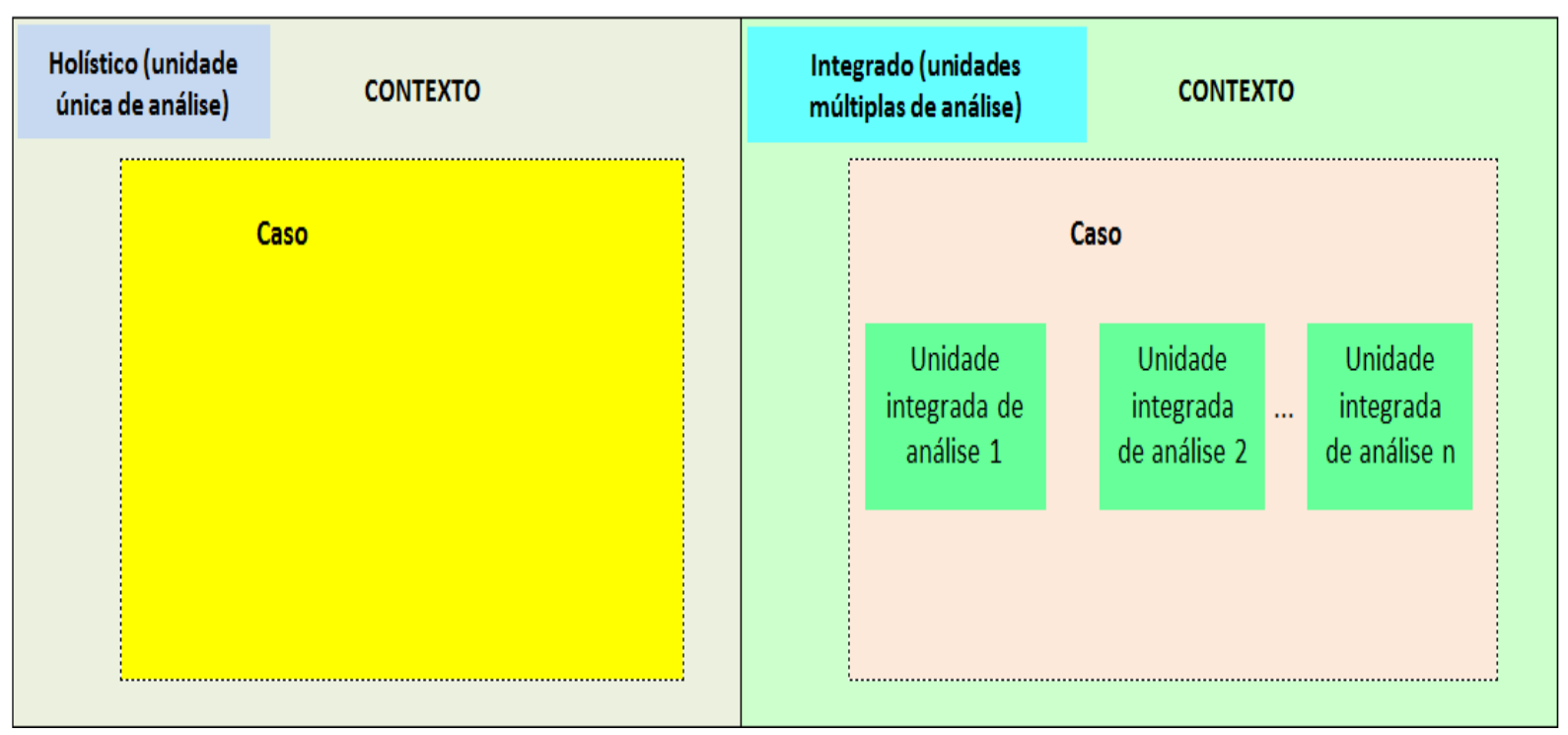

Figura 30 - Variações do Estudo de Caso Único

Fonte: Adaptado de Yin (2015).

Para a condução da presente pesquisa, foi utilizado o modelo destacado na Figura 31. A estrutura do estudo de caso foi dividida em seis partes: i) definição da estrutura conceitual teórica; ii) planejamento do(s) caso(s), iii) condução do teste piloto; iv) coleta de dados; v) análise dos dados; vi) geração do relatório. 


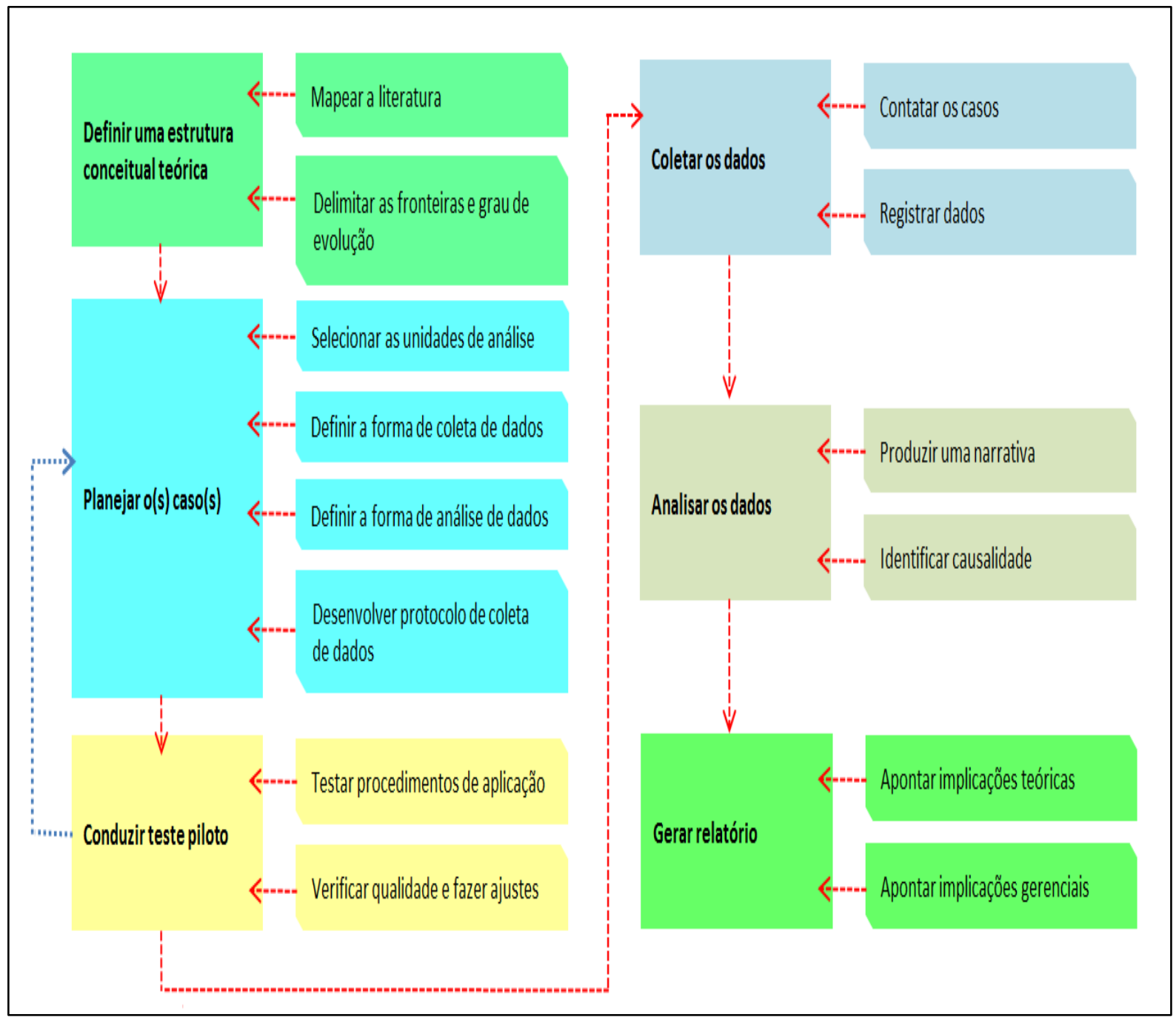

Figura 31 - Proposta para Condução do Estudo de Caso

Fonte: Adaptado de Miguel (2007), Miguel; Sousa, 2012.

\subsection{Definição da Estrutura Conceitual Teórica}

A estrutura conceitual teórica levou em consideração o mapeamento da literatura disponível, por meio de grandes bases de dados para pesquisa (Scopus, Web of Science e Scielo), teses, dissertações e anuários da área. Miguel; Sousa (2012) mostram que esta fase serve para destacar os gaps da literatura e posicionar a relevância e contribuição do trabalho que está sendo desenvolvido. 


\subsection{Planejamento do (s) caso (s)}

Esta tese utilizou o estudo de caso único com múltiplas unidades de análise, conforme a Figura 35. É considerado único, porque foi aplicado na indústria de apoio marítimo e várias unidades de análise, pois foram consideradas várias empresas da indústria de apoio marítimo para a coleta e análise de dados.

\subsubsection{Protocolo de Pesquisa}

Um protocolo de pesquisa é mais que um questionário ou instrumento, na verdade, não se resume apenas em um roteiro de pesquisas. Ele deve conter procedimentos e regras gerais para a condução da pesquisa. Além disso, o protocolo gera confiabilidade e validade da pesquisa (YIN, 2015; MIGUEL, 2007, MIGUEL; SOUSA, 2012). Este estudo se baseou em Yin (2015) para o desenvolvimento do protocolo de pesquisa do estudo de caso. Para maiores detalhes, vide o APÊNDICE B.

\subsection{Teste Piloto}

Segundo Miguel (2007), o teste piloto não é uma prática comum em projetos de estudo de caso, mas, é importante para o pesquisador, pois, possui o objetivo de verificar os procedimentos de aplicação do protocolo de pesquisa, e consequentemente melhorá-lo. O teste piloto foi aplicado via telefone com um ex-armador ${ }^{12}$ com vasta experiência de mercado e com cinco especialistas da indústria de petróleo.

É importante destacar, que mesmo com tais procedimentos, os estudos de caso podem conter alto grau de subjetividade, porém, é um método que tem alcançado grande aceitação na comunidade acadêmica, tanto na área quantitativa, quanto na qualitativa (YIN, 2015; MIGUEL, 2007, MIGUEL; SOUSA, 2012).

\footnotetext{
12 Armador é a pessoa ou empresa que, por sua própria conta e risco, equipa com materiais e tripulação embarcações comerciais, independentemente de ser proprietário da embarcação, com o objetivo de receber um retorno financeiro derivado dos fretes das cargas transportadas ou serviços prestados.
} 


\subsection{Coleta de Dados}

A coleta de dados foi realizada pelos seguintes instrumentos: entrevistas, documentação e registros em arquivos. A seguir, Yin (2015) destaca os pontos fortes e fracos de cada fonte:

\begin{tabular}{|c|c|c|}
\hline $\begin{array}{c}\text { Fonte de } \\
\text { dados }\end{array}$ & Pontos Fortes & Pontos Fracos \\
\hline Entrevistas & $\begin{array}{l}\text { - Direcionadas - focam diretamente os } \\
\text { tópicos do estudo de caso } \\
\text { • Perceptíveis - fornecem explicações, bem } \\
\text { como visões pessoais (ex: percepções, } \\
\text { atitudes e significados) }\end{array}$ & $\begin{array}{l}\text { - Parcialidade devido às questões mal } \\
\text { articuladas } \\
\text { - Parcialidade da resposta } \\
\text { - Incorreções devido à falta de memória } \\
\text { - Reflexividade - o entrevistado dá ao } \\
\text { entrevistador o que ele quer ouvir }\end{array}$ \\
\hline Documentação & $\begin{array}{l}\text { - Estável - pode ser revista rapidamente } \\
\text { - Discreta - não foi criada em consequência } \\
\text { do estudo de caso } \\
\text { - Exata - contém nomes, referências e } \\
\text { detalhes exatos de um evento } \\
\text { - Ampla cobertura - longo período de } \\
\text { tempo, muitos eventos e ambientes }\end{array}$ & $\begin{array}{l}\text { - Recuperabilidade - pode ser difícil de } \\
\text { encontrar } \\
\text { - Seletividade parcial, se a coleção for } \\
\text { incompleta } \\
\text { - Parcialidade do relatório - reflete } \\
\text { parcialidade (desconhecida) do autor } \\
\text { - Acesso - pode ser negado deliberadamente }\end{array}$ \\
\hline $\begin{array}{l}\text { Registros em } \\
\text { arquivo }\end{array}$ & $\begin{array}{l}\text { • [Idem à documentação] } \\
\text { - Precisos e geralmente quantitativos }\end{array}$ & $\begin{array}{l}\text { - [Idem à documentação] } \\
\text { - Acessibilidade devido a razões de } \\
\text { privacidade }\end{array}$ \\
\hline
\end{tabular}

Quadro 3 - Fontes de Evidência de Dados

Fonte: Yin (2015)

\subsection{Seleção das Unidades Múltiplas de Análise}

De acordo com Easterby-Smith et al. (2008) a unidade de análise é a entidade que forma a base de qualquer amostra. Assim, para atingir os objetivos e responder ao problema da pesquisa, foi utilizado o estudo o caso integrado com unidades múltiplas de análise, para compreender e mapear os Fatores Críticos de Sucesso da indústria de apoio marítimo na cadeia de petróleo no Brasil.

A seleção das unidades de análise do caso levou em consideração os seguintes critérios: i) as empresas de apoio marítimo deveriam ser classificadas na ANTAQ como "autorizadas a operar na navegação marítima, modalidade apoio marítimo" e ii) as empresas deveriam possuir operações no Brasil. As unidades de análise foram selecionadas por meio de amostra não 
probabilística intencional por conveniência, em que o pesquisador seleciona membros da população mais acessíveis (SCHIFFMAN; KANUK, 2000).

\subsection{Instrumentos de Pesquisa}

A presente pesquisa utilizou dados primários obtidos por meio dos websites das empresas, dados secundários de anuários estatísticos, entrevistas com ex-armador e especialistas da área. A partir destes dados, foi possível o mapeamento de 68 Fatores Críticos de Sucesso, que foram testados em 28 empresas, por meio de questionário estruturado. A Figura 32 demonstra o esquema adotado para a coleta de dados.

A entrevista estruturada, que é baseada na utilização de um questionário como instrumento de coleta de dados, possui uma vantagem importante que é a garantia que a mesma pergunta seja feita da mesma forma a todas as empresas que forem pesquisadas. A entrevista foi desenvolvida por meio de uma listagem de perguntas, em que a ordem e redação são invariáveis para todos os entrevistados, com isso, uma abordagem padronizada garante que as respostas possam ser comparáveis (GIL, 1999; HAIR JR et al., 2005).

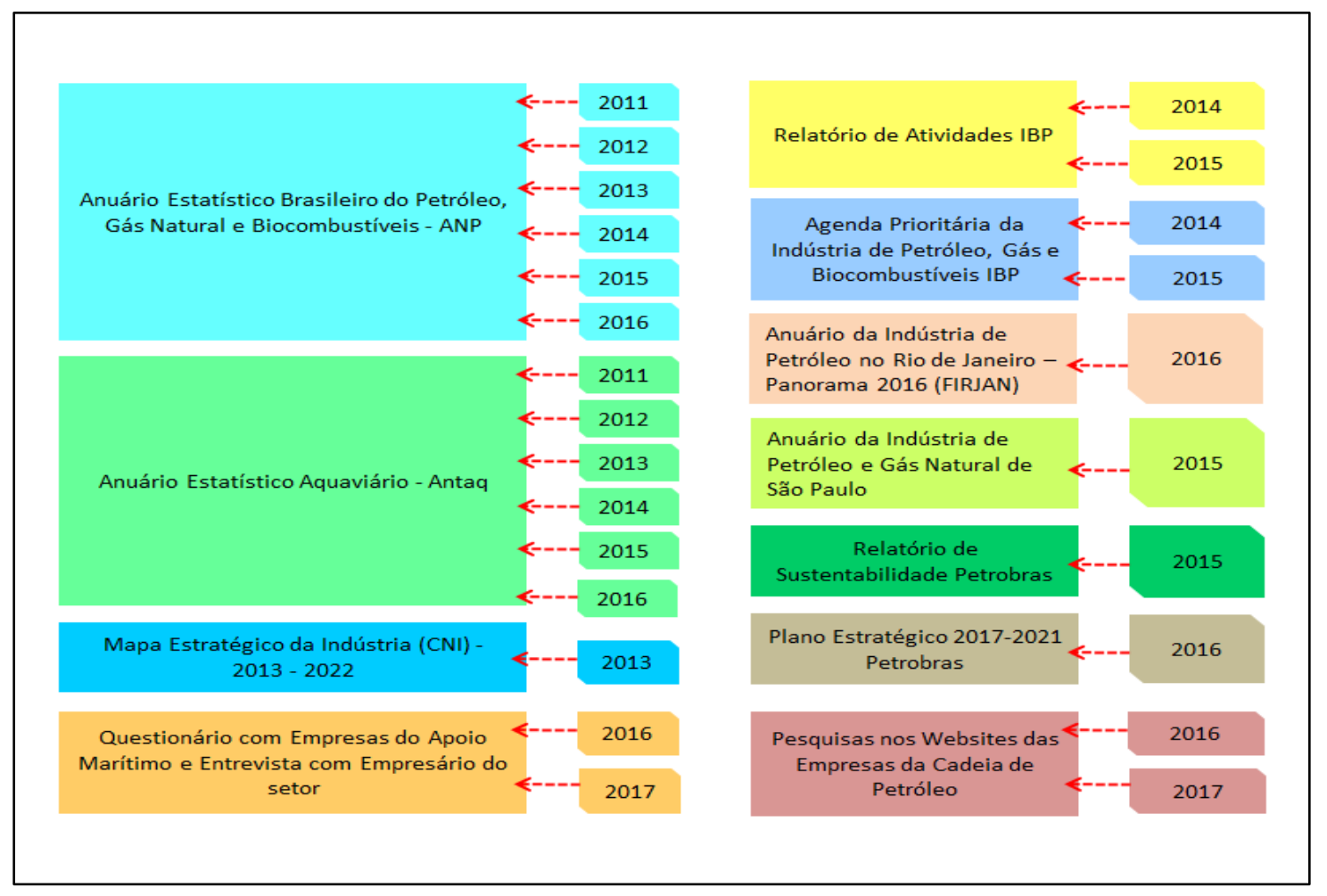

Figura 32 - Esquema dos Instrumentos de Pesquisa Utilizado 


\subsection{Fatores Críticos de Sucesso Identificados}

Por meio da Figura 32, foram identificados 68 Fatores Críticos de Sucesso. Baseado no Mapa Estratégico da Indústria, os FCSs foram divididos em categorias, para facilitar a análise e verificar o relacionamento com os outros. Eles foram distribuídos em 8 categorias. Cada categoria, possui uma determinada quantidade de FCS, da seguinte forma: i) Políticas: possui 12 FCS, que estão associados a políticas industriais e governamentais; ii) Mão de obra: está distribuído em 6 FCS, já que representam uma complexidade alta para o setor; iii) Inovação: é a categoria que possui mais FCS identificados, com 14; iv) Competitividade: está representada por 10 FCS, que procuram entender como as empresas são competitivas; v) Produtividade: está distribuído em 5 FCS, que são fundamentais para o segmento; vi) Fornecedores: categoria também representada por 5 FCS, que procura destacar a integração da indústria de apoio marítimo com o resto da cadeia de petróleo; vii) Financiamentos: categoria que está distribuída em 8 FCS que, a priori, é algo que representa uma dificuldade existente em qualquer segmento; e viii) Estratégias: também representada por $8 \mathrm{FCS}$, que procuram destacar as principais estratégias adotadas pelo setor.

O Quadro 4 a seguir, destaca os Fatores Críticos de Sucesso, e as suas respectivas categorias que foram propostos para esta pesquisa, com base na análise preliminar do setor de apoio marítimo no Brasil e a avaliação feita por meio do teste piloto. 


\begin{tabular}{|c|c|c|}
\hline Cat & Cód & Questão \\
\hline Pol & FCS 1 & $\begin{array}{l}\text { A indefinição do cenário político e econômico prejudica os investimentos de } \\
\text { longo prazo. }\end{array}$ \\
\hline Pol & FCS 2 & As incertezas do mercado são os aspectos mais complexos para monitorar. \\
\hline Pol & FCS 3 & $\begin{array}{l}\text { A lacuna de informações sobre o Prorefam (Programa de Renovação da Frota de } \\
\text { Apoio Marítimo) dificultou a estratégia das empresas na aquisição de } \\
\text { embarcações. }\end{array}$ \\
\hline Pol & FCS 4 & $\begin{array}{l}\text { Falta agilidade do governo federal na implementação de políticas públicas que } \\
\text { estimulem o setor de apoio marítimo }\end{array}$ \\
\hline Pol & FCS 5 & $\begin{array}{l}\text { A legislação atual provoca insegurança jurídica e impacta os investimentos do } \\
\text { setor. }\end{array}$ \\
\hline Pol & FCS 6 & As normas ambientais não são previsíveis. \\
\hline Pol & FCS 7 & $\begin{array}{l}\text { Existe grande dificuldade para conseguir documentações para atender aos } \\
\text { editais (contratos/concorrências). }\end{array}$ \\
\hline Pol & FCS 8 & $\begin{array}{l}\text { É fundamental a elaboração de manuais de procedimentos para gerenciamento } \\
\text { de riscos. }\end{array}$ \\
\hline Pol & FCS 9 & É fundamental as empresas possuírem um especialista em assuntos ambientais. \\
\hline Pol & FCS 10 & A carga tributária brasileira impacta de forma negativa o resultado da empresa. \\
\hline Pol & FCS 11 & Os custos com licenciamento ambiental oneram a indústria. \\
\hline Pol & FCS 12 & A atuação da empresa é impactada pela instabilidade política \\
\hline Mo & FCS 13 & $\begin{array}{l}\text { A composição da tripulação é um grande problema devido à falta de } \\
\text { qualificação dos trabalhadores. }\end{array}$ \\
\hline Mo & FCS 14 & $\begin{array}{l}\text { A falta de profissionais (tripulação e analistas) com prática no mercado } \\
\text { representa a maior limitação para a concorrência em editais/licitações de } \\
\text { contratação de serviço de apoio. }\end{array}$ \\
\hline Mo & FCS 15 & $\begin{array}{l}\text { A formação ou experiência anterior dos colaboradores contratados para } \\
\text { operarem os equipamentos e as embarcações não é suficiente, o que prejudica a } \\
\text { produtividade e eleva os custos. }\end{array}$ \\
\hline Mo & FCS 16 & A oferta de profissionais qualificados pelo mercado é baixa. \\
\hline Mo & FCS 17 & $\begin{array}{l}\text { É importantíssimo todos os funcionários terem conhecimento do Plano Nacional } \\
\text { de Contingência para Incidentes de Poluição por Óleo em Águas sob Jurisdição } \\
\text { Nacional - PNC. }\end{array}$ \\
\hline Mo & FCS 18 & A qualidade da mão de obra é fator decisivo para a competitividade da empresa. \\
\hline Inov & FCS 19 & $\begin{array}{l}\text { É fundamental a empresa possuir certificação ISO 9001, 14001 e OHSAS } \\
18001 .\end{array}$ \\
\hline Inov & FCS 20 & $\begin{array}{l}\text { A minha empresa utiliza ferramentas e técnicas para a identificação de } \\
\text { melhorias. }\end{array}$ \\
\hline Inov & FCS 21 & $\begin{array}{l}\text { A minha empresa possui ou já possuiu cooperação técnica com alguma } \\
\text { universidade nacional. }\end{array}$ \\
\hline Inov & FCS 22 & $\begin{array}{l}\text { A minha empresa possui ou já possuiu cooperação técnica com alguma } \\
\text { universidade do exterior. }\end{array}$ \\
\hline Inov & FCS 23 & A inovação no apoio marítimo é considerada baixa. \\
\hline
\end{tabular}




\section{Continuação}

\begin{tabular}{|c|c|c|}
\hline Inov & FCS 24 & A baixa competição contribui para a falta de inovação do setor. \\
\hline Inov & FCS 25 & Não existe a necessidade de integração/parcerias com empresas internacionais \\
\hline Inov & FCS 26 & Investimentos em tecnologia possuem relevância para a empresa. \\
\hline Inov & FCS 27 & Investimentos em sistemas de gestão de tráfego geram vantagem competitiva. \\
\hline Inov & FCS 28 & Na empresa existe área de Pesquisa e Desenvolvimento (P\&D). \\
\hline Inov & FCS 29 & A empresa possui plano de investimentos em novas tecnologias. \\
\hline Inov & FCS 30 & A minha empresa utiliza softwares específicos para a previsão de cenários. \\
\hline Inov & FCS 31 & A empresa utiliza software para planejar as atividades. \\
\hline Inov & FCS 32 & $\begin{array}{l}\text { A empresa utiliza pacotes computacionais para otimizar o planejamento de suas } \\
\text { operações. }\end{array}$ \\
\hline Comp & FCS 33 & $\begin{array}{l}\text { A utilização de bandeira brasileira representa uma desvantagem frente aos } \\
\text { armadores estrangeiros. }\end{array}$ \\
\hline Comp & FCS 34 & $\begin{array}{l}\text { Os custos para manter uma embarcação operacional (tripulação, manutenção, } \\
\text { seguro e administração) representam uma barreira para a entrada de novos } \\
\text { players }\end{array}$ \\
\hline Comp & FCS 35 & $\begin{array}{l}\text { A complexidade do mercado (excesso de burocracia) representa uma barreira de } \\
\text { entrada menor que o custo de manter uma embarcação. }\end{array}$ \\
\hline Comp & FCS 36 & $\begin{array}{l}\text { As empresas não sabem mensurar o quão competitivo são em relação aos seus } \\
\text { concorrentes. }\end{array}$ \\
\hline Comp & FCS 37 & $\begin{array}{l}\text { Possuir uma área de inteligência de mercado para estudar editais/licitações é } \\
\text { fundamental para ganhar as concorrências. }\end{array}$ \\
\hline Comp & FCS 38 & É imprescindível o acompanhamento dos leilões da ANP. \\
\hline Comp & FCS 39 & $\begin{array}{l}\text { As empresas de apoio marítimo possuem dificuldades para estimar o retorno dos } \\
\text { investimentos. }\end{array}$ \\
\hline Comp & FCS 40 & A empresa atua também no apoio portuário. \\
\hline Comp & FCS 41 & O mercado nacional crescerá nos próximos 24 meses. \\
\hline Comp & FCS 42 & A empresa estuda e monitora os concorrentes. \\
\hline Prod & FCS 43 & $\begin{array}{l}\text { A produtividade (viagens realizadas/viagens requisitadas) no segmento de apoio } \\
\text { marítimo é considerada baixa. }\end{array}$ \\
\hline Prod & FCS 44 & $\begin{array}{l}\text { A burocratização dos processos de licitação/concorrência minimiza a } \\
\text { produtividade das empresas. }\end{array}$ \\
\hline Prod & FCS 45 & $\begin{array}{l}\text { As multas e penalidades são importantes para garantir a produtividade das } \\
\text { empresas }\end{array}$ \\
\hline Prod & FCS 46 & Utilizo grande parte do meu tempo primordialmente em questões operacionais. \\
\hline
\end{tabular}


Continuação

\begin{tabular}{|c|c|c|}
\hline Prod & FCS 47 & A idade média da frota é menor que 10 anos. \\
\hline Forn & FCS 48 & $\begin{array}{l}\text { A minha empresa possui baixa integração com a cadeia de suprimentos offshore } \\
\text { (navipeças). }\end{array}$ \\
\hline Forn & FCS 49 & $\begin{array}{l}\text { A falta de interação do contratante com o fornecedor do serviço impacta de } \\
\text { forma negativa na qualidade do serviço prestado. }\end{array}$ \\
\hline Forn & FCS 50 & $\begin{array}{l}\text { Existe oferta suficiente de fornecedores de alta qualidade para a manutenção das } \\
\text { embarcações. }\end{array}$ \\
\hline Forn & FCS 51 & Na empresa existe sistema (procedimentos) de qualificação de fornecedores. \\
\hline Forn & FCS 52 & Todos os fornecedores cumprem com os prazos acordados. \\
\hline Fin & FCS 53 & A captação de recursos via BNDES é um processo muito complexo e dificultoso. \\
\hline Fin & FCS 54 & A minha empresa já utilizou fundos do Inova Empresa do BNDES. \\
\hline Fin & FCS 55 & A minha empresa já utilizou fundos da Marinha Mercante. \\
\hline Fin & FCS 56 & $\begin{array}{l}\text { Para financiamentos, a empresa tem utilizado mais bancos privados que } \\
\text { estatais/federais. }\end{array}$ \\
\hline Fin & FCS 57 & $\begin{array}{l}\text { A minha empresa tem utilizado mais recursos próprios para projetos que } \\
\text { financiamentos bancários. }\end{array}$ \\
\hline Fin & FCS 58 & $\begin{array}{l}\text { O prazo médio para obtenção de financiamento dificulta a capacidade de captar } \\
\text { projetos. }\end{array}$ \\
\hline Fin & FCS 59 & $\begin{array}{l}\text { Existe grande dificuldade em obter financiamentos devido ao rigor das garantias } \\
\text { exigidas pelos agentes financeiros. }\end{array}$ \\
\hline Fin & FCS 60 & $\begin{array}{l}\text { Os orçamentos para os projetos são adequados (taxas de afretamentos versus } \\
\text { tempo do contrato). }\end{array}$ \\
\hline Est & FCS 61 & $\begin{array}{l}\text { É importante as empresas possuírem estratégias para evitar demissões em } \\
\text { períodos de baixa demanda. }\end{array}$ \\
\hline Est & FCS 62 & $\begin{array}{l}\text { A maior preocupação da área estratégica da empresa é com a otimização dos } \\
\text { custos. }\end{array}$ \\
\hline Est & FCS 63 & $\begin{array}{l}\text { A empresa possui flexibilidade para mudanças no planejamento de curto e médio } \\
\text { prazo. }\end{array}$ \\
\hline Est & FCS 64 & Existe uma revisão periódica das estratégias. \\
\hline Est & FCS 65 & $\begin{array}{l}\text { O planejamento estratégico da empresa se dá a partir do conhecimento do plano } \\
\text { de negócios da Petrobras. }\end{array}$ \\
\hline Est & FCS 66 & Utilizo grande parte do meu tempo primordialmente em questões estratégicas. \\
\hline Est & FCS 67 & $\begin{array}{l}\text { A empresa define indicadores (KPI's) para acompanhamento das metas e estes } \\
\text { são de conhecimento de toda a empresa. }\end{array}$ \\
\hline Est & FCS 68 & A empresa conhece as ameaças ao modelo atual de negócio. \\
\hline
\end{tabular}

Quadro 4 - Fatores Críticos de Sucesso 
Por razões de confidencialidade, o nome das empresas participantes não será divulgado, porém, o quadro a seguir, destaca os principais segmentos de atuação das organizações.

\begin{tabular}{|l|}
\hline \multicolumn{1}{|c|}{ Principais Segmentos das empresas pesquisadas } \\
\hline Lançamento e instalação de dutos \\
\hline Monitoramento ambiental \\
\hline Reboque e Manuseio de Âncora \\
\hline Recolhimento de Óleo \\
\hline Suporte a Plataformas \\
\hline Suporte e estimulação de poços \\
\hline Suprimento as unidades de exploração \\
\hline
\end{tabular}

Quadro 5-Segmentos de atuação das empresas 


\section{ANÁLISE E DISCUSSÃO DOS RESULTADOS}

Este capítulo apresenta as análises e discussão dos principais resultados obtidos. Inicialmente é apresentada uma breve discussão por meio de estatística descritiva, seguido do teste de spearman para correlação não paramétrica e do teste de Kolmogorov-Smirnov. Na sequência, é proposta uma matriz de produtividade x competitividade. Por fim, são modelados os FCS no Mapa Estratégico da Indústria.

\subsection{Alfa de Cronbach}

A presente pesquisa utilizou uma escala Likert de 5 pontos. Para responder ao questionário, foram convidados executivos da indústria de apoio marítimo. Cada respondente deveria informar uma nota de 1 a 5 , onde 5 significava que concordava totalmente e 1 que discordava totalmente, ou seja, quanto mais próximo de 1, maior o nível de discordância e quanto mais próximo de 5, maior o nível de concordância. Foi enviado um questionário para 105 empresas por email. Após duas semanas do primeiro envio, um lembrete foi enviado. A taxa de respostas do questionário foi de $26,7 \%$, considerada adequada para questionários administrados pela web (COOK et al., 2000; NULTY, 2008).

Para medir a confiabilidade de um instrumento de pesquisa, uma parte fundamental é a consistência interna do teste ou questionário. O teste alfa de Cronbach foi criado em 1951 por Lee J. Cronbach para medir a consistência interna de uma escala ou teste. Assim, o teste verifica, por exemplo, para medir um mesmo constructo, a coerência das respostas dos participantes. A Tabela 14 a seguir, extraída de Landis e Koch (1977) ${ }^{13}$, mostra os valores referentes aos intervalos para a consistência interna de um questionário, de acordo com o Alfa de Cronbach.

Tabela 14 - Consistência Interna de Alfa de Cronbach

\begin{tabular}{|c|c|}
\hline Alfa & Consistência Interna \\
\hline $0,00-0,20$ & Pequeno \\
\hline $0,21-0,40$ & Razoável \\
\hline $0,41-0,60$ & Moderado \\
\hline $0,61-0,80$ & Substancial \\
\hline $0,80-1,00$ & Quase perfeito \\
\hline
\end{tabular}

\footnotetext{
${ }^{13}$ Artigo com aproximadamente 40 mil citações.
} 
A Tabela 15 destaca o resultado obtido para o teste de Alfa de Cronbach para a presente pesquisa. Foi utilizado o Software estatístico IBM SPSS versão 24.

Tabela 15 - Teste de Alfa de Cronbach

\begin{tabular}{cc}
\hline Alfa de Cronbach & N. de itens \\
\hline 0,85 & 68 \\
\hline
\end{tabular}

O resultado do alfa de Cronbach de 0,85 garante uma taxa alta de consistência interna das questões e coerência dos respondentes.

\subsection{Estatística Descritiva}

A Tabela a seguir, mostra as categorias dos FCSs e a distribuição (quantidade) por categoria. Por meio de um levantamento de dados e entrevista com especialista da área, foi possível modelar 8 categorias. Estas categorias também estão bem próximas ao Mapa Estratégico da Indústria da CNI.

Tabela 16 - Categorias dos FCS

\begin{tabular}{clc}
\hline Cód & \multicolumn{1}{c}{ Categoria do FCS } & Qtd \\
\hline Inov & Inovação & 14 \\
Pol & Políticas & 12 \\
Comp & Competitividade & 10 \\
Est & Estratégias & 8 \\
Fin & Financiamentos & 8 \\
Mo & Mão de Obra & 6 \\
Forn & Fornecedores & 5 \\
Prod & Produtividade & 5 \\
\hline & Total & $\mathbf{6 8}$
\end{tabular}


A Tabela 17 a seguir, mostra os resultados obtidos para a média, mediana moda, variância, amplitude e valores mínimos e máximos.

Tabela 17 - Resultados da estatística descritiva

\begin{tabular}{crrrrrrr}
\hline FCS & Média & Mediana & Moda & Variância & Amplitude & Mínimo & Máximo \\
\hline FCS1 & 4,4286 & 5,0000 & 5,00 & 0,550 & 2,00 & 3,00 & 5,00 \\
FCS2 & 3,7857 & 4,0000 & 5,00 & 1,508 & 4,00 & 1,00 & 5,00 \\
FCS3 & 3,1429 & 3,0000 & 3,00 & 1,608 & 4,00 & 1,00 & 5,00 \\
FCS4 & 4,1429 & 4,5000 & 5,00 & 1,016 & 3,00 & 2,00 & 5,00 \\
FCS5 & 4,1429 & 5,0000 & 5,00 & 1,905 & 5,00 & 0,00 & 5,00 \\
FCS6 & 3,3571 & 3,5000 & 4,00 & 0,831 & 3,00 & 2,00 & 5,00 \\
FCS7 & 3,2857 & 3,5000 & 4,00 & 1,397 & 4,00 & 1,00 & 5,00 \\
FCS8 & 4,2857 & 4,5000 & 5,00 & 0,656 & 2,00 & 3,00 & 5,00 \\
FCS9 & 3,6429 & 4,0000 & 5,00 & 2,016 & 4,00 & 1,00 & 5,00 \\
FCS10 & 4,7143 & 5,0000 & 5,00 & 0,360 & 2,00 & 3,00 & 5,00 \\
FCS11 & 3,8571 & 3,5000 & 3,00 & 0,868 & 2,00 & 3,00 & 5,00 \\
FCS12 & 4,0714 & 4,0000 & 5,00 & 0,958 & 3,00 & 2,00 & 5,00 \\
FCS13 & 3,2857 & 4,0000 & 4,00 & 1,841 & 5,00 & 0,00 & 5,00 \\
FCS14 & 3,0714 & 3,0000 & 3,00 & 1,698 & 5,00 & 0,00 & 5,00 \\
FCS15 & 3,1429 & 3,0000 & 3,00 & 1,016 & 3,00 & 2,00 & 5,00 \\
FCS16 & 3,2857 & 3,5000 & 4,00 & 1,693 & 5,00 & 0,00 & 5,00 \\
FCS17 & 3,9286 & 5,0000 & 5,00 & 2,884 & 5,00 & 0,00 & 5,00 \\
FCS18 & 4,3571 & 4,5000 & 5,00 & 0,534 & 2,00 & 3,00 & 5,00 \\
FCS19 & 3,2857 & 3,0000 & 3,00 & 1,397 & 4,00 & 1,00 & 5,00 \\
FCS20 & 3,2143 & 3,5000 & 5,00 & 3,138 & 5,00 & 0,00 & 5,00 \\
FCS21 & 2,1429 & 1,0000 & 1,00 & 3,238 & 5,00 & 0,00 & 5,00 \\
FCS22 & 1,2857 & 1,0000 & 1,00 & 1,989 & 5,00 & 0,00 & 5,00 \\
FCS23 & 3,8571 & 4,5000 & 5,00 & 1,757 & 4,00 & 1,00 & 5,00 \\
FCS24 & 3,0714 & 3,0000 & 1,00 & 2,587 & 4,00 & 1,00 & 5,00 \\
FCS25 & 2,0714 & 1,5000 & 1,00 & 1,847 & 4,00 & 1,00 & 5,00 \\
FCS26 & 4,2857 & 4,0000 & 4,00 & 0,508 & 2,00 & 3,00 & 5,00 \\
FCS27 & 3,4286 & 3,5000 & 3,00 & 1,439 & 5,00 & 0,00 & 5,00 \\
FCS28 & 2,7857 & 2,5000 & 1,00 & 3,286 & 5,00 & 0,00 & 5,00 \\
FCS29 & 2,5000 & 2,0000 & 1,00 & 3,370 & 5,00 & 0,00 & 5,00 \\
FCS30 & 1,8571 & 1,5000 & 1,00 & 2,349 & 5,00 & 0,00 & 5,00 \\
FCS31 & 2,7857 & 3,0000 & 4,00 & 2,545 & 5,00 & 0,00 & 5,00 \\
FCS32 & 2,5714 & 3,0000 & 1,00 & 2,921 & 5,00 & 0,00 & 5,00 \\
FCS33 & 2,1429 & 2,0000 & 2,00 & 0,868 & 3,00 & 1,00 & 4,00 \\
FCS34 & 3,5000 & 4,0000 & 4,00 & 2,037 & 4,00 & 1,00 & 5,00 \\
\hline & & & & & & &
\end{tabular}


Continuação Tabela 17

\begin{tabular}{cccccccc}
\hline FCS & Média & Mediana & Moda & Variância & Amplitude & Mínimo & Máximo \\
\hline FCS35 & 3,7143 & 4,0000 & 5,00 & 1,545 & 4,00 & 1,00 & 5,00 \\
FCS36 & 3,2143 & 3,0000 & 3,00 & 1,360 & 4,00 & 1,00 & 5,00 \\
FCS37 & 3,8571 & 4,0000 & 4,00 & 0,720 & 3,00 & 2,00 & 5,00 \\
FCS38 & 3,0000 & 3,0000 & 3,00 & 2,370 & 5,00 & 0,00 & 5,00 \\
FCS39 & 2,7857 & 3,0000 & 4,00 & 1,656 & 4,00 & 1,00 & 5,00 \\
FCS40 & 2,2857 & 1,5000 & 1,00 & 3,767 & 5,00 & 0,00 & 5,00 \\
FCS41 & 3,2857 & 3,0000 & 3,00 & 0,804 & 3,00 & 2,00 & 5,00 \\
FCS42 & 3,4286 & 3,0000 & 3,00 & 1,884 & 5,00 & 0,00 & 5,00 \\
FCS43 & 2,5714 & 3,0000 & 3,00 & 2,032 & 4,00 & 0,00 & 4,00 \\
FCS44 & 3,6429 & 3,0000 & 3,00 & 0,683 & 2,00 & 3,00 & 5,00 \\
FCS45 & 2,0714 & 2,0000 & 1,00 & 1,254 & 3,00 & 1,00 & 4,00 \\
FCS46 & 3,4286 & 3,5000 & 3,00 & 1,439 & 5,00 & 0,00 & 5,00 \\
FCS47 & 2,6429 & 3,0000 & 5,00 & 3,794 & 5,00 & 0,00 & 5,00 \\
FCS48 & 2,7143 & 3,0000 & 3,00 & 2,286 & 5,00 & 0,00 & 5,00 \\
FCS49 & 3,6429 & 4,0000 & 3,00 & 1,127 & 4,00 & 1,00 & 5,00 \\
FCS50 & 2,9286 & 3,0000 & 2,00 & 1,254 & 4,00 & 1,00 & 5,00 \\
FCS51 & 2,4286 & 2,0000 & 1,00 & 2,921 & 5,00 & 0,00 & 5,00 \\
FCS52 & 2,5714 & 2,5000 & 2,00 & 2,476 & 5,00 & 0,00 & 5,00 \\
FCS53 & 3,2143 & 3,0000 & 3,00 & 1,804 & 4,00 & 1,00 & 5,00 \\
FCS54 & 1,2143 & 1,0000 & 1,00 & 2,693 & 5,00 & 0,00 & 5,00 \\
FCS55 & 1,4286 & 1,0000 & 1,00 & 2,772 & 5,00 & 0,00 & 5,00 \\
FCS56 & 1,7143 & 1,0000 & 0,00 & 3,323 & 5,00 & 0,00 & 5,00 \\
FCS57 & 2,8571 & 3,0000 & 5,00 & 3,831 & 5,00 & 0,00 & 5,00 \\
FCS58 & 2,8571 & 3,0000 & 0,00 & 3,979 & 5,00 & 0,00 & 5,00 \\
FCS59 & 3,2857 & 3,5000 & 3,00 & 2,730 & 5,00 & 0,00 & 5,00 \\
FCS60 & 2,2857 & 2,5000 & 3,00 & 1,545 & 4,00 & 0,00 & 4,00 \\
FCS61 & 4,2857 & 4,0000 & 4,00 & 0,508 & 2,00 & 3,00 & 5,00 \\
FCS62 & 4,0714 & 4,0000 & 4,00 & 0,661 & 2,00 & 3,00 & 5,00 \\
FCS63 & 3,7857 & 4,0000 & 4,00 & 1,656 & 4,00 & 1,00 & 5,00 \\
FCS64 & 3,8571 & 4,0000 & 3,00 & 1,016 & 3,00 & 2,00 & 5,00 \\
FCS65 & 3,0000 & 3,5000 & 4,00 & 2,667 & 5,00 & 0,00 & 5,00 \\
FCS66 & 2,7143 & 3,0000 & 2,00 & 1,693 & 5,00 & 0,00 & 5,00 \\
FCS67 & 2,8571 & 2,5000 & 2,00 & 1,460 & 4,00 & 1,00 & 5,00 \\
FCS68 & 3,7857 & 4,0000 & 4,00 & 0,767 & 3,00 & 2,00 & 5,00 \\
\hline & & & & & & &
\end{tabular}

É importante destacar que, embora alguns FCSs possam ter médias baixas - por exemplo, o FCS 54 (A minha empresa já utilizou fundos do Inova Empresa do BNDES) teve média igual a 1,2143 - não significa que ele não seja importante para o setor, e sim, que existem grandes dificuldades da cadeia na interação com este órgão. A maioria dos FCSs Financeiros obtiveram médias baixas, o que acaba confirmando a existência de dificuldade em financiamentos para projetos. 
A Tabela 18 a seguir, mostra o ranking dos 20 FCS que obtiveram a maior média. Os FCSs baseados em Políticas Industriais/Governamentais para o setor correspondem a 45\%, acompanhado dos Estratégicos com 25\%. Na sequência, temos um empate triplo para os FCS relacionados à Mão-de-obra, Inovação e Competitividade, com 10\% cada.

Tabela 18 - Ranking Top 20 FCS Baseado na Média

\begin{tabular}{cccc}
\hline Ranking & FCS & Categoria & Média \\
\hline 1 & FCS10 & POL & 4,7143 \\
2 & FCS1 & POL & 4,4286 \\
3 & FCS18 & MO & 4,3571 \\
4 & FCS8 & POL & 4,2857 \\
5 & FCS26 & INOV & 4,2857 \\
6 & FCS61 & EST & 4,2857 \\
7 & FCS4 & POL & 4,1429 \\
8 & FCS5 & POL & 4,1429 \\
9 & FCS12 & POL & 4,0714 \\
10 & FCS62 & EST & 4,0714 \\
11 & FCS17 & MO & 3,9286 \\
12 & FCS11 & POL & 3,8571 \\
13 & FCS23 & INOV & 3,8571 \\
14 & FCS37 & COMP & 3,8571 \\
15 & FCS64 & EST & 3,8571 \\
16 & FCS2 & POL & 3,7857 \\
17 & FCS63 & EST & 3,7857 \\
18 & FCS68 & EST & 3,7857 \\
19 & FCS35 & COMP & 3,7143 \\
20 & FCS9 & POL & 3,6429 \\
\hline
\end{tabular}

A Tabela 19 destaca o ranking das médias dos Fatores Críticos de Sucesso por categoria. Os FCSs relacionados às políticas industriais/governamentais foram os que obtiveram a maior média (3,9048). Este resultado sinaliza que este grupo de fatores críticos afetam significativamente a atuação das empresas e, consequentemente, a dinâmica do setor. São FCSs sensíveis a cenários políticos, legislação, políticas de investimentos para setor etc.

Em segundo lugar, e de forma surpreendente, tem-se os FCSs ligados a estratégias. Este grupo é muito importante, pois está associado a variáveis que afetam as operações atuais (formas de gestão), e também as estratégias que estão sendo desenvolvidas para a continuidade do negócio. Alguns FCSs deste grupo obtiveram médias que merecem uma breve discussão, como o FCS 66 (Utilizo grande parte do meu tempo primordialmente em questões estratégicas). 
Neste caso, a média foi baixa $(=2,7143)$, mostrando que as atividades operacionais concorrem com o tempo do executivo tomador de decisões estratégicas. Outro FCS de destaque é o 60 ( Os orçamentos para os projetos são adequados - taxas de afretamentos versus tempo do contrato), com média igual a 2,2857. Este FCS mostra um desbalanceamento na cadeia de suprimentos e principalmente, falhas no processo de concorrência. Esta análise é interessante, pois este FCS possui uma relação muito próxima com os Financeiros, e estes, foram a categoria que obtiveram a menor média, mostrando a complexidade e dificuldade existente com os principais FCSs financeiros.

Tabela 19 - Ranking das Categorias dos FCSs

\begin{tabular}{lcc}
\hline \multicolumn{1}{c}{ Categoria } & Média & Ranking \\
\hline POL & 3,9048 & $1^{\circ}$ \\
EST & 3,5446 & $2^{\circ}$ \\
MO & 3,5119 & $3^{\circ}$ \\
COMP & 3,1214 & $4^{\circ}$ \\
PROD & 2,8714 & $5^{\circ}$ \\
FORN & 2,8571 & $6^{\circ}$ \\
INOV & 2,7959 & $7^{\circ}$ \\
FIN & 2,3571 & $8^{\circ}$ \\
\hline
\end{tabular}

Um grupo que surpreendeu de forma negativa foi à categoria Inovação, com média 2,7959, ficando em penúltimo lugar. Dentre os vários resultados que chamaram a atenção, podese destacar o FCS 21 (Cooperação técnica com alguma universidade nacional), com média 2,1419; o FCS 30 (Softwares para a previsão de cenários), com média 1,8571, e o FCS 32 (Pacotes computacionais para otimizar o planejamento das operações), com média 2,5714.

É importante destacar que somente a média não é suficiente para mensurar se um FCS é realmente importante ou não para o setor. Em muitos casos, é fundamental entender se existe correlação entre determinados FCSs pois, dependendo da correlação, isto poderá melhorar os processos de tomada de decisão dos executivos, e também entender melhor o impacto que um FCS pode provocar em outro. Sendo assim, os resultados também foram analisados por meio de testes de correlação. 


\subsection{Teste rho de Spearman}

O coeficiente de Correlação de Spearman é um teste não-paramétrico (FIELD, 2009) utilizado em substituição à Correlação de Pearson. A Correlação de Spearman tem sido muito utilizado em problemas logísticos (MURPHY et al., 1997; CULLINANE; TOY, 2000; MARTÍN; VOLTES-DORTA, 2009; AUTRY et al., 2014; NYAOGA et al., 2015). É utilizada para testar o relacionamento entre duas variáveis (MARTíN; VOLTES-DORTA, 2009). Os valores variam de 1 a -1 . Quanto mais próximo de 1, mais forte é a correlação positiva entre as variáveis, e quanto mais próximo de -1, maior será a correlação negativa. A Tabela 20 a seguir, destaca as maiores correlações positivas entre os FCSs, com nível de significância de 0,05.

Tabela 20 - Maiores Correlações Positivas entre FCSs

\begin{tabular}{|c|c|c|c|c|c|c|c|c|}
\hline \multicolumn{2}{|c|}{ Correlação FCS } & \multirow{2}{*}{$\begin{array}{c}\text { rho } \\
0,873\end{array}$} & \multicolumn{2}{|c|}{ Correlação FCS } & \multirow{2}{*}{$\begin{array}{c}\text { rho } \\
0,711\end{array}$} & \multicolumn{2}{|c|}{ Correlação FCS } & \multirow{2}{*}{$\begin{array}{c}\text { rho } \\
0,641\end{array}$} \\
\hline FCS12 & FCS13 & & FCS54 & FCS56 & & FCS26 & FCS38 & \\
\hline FCS 7 & FCS34 & 0,860 & FCS40 & FCS43 & 0,705 & FCS1 & FCS3 & 0,639 \\
\hline FCS 7 & FCS 13 & 0,845 & FCS23 & FCS61 & 0,704 & FCS47 & FCS54 & 0,639 \\
\hline FCS 2 & FCS 44 & 0,840 & FCS1 & FCS49 & 0,702 & FCS 10 & FCS60 & 0,636 \\
\hline FCS58 & FCS59 & 0,838 & FCS47 & FCS64 & 0,702 & FCS10 & FCS54 & 0,635 \\
\hline FCS12 & FCS14 & 0,813 & FCS13 & FCS40 & 0,699 & FCS62 & FCS66 & 0,634 \\
\hline FCS13 & FCS34 & 0,811 & FCS54 & FCS62 & 0,698 & FCS43 & FCS57 & 0,633 \\
\hline FCS13 & FCS14 & 0,805 & FCS15 & FCS59 & 0,697 & FCS34 & FCS43 & 0,632 \\
\hline FCS6 & $\mathrm{FCS} 12$ & 0,780 & FCS14 & FCS15 & 0,696 & FCS 20 & FCS42 & 0,629 \\
\hline FCS42 & FCS68 & 0,774 & FCS8 & FCS38 & 0,694 & FCS54 & FCS66 & 0,628 \\
\hline FCS6 & FCS7 & 0,771 & FCS30 & FCS67 & 0,690 & FCS4 & FCS12 & 0,625 \\
\hline FCS20 & FCS29 & 0,768 & FCS11 & FCS54 & 0,687 & FCS16 & FCS23 & 0,624 \\
\hline FCS7 & FCS14 & 0,762 & FCS54 & FCS68 & 0,685 & FCS54 & FCS63 & 0,622 \\
\hline FCS47 & FCS55 & 0,759 & FCS57 & FCS59 & 0,684 & FCS2 & FCS10 & 0,621 \\
\hline FCS14 & FCS43 & 0,755 & FCS52 & FCS68 & 0,681 & FCS6 & FCS34 & 0,621 \\
\hline FCS14 & FCS40 & 0,754 & FCS15 & FCS65 & 0,674 & FCS 20 & FCS37 & 0,621 \\
\hline FCS3 & FCS23 & 0,746 & FCS5 & FCS 10 & 0,673 & FCS5 & FCS43 & 0,619 \\
\hline FCS55 & FCS66 & 0,746 & FCS39 & FCS59 & 0,670 & FCS40 & FCS57 & 0,617 \\
\hline FCS63 & FCS64 & 0,744 & FCS43 & FCS54 & 0,668 & FCS34 & FCS54 & 0,615 \\
\hline FCS15 & FCS43 & 0,743 & FCS36 & FCS39 & 0,665 & FCS15 & FCS34 & 0,611 \\
\hline FCS30 & FCS32 & 0,743 & FCS9 & FCS41 & 0,662 & FCS47 & FCS52 & 0,610 \\
\hline FCS47 & FCS68 & 0,742 & FCS8 & FCS 21 & 0,660 & FCS47 & FCS67 & 0,610 \\
\hline FCS7 & FCS40 & 0,739 & FCS5 & FCS11 & 0,657 & FCS11 & FCS43 & 0,609 \\
\hline FCS56 & FCS58 & 0,739 & FCS46 & FCS60 & 0,655 & FCS10 & FCS42 & 0,608 \\
\hline FCS6 & FCS13 & 0,738 & FCS9 & FCS38 & 0,651 & FCS34 & FCS56 & 0,603 \\
\hline FCS30 & FCS31 & 0,738 & FCS 10 & FCS68 & 0,650 & FCS14 & FCS57 & 0,602 \\
\hline FCS7 & FCS12 & 0,733 & FCS28 & FCS 29 & 0,649 & FCS17 & FCS44 & 0,602 \\
\hline FCS12 & FCS34 & 0,730 & FCS51 & FCS52 & 0,648 & FCS7 & FCS43 & 0,601 \\
\hline FCS6 & FCS14 & 0,723 & FCS26 & FCS61 & 0,646 & FCS25 & FCS65 & 0,601 \\
\hline FCS11 & FCS62 & 0,718 & FCS4 & FCS62 & 0,643 & FCS29 & FCS67 & 0,601 \\
\hline FCS22 & FCS30 & 0,712 & $E C S$ & $\mathrm{FCC} 10$ & 0642 & $\mathrm{ECS47}$ & ECS 66 & 0601 \\
\hline FCS14 & FCS34 & 0,711 & FCS9 & FCS19 & 0,642 & FCS47 & FCS66 & 0,601 \\
\hline
\end{tabular}


A Tabela 21 a seguir, destaca as maiores correlações positivas entre os Fatores Críticos de Sucesso, organizado por dimensão (categoria), com nível de significância de 0,05.

Tabela 21 - Mapa das Maiores Correlações Positivas entre FCSs por Dimensão

\begin{tabular}{|c|c|c|c|c|c|c|c|c|}
\hline \multicolumn{2}{|c|}{ Correlação FCS } & rho & \multicolumn{2}{|c|}{ Correlação FCS } & \multirow{2}{*}{$\begin{array}{c}\text { rho } \\
0,811\end{array}$} & \multicolumn{2}{|c|}{ Correlação FCS } & rho \\
\hline FCS 1 & FCS 49 & 0,702 & FCS 13 & FCS 34 & & FCS 43 & FCS 54 & 0,668 \\
\hline FCS 1 & FCS 3 & 0,639 & FCS 13 & FCS 14 & 0,805 & FCS 43 & FCS 57 & 0,633 \\
\hline FCS 2 & FCS 44 & 0,840 & FCS 13 & FCS 40 & 0,699 & FCS 46 & FCS 60 & 0,655 \\
\hline FCS 2 & FCS 10 & 0,621 & FCS 14 & FCS 43 & 0,755 & FCS 47 & FCS 64 & 0,702 \\
\hline FCS 3 & FCS 23 & 0,746 & FCS 14 & FCS 40 & 0,754 & FCS 47 & FCS 55 & 0,759 \\
\hline FCS 4 & FCS 62 & 0,643 & FCS 14 & FCS 34 & 0,711 & FCS 47 & FCS 68 & 0,742 \\
\hline FCS 4 & FCS 12 & 0,625 & FCS 14 & FCS 15 & 0,696 & FCS 47 & FCS 54 & 0,639 \\
\hline FCS 5 & FCS 10 & 0,673 & FCS 14 & FCS 57 & 0,602 & FCS 47 & FCS 52 & 0,610 \\
\hline FCS 5 & FCS 11 & 0,657 & FCS 15 & FCS 43 & 0,743 & FCS 47 & FCS 67 & 0,610 \\
\hline FCS 5 & FCS 43 & 0,619 & FCS 15 & FCS 59 & 0,697 & FCS 47 & FCS 66 & 0,601 \\
\hline FCS 6 & FCS 12 & 0,780 & FCS 15 & FCS 65 & 0,674 & FCS 51 & FCS 52 & 0,648 \\
\hline FCS 6 & FCS 7 & 0,771 & FCS 15 & FCS 34 & 0,611 & FCS 52 & FCS 68 & 0,681 \\
\hline FCS 6 & FCS 13 & 0,738 & FCS 16 & FCS 23 & 0,624 & FCS 54 & FCS 56 & 0,711 \\
\hline FCS 6 & FCS 14 & 0,723 & FCS 17 & FCS 44 & 0,602 & FCS 54 & FCS 62 & 0,698 \\
\hline FCS 6 & FCS 34 & 0,621 & FCS 20 & FCS 29 & 0,768 & FCS 54 & FCS 68 & 0,685 \\
\hline FCS 7 & FCS 34 & 0,860 & FCS 20 & FCS 42 & 0,629 & FCS 54 & FCS 66 & 0,628 \\
\hline FCS 7 & FCS 13 & 0,845 & FCS 20 & FCS 37 & 0,621 & FCS 54 & FCS 63 & 0,622 \\
\hline FCS 7 & FCS 14 & 0,762 & FCS 22 & FCS 30 & 0,712 & FCS 55 & FCS 66 & 0,746 \\
\hline FCS 7 & FCS 40 & 0,739 & FCS 23 & FCS 61 & 0,704 & FCS 56 & FCS 58 & 0,739 \\
\hline FCS 7 & FCS 12 & 0,733 & FCS 25 & FCS 65 & 0,601 & FCS 57 & FCS 59 & 0,684 \\
\hline FCS 7 & FCS 43 & 0,601 & FCS 26 & FCS 61 & 0,646 & FCS 58 & FCS 59 & 0,838 \\
\hline FCS 8 & FCS 38 & 0,694 & FCS 26 & FCS 38 & 0,641 & FCS 62 & FCS 66 & 0,634 \\
\hline FCS 8 & FCS 21 & 0,660 & FCS 28 & FCS 29 & 0,649 & FCS 63 & FCS 64 & 0,744 \\
\hline FCS 9 & FCS 41 & 0,662 & FCS 29 & FCS 67 & 0,601 & & & \\
\hline FCS 9 & FCS 19 & 0,642 & FCS 30 & FCS 32 & 0,743 & & & \\
\hline FCS 9 & FCS 38 & 0,651 & FCS 30 & FCS 31 & 0,738 & & & \\
\hline FCS 10 & FCS 68 & 0,650 & FCS 30 & FCS 67 & 0,690 & & & \\
\hline FCS 10 & FCS 60 & 0,636 & FCS 34 & FCS 54 & 0,615 & & & \\
\hline FCS 10 & FCS 54 & 0,635 & FCS 34 & FCS 56 & 0,603 & & & \\
\hline FCS 10 & FCS 42 & 0,608 & FCS 34 & FCS 43 & 0,632 & & & \\
\hline FCS 11 & FCS 62 & 0,718 & FCS 36 & FCS 39 & 0,665 & & & \\
\hline FCS 11 & FCS 54 & 0,687 & FCS 39 & FCS 59 & 0,670 & & & \\
\hline FCS 11 & FCS 43 & 0,609 & FCS 40 & FCS 43 & 0,705 & & & \\
\hline FCS 12 & FCS 13 & 0,873 & FCS 40 & FCS 57 & 0,617 & & & \\
\hline FCS 12 & FCS 14 & 0,813 & FCS 42 & FCS 68 & 0,774 & & & \\
\hline FCS 12 & FCS 34 & 0,730 & & & & & & \\
\hline
\end{tabular}

Por meio deste mapa, fica evidenciado o impacto que os FCSs de Políticas (Governamentais/Industriais) exercem em relação aos outros. Já os FCSs de Inovação impactam mais significativamente nos Estratégicos e de Competitividade. Os FCSs de Fornecedores, mostraram pouco relacionamento com as demais categorias, sinalizando a necessidade de mais integração na cadeia de suprimentos. 
A Tabela 22 destaca as maiores correlações negativas entre os FCSs, com nível de significância de 0,05 . O critério utilizado para modelar a tabela foi considerar como maiores correlações negativas a partir de -0,600. Para outras correlações, vide o APÊNDICE C.

Tabela 22 - Maiores Correlações Negativas entre FCSs

\begin{tabular}{|c|c|c|}
\hline \multicolumn{2}{|c|}{ Correlação FCS } & \multirow{2}{*}{$\begin{array}{c}\text { rho } \\
-0,657\end{array}$} \\
\hline FCS 1 & FCS 42 & \\
\hline FCS 1 & FCS 55 & $-0,652$ \\
\hline FCS 3 & FCS 32 & $-0,770$ \\
\hline FCS 5 & FCS 24 & $-0,785$ \\
\hline FCS 6 & FCS 19 & $-0,690$ \\
\hline FCS 8 & FCS 25 & $-0,616$ \\
\hline FCS 10 & FCS 24 & $-0,662$ \\
\hline FCS 11 & FCS 24 & $-0,659$ \\
\hline FCS 12 & FCS 19 & $-0,631$ \\
\hline FCS 13 & FCS 19 & $-0,636$ \\
\hline FCS 14 & FCS 19 & $-0,667$ \\
\hline FCS 14 & FCS 51 & $-0,648$ \\
\hline FCS 19 & FCS 40 & $-0,605$ \\
\hline FCS 24 & FCS 43 & $-0,640$ \\
\hline FCS 24 & FCS 46 & $-0,616$ \\
\hline FCS 24 & FCS 54 & $-0,703$ \\
\hline FCS 24 & FCS 60 & $-0,649$ \\
\hline FCS 24 & FCS 68 & $-0,627$ \\
\hline FCS 30 & FCS 65 & $-0,635$ \\
\hline FCS 31 & FCS 65 & $-0,601$ \\
\hline FCS 32 & FCS 65 & $-0,706$ \\
\hline FCS 35 & FCS 53 & $-0,742$ \\
\hline FCS 49 & FCS 66 & $-0,675$ \\
\hline
\end{tabular}

A Tabela 23 a seguir, destaca as maiores correlações negativas entre os Fatores Críticos de Sucesso, organizado por dimensão (categoria), com nível de significância de 0,05. É interessante notar o comportamento dos FCSs de Inovação. Estes, são os que mais aparecem com forte correlação negativa, principalmente com a dimensão Políticas (Industriais/Governamentais). 
Tabela 23 - Mapa das Maiores Correlações Negativas entre FCSs por Dimensão

\begin{tabular}{|c|c|c|}
\hline \multicolumn{2}{|c|}{ Correlação FCS } & rho \\
\hline FCS 1 & FCS 42 & $-0,657$ \\
\hline FCS 1 & FCS 55 & $-0,652$ \\
\hline FCS 3 & FCS 32 & $-0,770$ \\
\hline FCS 5 & FCS 24 & $-0,785$ \\
\hline FCS 6 & FCS 19 & $-0,690$ \\
\hline FCS 8 & FCS 25 & $-0,616$ \\
\hline FCS 10 & FCS 24 & $-0,662$ \\
\hline FCS 11 & FCS 24 & $-0,659$ \\
\hline FCS 12 & FCS 19 & $-0,631$ \\
\hline FCS 13 & FCS 19 & $-0,636$ \\
\hline FCS 14 & FCS 19 & $-0,667$ \\
\hline FCS 14 & FCS 51 & $-0,648$ \\
\hline FCS 19 & FCS 40 & $-0,605$ \\
\hline FCS 24 & FCS 43 & $-0,640$ \\
\hline FCS 24 & FCS 46 & $-0,616$ \\
\hline FCS 24 & FCS 54 & $-0,703$ \\
\hline FCS 24 & FCS 60 & $-0,649$ \\
\hline FCS 24 & FCS 68 & $-0,627$ \\
\hline FCS 30 & FCS 65 & $-0,635$ \\
\hline FCS 31 & FCS 65 & $-0,601$ \\
\hline FCS 32 & FCS 65 & $-0,706$ \\
\hline FCS 35 & FCS 53 & $-0,742$ \\
\hline FCS 49 & FCS 66 & $-0,675$ \\
\hline
\end{tabular}

\begin{tabular}{|c|c|}
\hline FCS & Categoria \\
\hline 1 até 12 & Políticas Industrial/Governamental \\
\hline 13 até 18 & Mão de obra \\
\hline 19 até 32 & Inovação \\
\hline 33 até 42 & Competitividade \\
\hline 43 até 47 & Produtividade \\
\hline 48 até 52 & Fornecedores \\
\hline 53 até 60 & Financiamentos \\
\hline 61 até 68 & Estratégicos \\
\hline
\end{tabular}

Quadro 6 - Legenda dos FCSs 
A seguir, a Figura 33 destaca o FCS 7 (Existe grande dificuldade para conseguir documentações para atender aos editais contratos/concorrências.), classificado na dimensão Políticas (Industriais/Governamentais), escolhido aleatoriamente, para exemplificar as suas principais correlações.

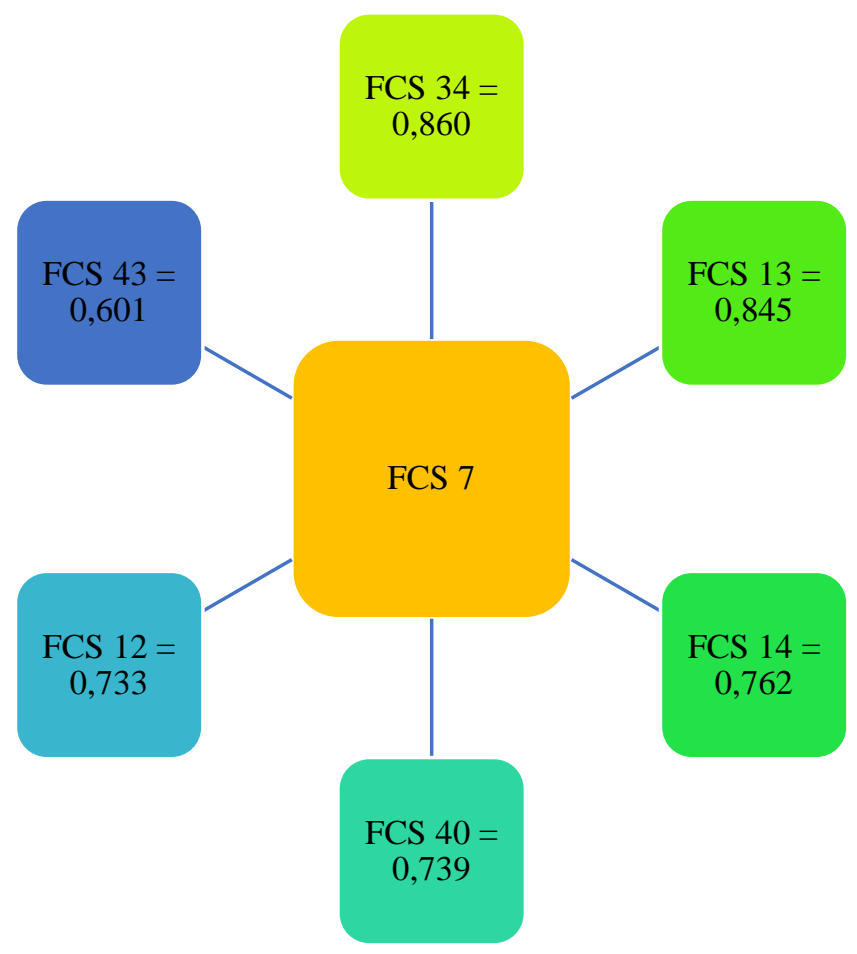

Figura 33 - Principais Correlações do FCS 7

Há forte correlação com o FCS 34 (Os custos para manter uma embarcação operacional (tripulação, manutenção, seguro e administração) representam uma barreira para a entrada de novos players); FCS 13 (A composição da tripulação é um grande problema devido à falta de qualificação dos trabalhadores); FCS 14 (A falta de profissionais (tripulação e analistas) com prática no mercado representa a maior limitação para a concorrência em editais/licitações de contratação de serviço de apoio); FCS 40 (A empresa atua também no apoio portuário); FCS 12 (A atuação da empresa é impactada pela instabilidade política) e FCS 43 (A produtividade (viagens realizadas/viagens requisitadas) no segmento de apoio marítimo é considerada baixa). É importante notar que o FCS 7 afeta significativamente FCSs relacionados a mão-de-obra (FCS 13 e 14) e também FCSs de Competitividade (34 e 40). 
A Figura 34 destaca as principais correlações do FCS 68 (A empresa conhece as ameaças ao modelo atual de negócio.) que faz parte dos FCSs de Estratégias, escolhido aleatoriamente.

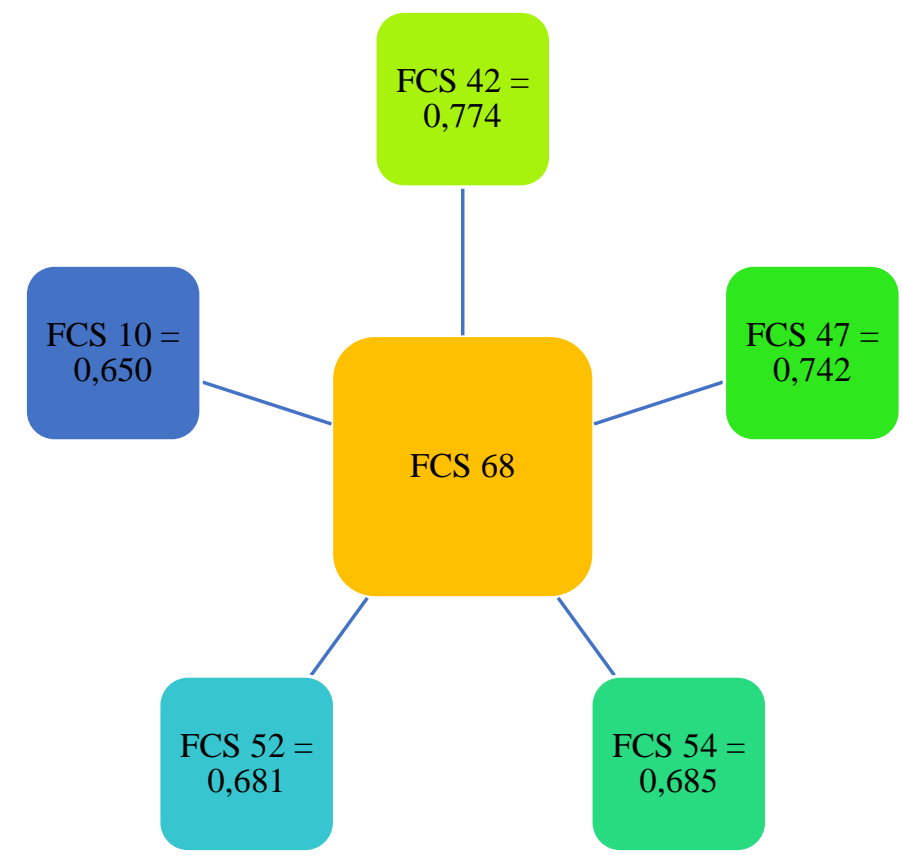

Figura 34 - Principais Correlações do FCS 47

A maior correlação foi obtida com o FCS 42 (A empresa estuda e monitora os concorrentes), que está na dimensão competitividade. Na sequência, o FCS 47 (A idade média da frota é menor que 10 anos), seguido do FCS 54 (A minha empresa já utilizou fundos do Inova Empresa do BNDES) e FCS 52 (Todos os fornecedores cumprem com os prazos acordados). Por fim, tem-se a correlação com o FCS 10 (A carga tributária brasileira impacta de forma negativa o resultado da empresa). Vale destacar que a maior correlação obtida do FCS 68, que está na categoria estratégias, foi com o 42 que é um FCS de competitividade. Nessa perspectiva, pode-se afirmar que, conhecer melhor as ameaças ao modelo atual de negócios, é condição fundamental para melhorar a competitividade.

Devido a Correlação de Spearman testar as variáveis par a par, os resultados detalhados estão no APÊNDICE C. 


\subsection{Teste Kolmogorov-Smirnov}

O teste Kolmogorov-Smirnov é utilizado para verificar a normalidade de uma determinada amostra (SIEGEL; CASTELLAN Jr, 2006; FIELD, 2009; LOPES; CASTELO BRANCO; SOARES, 2013). Assim, é considerado um teste de aderência, que verifica o grau de concordância entre a distribuição de um conjunto de valores observados, e outra distribuição teórica. Neste caso, tem-se como hipóteses:

$\mathbf{H}_{\mathbf{0}}$ : Os dados seguem uma distribuição normal

H1 : Os dados não seguem uma distribuição normal

Ho é a hipótese nula, ou seja, é a hipótese de teste que será confrontada. H1 é a hipótese de negação, também conhecida como hipótese alternativa.

Se a significância obtida for maior que o nível de significância adotado, aceita-se como condição verdadeira que a distribuição é normal. Neste caso, o nível de significância adotado foi de $5 \%$. Portanto, se $\boldsymbol{p}$-value $>0,05$, não podemos rejeitar a hipótese nula, logo a distribuição é normal.

Para verificar se a distribuição das categorias dos Fatores Críticos de Sucesso obedece a uma distribuição de normalidade, utilizou-se o software IBM SPSS versão 24. O teste Kolmogorov-Smirnov foi aplicado para cada categoria dos FCSs, obtendo os resultados reportados na Tabela 24.

Tabela 24 - Teste Kolmogorov-Smirnov

\begin{tabular}{llccc}
\hline Cód & Categoria do FCS & Kolmogorov-Smirnov & p-value & Distribuição \\
\hline Inov & Inovação & 0,253810 & 0,095786 & Normal \\
Pol & Políticas & 0,286334 & 0,060250 & Normal \\
Comp & Competitividade & 0,246850 & 0,120800 & Normal \\
Est & Estratégias & 0,247609 & 0,105500 & Normal \\
Fin & Financiamentos & 0,258577 & 0,126875 & Normal \\
Mo & Mão de Obra & 0,272150 & 0,070500 & Normal \\
Forn & Fornecedores & 0,247932 & 0,226800 & Normal \\
Prod & Produtividade & 0,295587 & 0,077000 & Normal \\
\hline Nivel de significância $=0,05$ & & &
\end{tabular}


Como os p-values de todas as categorias de FCSs são maiores que o nível de significância, pode-se concluir que todas as categorias dos Fatores Críticos de Sucesso, obedecem a uma distribuição normal. Isto implica diversas vantagens, pois pode-se desenvolver diversos modelos e frameworks a partir dos FCSs. Por exemplo, desenvolver modelos para realizar inferências estatísticas com o objetivo de mensurar as probabilidades de sucesso e fracasso em investimentos em novas embarcações, concorrências/licitações, captação de recursos financeiros, pacotes computacionais etc. Frameworks para modelagem do grau de competitividade em relação aos concorrentes, frameworks relacionados à inovação da empresa e do setor etc.

\subsection{Matriz de Produtividade $x$ Competitividade}

Esta tese também apresenta como contribuição uma proposta para mensurar o grau de produtividade e competitividade que um FCS pode possuir. A matriz será chamada de Matriz de Produtividade x Competitividade. A ideia básica da matriz é distribuir os Fatores Críticos de Sucesso de acordo com uma nota relativa baseada em duas dimensões: produtividade $\mathrm{x}$ competitividade. A matriz é formada por uma escala de 5 pontos em ambas as dimensões, totalizando 25 opções possíveis de um FCS se localizar. A Figura 35, a seguir, destaca a matriz.

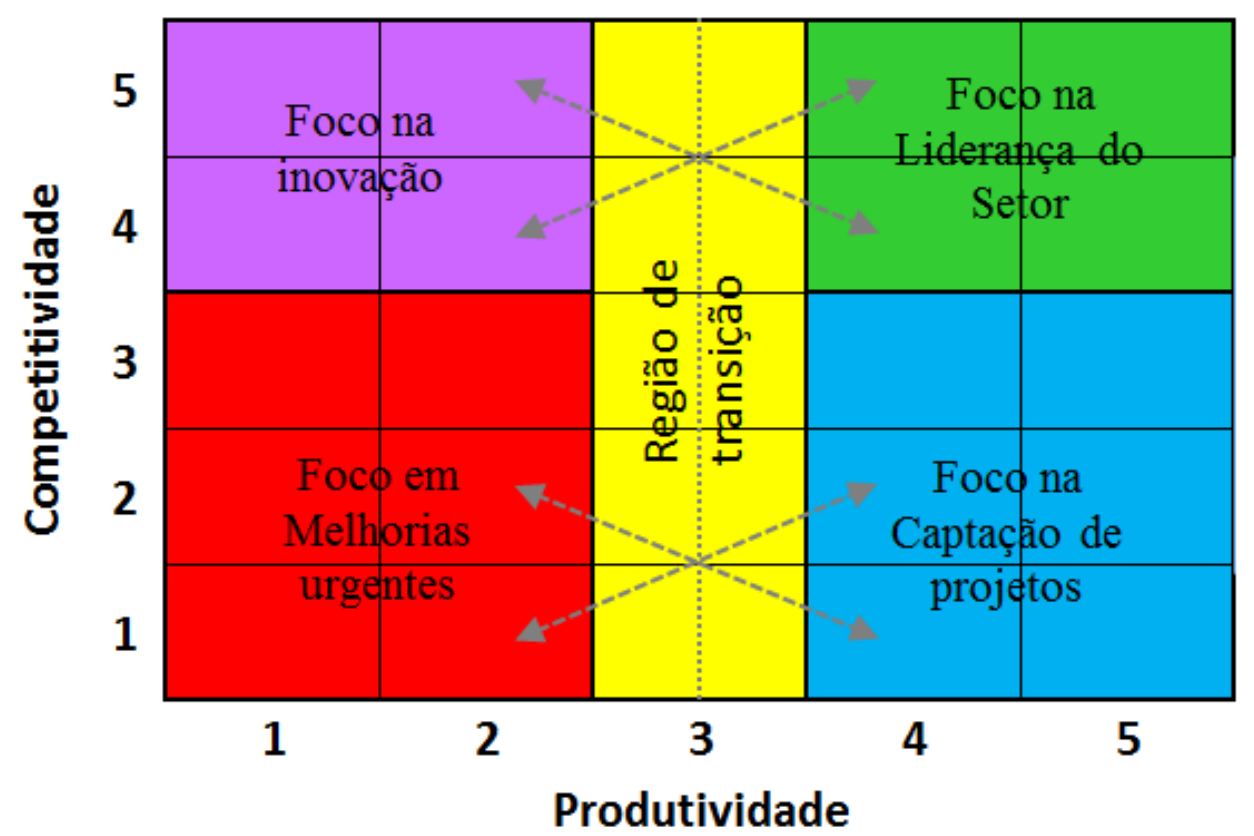

Figura 35 - Matriz de Produtividade x Competitividade 
Grupo 1 - Foco em Melhorias Urgentes: no quadrante vermelho, temos as notas [1,1], [1,2], [1,3], [2,1], [2,2], [2,3]. Esta região reflete os Fatores Críticos de Sucesso que atualmente estão gerando baixa produtividade e baixa competitividade. Eles necessitam de melhorias urgentes, pois impacta o resultado da organização no curto e médio prazo.

Grupo 2 - Foco na Inovação: No quadrante lilás, temos as notas [1,4], [1,5], [2,4], [2,5]. São Fatores Críticos de Sucesso que no momento apresentam baixa produtividade, porém são fundamentais para a empresa manter-se competitiva no mercado.

Grupo 3 - Foco na Captação de Projetos: no quadrante azul, temos as notas [4,1], [4,2], [4,3], [5,1], [5,2], [5,3]. Esta região possui Fatores Críticos de Sucesso que no momento geram alta produtividade para a organização, mas, contribuem de forma moderada para a competitividade.

Grupo 4 - Foco na Liderança do Setor: no quadrante verde, temos as notas $[4,4]$, [4,5], [5,4], [5,5]. Esta região é a ideal para os Fatores Críticos de Sucesso se localizarem. São FCS que no momento apresentam alta produtividade e alta contribuição para a competitividade da empresa. As empresas líderes de mercado apresentam a maior parte de seus FCS neste grupo.

Grupo 5 - Região de transição: no quadrante amarelo, temos as notas [3,1], [3,2], $[3,3],[3,4],[3,5]$. Esta é a região de transição. Um FCS localizado aqui, tem potencial tanto para migrar para o grupo 3 e 4 , quanto para os grupos 1 e 2 . A migração com sustentabilidade é feita de forma diagonal (conforme setas) da esquerda para a direita, exceto os FCSs do quadrante azul, que na sua forma sustentável deverá se locomover verticalmente de baixo para cima. Caso a migração ocorra da direita para a esquerda, significa que a empresa está ficando menos competitiva e/ou menos produtiva.

\subsection{Exemplo de Aplicação da Matriz Produtividade x Competitividade}

Para mostrar a robustez da Matriz de Produtividade x Competitividade, foi aplicado um teste com uma empresa do setor de apoio marítimo que ainda não havia participado do primeiro questionário. Com base nos resultados do primeiro questionário, foi elaborado um segundo questionário, com os três FCSs mais ranqueados de cada categoria. Assim, chegando em 24 questões (8 categorias). Para cada questão, o respondente deveria dar a sua resposta levando 
em consideração o quanto o FCS afeta a produtividade e a competitividade, totalizando assim

48 questões. A partir daí, foi possível plotar os FCSs na Matriz.

\begin{tabular}{|c|c|c|c|c|c|c|c|}
\hline Cat & FCS & Descrição & $\begin{array}{r}\mathbf{P} \\
\text { Com }\end{array}$ & $\begin{array}{l}\text { o } \\
\text { titivo }\end{array}$ & & $\begin{array}{r}M \\
\text { Com }\end{array}$ & $\begin{array}{l}\text { to } \\
\text { itivo }\end{array}$ \\
\hline Pol & $\begin{array}{c}\text { FCS } \\
10 \\
\end{array}$ & $\begin{array}{l}\text { A carga tributária brasileira impacta de forma negativa o resultado da } \\
\text { empresa. E este é um Fator... }\end{array}$ & 1 & 2 & 3 & 4 & 5 \\
\hline Pol & $\begin{array}{c}\text { FCS } \\
5\end{array}$ & $\begin{array}{l}\text { A legislação atual provoca insegurança jurídica e impacta os } \\
\text { investimentos do setor. E este é um Fator... }\end{array}$ & 1 & 2 & 3 & 4 & 5 \\
\hline Pol & $\begin{array}{c}\text { FCS } \\
2\end{array}$ & $\begin{array}{l}\text { As incertezas do mercado são os aspectos mais complexos para } \\
\text { monitorar. E este é um Fator... }\end{array}$ & 1 & 2 & 3 & 4 & 5 \\
\hline Mo & $\begin{array}{c}\text { FCS } \\
13 \\
\end{array}$ & $\begin{array}{l}\text { A composição da tripulação é um grande problema devido à falta de } \\
\text { qualificação dos trabalhadores. E este é um Fator... }\end{array}$ & 1 & 2 & 3 & 4 & 5 \\
\hline Mo & $\begin{array}{c}\text { FCS } \\
15\end{array}$ & $\begin{array}{l}\text { A formação ou experiência anterior dos colaboradores contratados } \\
\text { para operarem os equipamentos e as embarcações não é suficiente, o } \\
\text { que prejudica a produtividade e eleva os custos. E este é um Fator... }\end{array}$ & 1 & 2 & 3 & 4 & 5 \\
\hline Mo & $\begin{array}{c}\text { FCS } \\
17\end{array}$ & $\begin{array}{l}\text { É importantíssimo todos os funcionários terem conhecimento do } \\
\text { Plano Nacional de Contingência para Incidentes de Poluição por Óleo } \\
\text { em Águas sob Jurisdição Nacional - PNC. E este é um Fator... }\end{array}$ & 1 & 2 & 3 & 4 & 5 \\
\hline Inov & $\begin{array}{c}\text { FCS } \\
19\end{array}$ & $\begin{array}{l}\text { É fundamental a empresa possuir certificação ISO 9001, } 14001 \text { e } \\
\text { OHSAS 18001. E este é um Fator... }\end{array}$ & 1 & 2 & 3 & 4 & 5 \\
\hline Inov & $\begin{array}{c}\text { FCS } \\
21 \\
\end{array}$ & $\begin{array}{l}\text { A minha empresa possui ou já possuiu cooperação técnica com } \\
\text { alguma universidade nacional. E este é um Fator... }\end{array}$ & 1 & 2 & 3 & 4 & 5 \\
\hline Inov & $\begin{array}{l}\text { FCS } \\
26 \\
\end{array}$ & $\begin{array}{l}\text { Investimentos em tecnologia possuem relevância para a empresa. E } \\
\text { este é um Fator... }\end{array}$ & 1 & 2 & 3 & 4 & 5 \\
\hline Comp & $\begin{array}{l}\text { FCS } \\
34\end{array}$ & $\begin{array}{l}\text { Os custos para manter uma embarcação operacional (tripulação, } \\
\text { manutenção, seguro e administração) representam uma barreira para a } \\
\text { entrada de novos players. E este é um Fator... }\end{array}$ & 1 & 2 & 3 & 4 & 5 \\
\hline Comp & $\begin{array}{c}\text { FCS } \\
37\end{array}$ & $\begin{array}{l}\text { Possuir uma área de inteligência de mercado para estudar } \\
\text { editais/licitações é fundamental para ganhar as concorrências. E este é } \\
\text { um Fator... }\end{array}$ & 1 & 2 & 3 & 4 & 5 \\
\hline Comp & $\begin{array}{c}\text { FCS } \\
42\end{array}$ & A empresa estuda e monitora os concorrentes. E este é um Fator... & 1 & 2 & 3 & 4 & 5 \\
\hline Prod & $\begin{array}{c}\text { FCS } \\
44 \\
\end{array}$ & $\begin{array}{l}\text { A burocratização dos processos de licitação/concorrência minimiza a } \\
\text { produtividade das empresas. E este é um Fator... }\end{array}$ & 1 & 2 & 3 & 4 & 5 \\
\hline Prod & $\begin{array}{c}\text { FCS } \\
46\end{array}$ & $\begin{array}{l}\text { Utilizo grande parte do meu tempo primordialmente em questões } \\
\text { operacionais. E este é um Fator... }\end{array}$ & 1 & 2 & 3 & 4 & 5 \\
\hline Prod & $\begin{array}{c}\text { FCS } \\
45\end{array}$ & $\begin{array}{l}\text { As multas e penalidades são importantes para garantir a produtividade } \\
\text { das empresas. E este é um Fator... }\end{array}$ & 1 & 2 & 3 & 4 & 5 \\
\hline Forn & $\begin{array}{c}\text { FCS } \\
48 \\
\end{array}$ & $\begin{array}{l}\text { A minha empresa possui baixa integração com a cadeia de } \\
\text { suprimentos offshore (navipeças). E este é um Fator... }\end{array}$ & 1 & 2 & 3 & 4 & 5 \\
\hline Forn & $\begin{array}{c}\text { FCS } \\
50 \\
\end{array}$ & $\begin{array}{l}\text { Existe oferta suficiente de fornecedores de alta qualidade para a } \\
\text { manutenção das embarcações. E este é um Fator... }\end{array}$ & 1 & 2 & 3 & 4 & 5 \\
\hline Forn & $\begin{array}{c}\text { FCS } \\
52 \\
\end{array}$ & $\begin{array}{l}\text { Todos os fornecedores cumprem com os prazos acordados. E este é } \\
\text { um Fator... }\end{array}$ & 1 & 2 & 3 & 4 & 5 \\
\hline Fin & $\begin{array}{c}\text { FCS } \\
53 \\
\end{array}$ & $\begin{array}{l}\text { A captação de recursos via BNDES é um processo muito complexo e } \\
\text { dificultoso. E este é um Fator... }\end{array}$ & 1 & 2 & 3 & 4 & 5 \\
\hline Fin & $\begin{array}{c}\text { FCS } \\
55\end{array}$ & $\begin{array}{l}\text { A minha empresa já utilizou fundos da Marinha Mercante. E este é } \\
\text { um Fator... }\end{array}$ & 1 & 2 & 3 & 4 & 5 \\
\hline Fin & $\begin{array}{c}\text { FCS } \\
57\end{array}$ & $\begin{array}{l}\text { A minha empresa tem utilizado mais recursos próprios para projetos } \\
\text { que financiamentos bancários. E este é um Fator... }\end{array}$ & 1 & 2 & 3 & 4 & 5 \\
\hline Est & $\begin{array}{c}\text { FCS } \\
62 \\
\end{array}$ & $\begin{array}{l}\text { A maior preocupação da área estratégica da empresa é com a } \\
\text { otimização dos custos. E este é um Fator... }\end{array}$ & 1 & 2 & 3 & 4 & 5 \\
\hline Est & $\begin{array}{c}\text { FCS } \\
65 \\
\end{array}$ & $\begin{array}{l}\text { O planejamento estratégico da empresa se dá a partir do } \\
\text { conhecimento do plano de negócios da Petrobras. E este é um Fator... }\end{array}$ & 1 & 2 & 3 & 4 & 5 \\
\hline Est & $\begin{array}{c}\text { FCS } \\
68\end{array}$ & $\begin{array}{l}\text { A empresa conhece as ameaças ao modelo atual de negócio. E este é } \\
\text { um Fator... }\end{array}$ & 1 & 2 & 3 & 4 & 5 \\
\hline
\end{tabular}




\begin{tabular}{|c|c|c|c|c|c|c|c|}
\hline Cat & FCS & Descrição & $\begin{array}{r}\mathbf{B} \\
\text { Prod }\end{array}$ & idade & & Proc & idade \\
\hline Pol & $\begin{array}{c}\text { FCS } \\
10\end{array}$ & $\begin{array}{l}\text { A carga tributária brasileira impacta de forma negativa o resultado } \\
\text { da empresa. E este é um Fator que gera... }\end{array}$ & 1 & 2 & 3 & 4 & 5 \\
\hline Pol & $\begin{array}{c}\mathrm{FCS} \\
5\end{array}$ & $\begin{array}{l}\text { A legislação atual provoca insegurança jurídica e impacta os } \\
\text { investimentos do setor. E este é um Fator que gera... }\end{array}$ & 1 & 2 & 3 & 4 & 5 \\
\hline Pol & $\begin{array}{c}\text { FCS } \\
2\end{array}$ & $\begin{array}{l}\text { As incertezas do mercado são os aspectos mais complexos para } \\
\text { monitorar. E este é um Fator que gera... }\end{array}$ & 1 & 2 & 3 & 4 & 5 \\
\hline Mo & $\begin{array}{c}\text { FCS } \\
13\end{array}$ & $\begin{array}{l}\text { A composição da tripulação é um grande problema devido à falta } \\
\text { de qualificação dos trabalhadores. E este é um Fator que gera... }\end{array}$ & 1 & 2 & 3 & 4 & 5 \\
\hline Mo & $\begin{array}{c}\text { FCS } \\
15\end{array}$ & $\begin{array}{l}\text { A formação ou experiência anterior dos colaboradores contratados } \\
\text { para operarem os equipamentos e as embarcações não é suficiente, } \\
\text { o que prejudica a produtividade e eleva os custos. E este é um } \\
\text { Fator que gera... }\end{array}$ & 1 & 2 & 3 & 4 & 5 \\
\hline Mo & $\begin{array}{c}\text { FCS } \\
17\end{array}$ & $\begin{array}{l}\text { É importantíssimo todos os funcionários terem conhecimento do } \\
\text { Plano Nacional de Contingência para Incidentes de Poluição por } \\
\text { Óleo em Águas sob Jurisdição Nacional - PNC. E este é um Fator } \\
\text { que gera... }\end{array}$ & 1 & 2 & 3 & 4 & 5 \\
\hline Inov & $\begin{array}{c}\text { FCS } \\
19\end{array}$ & $\begin{array}{l}\text { É fundamental a empresa possuir certificação ISO 9001, } 14001 \text { e } \\
\text { OHSAS } 18001 . \text { E este é um Fator que gera... }\end{array}$ & 1 & 2 & 3 & 4 & 5 \\
\hline Inov & $\begin{array}{c}\text { FCS } \\
21\end{array}$ & $\begin{array}{l}\text { A minha empresa possui ou já possuiu cooperação técnica com } \\
\text { alguma universidade nacional. E este é um Fator que gera... }\end{array}$ & 1 & 2 & 3 & 4 & 5 \\
\hline Inov & $\begin{array}{c}\text { FCS } \\
26\end{array}$ & $\begin{array}{l}\text { Investimentos em tecnologia possuem relevância para a empresa. } \\
\text { E este é um Fator que gera... }\end{array}$ & 1 & 2 & 3 & 4 & 5 \\
\hline Comp & $\begin{array}{c}\text { FCS } \\
34\end{array}$ & $\begin{array}{l}\text { Os custos para manter uma embarcação operacional (tripulação, } \\
\text { manutenção, seguro e administração) representam uma barreira } \\
\text { para a entrada de novos players. E este é um Fator que gera... }\end{array}$ & 1 & 2 & 3 & 4 & 5 \\
\hline Comp & $\begin{array}{c}\text { FCS } \\
37\end{array}$ & $\begin{array}{l}\text { Possuir uma área de inteligência de mercado para estudar } \\
\text { editais/licitações é fundamental para ganhar as concorrências. E } \\
\text { este é um Fator que gera... }\end{array}$ & 1 & 2 & 3 & 4 & 5 \\
\hline Comp & $\begin{array}{c}\text { FCS } \\
42 \\
\end{array}$ & $\begin{array}{l}\text { A empresa estuda e monitora os concorrentes. E este é um Fator } \\
\text { que gera... }\end{array}$ & 1 & 2 & 3 & 4 & 5 \\
\hline Prod & $\begin{array}{c}\text { FCS } \\
44\end{array}$ & $\begin{array}{l}\text { A burocratização dos processos de licitação/concorrência } \\
\text { minimiza a produtividade das empresas. E este é um Fator que } \\
\text { gera... }\end{array}$ & 1 & 2 & 3 & 4 & 5 \\
\hline Prod & $\begin{array}{c}\text { FCS } \\
46 \\
\end{array}$ & $\begin{array}{l}\text { Utilizo grande parte do meu tempo primordialmente em questões } \\
\text { operacionais. E este é um Fator que gera... }\end{array}$ & 1 & 2 & 3 & 4 & 5 \\
\hline Prod & $\begin{array}{c}\text { FCS } \\
45\end{array}$ & $\begin{array}{l}\text { As multas e penalidades são importantes para garantir a } \\
\text { produtividade das empresas. E este é um Fator que gera... }\end{array}$ & 1 & 2 & 3 & 4 & 5 \\
\hline Forn & $\begin{array}{c}\text { FCS } \\
48\end{array}$ & $\begin{array}{l}\text { A minha empresa possui baixa integração com a cadeia de } \\
\text { suprimentos offshore (navipeças). E este é um Fator que gera... }\end{array}$ & 1 & 2 & 3 & 4 & 5 \\
\hline Forn & $\begin{array}{c}\text { FCS } \\
50\end{array}$ & $\begin{array}{l}\text { Existe oferta suficiente de fornecedores de alta qualidade para a } \\
\text { manutenção das embarcações. E este é um Fator que gera... }\end{array}$ & 1 & 2 & 3 & 4 & 5 \\
\hline Forn & $\begin{array}{c}\text { FCS } \\
52\end{array}$ & $\begin{array}{l}\text { Todos os fornecedores cumprem com os prazos acordados. E este } \\
\text { é um Fator que gera... }\end{array}$ & 1 & 2 & 3 & 4 & 5 \\
\hline Fin & $\begin{array}{c}\text { FCS } \\
53\end{array}$ & $\begin{array}{l}\text { A captação de recursos via BNDES é um processo muito } \\
\text { complexo e dificultoso. E este é um Fator que gera... }\end{array}$ & 1 & 2 & 3 & 4 & 5 \\
\hline Fin & $\begin{array}{c}\text { FCS } \\
55\end{array}$ & $\begin{array}{l}\text { A minha empresa já utilizou fundos da Marinha Mercante. E este } \\
\text { é um Fator que gera... }\end{array}$ & 1 & 2 & 3 & 4 & 5 \\
\hline Fin & $\begin{array}{c}\text { FCS } \\
57\end{array}$ & $\begin{array}{l}\text { A minha empresa tem utilizado mais recursos próprios para } \\
\text { projetos que financiamentos bancários. E este é um Fator que } \\
\text { gera... }\end{array}$ & 1 & 2 & 3 & 4 & 5 \\
\hline Est & $\begin{array}{c}\text { FCS } \\
62\end{array}$ & $\begin{array}{l}\text { A maior preocupação da área estratégica da empresa é com a } \\
\text { otimização dos custos. E este é um Fator que gera... }\end{array}$ & 1 & 2 & 3 & 4 & 5 \\
\hline Est & $\begin{array}{c}\text { FCS } \\
65\end{array}$ & $\begin{array}{l}\text { O planejamento estratégico da empresa se dá a partir do } \\
\text { conhecimento do plano de negócios da Petrobras. E este é um } \\
\text { Fator que gera... }\end{array}$ & 1 & 2 & 3 & 4 & 5 \\
\hline Est & $\begin{array}{c}\text { FCS } \\
68\end{array}$ & $\begin{array}{l}\text { A empresa conhece as ameaças ao modelo atual de negócio. E este } \\
\text { é um Fator que gera... }\end{array}$ & 1 & 2 & 3 & 4 & 5 \\
\hline
\end{tabular}

Quadro 8 - FCSs Produtividade 
A Figura 36 a seguir, mostra os resultados da potencialidade de utilização da Matriz Produtividade x Competitividade para a distribuição e análise dos FCSs.

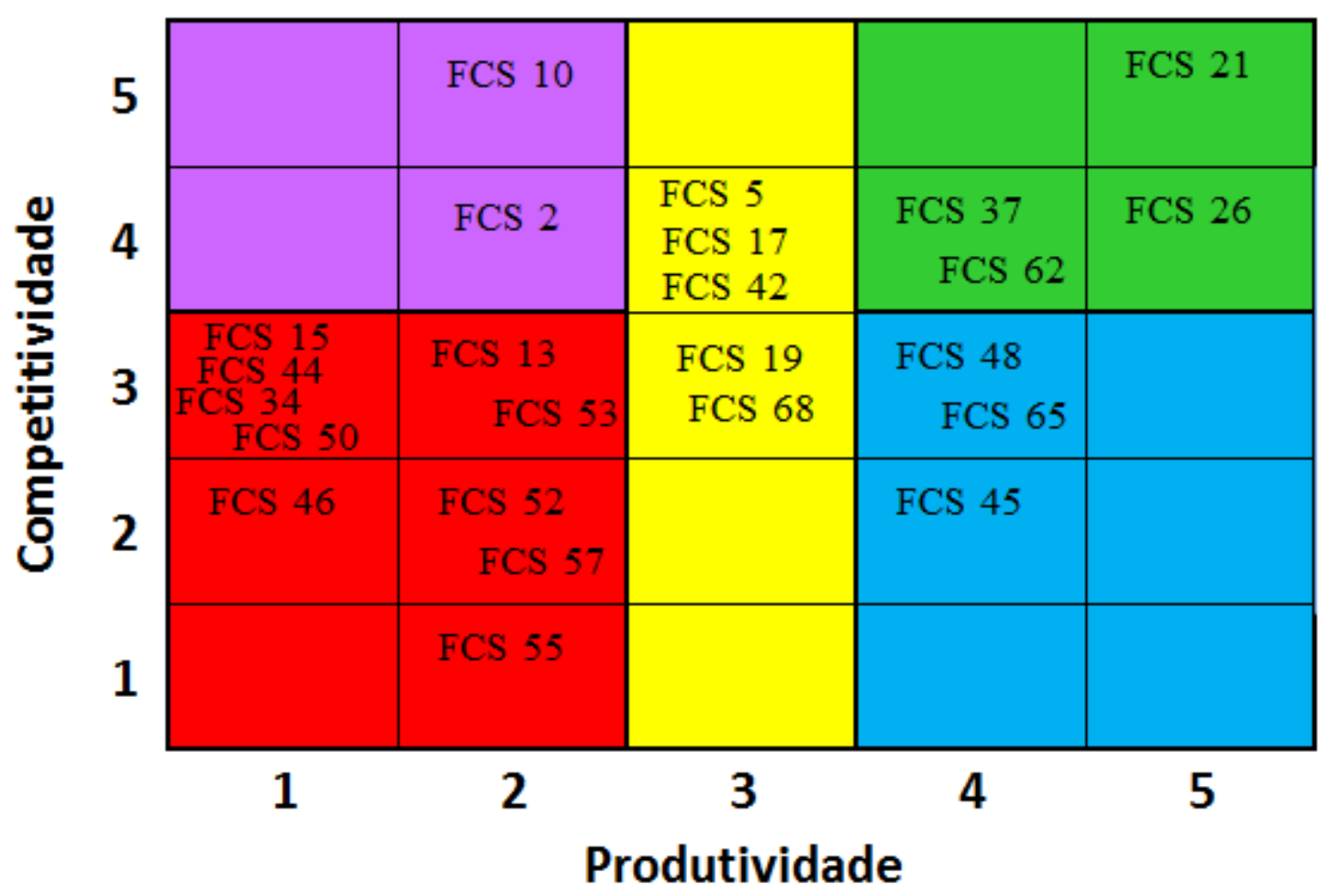

Figura 36 - Resultado da Matriz de Produtividade x Competitividade

Por meio deste teste, não é possível fazer generalizações para o setor, porém, o objetivo foi demonstrar a aplicabilidade deste framework, para as empresas poderem identificar a distribuição de seus FCSs. De acordo com a empresa respondente, os FCSs 21, 26, 37 e 62, são fatores críticos que contribuem significativamente para a empresa atingir alta produtividade e também alta competitividade. Assim, para uma empresa que possui FCSs predominantes neste quadrante, deverá focar em estratégias que gerem ou mantenham o foco na liderança do setor. Por exemplo, o FCS 21 que está associado com a cooperação técnica com universidade, deveria ser priorizado para continuar gerando alta produtividade e alta competitividade. Já o FCS 2 (As incertezas do mercado são os aspectos mais complexos para monitorar), foi classificado como um FCS que gera baixa produtividade, porém, é essencial para a empresa manter-se competitiva. 


\subsection{Modelagem do Mapa Estratégico da Indústria de Apoio Marítimo}

O Mapa Estratégico da Indústria desenvolvido pela CNI é uma ferramenta poderosa, porém subutilizada na academia. Uma exceção que pode ser destacada é na tese de Bartsch (2008) na UFRJ, em que utilizou o Mapa Estratégico da Indústria como principal ferramenta para analisar a indústria de biodiesel no Brasil. A Figura 37 a seguir, destaca o Mapa Estratégico da Indústria adaptado para a Indústria de Apoio Marítimo. É importante destacar que esta adaptação trabalha apenas os temas e objetivos prioritários do mapa.

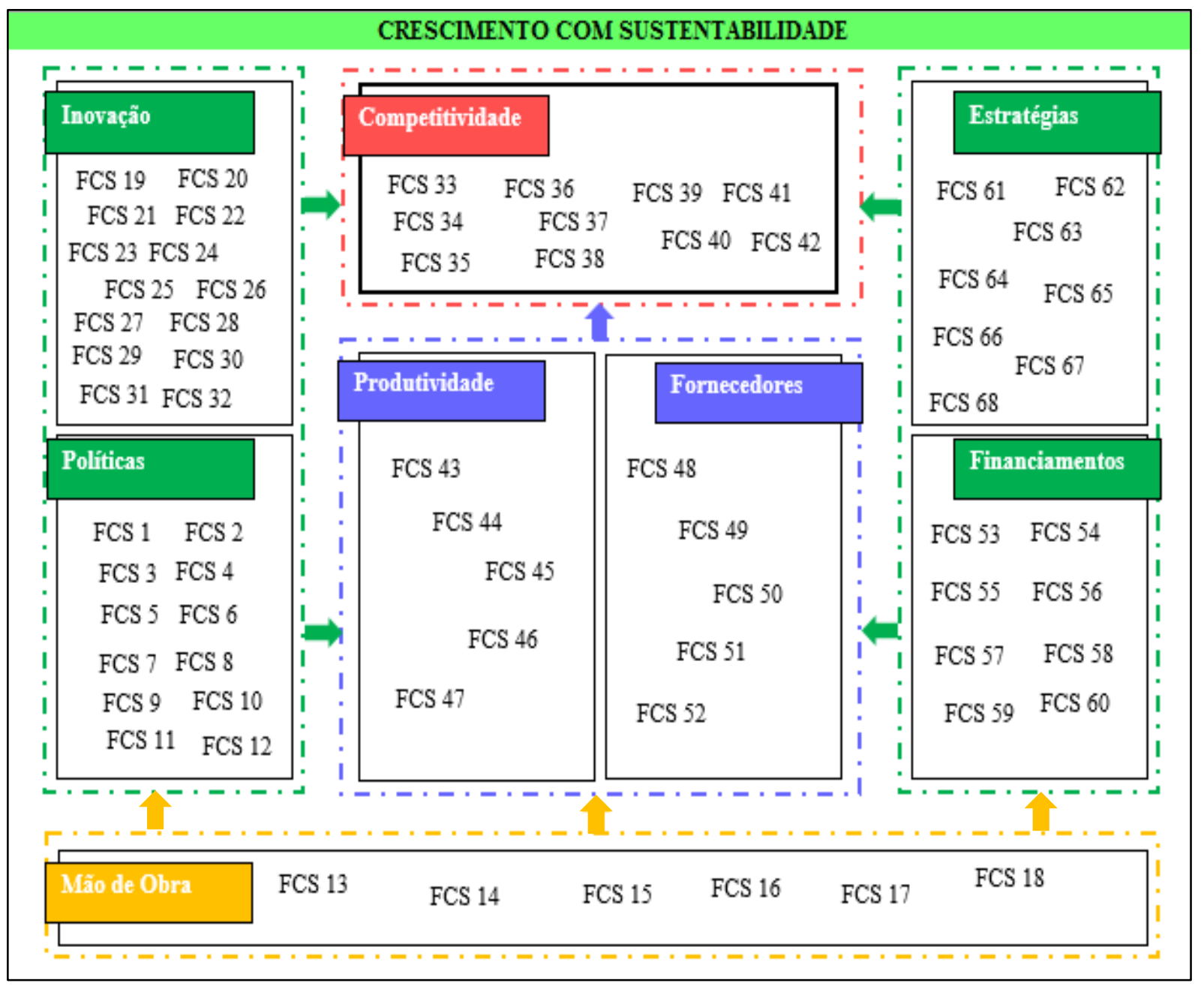

Figura 37 - Mapa Estratégico do Apoio Marítimo

A presente tese modelou o Mapa Estratégico da Indústria do Apoio Marítimo com 8 dimensões (Inovação, Competitividade, Estratégias, Financiamentos, Mão de obra, Políticas, Fornecedores e Produtividade). Para este modelo, levou-se em consideração a disposição das categorias do mapa da CNI, as categorias dos FCSs identificados e também os seguintes aspectos: i) como pilar, a qualidade e disponibilidade da mão de obra como fator fundamental 
para o segmento, pois se relaciona com todas as categorias; ii) na parte interna (centro) do mapa, tem-se as categorias produtividade e fornecedores, que são influenciadas pelas categorias das laterais: inovação, políticas, estratégias, financiamentos, além da mão de obra. Com isso, o nível de competitividade é determinado pelo relacionamento de todas as categorias, cujo objetivo é gerar crescimento com sustentabilidade.

A dimensão Inovação é a que possui mais FCSs, totalizando 14, porém, são FCSs que as organizações possuem dificuldade em gerenciar/implementar. Deve ser dado muita atenção para eles, pois o impacto é alto no médio e longo prazo.

\begin{tabular}{|l|l|}
\hline \multicolumn{1}{|c|}{ Temas Prioritários } & \multicolumn{1}{c|}{ Objetivos Prioritários } \\
\hline Aumento da inovação & Desenvolver políticas de inovação \\
\hline Parcerias com Universidades & $\begin{array}{l}\text { Aumentar a cooperação técnica com } \\
\text { Universidades e Institutos de Pesquisas }\end{array}$ \\
\hline
\end{tabular}

Quadro 9 - Temas e Objetivos Prioritários da Dimensão Inovação

A dimensão Políticas (Industriais e Governamentais) possui 12 FCS. É um dos grupos de fatores críticos mais sensíveis para a indústria de apoio marítimo. Assim, são mais vulneráveis a questões atuais e de curto prazo.

\begin{tabular}{|l|l|}
\hline \multicolumn{1}{|c|}{ Temas Prioritários } & \multicolumn{1}{c|}{ Objetivos Prioritários } \\
\hline Carga tributária & Desonerar/simplificar a carga tributária \\
\hline Incertezas políticas & Cobrar políticas que gerem maior previsibilidade para o médio e longo prazo \\
\hline \multicolumn{2}{|c|}{ Quadro 10 - Temas e Objetivos Prioritários da Dimensão Políticas (Industriais e }
\end{tabular}

Governamentais)

A dimensão Competitividade está representada por 10 FCSs. São fatores muito importantes, pois estão associados a diferenciações em relação à concorrência, e acabam sendo fatores determinantes nas concorrências e projetos.

\begin{tabular}{|l|l|}
\hline \multicolumn{1}{|c|}{ Temas Prioritários } & \multicolumn{1}{c|}{ Objetivos Prioritários } \\
\hline Inteligência de mercado & Desenvolver modelos para estudo da concorrência \\
\hline Vantagem competitiva & Mudar o foco de custos para qualidade \\
\hline
\end{tabular}

Quadro 11 - Temas e Objetivos Prioritários da Dimensão Competitividade 
$\mathrm{Na}$ dimensão Estratégias, temos 8 FCSs. Estes são fatores críticos associados primordialmente ao médio e longo prazo. Embora afetem significativamente a competitividade das empresas, esta dimensão sofre grande influência dos fatores financeiros.

\begin{tabular}{|l|l|}
\hline \multicolumn{1}{|c|}{ Temas Prioritários } & \multicolumn{1}{c|}{ Objetivos Prioritários } \\
\hline Reduzir demissões em períodos de baixa demanda & Diversificar os serviços oferecidos \\
\hline Redução de custos & Desenvolvimento de ferramentas de otimização \\
\hline
\end{tabular}

Quadro 12 - Temas e Objetivos Prioritários da Dimensão Estratégias

Na sequência, tem-se os Fatores Críticos de Sucesso relacionados à Financiamentos com 8 elementos. É o grupo que obteve a menor média, que acaba em certo ponto, confirmando a sua importância, já que estes FCSs estão atrelados às dificuldades existentes por parte das empresas, no tocante a financiamentos.

\begin{tabular}{|l|l|}
\hline \multicolumn{1}{|c|}{ Temas Prioritários } & \multicolumn{1}{c|}{ Objetivos Prioritários } \\
\hline Utilização de Fundos & $\begin{array}{l}\text { Melhoria e transparência nos processos de captação de recursos de } \\
\text { bancos de desenvolvimento }\end{array}$ \\
\hline $\begin{array}{l}\text { Desbalanceamento do contrato } \\
\text { (tempo x orçamento) }\end{array}$ & $\begin{array}{l}\text { Melhorar o processo de tomada de decisão com ferramentas que } \\
\text { mensurem melhor o fluxo de caixa dos projetos }\end{array}$ \\
\hline
\end{tabular}

Quadro 13 - Temas e Objetivos Prioritários da Dimensão Financiamentos

Os FCSs relacionados à mão de obra, totalizam 6. São fatores críticos de extrema importância, já que obtiveram a terceira posição (considerando a média). Dentre os FCSs deste grupo, tem-se um grande destaque que é a percepção da mão-de-obra como fator decisivo na competitividade. Porém, por meio do teste de Spearman, a correlação entre mão de obra e competitividade foi baixa.

\begin{tabular}{|l|l|}
\hline \multicolumn{1}{|c|}{ Temas Prioritários } & \multicolumn{1}{c|}{ Objetivos Prioritários } \\
\hline Qualificação da mão de obra (interna) & Desenvolver treinamentos \\
\hline Oferta de mão de obra pelo mercado & $\begin{array}{l}\text { Criar/aumentar a oferta de cursos e treinamentos pelas } \\
\text { principais entidades do setor }\end{array}$ \\
\hline
\end{tabular}

Quadro 14 - Temas e Objetivos Prioritários da Dimensão Mão-de-Obra 
Na sequência, estão os FCSs que tratam de fornecedores, totalizando 5. Estes são fatores críticos que mostram o grau de integração na cadeia de suprimentos. São FCSs importantíssimos, pois a indústria de apoio marítimo necessita constantemente de fornecedores altamente qualificados para as suas operações.

\begin{tabular}{|c|l|}
\hline \multicolumn{1}{|c|}{ Temas Prioritários } & \multicolumn{1}{c|}{ Objetivos Prioritários } \\
\hline Relacionamento entre contratante e fornecedor & $\begin{array}{l}\text { Melhorar as interações entre contratante e fornecedores, } \\
\text { por meio de ferramentas de TI }\end{array}$ \\
\hline Integração com a cadeia de suprimentos (SCM) & $\begin{array}{l}\text { Entender toda a SCM, de modo que possa escolher } \\
\text { melhor os fornecedores e também ofertar serviços }\end{array}$ \\
\hline
\end{tabular}

Quadro 15 - Temas e Objetivos Prioritários da Dimensão Fornecedores

Por fim, aparecem os FCSs de Produtividade, totalizando também 5. São FCSs que devem ser planejados para o horizonte de médio e longo prazo, pois esta dimensão é impactada por todos os outros. É fundamental para as empresas de apoio marítimo modelarem o seu mapa estratégico para visualizem a distribuição de seus FCSs, para que aprimorem o sistema de tomada de decisão, visando um crescimento sustentável.

\begin{tabular}{|l|l|}
\hline \multicolumn{1}{|c|}{ Temas Prioritários } & \multicolumn{1}{c|}{ Objetivos Prioritários } \\
\hline Aumento da produtividade & $\begin{array}{l}\text { Utilizar ferramentas de otimização para aumentar a } \\
\text { produtividade }\end{array}$ \\
\hline $\begin{array}{l}\text { Aumento da dedicação do tempo para questões mais } \\
\text { estratégicas }\end{array}$ & $\begin{array}{l}\text { Aumentar o tempo para assuntos mais estratégicos } \\
\text { que afetam diretamente a produtividade }\end{array}$ \\
\hline
\end{tabular}

Quadro 16 - Temas e Objetivos Prioritários da Dimensão Produtividade 


\section{CONCLUSÕES E RECOMENDAÇÕES}

Este capítulo apresenta as principais conclusões e recomendações do estudo da presente tese A CADEIA DE PETRÓLEO NO BRASIL: O CASO DA INDÚSTRIA DE APOIO MARÍTIMO.

Foi estudada a indústria de apoio marítimo no Brasil, com o objetivo de identificar e modelar os principais Fatores Críticos de Sucesso, desenvolver o Mapa Estratégico dessa indústria e também a criação de um framework para auxiliar e melhorar o processo de tomada de decisão das empresas.

A indústria de apoio marítimo, apesar de ser fundamental nos processos de Exploração \& Produção de petróleo, é visualizada pela cadeia de petróleo basicamente numa perspectiva operacional. Assim, a possibilidade de uma abordagem em uma esfera mais estratégica mostrou-se vital para que as empresas dessa indústria possam tomar decisões melhores em todos os horizontes (curto, médio e longo prazo) de planejamento e também em todos os níveis (operacional, tático e estratégico).

A revisão da literatura abordou o panorama da indústria nacional e internacional de petróleo, destacando as complexidades existentes na fase de Exploração \& Produção. Nesta fase, existe a necessidade de muitos investimentos em Pesquisa \& Desenvolvimento (P\&D) para desenvolver os campos de petróleo. Porém, a P\&D, deveria ser prioridade para toda a cadeia, incluindo o Apoio Marítimo, porém os resultados da pesquisa demonstram a necessidade de grandes avanços neste tema. Para que o Brasil possa elevar a sua posição e ser realmente um grande player em relação aos grandes produtores mundiais, é vital ser dado uma maior atenção às políticas de $\mathrm{P} \& \mathrm{D}$ pelas empresas.

A indústria de apoio marítimo é essencial nas atividades de E\&P, pois participa praticamente de todas as fases. Fases estas, que envolvem desde a coleta de dados (análise do potencial de um campo de petróleo), até a fase de desativação de um poço de petróleo. O apoio marítimo, por demandar diversas atividades logísticas, muitas vezes é chamado de apoio logístico ou logística de apoio offshore. As embarcações utilizadas são consideradas recursos críticos, pois existem muito mais tarefas para serem executadas, que o tamanho da frota suporta. 
Somando a esta complexidade, existem diversas outras, como o alto valor da diária das embarcações, a composição da tripulação, a necessidade de várias embarcações para executar determinadas tarefas, entre outros aspectos. Dessa forma, existe a necessidade de um tratamento mais estratégico para este importante segmento da cadeia de petróleo.

O Mapa Estratégico da Indústria, desenvolvido pela CNI, é uma importante ferramenta que contempla 10 dimensões que identificam as prioridades para o aumento da competitividade da indústria. As suas dimensões estão próximas das dimensões analisadas pelo WEF, no ranking de competitividade dos países, elaborado anualmente. Embora o Mapa Estratégico da Indústria seja uma ferramenta poderosa para os tomadores de decisão, ela é subutilizada pelas empresas e também pela academia.

Já a análise baseada nos Fatores Críticos de Sucesso não constitui uma abordagem nova, considerando que suas primeiras utilizações ocorreram na década de 60. Contudo, esta técnica nunca foi utilizada na indústria de apoio marítimo com exceção na Tese de Doutorado de Moura (2008), cujo autor analisou e modelou os FCSs de alguns segmentos da indústria marítima brasileira (construção náutica, construção naval, construção de plataforma e reparo naval).

Os resultados da pesquisa mostraram que os FCSs relacionados a Políticas (industriais e governamentais) são os mais sensíveis para a indústria de apoio marítimo, seguido pelos FCSs Estratégicos e de Mão de Obra. A dimensão Inovação ficou em penúltimo lugar, evidenciando a necessidade urgente de melhorias nas políticas governamentais e também das próprias empresas em relação à inovação. Dentre os resultados dos FCSs de Inovação, um FCS chamou bastante à atenção, que é o FCS 21 que aborda a cooperação técnica entre as empresas e as universidades. A cooperação técnica é baixíssima, o que acaba contribuindo para a baixa inovação do segmento.

FCSs relacionados à utilização de pacotes computacionais para previsão de cenários, planejamento de atividades e otimização das operações, também possuem baixa utilização. Já os FCSs relacionados a Financiamentos, mostram que praticamente todas as empresas de apoio marítimo possuem dificuldade em lidar com eles. Por exemplo, utilizar fundos de algum programa do BNDES ou da Marinha Mercante não é algo tão fácil, e sim um processo bastante complexo. Talvez uma parte do problema na utilização desses fundos seja das próprias empresas, por não possuir alguém especializado nesses assuntos. Já o FCS 60 que aborda os 
orçamentos dos projetos (taxas de afretamento versus tempo do contrato), mostra que a maioria das empresas enfrentam problemas em suas gestões dos fluxos de caixas.

Também foi utilizado um teste não paramétrico por meio da correlação de Spearman, para verificar as maiores correlações positivas e negativas entre os FCSs. Em relação às maiores correlações positivas, os FCSs de Políticas (Industriais/Governamentais) afetam significativamente todas as outras categorias, porém, vale destacar que correlação não implica necessariamente em relação causa-efeito. Este comportamento sinaliza certa vulnerabilidade/sensibilidade da indústria para estes FCSs, e que consequentemente impacta os demais. Assim, existe a necessidade de se desenvolver políticas mais previsíveis para o médio e longo prazo.

Embora os FCSs de Inovação tenham ficado em penúltimo lugar, ao ser considerada a média, quando são analisadas sob a perspectiva de correlações com outros fatores, eles apresentam forte relação com os FCSs Estratégicos e os de Competitividade. Este resultado é importante já que, atualmente, as empresas possuem poucas políticas voltadas para a inovação, e que no médio e longo prazo contribuem significativamente para a competitividade.

Já os FCS que tratam de integração com a cadeia de suprimentos (Fornecedores), mostraram a necessidade de maior integração entre as empresas que fazem parte desta cadeia. Ao analisar as maiores correlações negativas, fica mais evidente a necessidade do desenvolvimento de melhores políticas para os FCSs de Inovação, pois as correlações mais negativas estão associadas aos FCSs de Inovação com os FCSs de Política (Industrial/Governamental).

O teste de Kolmogorov-Smirnov mostrou que todas as categorias dos Fatores Críticos de Sucesso possuem distribuição normal. Este resultado é importantíssimo, ao permitir generalizações dos resultados obtidos, para toda a indústria de apoio marítimo e também, sugerir o desenvolvimento de outros frameworks, bem como modelar outros comportamentos do setor.

Outra contribuição fornecida pela presente tese foi o desenvolvimento de um framework (Matriz de Produtividade x Competitividade) para dar suporte na tomada de decisão dos executivos da indústria de apoio marítimo. O objetivo básico é distribuir os FCSs na matriz, 
levando em consideração a contribuição dos FCSs para a competitividade e a produtividade. Dessa forma, os executivos terão uma melhor ideia sobre o foco de suas ações (foco em melhorias urgentes, foco na inovação, foco na captação de projetos e foco na liderança do setor). Por fim, esta tese também foi a primeira que utilizou o Mapa Estratégico da Indústria da CNI associado à Fatores Críticos de Sucesso. Para os tomadores de decisão, é uma ferramenta muito importante, já que mostra numa perspectiva holística a distribuição dos FCSs em suas respectivas dimensões, e os relacionamentos existentes entre as categorias.

Portanto, para a pergunta central desta pesquisa que era: como a identificação dos fatores críticos de sucesso da indústria de apoio marítimo pode contribuir para o sistema de tomada de decisão das empresas, foi respondido; assim como os demais objetivos propostos foram alcançados, que eram: i) analisar a indústria de apoio marítimo no Brasil; ii) identificar os fatores críticos de sucesso (FCS) e analisar as principais relações entre eles; iii) desenvolver um framework a partir dos FCS para a melhoria da tomada de decisões; iv) adaptar o Mapa Estratégico da Indústria para a Indústria de Apoio Marítimo.

A pesquisa desenvolvida se mostrou limitada no tocante a fazer generalizações para a toda a cadeia de petróleo, já que o foco foi o segmento de apoio marítimo. É importante destacar que, mesmo operando no Brasil, algumas empresas apresentam tamanhos e nacionalidades diferentes, que também pode ser visto como uma limitação do trabalho.

Alguns possíveis desdobramentos e linhas de pesquisa que poderiam ser desenvolvidas, a partir dos resultados obtidos, são:

- Avaliar a aderência dos FCSs e suas respectivas dimensões/categorias em outros segmentos da indústria de petróleo;

- Estudar estratégias para o desenvolvimento e implementação de TIC (Technology Innovation Centers) para promover melhores colaborações entre universidades e indústria e Technology Transfer Offices - TTOs (HUYGHE, et al., 2016);

- Desenvolvimento de algoritmos de otimização para uma melhor compreensão dos níveis de produtividade;

- Utilizar técnicas de análise multi-critério (multiple-criteria decision analysis - MCDA) para a identificação de fatores críticos de sucesso na cadeia de petróleo; 
- Aplicar a Matriz de Produtividade x Competitividade em todo o segmento da indústria de apoio marítimo e também na cadeia de petróleo para comparar as localizações dos FCSs;

- Utilizar o Mapa Estratégico da Indústria de Apoio Marítimo no restante da cadeia de petróleo. 


\section{REFERÊNCIAS}

AAS, B., GRIBKOVSKAIA, I., HALSKAU Sr, Ø.; SHLOPAK, A. Routing of supply vessels to petroleum installations. International Journal of Physical Distribution \& Logistics Management, 37:2, p. 164-179, 2007.

AAS, B., HALSKAU Sr, Ø.; WALLACE, W. The role of supply vessels in offshore logistics. Maritime Economics \& Logistics, 11:3, p. 302-325, 2009.

ABEAM - ASSOCIAÇÃO BRASILEIRA DAS EMPRESAS DE APOIO MARÍTIMO. Frota de apoio marítimo no Brasil - Janeiro/2017. ABEAM, Rio de Janeiro, p. 1-13, 2017. Disponível em: 〈http://www.abeam.org.br/arquivos/1487679466.pdf>. Acesso em 15 fev. 2017.

ALMEIDA, E.; LOSEKANN, L.; CLAVIJO, W. Custos e benefícios da atual política de conteúdo local. Rio de Janeiro, 2016. Disponível em: <http://www.gee.ie.ufrj.br/index.php/get-working-paper/617-custos-e-beneficios-da-atualpolitica-de-conteudo-local>. Acesso em 10 nov. 2016.

ANP - AGÊNCIA NACIONAL DO PETRÓLEO, GÁS NATURAL E BIOCOMBUSTÍVEIS. Resolução ANP n⿳36, de 13.11.2007. Rio de Janeiro, ANP, 2007. Disponível em: 〈http://www.brasil-rounds.gov.br/arquivos/diario_oficial/resolucao36.pdf $>$. Acesso em 12 mar. 2017.

ANP - AGÊNCIA NACIONAL DO PETRÓLEO, GÁS NATURAL E BIOCOMBUSTÍVEIS. Anuário estatístico brasileiro do petróleo, Gás natural e biocombustíveis 2011. Rio de Janeiro, ANP, 2011. Disponível em: <http://www.anp.gov.br/wwwanp/publicacoes/anuarioestatistico/2436-anuario-estatistico-2011>. Acesso em 10 out. 2015.

ANP - AGÊNCIA NACIONAL DO PETRÓLEO, GÁS NATURAL E BIOCOMBUSTÍVEIS. Anuário estatístico brasileiro do petróleo, Gás natural e biocombustíveis 2012. Rio de Janeiro, ANP, 2012. Disponível em: <http://www.anp.gov.br/wwwanp/publicacoes/anuarioestatistico/2437-anuario-estatistico-2012>. Acesso em 10 out. 2015. 
ANP - AGÊNCIA NACIONAL DO PETRÓLEO, GÁS NATURAL E BIOCOMBUSTÍVEIS. Anuário estatístico brasileiro do petróleo, Gás natural e biocombustíveis 2013. Rio de Janeiro, ANP, 2013. Disponível em: <http://www.anp.gov.br/wwwanp/publicacoes/anuarioestatistico/2438-anuario-estatistico-2013 >. Acesso em 10 out. 2015.

ANP - AGÊNCIA NACIONAL DO PETRÓLEO, GÁS NATURAL E BIOCOMBUSTÍVEIS. Anuário estatístico brasileiro do petróleo, Gás natural e biocombustíveis 2014. Rio de Janeiro, ANP, 2014. Disponível em: <http://www.anp.gov.br/wwwanp/publicacoes/anuarioestatistico/2439-anuario-estatistico-2014>. Acesso em 10 out. 2015.

ANP - AGÊNCIA NACIONAL DO PETRÓLEO, GÁS NATURAL E BIOCOMBUSTÍVEIS. Anuário estatístico brasileiro do petróleo, gás natural e biocombustíveis 2015. Rio de Janeiro, ANP, 2015. Disponível em: <http://www.anp.gov.br/wwwanp/publicacoes/anuarioestatistico/2440-anuario-estatistico-2015>. Acesso em 23 set. 2016.

ANP - AGÊNCIA NACIONAL DO PETRÓLEO, GÁS NATURAL E BIOCOMBUSTÍVEIS. Anuário estatístico brasileiro do petróleo, gás natural e biocombustíveis 2016. Rio de Janeiro, ANP, 2016. Disponível em: <http://www.anp.gov.br/wwwanp/publicacoes/anuarioestatistico/2441-anuario-estatistico-2016>. Acesso em 23 set. 2016.

ANP - AGÊNCIA NACIONAL DO PETRÓLEO, GÁS NATURAL E BIOCOMBUSTÍVEIS. Brasil-Rounds Licitações de Petróleo e Gás. Rio de Janeiro, ANP, 2017. Disponível em: <http://www.brasil-rounds.gov.br/R_Bienio/portugues_R_Bienio/setores.asp>. Acesso em 13 abr. 2017.

ANTAQ - AGÊNCIA NACIONAL DE TRANSPORTES AQUAVIÁRIOS. Anuário estatístico 2011. Brasília, ANTAQ, 2011. Disponível em: $<$ http://web.antaq.gov.br/Portal/Anuarios/Anuario2011/body/index.htm>. Acesso em 10 out. 2015.

ANTAQ - AGÊNCIA NACIONAL DE TRANSPORTES AQUAVIÁRIOS SUPERINTENDÊNCIA DE NAVEGAÇÃO MARÍTIMA E DE APOIO. Raio x da frota brasileira na navegação de apoio marítimo - principais empresas e suas frotas. Rio de Janeiro, ANTAQ, 2012a. Disponível em: 
http://web.antaq.gov.br/Portal/pdf/BoletimPortuario/Frota_Apoio_Mar\%C3\%ADtimo_Outub ro_2012.pdf>. Acesso em 10 out. 2015.

ANTAQ - AGÊNCIA NACIONAL DE TRANSPORTES AQUAVIÁRIOS. Anuário estatístico 2012. Brasília, ANTAQ, 2012b. Disponível em: <http://web.antaq.gov.br/Portal/Anuarios/Anuario2012/index.htm>. Acesso em 10 out. 2015.

ANTAQ - AGÊNCIA NACIONAL DE TRANSPORTES AQUAVIÁRIOS. Anuário estatístico 2013. Brasília, ANTAQ, 2013. Disponível em: <http://web.antaq.gov.br/Portal/Anuarios/Anuario2013/index.htm>. Acesso em 10 out. 2015.

ANTAQ - AGÊNCIA NACIONAL DE TRANSPORTES AQUAVIÁRIOS. Anuário estatístico 2014. Brasília, ANTAQ, 2014. Disponível em: 〈http://web.antaq.gov.br/Portal/PDF/Anuarios/ApresentacaoAnuario2014.pdf>. Acesso em 10 out. 2015.

ANTAQ - AGÊNCIA NACIONAL DE TRANSPORTES AQUAVIÁRIOS. Anuário estatístico 2015. Brasília, ANTAQ, 2015. Disponível em: <http://web.antaq.gov.br/Portal/PDF/Anuarios/ApresentacaoAnuario2015.pdf>. Acesso em 23 set. 2016.

ANTAQ - AGÊNCIA NACIONAL DE TRANSPORTES AQUAVIÁRIOS. Anuário estatístico 2016. Brasília, ANTAQ, 2016. Disponível em:

$<$ http://web.antaq.gov.br/Portal/PDF/Anuarios/ApresentacaoAnuario2016.pdf $>$. Acesso em 23 set. 2016.

AUTRY, C. W.; WILLIAMS, B. D.; GOLICIC, S. Relational and process multiplexity in vertical supply chain triads: an exploration in the U.S. restaurant industry. Journal of Business Logistics, 35:1, p. 52-70, 2014.

BACON, M.; SIMM, R.; REDSHAW, T. 3-D Seismic Interpretation. Cambridge University Press: Cambridge, 2007. 
BAI, Y.; BAI, Q. Subsea Engineering Handbook. Gulf Professional Publishing: Amsterdam, 2012.

BARTSCH, A. S. O Mapa estratégico da indústria aplicado ao biodiesel no Brasil. 2008. 294 p. Tese (Doutorado). Escola de Química, Universidade Federal do Rio de Janeiro. Rio de Janeiro, 2008.

BASSI, H. V.; FERREIRA FILHO, V. J. M.; BAHIENSE, L. Planning and scheduling a fleet of rigs using simulation-optimization. Computers \& Industrial Engineering, 63, p. 10741088, 2012.

BELTRÃO, R. L. C.; SOMBRA, C. L.; LAGE, A. C. V. M.; FAGUNDES NETTO, J. R.; HENRIQUES, C. C. D. Challenges and new technologies for the development of the pre-salt cluster, Santos basin, Brazil. Offshore Technology Conference, p. 1-11, 2009.

BEN. BALANÇO ENERGÉtICO NACIONAL. Relatório 2016. Disponível em: <https://ben.epe.gov.br/BENRelatorioFinal.aspx?anoColeta=2016\&anoFimColeta=2015>. Acesso em 23 set. 2016.

BORCH, O. J.; BATALDEN, B-M. Business-process management in high-turbulence environments: the case of the offshore service vessel industry. Maritime Policy \& Management, 42:5, p. 491-498, 2014.

BP. BRITISH PETROLEUM. Statistical Review of World Energy 2016. Disponível em: <https://www.bp.com/content/dam/bp/pdf/energy-economics/statistical-review-2016/bpstatistical-review-of-world-energy-2016-full-report.pdf>. Acesso em 23 set. 2016

BRASIL. LEI N 9.432, DE 8 DE JANEIRO DE 1997.

BUCHEB, J. A. Os desafios do pré-sal: riscos e oportunidades para o país. Fórum: “Desafios do pré-sal: riscos e oportunidades para o país". Unicamp, 2014. Disponível em: <http://www.gr.unicamp.br/penses/wp-content/uploads/2016/03/Os-desafiosgeol\%C3\%B3gicos.pdf>. Acesso em 10 out. 2015. 
BULlEN, C.; ROCKART, J. A Primer on Critical Success Factors. Working Paper, Alfred Sloan School of Management. Center for Information Systems Research, n. 69, 1981.

\section{CNI - CONFEDERAÇÃO NACIONAL DA INDÚSTRIA. Mapa Estratégico da Indústria:} 2013 - 2022. Brasília, CNI, 2013. Disponível em: <http://www.portaldaindustria.com.br/cni/institucional/mapa-estrategico-da-industria-20132022/>. Acesso em 13 set. 2015.

CNT - CONFEDERAÇÃO NACIONAL DO TRANSPORTE. Matriz de Transportes. Brasília, CNT, 2014. Disponível em: < http://www.cnt.org.br/>. Acesso em 13 set. 2015.

COOK, C.; HEATH, F.; THOMPSON, R. L. A meta-analysis of response rates in web- or internet-based surveys. Educational and Psychological Measurement, 60:6, p. 821-836, 2000.

CORRÊA, H. L.; CORRÊA, C. A. Administração de produção e operações: manufatura e serviços: uma abordagem estratégica, 2a ed. São Paulo: Atlas, 2012.

CSCMP - COUNCIL OF SUPPLY CHAIN MANAGEMENT PROFESSIONALS. Definição de logística (1998). Disponível em: <https://cscmp.org/iMIS0/CSCMP/>. Acesso em 23 set. 2014.

CUESTA, E. F.; ANDERSSON, H.; FAGERHOLT, K.; LAPORTE, G. Vessel routing with pickups and deliveries: An application to the supply of offshore oil platforms. Computers \& Operations Research, 79, p. 140-147, 2017.

CULLINANE, K.; TOY, N. Identifying influential attributes in freight route/mode choice decisions: a content analysis. Transportation Research Part E, 36, p. 41-53, 2000.

D’ALMEIDA, A. L. Indústria de petróleo no Brasil e no mundo: formação, desenvolvimento e ambiência atual. São Paulo: Blucher, 2015.

DANIEL, D. R. Management information crisis. Harvard Business Review, 39, p. 111-121, 1961. 
De CARLI, P. C.; DELAMARO, M. C.; SALOMON, V. A. P. Identificação e priorização dos fatores críticos de sucesso na implantação de fábrica digital. Produção, 20:4, p. 549-564, 2010.

DI LUCCIO, F. B.; DORES, P. B. O mercado de apoio offshore: panorama e perspectivas. BNDES Setorial, Rio de Janeiro, n. 43, p. 295-323, 2016. Disponível em: <https://web.bndes.gov.br/bib/jspui/handle/1408/9581〉. Acesso em 15 jul. 2016.

DOING BUSINESS 2017 - BANCO MUNDIAL. Igualdade de oportunidade para todos. Disponível em: < http://portugues.doingbusiness.org/reports/global-reports/doing-business2017>. Acesso em 23 set. 2016.

EASTERBY-SMITH, M.; THORPE, R.; JACKSON, P. R. Management Research, $3^{\mathrm{a}}$ ed. Great Britain: Sage Publications, 2008.

EISENHARDT, K. M. Building Theories from Case Study Research. The Academy of Management Review, 14:4, p. 532-550, 1989.

EL-REEDY, M. Offshore Structures: Design, Construction and Maintenance. Amsterdam: Gulf Professional Publishing, 2012.

ESTRELLA, G. Pré-sal: regime de partilha. Apresentação na Comissão de Serviços de Infraestrutura do Senado Federal, realizada em 5 de outubro de 2009. Disponível em: <http://repositorio.ipea.gov.br/bitstream/11058/4701/1/BEPI_n4_brasil.pdf> Acesso em 10 out. 2015.

FAGERHOLT, K.; LINDSTAD, H. Optimal policies for maintaining a supply service in the Norwegian sea. Omega, 28, p. 269-275, 2000.

FALCÃO, J. L.; POIATE JÚNIOR, E.; COSTA, A. M.; ALVES, I. A. S.; ESTON, S. M. Perfuração em formações salinas. Boletim Técnico da Produção de Petróleo, Rio de Janeiro, 2:2, p. 261-286, 2007. 
FARIA, M. J. S. Programação linear de novo aplicada a projetos de explotação de petróleo. 2013. 107 p. Dissertação (Mestrado). Faculdade de Economia e Finanças, IBMEC. Rio de Janeiro, 2013.

FERDOWS, K.; De MEYER, A. Lasting Improvements in manufacturing performance: in search of a new theory. Journal of Operations Management, 9:2, p. 168-184, 1990.

FERREIRA FILHO, V. J. M. Gestão de operações e logística na produção de petróleo: fundamentos, metodologia e modelos quantitativos. $1^{\text {a }}$. ed. Rio de Janeiro: Elsevier, 2016.

FERRO, F.; TEIXEIRA, P. Os desafios do pré-sal. Brasília: Câmara dos Deputados, Edições Câmara, 2009. 78 p. Série Cadernos de Altos Estudos; n. 5.

FIELD, A. Descobrindo a Estatística usando o SPSS. $2^{\text {a }}$ ed. Porto Alegre: Artmed, 2009.

FIRJAN - FEDERAÇÃO DAS INDÚSTRIAS DO ESTADO DO RIO DE JANEIRO. Anuário da Indústria de Petróleo no Rio de Janeiro Panorama 2016. Rio de Janeiro, FIRJAN, 2016. Disponível em: http://www.firjan.com.br/publicacoes/publicacoes-de-economia/anuariopetroleo-e-gas.htm>. Acesso em 10 out. 2016.

GERWICK Jr, B.C. Construction of Marine and Offshore Structures. London: CRC Press, 2007.

GIL, A. C. Métodos e Técnicas de Pesquisa Social. $5^{\text {a }}$ ed. São Paulo: Atlas, 1999.

GIL, A. C. Como elaborar projetos de pesquisa. $4^{\text {a }}$ ed. São Paulo: Atlas, 2007.

GÓES, F.; NOGUEIRA, M. Pré-sal exige estrutura de portos que o país não tem. Valor Econômico, 2013. Disponível em: <http://www.valor.com.br/brasil/3306054/pre-sal-exigeestrutura-de-portos-que-o-pais-nao-tem\#>. Acesso em 10 out. 2015.

GRIBKOVSKAIA, I.; LAPORTE, G.; SHLOPAK A. A tabu search heuristic for a routing problem arising in the servicing offshore oil and gas platforms. Journal of the Operational Research Society, 59, p. 1449-1459, 2008. 
GUTMAN, J. Tributação e Outras Obrigações na Indústria do Petróleo. Rio de Janeiro: Freitas Bastos; Maria Augusta Delgado, 2007.

HAIR Jr, J. F.; BABIN, B.; MONEY, A. H.; SAMUEL, P. Fundamentos de métodos de pesquisa em administração. Porto Alegre: Bookman, 2005.

HALVORSEN-WEARE, E. E.; FAGERHOLT, K.; NONÅS, L. M.; ASBJØRNSLETT, B. E. Optimal fleet composition and periodic routing of offshore supply vessels. European Journal of Operational Research, 223, p. 508-517, 2012.

HILL, T. Manufacturing strategy. Milton Keynes: Open University Press, 1985.

HOFER, C. W.; SCHENDEL, D. Strategy formulation: analytical concepts. Saint Paul: West Publishing, 1978.

IBGE - INSTITUTO BRASILEIRO DE GEOGRAFIA E ESTATÍSTICA. Pesquisa Nacional por Amostra de Domicílios. Rio de Janeiro: IBGE, 2007.

IBP - INSTITUTO BRASILEIRO DE PETRÓLEO, GÁS E BIOCOMBUSTÍVEIS. Relatório de Atividades do IBP 2014. Rio de Janeiro, IBP, 2015. Disponível em: https://issuu.com/ibp_pub/docs/relatorio_atividades_ibp_2014>. Acesso em 10 dez. 2015.

IBP - INSTITUTO BRASILEIRO DE PETRÓLEO, GÁS E BIOCOMBUSTÍVEIS. Relatório de Atividades do IBP 2015. Rio de Janeiro, IBP, 2016. Disponível em: http://www.ibp.org.br/relatorio-de-atividades/2015/>. Acesso em 10 dez. 2015.

IBP - INSTITUTO BRASILEIRO DE PETRÓLEO, GÁS E BIOCOMBUSTÍVEIS. Agenda Prioritária da Indústria de Petróleo, Gás e Biocombustíveis 2014-2015. Rio de Janeiro, IBP, 2014. Disponível em: <http://www.ibp.org.br/publicacoes/agenda-prioritaria-da-industria-depetroleo-gas-e-biocombustiveis-2014-2015/> . Acesso em 23 set. 2016.

IEDI - INSTITUTO DE ESTUDOS PARA O DESENVOLVIMENTO INDUSTRIAL. A formação de engenheiros no Brasil: desafio ao crescimento e à inovação. São Paulo, IEDI, 
2010. Disponível em: < http://www.iedi.org.br/admin_ori/pdf/20100723_engenharia.pdf>. Acesso em 08 mai. 2015.

ILOS - Logística de apoio offshore - Integração e sincronização da cadeia de atendimento às unidades marítimas (2013). Disponível em: < http://www.ilos.com.br/web/logistica-deapoio-offshore-integracao-e-sincronizacao-da-cadeia-de-atendimento-as-unidadesmaritimas/>. Acesso em 23 jan. 2015.

JALONEN, H.; LÖNNQVIST, A. Exploring the critical success factors for developing and implementing a predictive capability in business. Knowledge and Process Management, 18:4, p. 207-219, 2011.

KAISER, M. J.; SNYDER, B. Modelling service vessel activity in the outer continental shelf Gulf of Mexico. International Journal of Logistics: Research and Applications, 16:1, p. 51 $85,2013$.

KAISER, M. J. Offshore service vessel activity forecast and regulatory modelling in the U.S. Gulf of Mexico, 2012 - 2017. Marine Policy, 57, p. 132-146, 2015.

LANDIS, J. R.; KOCH, G. G. The measurement of observer agreement for categorical data. Biometrics, 33, p. 159-174, 1977.

LEIDECKER, J. K.; BRUNO, A. V. Identifying and using critical success factors. Long Range Planning, 17:1, p. 23-32, 1984.

LOPES, M. M.; CASTELO BRANCO, V. T. F.; SOARES, J. B. Utilização dos testes estatísticos de Kolmogorov-Smirnov e Shapiro-Wilk para verificação da normalidade para materiais de pavimentação. Transportes, 21:1, p. 59-66, 2013.

MANUAL DE OSLO. Diretrizes para coleta e interpretação de dados sobre inovação. Rio de Janeiro, FINEP, 1997. Disponível em: < http://www.finep.gov.br/images/apoio-efinanciamento/manualoslo.pdf>. Acesso em 23 set. 2016. 
MARTÍN, J. C.; VOLTES-DORTA, A. A note on how to measure hubbing practices in airline networks. Transportation Research Part E, 45, p. 250-254, 2009.

MATHEDI, J. O. P. Embarcações de Apoio à Exploração de Petróleo e Gás. São Paulo: Agbook, 2010.

MENDES, A. B. Programação de frota de apoio a operações "offshore" sujeita à requisição de múltiplas embarcações para uma mesma tarefa. 2007. 224 p. Tese (Doutorado). Escola Politécnica, Universidade de São Paulo. São Paulo, 2007.

MENEZES, F.; PORTO, O.; REIS, M. L.; MORENO, L.; ARAGÃO, M. P.; UCHOA, E.; ABEDELOM, H.; NASCIMENTO, N. C. Optimizing Helicopter Transport of Oil Rig Crews at Petrobras. Interfaces, 40, p. 408-416, 2010.

MIGUEL, P. A. C. Estudo de caso na engenharia de produção: estruturação e recomendações para sua condução. Produção, 17:1, p. 216-229, 2007.

MIGUEL, P. A. C.; SOUSA, R. O método do estudo de caso na engenharia de produção, em Miguel, P. A. C (Coord), Metodologia de pesquisa em engenharia de produção e gestão de operações, Elsevier/Abepro, Rio de Janeiro, 131-148, 2012.

MOURA, D. A. Análise dos principais segmentos da indústria marítima brasileira: estudo das dimensões e dos fatores críticos de sucesso inerentes à sua competitividade. 2008. 304 p. Tese (Doutorado). Escola Politécnica, Universidade de São Paulo. São Paulo, 2008.

MPDG - MINISTÉRIO DO PLANEJAMENTO, DESENVOLVIMENTO E GESTÃO. Orçamentos Anuais. Brasília, MPDG, 2015. Disponível em: http://www.planejamento.gov.br/assuntos/orcamento-1/orcamentos-anuais>. Acesso em 15 set. 2015.

MURPHY, P. R.; DALEY, J. M.; HALL, P. K. Carrier selection: do shippers and carriers agree, or not? Transportation Research Part E: Logistics and Transportation Review, 33:1, p. 67-72, 1997. 
NULTY, D. D. The adequacy of response rates to online and paper surveys: what can be done? Assessment \& Evaluation in Higher Education, 33:3, p. 301-314, 2008.

NYAOGA, R. B.; MAGUTU, P. O.; ADUDA, J. Is there a link between supply chain strategies and firm performance? Evidence from large-scale manufacturing firms in Kenya. Journal of Operations and Supply Chain Management, 8:2, p. 1-22, 2015.

ONIP - ORGANIZAÇÃO NACIONAL DA INDÚSTRIA DO PETRÓlEO. Agenda de Competitividade 2010. Disponível em: 〈http://www1.onip.org.br/> . Acesso em 18 nov. 2014.

PETROBRAS - PETRÓLEO BRASILEIRO. Regulação de conteúdo local. Rio de Janeiro, 2013. Disponível em: <http://www.prominp.com.br/prominp/pt_br/conteudo/conteudolocal.htm>. Acesso em 10 nov. 2016.

PETROBRAS - PETRÓLEO BRASILEIRO. Entenda quais são e como funcionam nossos importantes programas. Rio de Janeiro, PETROBRAS, 2014. Disponível em: $<$ http://www.petrobras.com.br/fatos-e-dados/entenda-quais-sao-e-como-funcionam-nossosimportantes-programas.htm>. Acesso em 10 nov. 2016.

PETROBRAS - PETRÓLEO BRASILEIRO. Relatório de Sustentabilidade 2015. Rio de Janeiro, PETROBRAS, 2016a. Disponível em: http://www.petrobras.com.br/pt/sociedade-e-

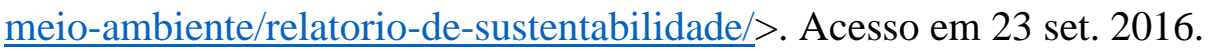

PETROBRAS - PETRÓLEO BRASILEIRO. Plano Estratégico Plano de Negócios e Gestão 2017-2021. Rio de Janeiro, PETROBRAS, 2016b. Disponível em: http://www.petrobras.com.br/pt/quem-somos/estrategia/plano-de-negocios-e-gestao/>. Acesso em 23 set. 2016.

PETROBRAS - PETRÓLEO BRASILEIRO. Pré-sal. Rio de Janeiro, PETROBRAS, 2017. Disponível em: $\quad$ http://www.petrobras.com.br/pt/nossas-atividades/areas-deatuacao/exploracao-e-producao-de-petroleo-e-gas/pre-sal/>. Acesso em 10 fev. 2017. 
PINTO, M. et al. Implantação e consolidação de laboratório de gestão de operações e da cadeia de suprimento da indústria de construção naval. Documento: Avaliação de nichos de mercado potencialmente atraentes ao Brasil. CEGN, São Paulo, nov. 2006.

PORTAL DA INDÚSTRIA. Financiamento à inovação despenca em 2016. Disponível em: <http://www.portaldaindustria.com.br/agenciacni/noticias/2016/10/financiamento-a-inovacaodespenca-em-2016-mostra-levantamento-da-mei/>. Acesso em 10 out. 2016.

PORTER, M. E. Estratégia Competitiva: técnicas para análise de indústrias e da concorrência, $2^{\mathrm{a}}$ ed. Rio de Janeiro: Elsevier, 2004.

QUEIROZ, M. M. Métodos heurísticos aplicados ao problema de programação de frota de navios PLVs. 2011. 102 p. Dissertação (Mestrado). Escola Politécnica, Universidade de São Paulo. São Paulo, 2011.

RITCHIE, G. Practical Introduction to Anchor Handling and Supply Vessel Operations. Oilfield Publications Ltd: London, 2004.

RITCHIE, G. Offshore support vessels: a practical guide. London: The Nautical Institute, 2008.

ROCKART, J. Chief executives define their own data needs. Harvard Business Review, 57, p. 81-83, 1979.

R\&D MAGAZINE. 2016 global R\&D funding forecast. Disponível em <https://www.iriweb.org/sites/default/files/2016GlobalR\%26DFundingForecast_2.pdf>. Acesso em 10 out. 2016.

SAMPIERI, R. H.; COLLADO, C. F.; LUCIO, P. B. Metodologia de pesquisa, $3^{\mathrm{a}}$ ed. São Paulo: McGraw-Hill, 2006.

SAUER, I. L.; RODRIGUES, L. A. Pré-sal e Petrobras além dos discursos e mitos: disputas, riscos e desafios. Estudos Avançados, 30:88, p. 185-229, 2016. 
SCHIFFMAN, L.; KANUK, L. Comportamento do consumidor. LTC Editora. $6^{\text {a }}$ ed. 2000.

SEBRAE RJ. SERVIÇO BRASILEIRO DE APOIO ÀS MICRO E PEQUENAS EMPRESAS. Petróleo e Gás: Informações para empresas fornecedoras de bens e serviços, 2014. Disponível em: $<$ https://www.sebrae.com.br/Sebrae/Portal\%20Sebrae/Anexos/Informacoes\%20sobre\%20 a\%20Cadeia\%20Produtiva\%20do\%20Petroleo.pdf>. Acesso em 10 out. 2016.

SEESP - SECRETARIA DE ENERGIA DO ESTADO DE SÃO PAULO. Anuário Estatístico da Indústria de Petróleo e Gás Natural de São Paulo. São Paulo, SEESP, 2015. Disponível em: http://www.energia.sp.gov.br/wp-content/uploads/2016/07/824.pdf>. Acesso em 23 set. 2016.

SHYSHOU, A.; GRIBKOVSKAIA, I.; BARCELÓ, J. A simulation study of the fleet sizing problem arising in offshore anchor handling operations. European Journal of Operational Research, 203, p. 230-240, 2010.

SIEGEL, S.; CASTELLAN Jr, N. J. Estatística não-paramétrica para ciências do comportamento, $2^{\text {a }}$ ed. Porto Alegre: Artmed, 2006.

SINAVAL. Gastos com afretamento de barcos de apoio no Brasil aumentam 50\% (2015a). Disponível em: < http://sinaval.org.br/2015/03/gastos-com-afretamento-de-barcos-de-apoiono-brasil-aumentam-50/> . Acesso em 10 dez. 2015.

SINAVAL. Curva negativa de aprendizagem (2015b). Disponível em: <http://sinaval.org.br/2015/07/curva-negativa-de-aprendizagem/>. Acesso em 13 abr. 2017.

SINAVAL. Barcos brasileiros já são quase $70 \%$ da frota de apoio marítimo (2016). Disponível em: <http://sinaval.org.br/2016/06/barcos-brasileiros-ja-sao-quase-70-da-frota-deapoio-maritimo/>. Acesso em 23 set. 2016.

SLACK, N. Vantagem competitiva em Manufatura, 2a ed. São Paulo: Atlas, 2002. 
SOUZA, A. P.; FIRPO, S. P.; PONCZEK, V. P.; ZYLBERSTAJN, E.; RIBEIRO, F. G. Custo do Trabalho no Brasil: proposta de uma nova metodologia de mensuração. Relatório Final. Fundação Getúlio Vargas: Maio/2012.

STOPFORD, M. Maritime Economics, $3^{\text {a }}$ ed. London: Routledge Taylor \& Francis, 2009.

TERRA, A. O.; FERREIRA, A. S.; NASCIMENTO, D. C. O. Os desafios do pré-sal brasileiro: um estudo da logística do campo de Tupi. Seget 2014: XI Simpósio de Excelência em Gestão e Tecnologia, p. 1-16, 2014.

VERGARA, S. C. Projetos e relatórios de pesquisa em administração, $4^{\mathrm{a}}$ ed. São Paulo: Atlas, 2003.

VOSS, C.; TSIKRIKTSIS, N.; FROHLICH, M. Case research in operations management. International Journal of Operations \& Production Management, 22:2, p. 195-219, 2002.

WEF - World Economic Forum. The global competitiveness report 2016-2017. Geneva: World Economic Forum. Disponível em: https://www.weforum.org/reports/the-globalcompetitiveness-report-2016-2017-1>. Acesso em 27 out. 2016.

YEOH, W.; POPOVIČ, A. Extending the understanding of critical success factors for implementing business intelligence systems. Journal of the Association for Information Science and Technology, 67:1, p. 134-147, 2016.

YIN, R. K. Estudo de caso: planejamento e métodos, 5ª ed. Porto Alegre: Bookman, 2015. 


\section{APÊNDICE A - POLÍTICA DE CONTEÚDO LOCAL}

O conteúdo local (CL) como é chamado, ou a política de conteúdo local (PCL) é uma maneira de proteger a indústria naval brasileira, ou seja, tem por objetivo proteger os fornecedores nacionais de bens e serviços e ao mesmo tempo incentivar as compras no mercado nacional, dessa forma, contribuindo para o desenvolvimento da indústria nacional (D’ALMEIDA, 2015). Seu principal instrumento é o compromisso de comprar um determinado percentual produzido pelos fornecedores nacionais, assumido pelas concessionárias nas rodadas de licitação nos blocos exploratórios (ALMEIDA; LOSEKANN; CLAVIJO, 2016).

O conteúdo local possui alguns problemas e é alvo, a todo momento, de muitas críticas, por exemplo, se uma empresa na fase de licitação prometer um CL alto para vencer o processo licitatório, e depois não cumprir, justificando que o mercado nacional não possui fornecedores qualificados, esta empresa, pagaria apenas uma pequena multa em relação aos lucros da exploração do bloco (D’ALMEIDA, 2015). Para tentar melhorar a dinâmica do CL, D'Almeida (2015) destaca que foi implementado um conceito de penalidade para o não cumprimento nos contratos de concessão, calculado proporcionalmente à parcela de CL não cumprida. $\mathrm{O}$ autor destaca, que com este mecanismo, foi possível alcançar propostas mais realistas. Porém, isto ainda não seria suficiente para resolver a PCL.

Uma boa parte da indústria de petróleo, vê com muitas ressalvas as políticas de conteúdo local. Uma das principais justificativas está associada à falta de capacidade dos fornecedores nacionais, o que acaba gerando diversos atrasos nos prazos de entrega dos projetos, aumento de preços, produtos e serviços com qualidade baixa e consequentemente, redução da competitividade de toda a cadeia.

A Tabela 25 e a Figura 38 a seguir, mostra o histórico das rodadas de licitações da ANP de 1999 a 2015 e os respectivos percentuais de CL exigido nas etapas de exploração e desenvolvimento do bloco exploratório. 
Tabela 25 - Rodadas de licitações 1999 - 2015 e o conteúdo local

\begin{tabular}{|c|c|c|c|c|c|c|c|c|c|c|c|c|}
\hline $\begin{array}{l}\text { RODADAS DE } \\
\text { LICITAÇÕES }\end{array}$ & $\begin{array}{c}\text { R1 } \\
1999\end{array}$ & $\begin{array}{c}\mathrm{R} 2 \\
2000 \\
\end{array}$ & $\begin{array}{c}\mathrm{R} 3 \\
2001 \\
\end{array}$ & $\begin{array}{c}\mathrm{R} 4 \\
2002 \\
\end{array}$ & $\begin{array}{c}\mathrm{R} 5 \\
2003 \\
\end{array}$ & $\begin{array}{c}\text { R6 } \\
2004 \\
\end{array}$ & $\begin{array}{c}\mathrm{R} 7 \\
2005 \\
\end{array}$ & $\begin{array}{c}\text { R9 } \\
2007 \\
\end{array}$ & $\begin{array}{c}\text { R10 } \\
2008 \\
\end{array}$ & $\begin{array}{c}\text { R11 } \\
2013 \\
\end{array}$ & $\begin{array}{r}\mathrm{R} 12 \\
2013 \\
\end{array}$ & $\begin{array}{r}\text { R13 } \\
2015 \\
\end{array}$ \\
\hline Blocos ofertados & 27 & 23 & 53 & 54 & 908 & 913 & 1.134 & 271 & 130 & 289 & 240 & 266 \\
\hline $\begin{array}{l}\text { Empresas habilitadas } \\
\text { nacionais }\end{array}$ & 3 & 4 & 5 & 4 & 3 & 8 & 19 & 30 & 24 & 17 & 10 & 11 \\
\hline $\begin{array}{l}\text { Empresas habilitadas } \\
\text { estrangeiras }\end{array}$ & 35 & 40 & 37 & 25 & 9 & 16 & 25 & 31 & 16 & 47 & 11 & 6 \\
\hline $\begin{array}{l}\text { Empresas vencedoras } \\
\text { nacionais }\end{array}$ & 1 & 4 & 4 & 4 & 2 & 7 & 14 & 20 & 12 & 12 & 8 & 11 \\
\hline $\begin{array}{l}\text { Empresas vencedoras } \\
\text { estrangeiras }\end{array}$ & 10 & 12 & 18 & 10 & 4 & 12 & 16 & 16 & 5 & 18 & 4 & 6 \\
\hline $\begin{array}{l}\text { Conteúdo local médio } \\
\text {-etapa de exploração }\end{array}$ & $25,00 \%$ & $42,00 \%$ & $28,00 \%$ & $39,00 \%$ & $78,80 \%$ & $85,70 \%$ & $74,00 \%$ & $68,90 \%$ & $79,00 \%$ & $61,50 \%$ & $72,60 \%$ & $73,10 \%$ \\
\hline $\begin{array}{l}\text { Conteúdo local médio - } \\
\text { etapa de desenvolvimento }\end{array}$ & $27,00 \%$ & $48,00 \%$ & $40,00 \%$ & $54,00 \%$ & $85,60 \%$ & $88,80 \%$ & $81,00 \%$ & $76,50 \%$ & $84,00 \%$ & $75,60 \%$ & $84,50 \%$ & $79,50 \%$ \\
\hline
\end{tabular}

Fonte: Adaptado de ANP, 2016.

Obs: A rodada 8 foi cancelada.

Por meio da Figura 38, percebe-se que o CL médio, tanto na etapa de exploração, quanto na de desenvolvimento, teve um aumento significativo, em que na $1^{\text {a }}$ rodada em 1999, os CLs estavam próximos a 30\%, e em 2015 na 13ª rodada, os CLs se encontravam próximos a 80\%.

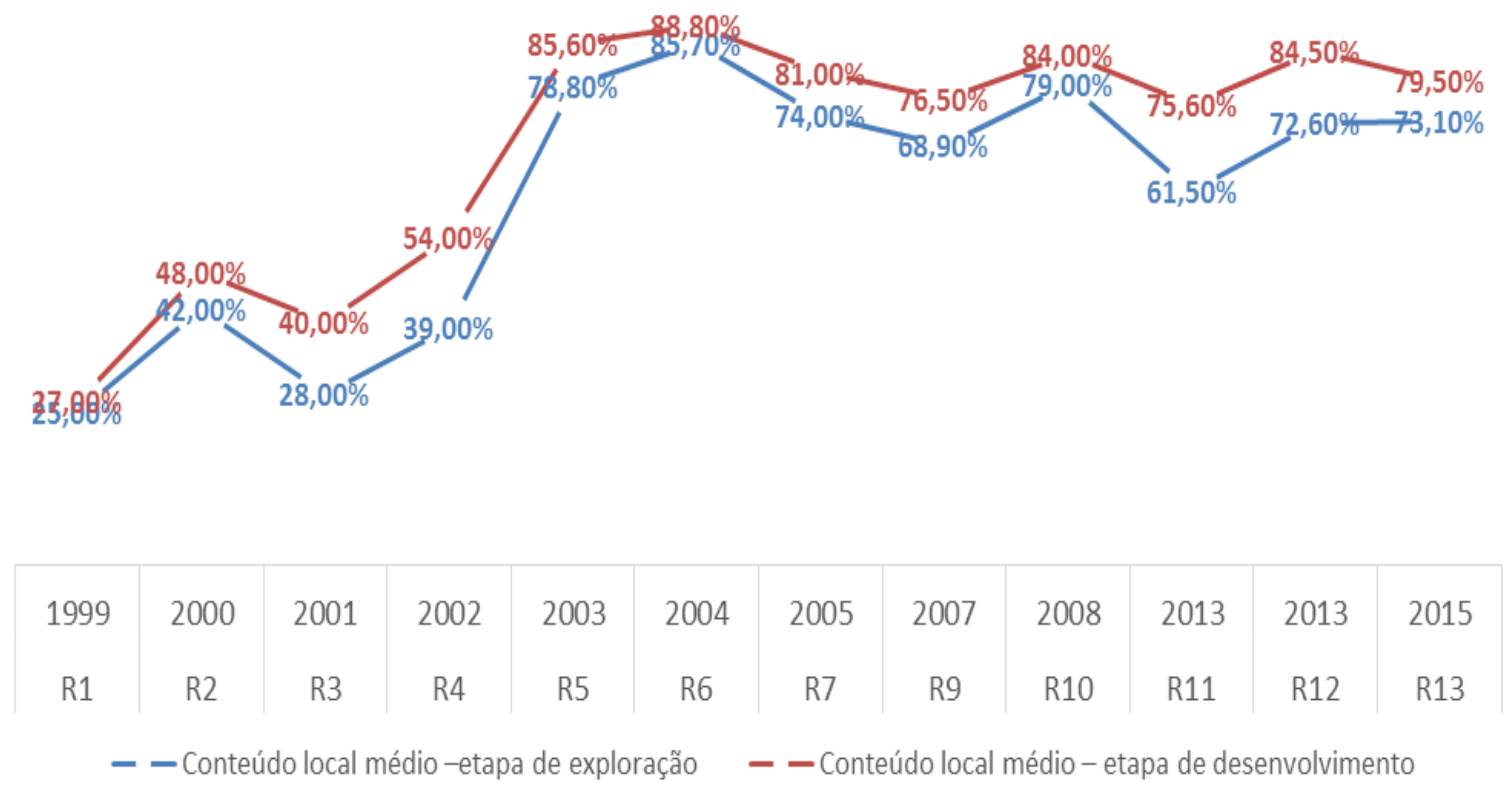

Figura 38 - Evolução das Rodadas de licitações 1999 - 2015 e o conteúdo local Fonte: Adaptado de ANP, 2016. 
Para disciplinar e transmitir mais transparência referente ao CL nos contratos de concessão para exploração, desenvolvimento e produção de petróleo e/ou gás natural, em 2007, foi instituído a Resolução ANP n³6, de 13.11.2007, composto pelos seguintes documentos:

i. Regulamento de Certificação de Conteúdo Local: tem por objetivo definir critérios e procedimentos para o processo de Certificação de Conteúdo Local;

ii. Certificado de Conteúdo Local: Certificado emitido por uma Certificadora que atesta o fornecimento do bem/serviço e o \% de CL;

iii. Relatório Trimestral de Certificação: Relatório emitido por uma Certificadora e enviado à ANP sobre todas as certificações realizadas no período;

iv. Cartilha de Conteúdo Local: estabelece os critérios, instruções, e as fórmulas para apurar o CL.

A Cartilha de Conteúdo Local gerou uma grande contribuição para o setor, ao promover maior transparência no processo de apuração do CL. A Figura 39 a seguir, mostra os principais componentes para identificação do CL.
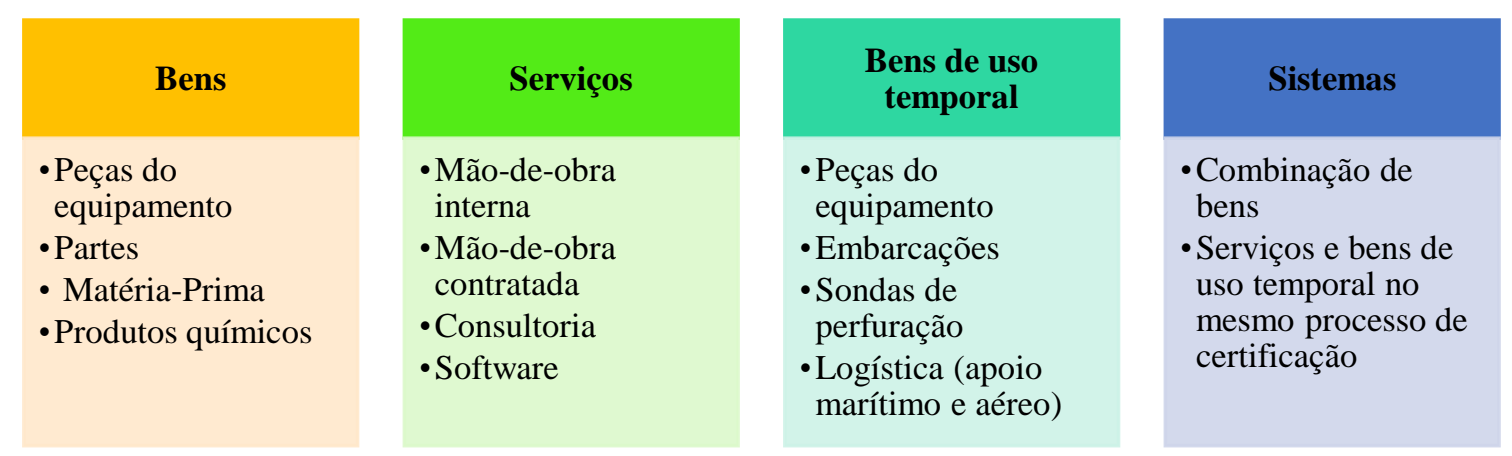

Figura 39 - Principais componentes para identificação do CL Fonte: Adaptado de Petrobras, 2013 e Resolução ANP nº 36, 2007.

De acordo com a Resolução ANP nº 36, 2007 e Petrobras (2013), um item que não é nacional, porém pode conter X\% de CL. A partir desta definição, têm-se as seguintes equações para o cálculo do CL:

Bens $(\%)=1-[$ custo dos insumos importados / preço de venda sem impostos] x 100

Serviços $(\%)=$ [custo da mão de obra local / custo total da mão de obra] x 100

A seguir, a Figura 40, exemplifica o cálculo do conteúdo local de um bem. 


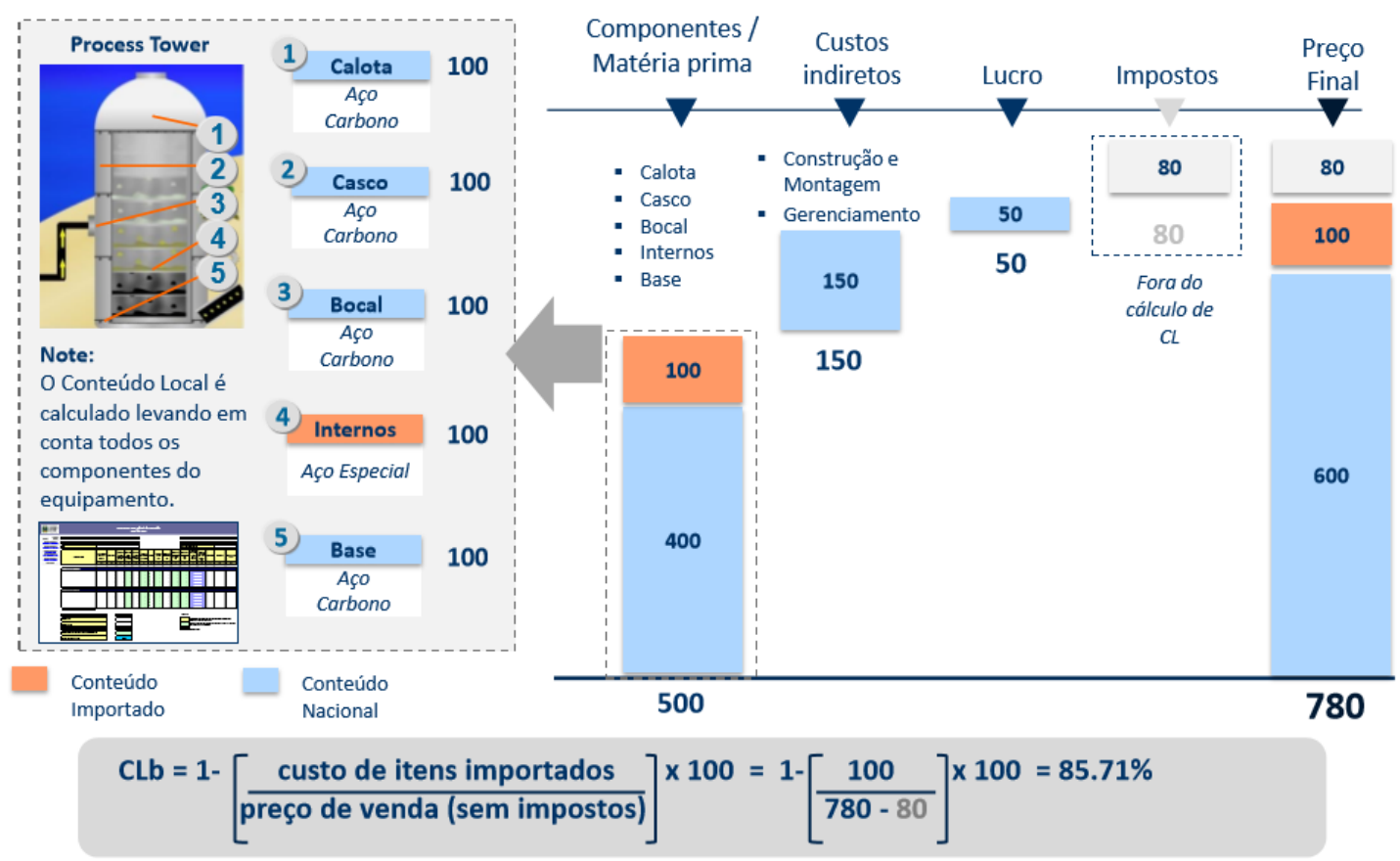

Figura 40 - Exemplo de cálculo de CL para um bem

Fonte: Petrobras, 2013.

Já a Figura 41, mostra o exemplo do cálculo do conteúdo local de um sistema completo.

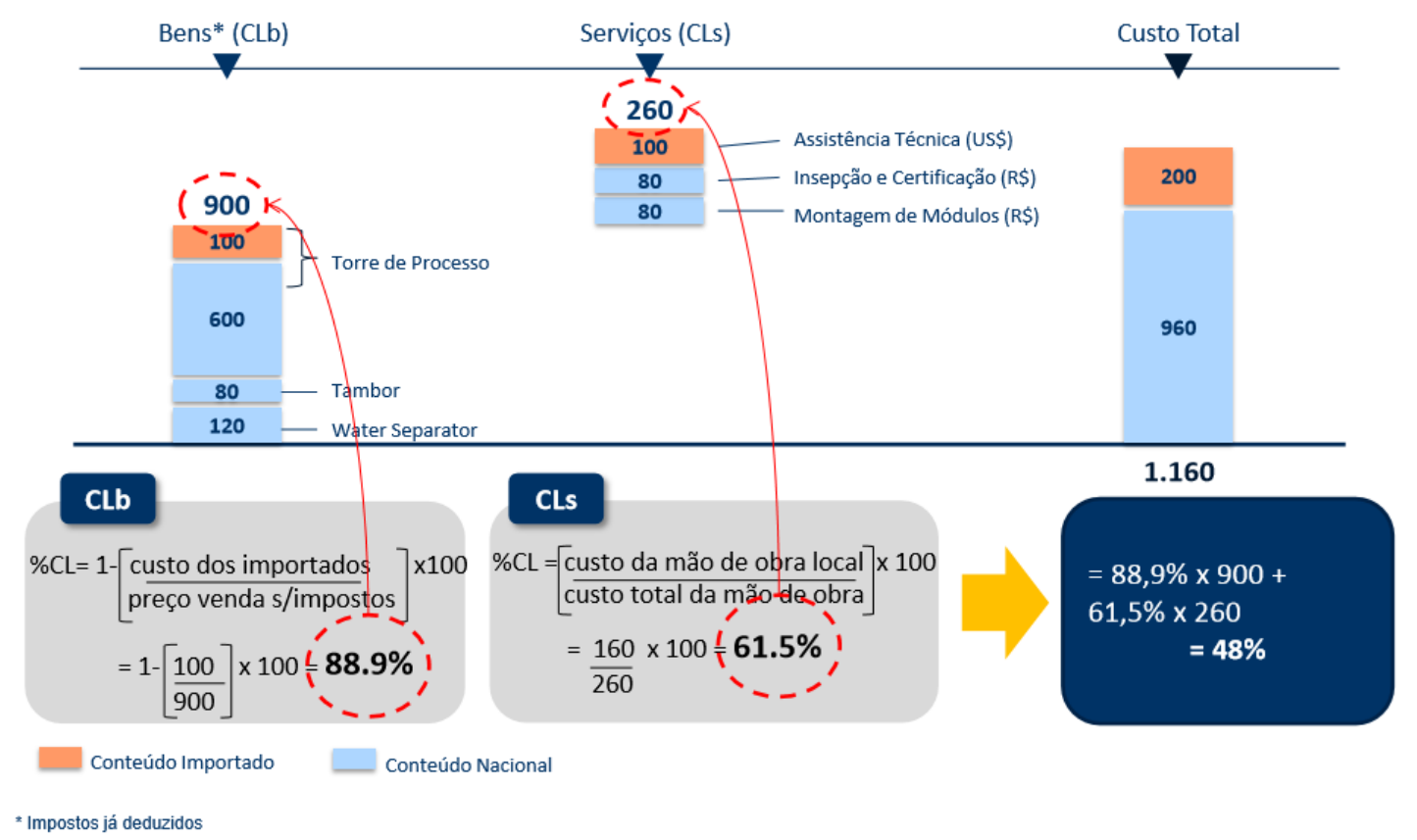

Figura 41 - Exemplo de cálculo de CL para um sistema Fonte: de Petrobras, 2013. 
De acordo com a Petrobras (2013) após a $7^{\text {a }}$ Rodada de Licitação da ANP, o critério de multa pelo não cumprimento do compromisso de Conteúdo Local, passou a ser da seguinte forma:

\section{Caso 1:}

Se $0<\mathrm{NR}(\%)<65 \%$, então, Penalidade $=60 \% \times$ CL NR

\section{Caso 2:}

Se NR(\%) $\geq 65 \%$, então, Penalidade $=(1.143 \times$ NR -14.285$) \% \times$ CL NR

Onde:

CL NR = CL Não Realizado

$\mathrm{NR}(\%)=(\%$ CL contratado $-\%$ CL realizado $) / \%$ CL contratado

\section{Exemplos Caso 1 e Caso $2^{14}$}

Valor contratado: $\mathrm{R} \$ 1.000 \mathrm{mi}$

CL contratado: $80 \%=800 \mathrm{mi}$

\section{Caso 1}

CL realizado $=70 \%$

$\mathrm{NR}(\%)=(80 \%-70 \%) / 80 \%=12.5 \%$

CL NR $(\mathrm{R} \$)=800 \mathrm{mi} \times 12.5 \%=100 \mathrm{mi}$

Penalidade $=60 \% \times 100 \mathrm{mi}=60 \mathrm{mi}$

\section{Caso 2}

CL realizado $=20 \%$

$\operatorname{CL~NR}(\%)=(80 \%-20 \%) / 80 \%=75 \%$

$\operatorname{CL~NR}(\%)=800 \mathrm{mi} \times 75 \%=600 \mathrm{mi}$

Penalidade $=[(1.143 \times 75)-14.285] \% \times 600 \mathrm{mi}=428.64 \mathrm{mi}$

\footnotetext{
${ }^{14}$ Extraídos da Regulação de Conteúdo Local, novembro de 2013, Petrobras.
} 
A Figura 42 a seguir, extraída de Petrobras (2013) exemplifica graficamente as penalidades aplicadas no caso 1 e caso 2 .

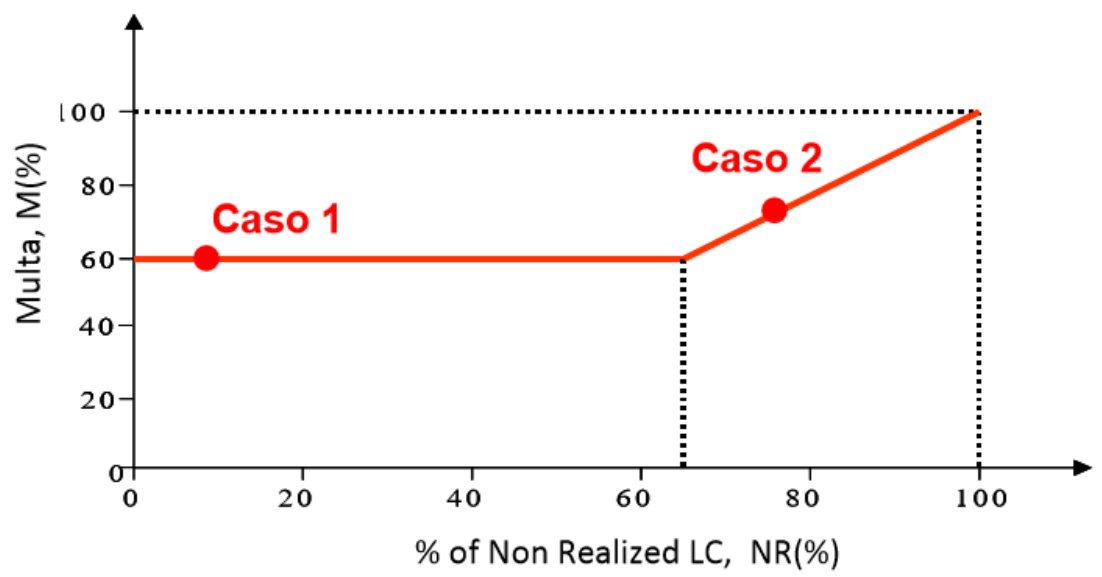

Figura 42 - Conteúdo local não realizado

Fonte: Petrobras, 2013.

Existem também os critérios de exceção para o não cumprimento do CL. As exceções são conhecidas no mercado como waiver. Os waivers podem ocorrer em três situações específicas: i) preço: caso os preços dos fornecedores nacionais forem excessivamente superiores aos praticados no exterior; ii) prazo de entrega: caso os prazos dos fornecedores locais sejam superiores aos do exterior, de modo que possa comprometer a produção e iii) nova tecnologia: caso não haja tecnologia disponível no mercado nacional, que atenda aos critérios de licitação. 


\section{APÊNDICE B - PROTOCOLO DE PESQUISA}

\section{A) Visão geral do estudo de caso e finalidade do protocolo}

a) Título

A cadeia de petróleo no Brasil: o caso da indústria de apoio marítimo.

b) Objetivo Geral

Identificação e mapeamento dos Fatores Críticos de Sucesso (FCS) da indústria de apoio marítimo no Brasil.

\section{c) Objetivos Específicos}

i. Analisar a indústria de apoio marítimo no Brasil;

ii. Identificar os fatores críticos de sucesso (FCS) e analisar as principais relações entre eles;

iii. Desenvolver um framework a partir dos FCS para a melhoria da tomada de decisões; iv. Adaptar o Mapa Estratégico da Indústria para a Indústria de Apoio Marítimo.

\section{d) Problema de Pesquisa}

Como a identificação dos fatores críticos de sucesso da indústria de apoio marítimo pode contribuir para o sistema de tomada de decisão das empresas?

\section{e) Estrutura do trabalho}

1. Introdução

2. Revisão da Literatura

3. Método

4. Análise e Discussão dos Resultados

5. Conclusões e Recomendações

6. Referências

7. Apêndices 


\section{B) Procedimentos de coleta de dados}

\section{a) Aspectos metodológicos}

Pesquisa exploratória, que utilizou a estratégia do estudo de caso único com múltiplas unidades de análise (integrado).

\section{b) Setor alvo}

Indústria de apoio marítimo no contexto da cadeia de petróleo no Brasil.

\section{c) Organizações}

Empresas que estão autorizadas a operar em operações de apoio marítimo, segundo a Antaq.

\section{d) Coleta de dados}

Pesquisa realizada por meio de entrevistas estruturada (questionário) e documentos de domínio público.

\section{e) Fontes dos dados e instrumentos de coleta de dados}

1. Primárias

a. Executivos das empresas.

2. Secundárias

a. Internas: documentos e registros nos websites oficiais das empresas.

b. Externas: anuários estatísticos da ANP, Antaq, Firjan e da indústria de petróleo de São Paulo, relatório de atividades do IBP, Agenda prioritária do IBP, relatório de sustentabilidade da Petrobras, plano estratégico da Petrobras 2017-2021. 


\section{C) Questões do estudo de caso}

As questões foram desenvolvidas com base nos aspectos teórico-conceituais

\section{QUESTIONÁTIO FATORES CRÍTICOS DE SUCESSO NA INDÚSTRIA DE APOIO MARÍTIMO}

Prezado Senhor (a), estamos realizando uma pesquisa de Doutorado no âmbito do Programa de Pós-Graduação em Engenharia Naval e Oceânica da Escola Politécnica da Universidade de São Paulo (USP) com objetivo de identificar e mapear os Fatores Críticos de Sucesso (FCS) da indústria de Apoio Marítimo. A sua contribuição é muito importante, pois esta pesquisa inédita pretende contribuir para o avanço da área, e melhorar o sistema de tomada de decisão das empresas. As informações serão mantidas em sigilo. Para o sucesso da pesquisa, solicitamos sua contribuição respondendo o questionário a seguir, que apresenta 68 questões e tempo estimado de resposta de 10 minutos.

Para cada questão, dê uma nota de 1 a 5 , onde 5 significa que você CONCORDA TOTALMENTE e 1 que você DISCORDA TOTALMENTE.

Quanto mais você concordar com a questão, mais próximo de 5 deverá ser sua nota, quanto mais você discordar, mais próxima de 1 deverá ser a nota. 


\begin{tabular}{|c|c|c|c|c|c|c|c|}
\hline Cat. & Cód. & Questão & $\begin{array}{c}\text { Discordo } \\
\text { totalmente }\end{array}$ & & & & $\begin{array}{l}\text { Concordo } \\
\text { totalmente }\end{array}$ \\
\hline Pol & FCS 1 & $\begin{array}{l}\text { A indefinição do cenário político e } \\
\text { econômico prejudica os investimentos } \\
\text { de longo prazo. }\end{array}$ & 1 & 2 & 3 & 4 & 5 \\
\hline Pol & FCS 2 & $\begin{array}{l}\text { As incertezas do mercado são os } \\
\text { aspectos mais complexos para } \\
\text { monitorar. }\end{array}$ & 1 & 2 & 3 & 4 & 5 \\
\hline Pol & FCS 3 & $\begin{array}{l}\text { A lacuna de informações sobre o } \\
\text { Prorefam (Programa de Renovação da } \\
\text { Frota de Apoio Marítimo) dificultou a } \\
\text { estratégia das empresas na aquisição de } \\
\text { embarcações. }\end{array}$ & 1 & 2 & 3 & 4 & 5 \\
\hline Pol & FCS 4 & $\begin{array}{l}\text { Falta agilidade do governo federal na } \\
\text { implementação de políticas públicas } \\
\text { que estimulem o setor de apoio } \\
\text { marítimo }\end{array}$ & 1 & 2 & 3 & 4 & 5 \\
\hline Pol & FCS 5 & $\begin{array}{l}\text { A legislação atual provoca insegurança } \\
\text { jurídica e impacta os investimentos do } \\
\text { setor. }\end{array}$ & 1 & 2 & 3 & 4 & 5 \\
\hline Pol & FCS 6 & $\begin{array}{l}\text { As normas ambientais não são } \\
\text { previsíveis. }\end{array}$ & 1 & 2 & 3 & 4 & 5 \\
\hline Pol & FCS 7 & $\begin{array}{l}\text { Existe grande dificuldade para } \\
\text { conseguir documentações para atender } \\
\text { aos editais (contratos/concorrências). }\end{array}$ & 1 & 2 & 3 & 4 & 5 \\
\hline Pol & FCS 8 & $\begin{array}{l}\text { É fundamental a elaboração de manuais } \\
\text { de procedimentos para gerenciamento } \\
\text { de riscos. }\end{array}$ & 1 & 2 & 3 & 4 & 5 \\
\hline Pol & FCS 9 & $\begin{array}{l}\text { É fundamental as empresas possuírem } \\
\text { um especialista em assuntos } \\
\text { ambientais. }\end{array}$ & 1 & 2 & 3 & 4 & 5 \\
\hline Pol & FCS 10 & $\begin{array}{l}\text { A carga tributária brasileira impacta de } \\
\text { forma negativa o resultado da empresa. }\end{array}$ & 1 & 2 & 3 & 4 & 5 \\
\hline Pol & FCS 11 & $\begin{array}{l}\text { Os custos com licenciamento ambiental } \\
\text { oneram a indústria. }\end{array}$ & 1 & 2 & 3 & 4 & 5 \\
\hline Pol & FCS 12 & $\begin{array}{l}\text { A atuação da empresa é impactada pela } \\
\text { instabilidade política }\end{array}$ & 1 & 2 & 3 & 4 & 5 \\
\hline Mo & FCS 13 & $\begin{array}{l}\text { A composição da tripulação é um } \\
\text { grande problema devido à falta de } \\
\text { qualificação dos trabalhadores. }\end{array}$ & 1 & 2 & 3 & 4 & 5 \\
\hline Mo & FCS 14 & $\begin{array}{l}\text { A falta de profissionais (tripulação e } \\
\text { analistas) com prática no mercado } \\
\text { representa a maior limitação para a } \\
\text { concorrência em editais/licitações de } \\
\text { contratação de serviço de apoio. }\end{array}$ & 1 & 2 & 3 & 4 & 5 \\
\hline Mo & FCS 15 & $\begin{array}{l}\text { A formação ou experiência anterior dos } \\
\text { colaboradores contratados para } \\
\text { operarem os equipamentos e as } \\
\text { embarcações não é suficiente, o que }\end{array}$ & 1 & 2 & 3 & 4 & 5 \\
\hline
\end{tabular}




\begin{tabular}{|c|c|c|c|c|c|c|c|}
\hline Cat. & Cód. & Questão & $\begin{array}{c}\text { Discordo } \\
\text { totalmente }\end{array}$ & & & & $\begin{array}{l}\text { Concordo } \\
\text { totalmente }\end{array}$ \\
\hline & & $\begin{array}{l}\text { prejudica a produtividade e eleva os } \\
\text { custos. }\end{array}$ & & & & & \\
\hline Mo & FCS 16 & $\begin{array}{l}\text { A oferta de profissionais qualificados } \\
\text { pelo mercado é baixa. }\end{array}$ & 1 & 2 & 3 & 4 & 5 \\
\hline Mo & FCS 17 & $\begin{array}{l}\text { É importantíssimo todos os } \\
\text { funcionários terem conhecimento do } \\
\text { Plano Nacional de Contingência para } \\
\text { Incidentes de Poluição por Óleo em } \\
\text { Águas sob Jurisdição Nacional - PNC. }\end{array}$ & 1 & 2 & 3 & 4 & 5 \\
\hline Mo & FCS 18 & $\begin{array}{l}\text { A qualidade da mão de obra é fator } \\
\text { decisivo para a competitividade da } \\
\text { empresa. }\end{array}$ & 1 & 2 & 3 & 4 & 5 \\
\hline Inov & FCS 19 & $\begin{array}{l}\text { É fundamental a empresa possuir } \\
\text { certificação ISO 9001, } 14001 \text { e OHSAS } \\
18001 \text {. }\end{array}$ & 1 & 2 & 3 & 4 & 5 \\
\hline Inov & FCS 20 & $\begin{array}{l}\text { A minha empresa utiliza ferramentas e } \\
\text { técnicas para a identificação de } \\
\text { melhorias. }\end{array}$ & 1 & 2 & 3 & 4 & 5 \\
\hline Inov & FCS 21 & $\begin{array}{l}\text { A minha empresa possui ou já possuiu } \\
\text { cooperação técnica com alguma } \\
\text { universidade nacional. }\end{array}$ & 1 & 2 & 3 & 4 & 5 \\
\hline Inov & FCS 22 & $\begin{array}{l}\text { A minha empresa possui ou já possuiu } \\
\text { cooperação técnica com alguma } \\
\text { universidade do exterior. }\end{array}$ & 1 & 2 & 3 & 4 & 5 \\
\hline Inov & FCS 23 & $\begin{array}{l}\text { A inovação no apoio marítimo é } \\
\text { considerada baixa. }\end{array}$ & 1 & 2 & 3 & 4 & 5 \\
\hline Inov & FCS 24 & $\begin{array}{l}\text { A baixa competição contribui para a } \\
\text { falta de inovação do setor. }\end{array}$ & 1 & 2 & 3 & 4 & 5 \\
\hline Inov & FCS 25 & $\begin{array}{l}\text { Não existe a necessidade de } \\
\text { integração/parcerias com empresas } \\
\text { internacionais }\end{array}$ & 1 & 2 & 3 & 4 & 5 \\
\hline Inov & FCS 26 & $\begin{array}{l}\text { Investimentos em tecnologia possuem } \\
\text { relevância para a empresa. }\end{array}$ & 1 & 2 & 3 & 4 & 5 \\
\hline Inov & FCS 27 & $\begin{array}{l}\text { Investimentos em sistemas de gestão de } \\
\text { tráfego geram vantagem competitiva. }\end{array}$ & 1 & 2 & 3 & 4 & 5 \\
\hline Inov & FCS 28 & $\begin{array}{l}\text { Na empresa existe área de Pesquisa e } \\
\text { Desenvolvimento (P\&D). }\end{array}$ & 1 & 2 & 3 & 4 & 5 \\
\hline Inov & FCS 29 & $\begin{array}{l}\text { A empresa possui plano de } \\
\text { investimentos em novas tecnologias. }\end{array}$ & 1 & 2 & 3 & 4 & 5 \\
\hline Inov & FCS 30 & $\begin{array}{l}\text { A minha empresa utiliza softwares } \\
\text { específicos para a previsão de cenários. }\end{array}$ & 1 & 2 & 3 & 4 & 5 \\
\hline
\end{tabular}




\begin{tabular}{|c|c|c|c|c|c|c|c|}
\hline Cat. & Cód. & Questão & $\begin{array}{c}\text { Discordo } \\
\text { totalmente }\end{array}$ & & & & $\begin{array}{l}\text { Concordo } \\
\text { totalmente }\end{array}$ \\
\hline Inov & FCS 31 & $\begin{array}{l}\text { A empresa utiliza software para } \\
\text { planejar as atividades. }\end{array}$ & 1 & 2 & 3 & 4 & 5 \\
\hline Inov & FCS 32 & $\begin{array}{l}\text { A empresa utiliza pacotes } \\
\text { computacionais para otimizar o } \\
\text { planejamento de suas operações. }\end{array}$ & 1 & 2 & 3 & 4 & 5 \\
\hline Comp & FCS 33 & $\begin{array}{l}\text { A utilização de bandeira brasileira } \\
\text { representa uma desvantagem frente aos } \\
\text { armadores estrangeiros. }\end{array}$ & 1 & 2 & 3 & 4 & 5 \\
\hline Comp & FCS 34 & $\begin{array}{l}\text { Os custos para manter uma embarcação } \\
\text { operacional (tripulação, manutenção, } \\
\text { seguro e administração) representam } \\
\text { uma barreira para a entrada de novos } \\
\text { players }\end{array}$ & 1 & 2 & 3 & 4 & 5 \\
\hline Comp & FCS 35 & $\begin{array}{l}\text { A complexidade do mercado (excesso } \\
\text { de burocracia) representa uma barreira } \\
\text { de entrada menor que o custo de manter } \\
\text { uma embarcação. }\end{array}$ & 1 & 2 & 3 & 4 & 5 \\
\hline Comp & FCS 36 & $\begin{array}{l}\text { As empresas não sabem mensurar o } \\
\text { quão competitivo são em relação aos } \\
\text { seus concorrentes. }\end{array}$ & 1 & 2 & 3 & 4 & 5 \\
\hline Comp & FCS 37 & $\begin{array}{l}\text { Possuir uma área de inteligência de } \\
\text { mercado para estudar editais/licitações } \\
\text { é fundamental para ganhar as } \\
\text { concorrências. }\end{array}$ & 1 & 2 & 3 & 4 & 5 \\
\hline Comp & FCS 38 & $\begin{array}{l}\text { É imprescindível o acompanhamento } \\
\text { dos leilões da ANP. }\end{array}$ & 1 & 2 & 3 & 4 & 5 \\
\hline Comp & FCS 39 & $\begin{array}{l}\text { As empresas de apoio marítimo } \\
\text { possuem dificuldades para estimar o } \\
\text { retorno dos investimentos. }\end{array}$ & 1 & 2 & 3 & 4 & 5 \\
\hline Comp & FCS 40 & $\begin{array}{l}\text { A empresa atua também no apoio } \\
\text { portuário. }\end{array}$ & 1 & 2 & 3 & 4 & 5 \\
\hline Comp & FCS 41 & $\begin{array}{l}\text { O mercado nacional crescerá nos } \\
\text { próximos } 24 \text { meses. }\end{array}$ & 1 & 2 & 3 & 4 & 5 \\
\hline Comp & FCS 42 & $\begin{array}{l}\text { A empresa estuda e monitora os } \\
\text { concorrentes. }\end{array}$ & 1 & 2 & 3 & 4 & 5 \\
\hline Prod & FCS 43 & $\begin{array}{l}\text { A produtividade (viagens } \\
\text { realizadas/viagens requisitadas) no } \\
\text { segmento de apoio marítimo é } \\
\text { considerada baixa. }\end{array}$ & 1 & 2 & 3 & 4 & 5 \\
\hline Prod & FCS 44 & $\begin{array}{l}\text { A burocratização dos processos de } \\
\text { licitação/concorrência minimiza a } \\
\text { produtividade das empresas. }\end{array}$ & 1 & 2 & 3 & 4 & 5 \\
\hline Prod & FCS 45 & $\begin{array}{l}\text { As multas e penalidades são } \\
\text { importantes para garantir a } \\
\text { produtividade das empresas }\end{array}$ & 1 & 2 & 3 & 4 & 5 \\
\hline
\end{tabular}




\begin{tabular}{|c|c|c|c|c|c|c|c|}
\hline Cat. & Cód. & Questão & $\begin{array}{l}\text { Discordo } \\
\text { totalmente }\end{array}$ & & & & $\begin{array}{c}\text { Concordo } \\
\text { totalmente }\end{array}$ \\
\hline Prod & FCS 46 & $\begin{array}{l}\text { Utilizo grande parte do meu tempo } \\
\text { primordialmente em questões } \\
\text { operacionais. }\end{array}$ & 1 & 2 & 3 & 4 & 5 \\
\hline Prod & FCS 47 & $\begin{array}{l}\text { A idade média da frota é menor que } 10 \\
\text { anos. }\end{array}$ & 1 & 2 & 3 & 4 & 5 \\
\hline Forn & FCS 48 & $\begin{array}{l}\text { A minha empresa possui baixa } \\
\text { integração com a cadeia de suprimentos } \\
\text { offshore (navipeças). }\end{array}$ & 1 & 2 & 3 & 4 & 5 \\
\hline Forn & FCS 49 & $\begin{array}{l}\text { A falta de interação do contratante com } \\
\text { o fornecedor do serviço impacta de } \\
\text { forma negativa na qualidade do serviço } \\
\text { prestado. }\end{array}$ & 1 & 2 & 3 & 4 & 5 \\
\hline Forn & FCS 50 & $\begin{array}{l}\text { Existe oferta suficiente de fornecedores } \\
\text { de alta qualidade para a manutenção } \\
\text { das embarcações. }\end{array}$ & 1 & 2 & 3 & 4 & 5 \\
\hline Forn & FCS 51 & $\begin{array}{l}\text { Na empresa existe sistema } \\
\text { (procedimentos) de qualificação de } \\
\text { fornecedores. }\end{array}$ & 1 & 2 & 3 & 4 & 5 \\
\hline Forn & FCS 52 & $\begin{array}{l}\text { Todos os fornecedores cumprem com } \\
\text { os prazos acordados. }\end{array}$ & 1 & 2 & 3 & 4 & 5 \\
\hline Fin & FCS 53 & $\begin{array}{l}\text { A captação de recursos via BNDES é } \\
\text { um processo muito complexo e } \\
\text { dificultoso. }\end{array}$ & 1 & 2 & 3 & 4 & 5 \\
\hline Fin & FCS 54 & $\begin{array}{l}\text { A minha empresa já utilizou fundos do } \\
\text { Inova Empresa do BNDES. }\end{array}$ & 1 & 2 & 3 & 4 & 5 \\
\hline Fin & FCS 55 & $\begin{array}{l}\text { A minha empresa já utilizou fundos da } \\
\text { Marinha Mercante. }\end{array}$ & 1 & 2 & 3 & 4 & 5 \\
\hline Fin & FCS 56 & $\begin{array}{l}\text { Para financiamentos, a empresa tem } \\
\text { utilizado mais bancos privados que } \\
\text { estatais/federais. }\end{array}$ & 1 & 2 & 3 & 4 & 5 \\
\hline Fin & FCS 57 & $\begin{array}{l}\text { A minha empresa tem utilizado mais } \\
\text { recursos próprios para projetos que } \\
\text { financiamentos bancários. }\end{array}$ & 1 & 2 & 3 & 4 & 5 \\
\hline Fin & FCS 58 & $\begin{array}{l}\text { O prazo médio para obtenção de } \\
\text { financiamento dificulta a capacidade de } \\
\text { captar projetos. }\end{array}$ & 1 & 2 & 3 & 4 & 5 \\
\hline Fin & FCS 59 & $\begin{array}{l}\text { Existe grande dificuldade em obter } \\
\text { financiamentos devido ao rigor das } \\
\text { garantias exigidas pelos agentes } \\
\text { financeiros. }\end{array}$ & 1 & 2 & 3 & 4 & 5 \\
\hline Fin & FCS 60 & $\begin{array}{l}\text { Os orçamentos para os projetos são } \\
\text { adequados (taxas de afretamentos } \\
\text { versus tempo do contrato). }\end{array}$ & 1 & 2 & 3 & 4 & 5 \\
\hline Est & FCS 61 & $\begin{array}{l}\text { É importante as empresas possuírem } \\
\text { estratégias para evitar demissões em } \\
\text { períodos de baixa demanda. }\end{array}$ & 1 & 2 & 3 & 4 & 5 \\
\hline
\end{tabular}




\begin{tabular}{|c|c|c|c|c|c|c|c|}
\hline Cat. & Cód. & Questão & $\begin{array}{l}\text { Discordo } \\
\text { totalmente }\end{array}$ & & & & $\begin{array}{l}\text { Concordo } \\
\text { totalmente }\end{array}$ \\
\hline Est & FCS 62 & $\begin{array}{l}\text { A maior preocupação da área } \\
\text { estratégica da empresa é com a } \\
\text { otimização dos custos. }\end{array}$ & 1 & 2 & 3 & 4 & 5 \\
\hline Est & FCS 63 & $\begin{array}{l}\text { A empresa possui flexibilidade para } \\
\text { mudanças no planejamento de curto e } \\
\text { médio prazo. }\end{array}$ & 1 & 2 & 3 & 4 & 5 \\
\hline Est & FCS 64 & $\begin{array}{l}\text { Existe uma revisão periódica das } \\
\text { estratégias. }\end{array}$ & 1 & 2 & 3 & 4 & 5 \\
\hline Est & FCS 65 & $\begin{array}{l}\text { O planejamento estratégico da empresa } \\
\text { se dá a partir do conhecimento do plano } \\
\text { de negócios da Petrobras. }\end{array}$ & 1 & 2 & 3 & 4 & 5 \\
\hline Est & FCS 66 & $\begin{array}{l}\text { Utilizo grande parte do meu tempo } \\
\text { primordialmente em questões } \\
\text { estratégicas. }\end{array}$ & 1 & 2 & 3 & 4 & 5 \\
\hline Est & FCS 67 & $\begin{array}{l}\text { A empresa define indicadores (KPI's) } \\
\text { para acompanhamento das metas e } \\
\text { estes são de conhecimento de toda a } \\
\text { empresa. }\end{array}$ & 1 & 2 & 3 & 4 & 5 \\
\hline Est & FCS 68 & $\begin{array}{l}\text { A empresa conhece as ameaças ao } \\
\text { modelo atual de negócio. }\end{array}$ & 1 & 2 & 3 & 4 & 5 \\
\hline
\end{tabular}

\section{Legenda}

\begin{tabular}{clc}
\hline Cód & \multicolumn{1}{c}{ Categoria do FCS } & Qtd \\
\hline Inov & Inovação & 14 \\
Pol & Políticas & 12 \\
Comp & Competitividade & 10 \\
Est & Estratégias & 8 \\
Fin & Financiamentos & 8 \\
Mo & Mão de Obra & 6 \\
Forn & Fornecedores & 5 \\
Prod & Produtividade & 5 \\
\hline & Total & $\mathbf{6 8}$
\end{tabular}




\section{APÊNDICE C - RESULTADOS CORRELAÇÃO DE SPEARMAN (CCS) ${ }^{15}$}

\begin{tabular}{|c|c|c|c|c|c|c|c|c|c|c|c|c|c|}
\hline & & FCS1 & FCS2 & FCS3 & FCS4 & FCS5 & FCS6 & FCS7 & FCS8 & FCS9 & FCS10 & FCS11 & FCS12 \\
\hline FCS1 & CCS & 1,000 & 0,354 & 0,639 & 0,336 & $-0,033$ & 0,157 & 0,214 & 0,000 & $-0,392$ & $-0,103$ & 0,000 & 0,243 \\
\hline FCS2 & CCS & 0,354 & 1,000 & 0,349 & 0,234 & 0,223 & 0,473 & 0,485 & 0,201 & $-0,252$ & 0,621 & 0,000 & 0,381 \\
\hline FCS3 & CCS & 0,639 & 0,349 & 1,000 & 0,273 & 0,231 & $-0,129$ & 0,200 & 0,150 & $-0,197$ & $-0,044$ & 0,032 & 0,241 \\
\hline FCS4 & CCS & 0,336 & 0,234 & 0,273 & 1,000 & 0,256 & 0,570 & 0,414 & 0,369 & $-0,096$ & 0,337 & 0,559 & 0,625 \\
\hline FCS5 & CCS & $-0,033$ & 0,223 & 0,231 & 0,256 & 1,000 & 0,008 & 0,014 & 0,377 & $-0,259$ & 0,673 & 0,657 & $-0,003$ \\
\hline FCS6 & CCS & 0,157 & 0,473 & $-0,129$ & 0,570 & 0,008 & 1,000 & 0,771 & 0,019 & $-0,492$ & 0,308 & 0,370 & 0,780 \\
\hline FCS7 & CCS & 0,214 & 0,485 & 0,200 & 0,414 & 0,014 & 0,771 & 1,000 & 0,086 & $-0,410$ & 0,244 & 0,191 & 0,733 \\
\hline FCS8 & CCS & 0,000 & 0,201 & 0,150 & 0,369 & 0,377 & 0,019 & 0,086 & 1,000 & 0,457 & 0,431 & 0,060 & 0,226 \\
\hline FCS9 & CCS & $-0,392$ & $-0,252$ & $-0,197$ & $-0,096$ & $-0,259$ & $-0,492$ & $-0,410$ & 0,457 & 1,000 & $-0,062$ & $-0,499$ & $-0,293$ \\
\hline FCS 10 & CCS & $-0,103$ & 0,621 & $-0,044$ & 0,337 & 0,673 & 0,308 & 0,244 & 0,431 & $-0,062$ & 1,000 & 0,494 & 0,172 \\
\hline FCS 11 & CCS & 0,000 & 0,000 & 0,032 & 0,559 & 0,657 & 0,370 & 0,191 & 0,060 & $-0,499$ & 0,494 & 1,000 & 0,245 \\
\hline FCS12 & CCS & 0,243 & 0,381 & 0,241 & 0,625 & $-0,003$ & 0,780 & 0,733 & 0,226 & $-0,293$ & 0,172 & 0,245 & 1,000 \\
\hline FCS13 & CCS & 0,070 & 0,404 & 0,116 & 0,564 & 0,054 & 0,738 & 0,845 & 0,147 & $-0,226$ & 0,357 & 0,253 & 0,873 \\
\hline FCS14 & CCS & $-0,092$ & 0,455 & 0,189 & 0,365 & 0,182 & 0,723 & 0,762 & 0,067 & $-0,399$ & 0,276 & 0,283 & 0,813 \\
\hline FCS15 & CCS & $-0,157$ & $-0,041$ & 0,229 & 0,476 & 0,119 & 0,462 & 0,523 & $-0,050$ & $-0,303$ & 0,003 & 0,545 & 0,590 \\
\hline FCS16 & CCS & 0,300 & 0,572 & 0,512 & 0,570 & $-0,042$ & 0,358 & 0,458 & 0,244 & $-0,014$ & 0,310 & 0,171 & 0,472 \\
\hline FCS17 & CCS & $-0,052$ & 0,554 & 0,310 & 0,146 & 0,157 & $-0,103$ & $-0,074$ & 0,510 & 0,398 & 0,418 & $-0,112$ & $-0,076$ \\
\hline
\end{tabular}

\footnotetext{
${ }^{15}$ Nível de significância $=0,05$.
} 


\begin{tabular}{|c|c|c|c|c|c|c|c|c|c|c|c|c|c|}
\hline & & FCS13 & FCS14 & FCS15 & FCS16 & FCS17 & FCS18 & FCS19 & FCS20 & FCS21 & FCS22 & FCS23 & $\mathrm{FCS} 24$ \\
\hline FCS1 & CCS & 0,070 & $-0,092$ & $-0,157$ & 0,300 & $-0,052$ & 0,407 & $-0,117$ & $-0,527$ & $-0,078$ & $-0,225$ & 0,545 & 0,160 \\
\hline FCS2 & $\mathrm{CCS}$ & 0,404 & 0,455 & $-0,041$ & 0,572 & 0,554 & 0,341 & $-0,255$ & 0,159 & 0,416 & 0,057 & 0,264 & $-0,148$ \\
\hline FCS3 & CCS & 0,116 & 0,189 & 0,229 & 0,512 & 0,310 & 0,376 & 0,057 & $-0,300$ & 0,128 & $-0,318$ & 0,746 & $-0,146$ \\
\hline FCS4 & CCS & 0,564 & 0,365 & 0,476 & 0,570 & 0,146 & 0,312 & $-0,281$ & 0,193 & 0,225 & $-0,259$ & 0,282 & $-0,188$ \\
\hline FCS5 & $\mathrm{CCS}$ & 0,054 & 0,182 & 0,119 & $-0,042$ & 0,157 & 0,183 & $-0,215$ & 0,427 & 0,344 & 0,296 & $-0,111$ & $-0,785$ \\
\hline FCS6 & CCS & 0,738 & 0,723 & 0,462 & 0,358 & $-0,103$ & 0,059 & $-0,690$ & 0,225 & 0,267 & 0,160 & $-0,028$ & $-0,008$ \\
\hline FCS7 & CCS & 0,845 & 0,762 & 0,523 & 0,458 & $-0,074$ & 0,319 & $-0,545$ & 0,084 & 0,305 & 0,194 & 0,165 & $-0,155$ \\
\hline FCS8 & CCS & 0,147 & 0,067 & $-0,050$ & 0,244 & 0,510 & 0,278 & 0,218 & 0,523 & 0,660 & 0,158 & 0,251 & $-0,088$ \\
\hline FCS9 & CCS & $-0,226$ & $-0,399$ & $-0,303$ & $-0,014$ & 0,398 & 0,053 & 0,642 & 0,317 & 0,263 & $-0,185$ & $-0,115$ & 0,232 \\
\hline FCS10 & CCS & 0,357 & 0,276 & 0,003 & 0,310 & 0,418 & 0,279 & $-0,304$ & 0,543 & 0,374 & 0,166 & $-0,143$ & $-0,662$ \\
\hline FCS11 & CCS & 0,253 & 0,283 & 0,545 & 0,171 & $-0,112$ & $-0,003$ & $-0,531$ & 0,241 & $-0,143$ & $-0,001$ & $-0,065$ & $-0,659$ \\
\hline FCS12 & CCS & 0,873 & 0,813 & 0,590 & 0,472 & $-0,076$ & 0,069 & $-0,631$ & 0,139 & 0,466 & $-0,059$ & 0,346 & $-0,057$ \\
\hline FCS 13 & CCS & 1,000 & 0,805 & 0,530 & 0,474 & $-0,124$ & 0,273 & $-0,636$ & 0,216 & 0,421 & $-0,034$ & 0,143 & $-0,263$ \\
\hline FCS14 & CCS & 0,805 & 1,000 & 0,696 & 0,438 & 0,029 & $-0,007$ & $-0,667$ & 0,321 & 0,497 & 0,112 & 0,169 & $-0,231$ \\
\hline FCS15 & CCS & 0,530 & 0,696 & 1,000 & 0,392 & $-0,032$ & $-0,224$ & $-0,431$ & 0,108 & 0,017 & $-0,063$ & 0,196 & $-0,320$ \\
\hline FCS16 & CCS & 0,474 & 0,438 & 0,392 & 1,000 & 0,579 & 0,441 & $-0,161$ & 0,123 & 0,106 & $-0,559$ & 0,624 & 0,025 \\
\hline FCS17 & CCS & $-0,124$ & 0,029 & $-0,032$ & 0,579 & 1,000 & 0,166 & 0,438 & 0,335 & 0,288 & $-0,139$ & 0,341 & 0,013 \\
\hline
\end{tabular}




\begin{tabular}{|c|c|c|c|c|c|c|c|c|c|c|c|c|c|}
\hline & & FCS25 & FCS26 & FCS27 & FCS28 & FCS29 & FCS30 & FCS31 & FCS32 & FCS33 & FCS34 & FCS35 & FCS36 \\
\hline FCS1 & CCS & $-0,327$ & 0,097 & $-0,055$ & $-0,198$ & $-0,470$ & $-0,295$ & 0,092 & $-0,474$ & $-0,248$ & 0,146 & $-0,200$ & 0,252 \\
\hline $\mathrm{FCS} 2$ & CCS & $-0,324$ & $-0,020$ & 0,292 & $-0,142$ & $-0,223$ & $-0,009$ & 0,232 & $-0,082$ & $-0,002$ & 0,422 & $-0,119$ & 0,599 \\
\hline FCS3 & CCS & $-0,017$ & 0,079 & 0,207 & $-0,069$ & $-0,197$ & $-0,486$ & $-0,316$ & $-0,770$ & $-0,217$ & 0,316 & 0,066 & 0,211 \\
\hline FCS4 & CCS & $-0,359$ & 0,516 & 0,104 & 0,153 & 0,037 & $-0,148$ & $-0,079$ & $-0,217$ & $-0,186$ & 0,445 & 0,180 & 0,078 \\
\hline FCS5 & CCS & $-0,291$ & $-0,208$ & $-0,334$ & 0,183 & 0,299 & 0,232 & 0,146 & $-0,132$ & $-0,272$ & 0,111 & 0,200 & $-0,387$ \\
\hline FCS6 & CCS & $-0,264$ & 0,071 & 0,129 & $-0,178$ & $-0,120$ & 0,139 & 0,311 & 0,079 & 0,398 & 0,621 & $-0,162$ & 0,359 \\
\hline FCS7 & CCS & $-0,103$ & 0,099 & 0,135 & $-0,255$ & $-0,203$ & $-0,088$ & 0,044 & $-0,256$ & 0,436 & 0,860 & 0,012 & 0,360 \\
\hline FCS8 & CCS & $-0,616$ & 0,567 & 0,350 & 0,520 & 0,482 & 0,444 & 0,138 & 0,212 & $-0,194$ & 0,161 & $-0,055$ & $-0,057$ \\
\hline FCS9 & CCS & $-0,007$ & 0,536 & 0,431 & 0,452 & 0,434 & 0,185 & $-0,096$ & 0,354 & $-0,290$ & $-0,287$ & 0,046 & $-0,095$ \\
\hline FCS10 & CCS & $-0,357$ & 0,020 & $-0,110$ & 0,083 & 0,121 & 0,172 & 0,111 & 0,129 & $-0,104$ & 0,305 & 0,194 & 0,112 \\
\hline FCS11 & CCS & $-0,158$ & $-0,063$ & $-0,466$ & $-0,194$ & $-0,006$ & $-0,107$ & $-0,185$ & $-0,278$ & $-0,021$ & 0,305 & 0,203 & $-0,233$ \\
\hline FCS12 & CCS & $-0,106$ & 0,152 & 0,416 & 0,125 & 0,029 & $-0,033$ & 0,030 & $-0,137$ & 0,509 & 0,730 & $-0,048$ & 0,468 \\
\hline FCS13 & CCS & 0,061 & 0,150 & 0,252 & 0,105 & 0,024 & $-0,144$ & $-0,042$ & $-0,126$ & 0,480 & 0,811 & 0,216 & 0,357 \\
\hline FCS14 & CCS & 0,149 & $-0,059$ & 0,409 & $-0,012$ & 0,070 & $-0,038$ & 0,037 & $-0,202$ & 0,502 & 0,711 & $-0,047$ & 0,350 \\
\hline FCS 15 & CCS & 0,187 & 0,030 & 0,126 & $-0,271$ & $-0,068$ & $-0,280$ & $-0,455$ & $-0,469$ & 0,377 & 0,611 & 0,101 & 0,177 \\
\hline FCS16 & CCS & $-0,004$ & 0,571 & 0,473 & $-0,166$ & $-0,179$ & $-0,555$ & $-0,385$ & $-0,470$ & $-0,088$ & 0,545 & 0,045 & 0,467 \\
\hline FCS17 & CCS & $-0,344$ & 0,379 & 0,457 & 0,034 & 0,088 & 0,013 & $-0,141$ & $-0,003$ & $-0,341$ & 0,043 & $-0,029$ & 0,337 \\
\hline
\end{tabular}




\begin{tabular}{|c|c|c|c|c|c|c|c|c|c|c|c|c|c|}
\hline & & FCS37 & FCS38 & FCS39 & FCS40 & FCS41 & FCS42 & FCS43 & FCS44 & FCS45 & FCS46 & FCS47 & FCS48 \\
\hline FCS1 & CCS & $-0,592$ & $-0,237$ & 0,175 & $-0,326$ & $-0,231$ & $-0,657$ & $-0,183$ & 0,091 & $-0,039$ & $-0,230$ & $-0,424$ & $-0,048$ \\
\hline FCS2 & CCS & 0,067 & $-0,280$ & 0,300 & 0,209 & 0,089 & 0,188 & 0,324 & 0,840 & $-0,025$ & 0,284 & $-0,308$ & 0,155 \\
\hline FCS3 & CCS & $-0,302$ & 0,153 & 0,178 & $-0,134$ & $-0,025$ & $-0,252$ & 0,278 & 0,111 & $-0,415$ & $-0,005$ & $-0,449$ & 0,087 \\
\hline FCS4 & CCS & 0,003 & 0,034 & $-0,068$ & 0,223 & 0,100 & 0,113 & 0,380 & $-0,098$ & $-0,242$ & $-0,119$ & 0,148 & $-0,236$ \\
\hline FCS5 & $\mathrm{CCS}$ & 0,180 & 0,120 & $-0,247$ & 0,202 & 0,079 & 0,465 & 0,619 & 0,152 & $-0,324$ & 0,445 & 0,417 & 0,098 \\
\hline FCS6 & CCS & $-0,143$ & $-0,443$ & 0,354 & 0,569 & $-0,142$ & 0,110 & 0,444 & 0,346 & 0,217 & $-0,042$ & 0,074 & 0,151 \\
\hline FCS7 & CCS & $-0,221$ & $-0,242$ & 0,305 & 0,739 & 0,111 & 0,168 & 0,601 & 0,289 & 0,176 & 0,253 & 0,056 & 0,332 \\
\hline FCS8 & CCS & 0,214 & 0,694 & $-0,160$ & 0,016 & 0,499 & 0,168 & 0,265 & 0,215 & 0,163 & 0,189 & 0,250 & 0,058 \\
\hline FCS9 & $\mathrm{CCS}$ & 0,502 & 0,651 & $-0,452$ & $-0,290$ & 0,662 & 0,206 & $-0,379$ & $-0,176$ & 0,076 & 0,040 & 0,098 & $-0,264$ \\
\hline FCS10 & CCS & 0,410 & $-0,077$ & $-0,086$ & 0,373 & 0,365 & 0,608 & 0,491 & 0,432 & $-0,034$ & 0,561 & 0,423 & 0,038 \\
\hline FCS11 & $\mathrm{CCS}$ & 0,044 & $-0,147$ & 0,094 & 0,386 & $-0,188$ & 0,272 & 0,609 & $-0,189$ & $-0,279$ & 0,032 & 0,516 & $-0,018$ \\
\hline FCS12 & $\mathrm{CCS}$ & $-0,266$ & $-0,231$ & 0,366 & 0,459 & 0,129 & $-0,039$ & 0,487 & 0,132 & 0,230 & 0,062 & 0,017 & 0,152 \\
\hline FCS13 & CCS & $-0,070$ & $-0,274$ & 0,131 & 0,699 & 0,323 & 0,262 & 0,539 & 0,074 & 0,213 & 0,384 & 0,195 & 0,187 \\
\hline FCS14 & $\mathrm{CCS}$ & 0,039 & $-0,219$ & 0,419 & 0,754 & $-0,010$ & 0,290 & 0,755 & 0,347 & 0,006 & 0,284 & $-0,043$ & 0,293 \\
\hline FCS15 & CCS & $-0,035$ & $-0,033$ & 0,414 & 0,588 & $-0,067$ & 0,237 & 0,743 & $-0,159$ & $-0,303$ & $-0,092$ & 0,159 & 0,035 \\
\hline FCS16 & CCS & 0,221 & 0,133 & 0,370 & 0,305 & 0,061 & 0,040 & 0,323 & 0,282 & $-0,213$ & $-0,055$ & $-0,338$ & 0,060 \\
\hline FCS17 & $\mathrm{CCS}$ & 0,456 & 0,456 & 0,126 & $-0,120$ & 0,228 & 0,319 & 0,189 & 0,602 & $-0,307$ & $-0,027$ & $-0,270$ & $-0,052$ \\
\hline
\end{tabular}




\begin{tabular}{|c|c|c|c|c|c|c|c|c|c|c|c|}
\hline & & FCS49 & FCS50 & FCS51 & FCS52 & FCS53 & FCS54 & FCS55 & FCS56 & FCS57 & FCS58 \\
\hline FCS1 & CCS & 0,702 & $-0,408$ & $-0,248$ & $-0,582$ & 0,197 & $-0,146$ & $-0,682$ & 0,031 & $-0,324$ & $-0,169$ \\
\hline FCS2 & $\mathrm{CCS}$ & 0,329 & $-0,242$ & $-0,254$ & $-0,171$ & $-0,088$ & 0,237 & $-0,428$ & 0,253 & 0,321 & 0,275 \\
\hline FCS3 & CCS & 0,199 & $-0,159$ & $-0,472$ & $-0,283$ & $-0,152$ & $-0,007$ & $-0,562$ & 0,334 & 0,080 & 0,248 \\
\hline FCS4 & CCS & 0,057 & 0,057 & $-0,132$ & 0,010 & $-0,342$ & 0,336 & 0,054 & 0,215 & $-0,187$ & 0,167 \\
\hline FCS5 & CCS & 0,088 & $-0,056$ & 0,119 & 0,247 & $-0,014$ & 0,448 & 0,317 & 0,231 & 0,246 & 0,221 \\
\hline FCS6 & CCS & 0,103 & $-0,050$ & $-0,339$ & $-0,312$ & 0,048 & 0,352 & 0,227 & 0,144 & 0,163 & 0,152 \\
\hline FCS7 & CCS & 0,122 & 0,077 & $-0,524$ & $-0,289$ & 0,003 & 0,475 & 0,076 & 0,394 & 0,358 & 0,174 \\
\hline FCS8 & CCS & 0,091 & 0,072 & 0,011 & 0,270 & $-0,143$ & 0,114 & 0,016 & 0,340 & 0,236 & 0,166 \\
\hline FCS9 & CCS & $-0,266$ & 0,089 & 0,361 & 0,519 & $-0,364$ & $-0,315$ & $-0,122$ & $-0,120$ & $-0,146$ & $-0,092$ \\
\hline FCS10 & CCS & 0,055 & $-0,046$ & 0,258 & 0,462 & $-0,186$ & 0,635 & 0,192 & 0,330 & 0,331 & 0,378 \\
\hline FCS11 & CCS & $-0,094$ & 0,040 & 0,147 & 0,225 & $-0,017$ & 0,687 & 0,588 & 0,404 & 0,102 & 0,450 \\
\hline FCS12 & CCS & $-0,154$ & $-0,050$ & $-0,591$ & $-0,221$ & $-0,146$ & 0,245 & 0,094 & 0,186 & 0,279 & 0,287 \\
\hline FCS13 & CCS & $-0,182$ & 0,135 & $-0,438$ & 0,014 & $-0,256$ & 0,455 & 0,163 & 0,184 & 0,296 & 0,212 \\
\hline FCS14 & CCS & $-0,265$ & 0,124 & $-0,648$ & $-0,168$ & $-0,057$ & 0,321 & 0,258 & 0,234 & 0,602 & 0,419 \\
\hline FCS15 & CCS & $-0,498$ & 0,166 & $-0,448$ & $-0,026$ & $-0,178$ & 0,474 & 0,495 & 0,497 & 0,374 & 0,577 \\
\hline FCS16 & CCS & 0,012 & 0,142 & $-0,256$ & 0,080 & $-0,333$ & 0,278 & $-0,346$ & 0,512 & 0,203 & 0,576 \\
\hline FCS17 & CCS & $-0,024$ & 0,021 & 0,036 & 0,243 & $-0,367$ & 0,084 & $-0,327$ & 0,446 & 0,242 & 0,451 \\
\hline
\end{tabular}




\begin{tabular}{|c|c|c|c|c|c|c|c|c|c|c|c|}
\hline & & FCS59 & FCS60 & FCS61 & FCS62 & FCS63 & FCS64 & FCS65 & FCS66 & FCS67 & FCS68 \\
\hline FCS1 & CCS & $-0,267$ & $-0,177$ & 0,581 & 0,071 & $-0,420$ & $-0,109$ & 0,046 & $-0,526$ & $-0,241$ & $-0,416$ \\
\hline FCS2 & $\mathrm{CCS}$ & 0,156 & 0,291 & 0,209 & 0,107 & 0,105 & $-0,209$ & $-0,274$ & $-0,181$ & $-0,358$ & 0,129 \\
\hline FCS3 & CCS & 0,218 & $-0,035$ & 0,521 & 0,277 & $-0,558$ & $-0,441$ & 0,413 & $-0,220$ & $-0,343$ & $-0,248$ \\
\hline FCS4 & $\mathrm{CCS}$ & 0,054 & $-0,086$ & 0,568 & 0,643 & 0,114 & 0,272 & 0,059 & 0,317 & 0,070 & 0,206 \\
\hline FCS5 & $\mathrm{CCS}$ & 0,154 & 0,295 & $-0,037$ & 0,562 & 0,108 & 0,253 & $-0,021$ & 0,272 & 0,306 & 0,450 \\
\hline FCS6 & $\mathrm{CCS}$ & 0,205 & $-0,068$ & 0,142 & 0,243 & 0,451 & 0,304 & $-0,038$ & 0,286 & $-0,088$ & 0,054 \\
\hline FCS7 & $\mathrm{CCS}$ & 0,188 & 0,119 & 0,188 & 0,274 & 0,355 & 0,203 & 0,185 & 0,279 & $-0,341$ & $-0,017$ \\
\hline FCS8 & CCS & 0,113 & 0,232 & 0,525 & 0,441 & 0,224 & 0,279 & $-0,520$ & 0,221 & 0,250 & 0,247 \\
\hline FCS9 & $\mathrm{CCS}$ & $-0,130$ & 0,078 & 0,134 & $-0,170$ & $-0,025$ & $-0,029$ & $-0,366$ & $-0,046$ & 0,247 & 0,210 \\
\hline FCS10 & CCS & 0,109 & 0,636 & 0,020 & 0,492 & 0,443 & 0,268 & $-0,331$ & 0,339 & 0,045 & 0,650 \\
\hline FCS11 & $\mathrm{CCS}$ & 0,289 & 0,191 & 0,021 & 0,718 & 0,326 & 0,449 & 0,299 & 0,562 & 0,167 & 0,414 \\
\hline FCS12 & CCS & 0,401 & 0,066 & 0,471 & 0,339 & 0,071 & $-0,005$ & 0,216 & 0,426 & $-0,149$ & $-0,050$ \\
\hline FCS13 & CCS & 0,200 & 0,252 & 0,276 & 0,380 & 0,234 & 0,107 & 0,221 & 0,535 & $-0,246$ & 0,121 \\
\hline FCS14 & $\mathrm{CCS}$ & 0,598 & 0,080 & 0,138 & 0,253 & 0,164 & $-0,098$ & 0,301 & 0,494 & $-0,291$ & $-0,017$ \\
\hline FCS15 & $\mathrm{CCS}$ & 0,697 & 0,014 & 0,101 & 0,416 & 0,144 & 0,015 & 0,674 & 0,599 & $-0,122$ & 0,133 \\
\hline FCS16 & CCS & 0,333 & 0,080 & 0,571 & 0,439 & 0,056 & $-0,163$ & 0,120 & 0,176 & $-0,574$ & $-0,025$ \\
\hline FCS17 & CCS & 0,306 & 0,181 & 0,223 & 0,179 & 0,105 & $-0,245$ & $-0,356$ & $-0,111$ & $-0,137$ & 0,298 \\
\hline
\end{tabular}




\begin{tabular}{|c|c|c|c|c|c|c|c|c|c|c|c|c|c|}
\hline & & FCS1 & FCS2 & FCS3 & FCS4 & FCS5 & FCS6 & FCS7 & FCS8 & FCS9 & FCS10 & FCS11 & FCS12 \\
\hline FCS18 & $\mathrm{CCS}$ & 0,407 & 0,341 & 0,376 & 0,312 & 0,183 & 0,059 & 0,319 & 0,278 & 0,053 & 0,279 & $-0,003$ & 0,069 \\
\hline FCS19 & $\mathrm{CCS}$ & $-0,117$ & $-0,255$ & 0,057 & $-0,281$ & $-0,215$ & $-0,690$ & $-0,545$ & 0,218 & 0,642 & $-0,304$ & $-0,531$ & $-0,631$ \\
\hline FCS20 & $\mathrm{CCS}$ & $-0,527$ & 0,159 & $-0,300$ & 0,193 & 0,427 & 0,225 & 0,084 & 0,523 & 0,317 & 0,543 & 0,241 & 0,139 \\
\hline FCS21 & CCS & $-0,078$ & 0,416 & 0,128 & 0,225 & 0,344 & 0,267 & 0,305 & 0,660 & 0,263 & 0,374 & $-0,143$ & 0,466 \\
\hline FCS22 & CCS & $-0,225$ & 0,057 & $-0,318$ & $-0,259$ & 0,296 & 0,160 & 0,194 & 0,158 & $-0,185$ & 0,166 & $-0,001$ & $-0,059$ \\
\hline FCS23 & $\mathrm{CCS}$ & 0,545 & 0,264 & 0,746 & 0,282 & $-0,111$ & $-0,028$ & 0,165 & 0,251 & $-0,115$ & $-0,143$ & $-0,065$ & 0,346 \\
\hline $\mathrm{FCS} 24$ & $\mathrm{CCS}$ & 0,160 & $-0,148$ & $-0,146$ & $-0,188$ & $-0,785$ & $-0,008$ & $-0,155$ & $-0,088$ & 0,232 & $-0,662$ & $-0,659$ & $-0,057$ \\
\hline FCS25 & $\mathrm{CCS}$ & $-0,327$ & $-0,324$ & $-0,017$ & $-0,359$ & $-0,291$ & $-0,264$ & $-0,103$ & $-0,616$ & $-0,007$ & $-0,357$ & $-0,158$ & $-0,106$ \\
\hline FCS26 & CCS & 0,097 & $-0,020$ & 0,079 & 0,516 & $-0,208$ & 0,071 & 0,099 & 0,567 & 0,536 & 0,020 & $-0,063$ & 0,152 \\
\hline FCS27 & CCS & $-0,055$ & 0,292 & 0,207 & 0,104 & $-0,334$ & 0,129 & 0,135 & 0,350 & 0,431 & $-0,110$ & $-0,466$ & 0,416 \\
\hline FCS28 & CCS & $-0,198$ & $-0,142$ & $-0,069$ & 0,153 & 0,183 & $-0,178$ & $-0,255$ & 0,520 & 0,452 & 0,083 & $-0,194$ & 0,125 \\
\hline FCS29 & CCS & $-0,470$ & $-0,223$ & $-0,197$ & 0,037 & 0,299 & $-0,120$ & $-0,203$ & 0,482 & 0,434 & 0,121 & $-0,006$ & 0,029 \\
\hline FCS30 & $\mathrm{CCS}$ & $-0,295$ & $-0,009$ & $-0,486$ & $-0,148$ & 0,232 & 0,139 & $-0,088$ & 0,444 & 0,185 & 0,172 & $-0,107$ & $-0,033$ \\
\hline FCS31 & CCS & 0,092 & 0,232 & $-0,316$ & $-0,079$ & 0,146 & 0,311 & 0,044 & 0,138 & $-0,096$ & 0,111 & $-0,185$ & 0,030 \\
\hline FCS32 & CCS & $-0,474$ & $-0,082$ & $-0,770$ & $-0,217$ & $-0,132$ & 0,079 & $-0,256$ & 0,212 & 0,354 & 0,129 & $-0,278$ & $-0,137$ \\
\hline FCS33 & CCS & $-0,248$ & $-0,002$ & $-0,217$ & $-0,186$ & $-0,272$ & 0,398 & 0,436 & $-0,194$ & $-0,290$ & $-0,104$ & $-0,021$ & 0,509 \\
\hline FCS34 & CCS & 0,146 & 0,422 & 0,316 & 0,445 & 0,111 & 0,621 & 0,860 & 0,161 & $-0,287$ & 0,305 & 0,305 & 0,730 \\
\hline
\end{tabular}




\begin{tabular}{|c|c|c|c|c|c|c|c|c|c|c|c|c|c|}
\hline & & FCS13 & FCS14 & FCS15 & FCS16 & FCS17 & FCS18 & FCS19 & FCS20 & FCS21 & FCS22 & FCS23 & FCS24 \\
\hline FCS18 & $\mathrm{CCS}$ & 0,273 & $-0,007$ & $-0,224$ & 0,441 & 0,166 & 1,000 & $-0,004$ & 0,224 & 0,174 & $-0,367$ & 0,156 & $-0,030$ \\
\hline FCS19 & $\mathrm{CCS}$ & $-0,636$ & $-0,667$ & $-0,431$ & $-0,161$ & 0,438 & $-0,004$ & 1,000 & $-0,181$ & $-0,139$ & 0,012 & 0,120 & 0,334 \\
\hline FCS20 & CCS & 0,216 & 0,321 & 0,108 & 0,123 & 0,335 & 0,224 & $-0,181$ & 1,000 & 0,597 & 0,055 & $-0,413$ & $-0,217$ \\
\hline FCS21 & CCS & 0,421 & 0,497 & 0,017 & 0,106 & 0,288 & 0,174 & $-0,139$ & 0,597 & 1,000 & 0,306 & $-0,009$ & $-0,112$ \\
\hline FCS22 & CCS & $-0,034$ & 0,112 & $-0,063$ & $-0,559$ & $-0,139$ & $-0,367$ & 0,012 & 0,055 & 0,306 & 1,000 & $-0,372$ & $-0,229$ \\
\hline FCS23 & CCS & 0,143 & 0,169 & 0,196 & 0,624 & 0,341 & 0,156 & 0,120 & $-0,413$ & $-0,009$ & $-0,372$ & 1,000 & 0,209 \\
\hline FCS24 & CCS & $-0,263$ & $-0,231$ & $-0,320$ & 0,025 & 0,013 & $-0,030$ & 0,334 & $-0,217$ & $-0,112$ & $-0,229$ & 0,209 & 1,000 \\
\hline FCS25 & CCS & 0,061 & 0,149 & 0,187 & $-0,004$ & $-0,344$ & $-0,122$ & $-0,203$ & $-0,149$ & $-0,271$ & $-0,421$ & $-0,060$ & $-0,002$ \\
\hline FCS26 & CCS & 0,150 & $-0,059$ & 0,030 & 0,571 & 0,379 & 0,462 & 0,241 & 0,301 & 0,186 & $-0,440$ & 0,316 & 0,374 \\
\hline FCS27 & CCS & 0,252 & 0,409 & 0,126 & 0,473 & 0,457 & $-0,022$ & 0,038 & 0,276 & 0,591 & $-0,257$ & 0,378 & 0,443 \\
\hline FCS28 & CCS & 0,105 & $-0,012$ & $-0,271$ & $-0,166$ & 0,034 & 0,087 & 0,233 & 0,296 & 0,555 & 0,021 & 0,078 & 0,064 \\
\hline FCS29 & $\mathrm{CCS}$ & 0,024 & 0,070 & $-0,068$ & $-0,179$ & 0,088 & 0,218 & 0,096 & 0,768 & 0,523 & $-0,046$ & $-0,293$ & $-0,012$ \\
\hline FCS30 & CCS & $-0,144$ & $-0,038$ & $-0,280$ & $-0,555$ & 0,013 & $-0,230$ & 0,093 & 0,480 & 0,537 & 0,712 & $-0,507$ & 0,054 \\
\hline FCS31 & CCS & $-0,042$ & 0,037 & $-0,455$ & $-0,385$ & $-0,141$ & 0,136 & $-0,168$ & 0,367 & 0,505 & 0,436 & $-0,472$ & 0,232 \\
\hline FCS32 & CCS & $-0,126$ & $-0,202$ & $-0,469$ & $-0,470$ & $-0,003$ & $-0,201$ & 0,206 & 0,390 & 0,233 & 0,366 & $-0,523$ & 0,277 \\
\hline FCS33 & $\mathrm{CCS}$ & 0,480 & 0,502 & 0,377 & $-0,088$ & $-0,341$ & $-0,292$ & $-0,435$ & $-0,012$ & 0,008 & 0,163 & $-0,026$ & 0,006 \\
\hline FCS34 & $\mathrm{CCS}$ & 0,811 & 0,711 & 0,611 & 0,545 & 0,043 & 0,410 & $-0,526$ & 0,251 & 0,265 & $-0,088$ & 0,184 & $-0,290$ \\
\hline
\end{tabular}




\begin{tabular}{|c|c|c|c|c|c|c|c|c|c|c|c|c|c|}
\hline & & FCS25 & FCS26 & FCS27 & FCS28 & FCS29 & FCS30 & FCS31 & FCS32 & FCS33 & FCS34 & FCS35 & FCS36 \\
\hline FCS18 & CCS & $-0,122$ & 0,462 & $-0,022$ & 0,087 & 0,218 & $-0,230$ & 0,136 & $-0,201$ & $-0,292$ & 0,410 & 0,256 & $-0,248$ \\
\hline FCS19 & CCS & $-0,203$ & 0,241 & 0,038 & 0,233 & 0,096 & 0,093 & $-0,168$ & 0,206 & $-0,435$ & $-0,526$ & 0,207 & $-0,145$ \\
\hline FCS20 & CCS & $-0,149$ & 0,301 & 0,276 & 0,296 & 0,768 & 0,480 & 0,367 & 0,390 & $-0,012$ & 0,251 & $-0,071$ & $-0,315$ \\
\hline FCS21 & CCS & $-0,271$ & 0,186 & 0,591 & 0,555 & 0,523 & 0,537 & 0,505 & 0,233 & 0,008 & 0,265 & $-0,230$ & 0,068 \\
\hline FCS22 & CCS & $-0,421$ & $-0,440$ & $-0,257$ & 0,021 & $-0,046$ & 0,712 & 0,436 & 0,366 & 0,163 & $-0,088$ & $-0,158$ & $-0,047$ \\
\hline FCS23 & CCS & $-0,060$ & 0,316 & 0,378 & 0,078 & $-0,293$ & $-0,507$ & $-0,472$ & $-0,523$ & $-0,026$ & 0,184 & 0,044 & 0,439 \\
\hline FCS24 & $\mathrm{CCS}$ & $-0,002$ & 0,374 & 0,443 & 0,064 & $-0,012$ & 0,054 & 0,232 & 0,277 & 0,006 & $-0,290$ & $-0,394$ & 0,123 \\
\hline FCS25 & CCS & 1,000 & $-0,185$ & 0,137 & $-0,080$ & $-0,047$ & $-0,587$ & $-0,387$ & $-0,333$ & 0,174 & $-0,060$ & 0,130 & $-0,081$ \\
\hline FCS26 & CCS & $-0,185$ & 1,000 & 0,460 & 0,245 & 0,224 & $-0,127$ & $-0,109$ & $-0,029$ & $-0,386$ & 0,114 & $-0,075$ & $-0,084$ \\
\hline FCS27 & CCS & 0,137 & 0,460 & 1,000 & 0,302 & 0,217 & 0,013 & 0,056 & 0,006 & 0,042 & 0,125 & $-0,412$ & 0,429 \\
\hline FCS28 & $\mathrm{CCS}$ & $-0,080$ & 0,245 & 0,302 & 1,000 & 0,649 & 0,333 & 0,217 & 0,457 & $-0,104$ & $-0,248$ & 0,293 & $-0,264$ \\
\hline FCS29 & CCS & $-0,047$ & 0,224 & 0,217 & 0,649 & 1,000 & 0,483 & 0,334 & 0,472 & 0,051 & 0,043 & 0,160 & $-0,552$ \\
\hline FCS30 & CCS & $-0,587$ & $-0,127$ & 0,013 & 0,333 & 0,483 & 1,000 & 0,738 & 0,743 & 0,086 & $-0,173$ & $-0,314$ & $-0,211$ \\
\hline FCS31 & CCS & $-0,387$ & $-0,109$ & 0,056 & 0,217 & 0,334 & 0,738 & 1,000 & 0,538 & $-0,098$ & $-0,137$ & $-0,456$ & $-0,237$ \\
\hline FCS32 & CCS & $-0,333$ & $-0,029$ & 0,006 & 0,457 & 0,472 & 0,743 & 0,538 & 1,000 & 0,199 & $-0,307$ & 0,027 & $-0,109$ \\
\hline FCS33 & CCS & 0,174 & $-0,386$ & 0,042 & $-0,104$ & 0,051 & 0,086 & $-0,098$ & 0,199 & 1,000 & 0,522 & 0,115 & 0,372 \\
\hline FCS34 & $\mathrm{CCS}$ & $-0,060$ & 0,114 & 0,125 & $-0,248$ & 0,043 & $-0,173$ & $-0,137$ & $-0,307$ & 0,522 & 1,000 & 0,167 & 0,300 \\
\hline
\end{tabular}




\begin{tabular}{|c|c|c|c|c|c|c|c|c|c|c|c|c|c|}
\hline & & FCS37 & FCS38 & FCS39 & FCS40 & FCS41 & FCS42 & FCS43 & FCS44 & FCS45 & FCS46 & FCS47 & FCS48 \\
\hline FCS18 & CCS & 0,026 & 0,248 & $-0,419$ & 0,084 & 0,263 & 0,086 & 0,000 & 0,065 & 0,134 & 0,148 & $-0,006$ & 0,431 \\
\hline FCS19 & CCS & 0,097 & 0,571 & $-0,376$ & $-0,605$ & 0,161 & 0,018 & $-0,411$ & $-0,032$ & $-0,235$ & $-0,223$ & $-0,189$ & $-0,237$ \\
\hline FCS20 & CCS & 0,621 & 0,420 & $-0,261$ & 0,360 & 0,380 & 0,629 & 0,363 & 0,240 & 0,198 & 0,198 & 0,426 & 0,334 \\
\hline FCS21 & CCS & 0,244 & 0,285 & $-0,156$ & 0,243 & 0,468 & 0,293 & 0,356 & 0,435 & 0,159 & 0,443 & 0,031 & 0,123 \\
\hline FCS22 & CCS & $-0,134$ & $-0,107$ & $-0,001$ & 0,225 & 0,000 & 0,256 & 0,322 & 0,354 & 0,079 & 0,353 & 0,281 & $-0,020$ \\
\hline FCS23 & CCS & $-0,292$ & 0,197 & 0,463 & $-0,125$ & $-0,180$ & $-0,481$ & 0,117 & 0,108 & $-0,191$ & $-0,147$ & $-0,548$ & $-0,008$ \\
\hline FCS24 & CCS & $-0,146$ & 0,163 & 0,160 & $-0,381$ & $-0,327$ & $-0,582$ & $-0,640$ & 0,081 & 0,318 & $-0,616$ & $-0,597$ & 0,051 \\
\hline FCS25 & $\mathrm{CCS}$ & 0,252 & $-0,176$ & 0,052 & 0,258 & $-0,113$ & $-0,004$ & $-0,102$ & $-0,395$ & $-0,147$ & 0,193 & $-0,216$ & 0,030 \\
\hline FCS26 & $\mathrm{CCS}$ & 0,372 & 0,641 & $-0,142$ & 0,059 & 0,234 & $-0,076$ & $-0,118$ & $-0,118$ & 0,025 & $-0,204$ & $-0,093$ & $-0,113$ \\
\hline FCS27 & CCS & 0,334 & 0,328 & 0,286 & 0,082 & 0,201 & $-0,105$ & 0,000 & 0,335 & 0,063 & $-0,019$ & $-0,520$ & $-0,031$ \\
\hline FCS28 & CCS & 0,173 & 0,372 & $-0,528$ & $-0,171$ & 0,328 & 0,120 & $-0,097$ & $-0,129$ & 0,133 & 0,291 & 0,105 & $-0,090$ \\
\hline FCS29 & CCS & 0,293 & 0,565 & $-0,529$ & $-0,030$ & 0,368 & 0,386 & 0,084 & $-0,100$ & 0,307 & 0,043 & 0,383 & 0,422 \\
\hline FCS30 & CCS & 0,019 & 0,177 & $-0,227$ & $-0,095$ & 0,185 & 0,215 & 0,028 & 0,328 & 0,393 & 0,046 & 0,358 & 0,109 \\
\hline FCS31 & CCS & $-0,022$ & $-0,119$ & $-0,259$ & $-0,080$ & $-0,089$ & $-0,014$ & $-0,168$ & 0,429 & 0,368 & 0,019 & $-0,023$ & 0,204 \\
\hline FCS32 & CCS & 0,142 & 0,033 & $-0,328$ & $-0,188$ & 0,199 & 0,251 & $-0,316$ & 0,186 & 0,538 & $-0,018$ & 0,320 & 0,066 \\
\hline FCS33 & CCS & $-0,425$ & $-0,347$ & 0,420 & 0,335 & 0,079 & 0,030 & 0,255 & 0,019 & 0,598 & 0,018 & 0,249 & 0,505 \\
\hline FCS34 & CCS & $-0,221$ & $-0,093$ & 0,243 & 0,596 & 0,309 & 0,260 & 0,632 & 0,147 & 0,242 & 0,131 & 0,239 & 0,523 \\
\hline
\end{tabular}




\begin{tabular}{|c|c|c|c|c|c|c|c|c|c|c|c|}
\hline & & FCS49 & FCS50 & FCS51 & FCS52 & FCS53 & FCS54 & FCS55 & FCS56 & FCS57 & FCS58 \\
\hline FCS18 & CCS & 0,444 & 0,023 & 0,190 & 0,167 & $-0,286$ & 0,151 & $-0,427$ & 0,161 & $-0,305$ & $-0,090$ \\
\hline FCS19 & CCS & 0,000 & 0,220 & 0,199 & 0,113 & $-0,285$ & $-0,334$ & $-0,336$ & $-0,032$ & $-0,305$ & $-0,322$ \\
\hline FCS20 & CCS & $-0,219$ & 0,007 & 0,335 & 0,549 & $-0,218$ & 0,201 & 0,426 & 0,146 & 0,220 & 0,329 \\
\hline FCS21 & CCS & 0,036 & $-0,136$ & $-0,304$ & $-0,009$ & $-0,039$ & $-0,137$ & $-0,033$ & $-0,095$ & 0,377 & 0,000 \\
\hline FCS22 & CCS & 0,175 & 0,002 & $-0,201$ & $-0,312$ & 0,421 & 0,133 & 0,372 & $-0,020$ & 0,379 & $-0,308$ \\
\hline FCS23 & CCS & 0,083 & 0,216 & $-0,592$ & $-0,280$ & $-0,095$ & $-0,055$ & $-0,515$ & 0,345 & 0,204 & 0,278 \\
\hline FCS24 & CCS & 0,207 & 0,081 & $-0,139$ & $-0,411$ & 0,145 & $-0,703$ & $-0,441$ & $-0,326$ & $-0,317$ & $-0,351$ \\
\hline FCS25 & CCS & $-0,442$ & 0,250 & $-0,115$ & 0,162 & $-0,005$ & $-0,194$ & 0,045 & $-0,297$ & 0,137 & 0,095 \\
\hline FCS26 & CCS & 0,141 & 0,289 & 0,102 & 0,210 & $-0,196$ & $-0,110$ & $-0,212$ & 0,172 & $-0,164$ & 0,069 \\
\hline FCS27 & CCS & $-0,168$ & 0,004 & $-0,439$ & $-0,091$ & $-0,078$ & $-0,463$ & $-0,341$ & $-0,073$ & 0,345 & 0,233 \\
\hline FCS28 & CCS & $-0,199$ & 0,343 & $-0,076$ & 0,254 & $-0,298$ & $-0,300$ & $-0,001$ & $-0,451$ & $-0,062$ & $-0,352$ \\
\hline FCS29 & CCS & $-0,341$ & 0,103 & 0,276 & 0,507 & $-0,374$ & $-0,098$ & 0,322 & $-0,116$ & $-0,080$ & 0,005 \\
\hline FCS30 & CCS & 0,113 & $-0,224$ & 0,155 & $-0,051$ & 0,208 & $-0,133$ & 0,334 & $-0,176$ & 0,068 & $-0,286$ \\
\hline FCS31 & CCS & 0,516 & $-0,367$ & 0,098 & $-0,337$ & 0,354 & $-0,375$ & $-0,067$ & $-0,485$ & $-0,168$ & $-0,491$ \\
\hline FCS32 & CCS & $-0,132$ & 0,082 & 0,357 & 0,235 & $-0,118$ & $-0,140$ & 0,267 & $-0,363$ & $-0,158$ & $-0,363$ \\
\hline FCS33 & CCS & $-0,511$ & 0,038 & $-0,323$ & $-0,007$ & $-0,108$ & 0,318 & 0,404 & 0,213 & 0,345 & 0,262 \\
\hline FCS34 & CCS & $-0,142$ & $-0,070$ & $-0,299$ & 0,049 & $-0,311$ & 0,615 & 0,146 & 0,603 & 0,268 & 0,475 \\
\hline
\end{tabular}




\begin{tabular}{|c|c|c|c|c|c|c|c|c|c|c|c|}
\hline & & FCS59 & FCS60 & FCS61 & FCS62 & FCS63 & FCS64 & FCS65 & FCS66 & FCS67 & FCS68 \\
\hline FCS18 & CCS & $-0,425$ & $-0,105$ & 0,262 & 0,451 & 0,139 & 0,332 & $-0,132$ & $-0,095$ & $-0,112$ & 0,023 \\
\hline FCS19 & CCS & $-0,340$ & $-0,147$ & $-0,075$ & $-0,204$ & $-0,161$ & $-0,208$ & $-0,320$ & $-0,394$ & 0,156 & 0,049 \\
\hline FCS20 & CCS & 0,286 & 0,048 & $-0,094$ & 0,361 & 0,554 & 0,479 & $-0,334$ & 0,426 & 0,410 & 0,479 \\
\hline FCS21 & CCS & 0,218 & 0,089 & 0,322 & 0,049 & $-0,002$ & $-0,002$ & $-0,363$ & 0,088 & 0,196 & 0,077 \\
\hline FCS22 & CCS & $-0,029$ & 0,200 & $-0,347$ & $-0,235$ & 0,279 & 0,193 & $-0,333$ & $-0,044$ & 0,272 & 0,149 \\
\hline FCS23 & CCS & 0,230 & 0,011 & 0,704 & 0,254 & $-0,426$ & $-0,503$ & 0,181 & $-0,012$ & $-0,586$ & $-0,434$ \\
\hline FCS24 & CCS & $-0,222$ & $-0,649$ & 0,187 & $-0,464$ & $-0,116$ & $-0,145$ & $-0,320$ & $-0,431$ & $-0,149$ & $-0,627$ \\
\hline FCS25 & CCS & 0,154 & $-0,062$ & $-0,216$ & $-0,289$ & $-0,360$ & $-0,415$ & 0,601 & 0,180 & $-0,435$ & $-0,324$ \\
\hline FCS26 & CCS & $-0,108$ & $-0,228$ & 0,646 & 0,299 & 0,155 & 0,272 & $-0,315$ & 0,098 & $-0,120$ & $-0,117$ \\
\hline FCS27 & CCS & 0,431 & $-0,145$ & 0,516 & $-0,236$ & $-0,250$ & $-0,442$ & $-0,149$ & $-0,036$ & $-0,293$ & $-0,338$ \\
\hline FCS28 & CCS & $-0,236$ & $-0,026$ & 0,245 & 0,135 & $-0,200$ & $-0,090$ & $-0,374$ & 0,238 & 0,276 & 0,012 \\
\hline FCS29 & CCS & 0,056 & $-0,187$ & $-0,119$ & 0,325 & 0,242 & 0,339 & $-0,219$ & 0,366 & 0,601 & 0,293 \\
\hline FCS30 & CCS & $-0,049$ & $-0,038$ & $-0,235$ & $-0,151$ & 0,377 & 0,404 & $-0,635$ & $-0,060$ & 0,690 & 0,260 \\
\hline FCS31 & CCS & $-0,304$ & $-0,363$ & $-0,124$ & $-0,278$ & 0,160 & 0,333 & $-0,601$ & $-0,383$ & 0,427 & $-0,105$ \\
\hline FCS32 & CCS & $-0,300$ & $-0,001$ & $-0,384$ & $-0,186$ & 0,462 & 0,294 & $-0,706$ & 0,070 & 0,517 & 0,311 \\
\hline FCS33 & CCS & 0,380 & 0,240 & $-0,296$ & 0,038 & 0,320 & $-0,005$ & 0,318 & 0,491 & $-0,039$ & 0,083 \\
\hline FCS34 & $\mathrm{CCS}$ & 0,368 & 0,208 & 0,144 & 0,534 & 0,392 & 0,249 & 0,370 & 0,441 & $-0,147$ & 0,243 \\
\hline
\end{tabular}




\begin{tabular}{|c|c|c|c|c|c|c|c|c|c|c|c|c|c|}
\hline & & FCS1 & FCS2 & FCS3 & FCS4 & FCS5 & FCS6 & FCS7 & FCS8 & FCS9 & FCS10 & FCS11 & FCS12 \\
\hline FCS35 & CCS & $-0,200$ & $-0,119$ & 0,066 & 0,180 & 0,200 & $-0,162$ & 0,012 & $-0,055$ & 0,046 & 0,194 & 0,203 & $-0,048$ \\
\hline FCS36 & CCS & 0,252 & 0,599 & 0,211 & 0,078 & $-0,387$ & 0,359 & 0,360 & $-0,057$ & $-0,095$ & 0,112 & $-0,233$ & 0,468 \\
\hline FCS37 & CCS & $-0,592$ & 0,067 & $-0,302$ & 0,003 & 0,180 & $-0,143$ & $-0,221$ & 0,214 & 0,502 & 0,410 & 0,044 & $-0,266$ \\
\hline FCS38 & CCS & $-0,237$ & $-0,280$ & 0,153 & 0,034 & 0,120 & $-0,443$ & $-0,242$ & 0,694 & 0,651 & $-0,077$ & $-0,147$ & $-0,231$ \\
\hline FCS39 & CCS & 0,175 & 0,300 & 0,178 & $-0,068$ & $-0,247$ & 0,354 & 0,305 & $-0,160$ & $-0,452$ & $-0,086$ & 0,094 & 0,366 \\
\hline FCS40 & $\mathrm{CCS}$ & $-0,326$ & 0,209 & $-0,134$ & 0,223 & 0,202 & 0,569 & 0,739 & 0,016 & $-0,290$ & 0,373 & 0,386 & 0,459 \\
\hline FCS41 & $\mathrm{CCS}$ & $-0,231$ & 0,089 & $-0,025$ & 0,100 & 0,079 & $-0,142$ & 0,111 & 0,499 & 0,662 & 0,365 & $-0,188$ & 0,129 \\
\hline FCS42 & CCS & $-0,657$ & 0,188 & $-0,252$ & 0,113 & 0,465 & 0,110 & 0,168 & 0,168 & 0,206 & 0,608 & 0,272 & $-0,039$ \\
\hline FCS43 & CCS & $-0,183$ & 0,324 & 0,278 & 0,380 & 0,619 & 0,444 & 0,601 & 0,265 & $-0,379$ & 0,491 & 0,609 & 0,487 \\
\hline FCS44 & CCS & 0,091 & 0,840 & 0,111 & $-0,098$ & 0,152 & 0,346 & 0,289 & 0,215 & $-0,176$ & 0,432 & $-0,189$ & 0,132 \\
\hline FCS45 & $\mathrm{CCS}$ & $-0,039$ & $-0,025$ & $-0,415$ & $-0,242$ & $-0,324$ & 0,217 & 0,176 & 0,163 & 0,076 & $-0,034$ & $-0,279$ & 0,230 \\
\hline FCS46 & CCS & $-0,230$ & 0,284 & $-0,005$ & $-0,119$ & 0,445 & $-0,042$ & 0,253 & 0,189 & 0,040 & 0,561 & 0,032 & 0,062 \\
\hline FCS47 & $\mathrm{CCS}$ & $-0,424$ & $-0,308$ & $-0,449$ & 0,148 & 0,417 & 0,074 & 0,056 & 0,250 & 0,098 & 0,423 & 0,516 & 0,017 \\
\hline FCS48 & CCS & $-0,048$ & 0,155 & 0,087 & $-0,236$ & 0,098 & 0,151 & 0,332 & 0,058 & $-0,264$ & 0,038 & $-0,018$ & 0,152 \\
\hline FCS49 & CCS & 0,702 & 0,329 & 0,199 & 0,057 & 0,088 & 0,103 & 0,122 & 0,091 & $-0,266$ & 0,055 & $-0,094$ & $-0,154$ \\
\hline FCS50 & $\mathrm{CCS}$ & $-0,408$ & $-0,242$ & $-0,159$ & 0,057 & $-0,056$ & $-0,050$ & 0,077 & 0,072 & 0,089 & $-0,046$ & 0,040 & $-0,050$ \\
\hline FCS51 & $\mathrm{CCS}$ & $-0,248$ & $-0,254$ & $-0,472$ & $-0,132$ & 0,119 & $-0,339$ & $-0,524$ & 0,011 & 0,361 & 0,258 & 0,147 & $-0,591$ \\
\hline
\end{tabular}




\begin{tabular}{|c|c|c|c|c|c|c|c|c|c|c|c|c|c|}
\hline & & FCS13 & FCS14 & FCS15 & FCS16 & FCS17 & FCS18 & FCS19 & FCS20 & FCS21 & FCS22 & FCS23 & FCS24 \\
\hline FCS35 & CCS & 0,216 & $-0,047$ & 0,101 & 0,045 & $-0,029$ & 0,256 & 0,207 & $-0,071$ & $-0,230$ & $-0,158$ & 0,044 & $-0,394$ \\
\hline FCS36 & CCS & 0,357 & 0,350 & 0,177 & 0,467 & 0,337 & $-0,248$ & $-0,145$ & $-0,315$ & 0,068 & $-0,047$ & 0,439 & 0,123 \\
\hline FCS37 & CCS & $-0,070$ & 0,039 & $-0,035$ & 0,221 & 0,456 & 0,026 & 0,097 & 0,621 & 0,244 & $-0,134$ & $-0,292$ & $-0,146$ \\
\hline FCS38 & CCS & $-0,274$ & $-0,219$ & $-0,033$ & 0,133 & 0,456 & 0,248 & 0,571 & 0,420 & 0,285 & $-0,107$ & 0,197 & 0,163 \\
\hline FCS39 & CCS & 0,131 & 0,419 & 0,414 & 0,370 & 0,126 & $-0,419$ & $-0,376$ & $-0,261$ & $-0,156$ & $-0,001$ & 0,463 & 0,160 \\
\hline FCS40 & CCS & 0,699 & 0,754 & 0,588 & 0,305 & $-0,120$ & 0,084 & $-0,605$ & 0,360 & 0,243 & 0,225 & $-0,125$ & $-0,381$ \\
\hline FCS41 & CCS & 0,323 & $-0,010$ & $-0,067$ & 0,061 & 0,228 & 0,263 & 0,161 & 0,380 & 0,468 & 0,000 & $-0,180$ & $-0,327$ \\
\hline FCS42 & CCS & 0,262 & 0,290 & 0,237 & 0,040 & 0,319 & 0,086 & 0,018 & 0,629 & 0,293 & 0,256 & $-0,481$ & $-0,582$ \\
\hline FCS43 & CCS & 0,539 & 0,755 & 0,743 & 0,323 & 0,189 & 0,000 & $-0,411$ & 0,363 & 0,356 & 0,322 & 0,117 & $-0,640$ \\
\hline FCS44 & CCS & 0,074 & 0,347 & $-0,159$ & 0,282 & 0,602 & 0,065 & $-0,032$ & 0,240 & 0,435 & 0,354 & 0,108 & 0,081 \\
\hline FCS45 & CCS & 0,213 & 0,006 & $-0,303$ & $-0,213$ & $-0,307$ & 0,134 & $-0,235$ & 0,198 & 0,159 & 0,079 & $-0,191$ & 0,318 \\
\hline FCS46 & CCS & 0,384 & 0,284 & $-0,092$ & $-0,055$ & $-0,027$ & 0,148 & $-0,223$ & 0,198 & 0,443 & 0,353 & $-0,147$ & $-0,616$ \\
\hline FCS47 & $\mathrm{CCS}$ & 0,195 & $-0,043$ & 0,159 & $-0,338$ & $-0,270$ & $-0,006$ & $-0,189$ & 0,426 & 0,031 & 0,281 & $-0,548$ & $-0,597$ \\
\hline FCS48 & CCS & 0,187 & 0,293 & 0,035 & 0,060 & $-0,052$ & 0,431 & $-0,237$ & 0,334 & 0,123 & $-0,020$ & $-0,008$ & 0,051 \\
\hline FCS49 & CCS & $-0,182$ & $-0,265$ & $-0,498$ & 0,012 & $-0,024$ & 0,444 & 0,000 & $-0,219$ & 0,036 & 0,175 & 0,083 & 0,207 \\
\hline FCS50 & CCS & 0,135 & 0,124 & 0,166 & 0,142 & 0,021 & 0,023 & 0,220 & 0,007 & $-0,136$ & 0,002 & 0,216 & 0,081 \\
\hline FCS51 & $\mathrm{CCS}$ & $-0,438$ & $-0,648$ & $-0,448$ & $-0,256$ & 0,036 & 0,190 & 0,199 & 0,335 & $-0,304$ & $-0,201$ & $-0,592$ & $-0,139$ \\
\hline
\end{tabular}




\begin{tabular}{|c|c|c|c|c|c|c|c|c|c|c|c|c|c|}
\hline & & FCS25 & FCS26 & FCS27 & FCS28 & FCS29 & FCS30 & FCS31 & FCS32 & FCS33 & FCS34 & FCS35 & FCS36 \\
\hline FCS35 & CCS & 0,130 & $-0,075$ & $-0,412$ & 0,293 & 0,160 & $-0,314$ & $-0,456$ & 0,027 & 0,115 & 0,167 & 1,000 & $-0,174$ \\
\hline FCS36 & CCS & $-0,081$ & $-0,084$ & 0,429 & $-0,264$ & $-0,552$ & $-0,211$ & $-0,237$ & $-0,109$ & 0,372 & 0,300 & $-0,174$ & 1,000 \\
\hline FCS37 & CCS & 0,252 & 0,372 & 0,334 & 0,173 & 0,293 & 0,019 & $-0,022$ & 0,142 & $-0,425$ & $-0,221$ & $-0,069$ & $-0,180$ \\
\hline FCS38 & CCS & $-0,176$ & 0,641 & 0,328 & 0,372 & 0,565 & 0,177 & $-0,119$ & 0,033 & $-0,347$ & $-0,093$ & $-0,007$ & $-0,414$ \\
\hline FCS39 & CCS & 0,052 & $-0,142$ & 0,286 & $-0,528$ & $-0,529$ & $-0,227$ & $-0,259$ & $-0,328$ & 0,420 & 0,243 & $-0,479$ & 0,665 \\
\hline FCS40 & CCS & 0,258 & 0,059 & 0,082 & $-0,171$ & $-0,030$ & $-0,095$ & $-0,080$ & $-0,188$ & 0,335 & 0,596 & 0,046 & 0,052 \\
\hline FCS41 & CCS & $-0,113$ & 0,234 & 0,201 & 0,328 & 0,368 & 0,185 & $-0,089$ & 0,199 & 0,079 & 0,309 & 0,267 & 0,096 \\
\hline FCS42 & CCS & $-0,004$ & $-0,076$ & $-0,105$ & 0,120 & 0,386 & 0,215 & $-0,014$ & 0,251 & 0,030 & 0,260 & 0,477 & $-0,161$ \\
\hline FCS43 & CCS & $-0,102$ & $-0,118$ & 0,000 & $-0,097$ & 0,084 & 0,028 & $-0,168$ & $-0,316$ & 0,255 & 0,632 & 0,183 & 0,070 \\
\hline FCS44 & CCS & $-0,395$ & $-0,118$ & 0,335 & $-0,129$ & $-0,100$ & 0,328 & 0,429 & 0,186 & 0,019 & 0,147 & $-0,335$ & 0,470 \\
\hline FCS45 & CCS & $-0,147$ & 0,025 & 0,063 & 0,133 & 0,307 & 0,393 & 0,368 & 0,538 & 0,598 & 0,242 & $-0,159$ & 0,064 \\
\hline FCS46 & CCS & 0,193 & $-0,204$ & $-0,019$ & 0,291 & 0,043 & 0,046 & 0,019 & $-0,018$ & 0,018 & 0,131 & 0,240 & 0,010 \\
\hline FCS47 & CCS & $-0,216$ & $-0,093$ & $-0,520$ & 0,105 & 0,383 & 0,358 & $-0,023$ & 0,320 & 0,249 & 0,239 & 0,379 & $-0,379$ \\
\hline FCS48 & CCS & 0,030 & $-0,113$ & $-0,031$ & $-0,090$ & 0,422 & 0,109 & 0,204 & 0,066 & 0,505 & 0,523 & 0,077 & $-0,178$ \\
\hline FCS49 & CCS & $-0,442$ & 0,141 & $-0,168$ & $-0,199$ & $-0,341$ & 0,113 & 0,516 & $-0,132$ & $-0,511$ & $-0,142$ & $-0,430$ & $-0,093$ \\
\hline FCS50 & CCS & 0,250 & 0,289 & 0,004 & 0,343 & 0,103 & $-0,224$ & $-0,367$ & 0,082 & 0,038 & $-0,070$ & 0,518 & $-0,206$ \\
\hline FCS51 & CCS & $-0,115$ & 0,102 & $-0,439$ & $-0,076$ & 0,276 & 0,155 & 0,098 & 0,357 & $-0,323$ & $-0,299$ & 0,116 & $-0,452$ \\
\hline
\end{tabular}




\begin{tabular}{|c|c|c|c|c|c|c|c|c|c|c|c|c|c|}
\hline & & FCS37 & FCS38 & FCS39 & FCS40 & FCS41 & FCS42 & FCS43 & FCS44 & FCS45 & FCS46 & FCS47 & FCS48 \\
\hline FCS35 & CCS & $-0,069$ & $-0,007$ & $-0,479$ & 0,046 & 0,267 & 0,477 & 0,183 & $-0,335$ & $-0,159$ & 0,240 & 0,379 & 0,077 \\
\hline FCS36 & CCS & $-0,180$ & $-0,414$ & 0,665 & 0,052 & 0,096 & $-0,161$ & 0,070 & 0,470 & 0,064 & 0,010 & $-0,379$ & $-0,178$ \\
\hline FCS37 & CCS & 1,000 & 0,354 & $-0,197$ & 0,310 & 0,221 & 0,543 & 0,088 & 0,133 & $-0,297$ & 0,334 & 0,044 & $-0,246$ \\
\hline FCS38 & CCS & 0,354 & 1,000 & $-0,275$ & $-0,121$ & 0,299 & 0,109 & 0,042 & $-0,108$ & $-0,048$ & $-0,099$ & 0,067 & 0,131 \\
\hline FCS39 & CCS & $-0,197$ & $-0,275$ & 1,000 & 0,231 & $-0,431$ & $-0,389$ & 0,250 & 0,361 & 0,040 & $-0,220$ & $-0,387$ & 0,076 \\
\hline FCS40 & CCS & 0,310 & $-0,121$ & 0,231 & 1,000 & 0,060 & 0,459 & 0,705 & 0,122 & $-0,001$ & 0,507 & 0,249 & 0,212 \\
\hline FCS41 & CCS & 0,221 & 0,299 & $-0,431$ & 0,060 & 1,000 & 0,451 & 0,060 & $-0,101$ & 0,265 & 0,454 & 0,492 & $-0,010$ \\
\hline FCS42 & CCS & 0,543 & 0,109 & $-0,389$ & 0,459 & 0,451 & 1,000 & 0,542 & 0,187 & $-0,213$ & 0,464 & 0,514 & 0,083 \\
\hline FCS43 & CCS & 0,088 & 0,042 & 0,250 & 0,705 & 0,060 & 0,542 & 1,000 & 0,258 & $-0,285$ & 0,361 & 0,290 & 0,232 \\
\hline FCS44 & CCS & 0,133 & $-0,108$ & 0,361 & 0,122 & $-0,101$ & 0,187 & 0,258 & 1,000 & 0,025 & 0,145 & $-0,381$ & 0,225 \\
\hline FCS45 & CCS & $-0,297$ & $-0,048$ & 0,040 & $-0,001$ & 0,265 & $-0,213$ & $-0,285$ & 0,025 & 1,000 & $-0,028$ & 0,293 & 0,555 \\
\hline FCS46 & CCS & 0,334 & $-0,099$ & $-0,220$ & 0,507 & 0,454 & 0,464 & 0,361 & 0,145 & $-0,028$ & 1,000 & 0,259 & $-0,033$ \\
\hline FCS47 & CCS & 0,044 & 0,067 & $-0,387$ & 0,249 & 0,492 & 0,514 & 0,290 & $-0,381$ & 0,293 & 0,259 & 1,000 & 0,123 \\
\hline FCS48 & CCS & $-0,246$ & 0,131 & 0,076 & 0,212 & $-0,010$ & 0,083 & 0,232 & 0,225 & 0,555 & $-0,033$ & 0,123 & 1,000 \\
\hline FCS49 & CCS & $-0,202$ & $-0,083$ & $-0,043$ & $-0,168$ & $-0,283$ & $-0,429$ & $-0,256$ & 0,316 & 0,022 & $-0,030$ & $-0,321$ & $-0,027$ \\
\hline FCS50 & CCS & 0,269 & 0,286 & $-0,100$ & 0,375 & $-0,160$ & 0,245 & 0,197 & $-0,162$ & $-0,171$ & 0,190 & 0,000 & 0,002 \\
\hline FCS51 & CCS & 0,335 & 0,140 & $-0,499$ & $-0,316$ & 0,261 & 0,240 & $-0,412$ & $-0,260$ & 0,169 & $-0,118$ & 0,509 & $-0,014$ \\
\hline
\end{tabular}




\begin{tabular}{|c|c|c|c|c|c|c|c|c|c|c|c|}
\hline & & FCS49 & FCS50 & FCS51 & FCS52 & FCS53 & FCS54 & FCS55 & FCS56 & FCS57 & FCS58 \\
\hline FCS35 & CCS & $-0,430$ & 0,518 & 0,116 & 0,486 & $-0,742$ & 0,504 & 0,172 & 0,118 & $-0,222$ & $-0,066$ \\
\hline FCS36 & $\mathrm{CCS}$ & $-0,093$ & $-0,206$ & $-0,452$ & $-0,260$ & $-0,077$ & 0,097 & $-0,343$ & 0,235 & 0,354 & 0,342 \\
\hline FCS37 & CCS & $-0,202$ & 0,269 & 0,335 & 0,551 & $-0,075$ & $-0,023$ & 0,162 & $-0,071$ & 0,271 & 0,246 \\
\hline FCS38 & CCS & $-0,083$ & 0,286 & 0,140 & 0,348 & $-0,176$ & $-0,153$ & 0,004 & 0,288 & 0,058 & 0,122 \\
\hline FCS39 & CCS & $-0,043$ & $-0,100$ & $-0,499$ & $-0,396$ & 0,389 & 0,100 & $-0,017$ & 0,420 & 0,577 & 0,579 \\
\hline FCS40 & CCS & $-0,168$ & 0,375 & $-0,316$ & 0,081 & 0,126 & 0,525 & 0,484 & 0,295 & 0,617 & 0,321 \\
\hline FCS41 & CCS & $-0,283$ & $-0,160$ & 0,261 & 0,585 & $-0,482$ & 0,233 & 0,037 & 0,156 & 0,046 & 0,091 \\
\hline FCS42 & CCS & $-0,429$ & 0,245 & 0,240 & 0,579 & $-0,501$ & 0,549 & 0,484 & 0,211 & 0,227 & 0,209 \\
\hline FCS43 & CCS & $-0,256$ & 0,197 & $-0,412$ & 0,055 & $-0,111$ & 0,668 & 0,484 & 0,585 & 0,633 & 0,533 \\
\hline FCS44 & CCS & 0,316 & $-0,162$ & $-0,260$ & $-0,287$ & 0,123 & 0,020 & $-0,298$ & 0,182 & 0,432 & 0,171 \\
\hline FCS45 & CCS & 0,022 & $-0,171$ & 0,169 & 0,106 & 0,086 & $-0,015$ & 0,098 & $-0,032$ & $-0,026$ & $-0,089$ \\
\hline FCS46 & CCS & $-0,030$ & 0,190 & $-0,118$ & 0,270 & 0,068 & 0,282 & 0,107 & $-0,076$ & 0,532 & $-0,034$ \\
\hline FCS47 & CCS & $-0,321$ & 0,000 & 0,509 & 0,610 & $-0,216$ & 0,639 & 0,759 & 0,251 & $-0,028$ & 0,114 \\
\hline FCS48 & CCS & $-0,027$ & 0,002 & $-0,014$ & 0,092 & $-0,102$ & 0,225 & 0,094 & 0,344 & 0,143 & 0,227 \\
\hline FCS49 & CCS & 1,000 & $-0,298$ & 0,031 & $-0,544$ & 0,553 & $-0,244$ & $-0,538$ & $-0,133$ & $-0,238$ & $-0,431$ \\
\hline FCS50 & CCS & $-0,298$ & 1,000 & $-0,232$ & 0,196 & $-0,194$ & 0,162 & 0,241 & 0,036 & 0,208 & $-0,092$ \\
\hline FCS51 & $\mathrm{CCS}$ & 0,031 & $-0,232$ & 1,000 & 0,648 & $-0,164$ & 0,132 & 0,176 & $-0,032$ & $-0,490$ & $-0,014$ \\
\hline
\end{tabular}




\begin{tabular}{|c|c|c|c|c|c|c|c|c|c|c|c|}
\hline & & FCS59 & FCS60 & FCS61 & FCS62 & FCS63 & FCS64 & FCS65 & FCS66 & FCS67 & FCS68 \\
\hline FCS35 & $\mathrm{CCS}$ & $-0,295$ & 0,255 & $-0,289$ & 0,518 & 0,127 & 0,005 & 0,254 & 0,453 & 0,049 & 0,479 \\
\hline FCS36 & $\mathrm{CCS}$ & 0,360 & 0,390 & 0,266 & $-0,225$ & $-0,110$ & $-0,538$ & 0,033 & $-0,099$ & $-0,492$ & $-0,042$ \\
\hline FCS37 & $\mathrm{CCS}$ & 0,159 & 0,135 & $-0,031$ & $-0,033$ & 0,179 & 0,022 & $-0,291$ & 0,197 & $-0,089$ & 0,233 \\
\hline FCS38 & $\mathrm{CCS}$ & 0,095 & $-0,156$ & 0,286 & 0,269 & 0,084 & 0,188 & $-0,239$ & 0,113 & 0,199 & 0,028 \\
\hline FCS39 & CCS & 0,670 & 0,140 & 0,221 & $-0,122$ & $-0,011$ & $-0,329$ & 0,231 & 0,063 & $-0,547$ & $-0,335$ \\
\hline FCS40 & CCS & 0,343 & 0,246 & $-0,039$ & 0,249 & 0,447 & 0,246 & 0,213 & 0,599 & $-0,360$ & 0,080 \\
\hline FCS41 & CCS & $-0,033$ & 0,545 & 0,085 & 0,145 & 0,151 & 0,139 & $-0,126$ & 0,211 & 0,287 & 0,559 \\
\hline FCS42 & CCS & 0,132 & 0,339 & $-0,490$ & 0,318 & 0,515 & 0,224 & $-0,050$ & 0,451 & 0,260 & 0,774 \\
\hline FCS43 & CCS & 0,599 & 0,295 & 0,000 & 0,559 & 0,312 & 0,114 & 0,321 & 0,584 & $-0,071$ & 0,344 \\
\hline FCS44 & $\mathrm{CCS}$ & 0,221 & 0,106 & $-0,027$ & $-0,143$ & 0,209 & $-0,199$ & $-0,485$ & $-0,289$ & $-0,222$ & 0,034 \\
\hline FCS45 & CCS & $-0,138$ & 0,109 & $-0,065$ & $-0,047$ & 0,408 & 0,389 & $-0,314$ & 0,139 & 0,194 & $-0,020$ \\
\hline FCS46 & $\mathrm{CCS}$ & $-0,054$ & 0,655 & $-0,041$ & 0,010 & $-0,018$ & $-0,099$ & $-0,082$ & 0,259 & $-0,228$ & 0,195 \\
\hline FCS47 & CCS & $-0,035$ & 0,448 & $-0,332$ & 0,480 & 0,593 & 0,702 & 0,009 & 0,601 & 0,610 & 0,742 \\
\hline FCS48 & $\mathrm{CCS}$ & 0,144 & $-0,099$ & $-0,271$ & 0,322 & 0,413 & 0,297 & 0,086 & 0,215 & 0,037 & 0,014 \\
\hline FCS49 & $\mathrm{CCS}$ & $-0,509$ & $-0,245$ & 0,312 & $-0,159$ & $-0,095$ & 0,221 & $-0,443$ & $-0,675$ & $-0,128$ & $-0,397$ \\
\hline FCS50 & $\mathrm{CCS}$ & $-0,122$ & $-0,040$ & $-0,040$ & 0,246 & 0,193 & $-0,036$ & $-0,027$ & 0,505 & $-0,365$ & $-0,108$ \\
\hline FCS51 & CCS & $-0,355$ & 0,116 & $-0,355$ & 0,116 & 0,372 & 0,536 & $-0,291$ & $-0,046$ & 0,506 & 0,529 \\
\hline
\end{tabular}




\begin{tabular}{|c|c|c|c|c|c|c|c|c|c|c|c|c|c|}
\hline & & FCS1 & FCS2 & FCS3 & FCS4 & FCS5 & FCS6 & FCS7 & FCS8 & FCS9 & FCS10 & FCS11 & FCS12 \\
\hline FCS52 & CCS & $-0,582$ & $-0,171$ & $-0,283$ & 0,010 & 0,247 & $-0,312$ & $-0,289$ & 0,270 & 0,519 & 0,462 & 0,225 & $-0,221$ \\
\hline FCS53 & CCS & 0,197 & $-0,088$ & $-0,152$ & $-0,342$ & $-0,014$ & 0,048 & 0,003 & $-0,143$ & $-0,364$ & $-0,186$ & $-0,017$ & $-0,146$ \\
\hline FCS54 & CCS & $-0,146$ & 0,237 & $-0,007$ & 0,336 & 0,448 & 0,352 & 0,475 & 0,114 & $-0,315$ & 0,635 & 0,687 & 0,245 \\
\hline FCS55 & $\mathrm{CCS}$ & $-0,682$ & $-0,428$ & $-0,562$ & 0,054 & 0,317 & 0,227 & 0,076 & 0,016 & $-0,122$ & 0,192 & 0,588 & 0,094 \\
\hline FCS56 & CCS & 0,031 & 0,253 & 0,334 & 0,215 & 0,231 & 0,144 & 0,394 & 0,340 & $-0,120$ & 0,330 & 0,404 & 0,186 \\
\hline FCS57 & CCS & $-0,324$ & 0,321 & 0,080 & $-0,187$ & 0,246 & 0,163 & 0,358 & 0,236 & $-0,146$ & 0,331 & 0,102 & 0,279 \\
\hline FCS58 & CCS & $-0,169$ & 0,275 & 0,248 & 0,167 & 0,221 & 0,152 & 0,174 & 0,166 & $-0,092$ & 0,378 & 0,450 & 0,287 \\
\hline FCS59 & CCS & $-0,267$ & 0,156 & 0,218 & 0,054 & 0,154 & 0,205 & 0,188 & 0,113 & $-0,130$ & 0,109 & 0,289 & 0,401 \\
\hline FCS60 & CCS & $-0,177$ & 0,291 & $-0,035$ & $-0,086$ & 0,295 & $-0,068$ & 0,119 & 0,232 & 0,078 & 0,636 & 0,191 & 0,066 \\
\hline FCS61 & $\mathrm{CCS}$ & 0,581 & 0,209 & 0,521 & 0,568 & $-0,037$ & 0,142 & 0,188 & 0,525 & 0,134 & 0,020 & 0,021 & 0,471 \\
\hline FCS62 & CCS & 0,071 & 0,107 & 0,277 & 0,643 & 0,562 & 0,243 & 0,274 & 0,441 & $-0,170$ & 0,492 & 0,718 & 0,339 \\
\hline FCS63 & $\mathrm{CCS}$ & $-0,420$ & 0,105 & $-0,558$ & 0,114 & 0,108 & 0,451 & 0,355 & 0,224 & $-0,025$ & 0,443 & 0,326 & 0,071 \\
\hline FCS64 & $\mathrm{CCS}$ & $-0,109$ & $-0,209$ & $-0,441$ & 0,272 & 0,253 & 0,304 & 0,203 & 0,279 & $-0,029$ & 0,268 & 0,449 & $-0,005$ \\
\hline FCS65 & CCS & 0,046 & $-0,274$ & 0,413 & 0,059 & $-0,021$ & $-0,038$ & 0,185 & $-0,520$ & $-0,366$ & $-0,331$ & 0,299 & 0,216 \\
\hline FCS66 & $\mathrm{CCS}$ & $-0,526$ & $-0,181$ & $-0,220$ & 0,317 & 0,272 & 0,286 & 0,279 & 0,221 & $-0,046$ & 0,339 & 0,562 & 0,426 \\
\hline FCS67 & $\mathrm{CCS}$ & $-0,241$ & $-0,358$ & $-0,343$ & 0,070 & 0,306 & $-0,088$ & $-0,341$ & 0,250 & 0,247 & 0,045 & 0,167 & $-0,149$ \\
\hline FCS68 & $\mathrm{CCS}$ & $-0,416$ & 0,129 & $-0,248$ & 0,206 & 0,450 & 0,054 & $-0,017$ & 0,247 & 0,210 & 0,650 & 0,414 & $-0,050$ \\
\hline
\end{tabular}




\begin{tabular}{|c|c|c|c|c|c|c|c|c|c|c|c|c|c|}
\hline & & FCS13 & FCS14 & FCS15 & FCS16 & FCS17 & FCS18 & FCS19 & FCS20 & FCS21 & FCS22 & FCS23 & $\mathrm{FCS} 24$ \\
\hline FCS52 & CCS & 0,014 & $-0,168$ & $-0,026$ & 0,080 & 0,243 & 0,167 & 0,113 & 0,549 & $-0,009$ & $-0,312$ & $-0,280$ & $-0,411$ \\
\hline FCS53 & CCS & $-0,256$ & $-0,057$ & $-0,178$ & $-0,333$ & $-0,367$ & $-0,286$ & $-0,285$ & $-0,218$ & $-0,039$ & 0,421 & $-0,095$ & 0,145 \\
\hline FCS54 & CCS & 0,455 & 0,321 & 0,474 & 0,278 & 0,084 & 0,151 & $-0,334$ & 0,201 & $-0,137$ & 0,133 & $-0,055$ & $-0,703$ \\
\hline FCS55 & CCS & 0,163 & 0,258 & 0,495 & $-0,346$ & $-0,327$ & $-0,427$ & $-0,336$ & 0,426 & $-0,033$ & 0,372 & $-0,515$ & $-0,441$ \\
\hline FCS56 & CCS & 0,184 & 0,234 & 0,497 & 0,512 & 0,446 & 0,161 & $-0,032$ & 0,146 & $-0,095$ & $-0,020$ & 0,345 & $-0,326$ \\
\hline FCS57 & CCS & 0,296 & 0,602 & 0,374 & 0,203 & 0,242 & $-0,305$ & $-0,305$ & 0,220 & 0,377 & 0,379 & 0,204 & $-0,317$ \\
\hline FCS58 & CCS & 0,212 & 0,419 & 0,577 & 0,576 & 0,451 & $-0,090$ & $-0,322$ & 0,329 & 0,000 & $-0,308$ & 0,278 & $-0,351$ \\
\hline FCS59 & CCS & 0,200 & 0,598 & 0,697 & 0,333 & 0,306 & $-0,425$ & $-0,340$ & 0,286 & 0,218 & $-0,029$ & 0,230 & $-0,222$ \\
\hline FCS60 & CCS & 0,252 & 0,080 & 0,014 & 0,080 & 0,181 & $-0,105$ & $-0,147$ & 0,048 & 0,089 & 0,200 & 0,011 & $-0,649$ \\
\hline FCS61 & CCS & 0,276 & 0,138 & 0,101 & 0,571 & 0,223 & 0,262 & $-0,075$ & $-0,094$ & 0,322 & $-0,347$ & 0,704 & 0,187 \\
\hline FCS62 & CCS & 0,380 & 0,253 & 0,416 & 0,439 & 0,179 & 0,451 & $-0,204$ & 0,361 & 0,049 & $-0,235$ & 0,254 & $-0,464$ \\
\hline FCS63 & CCS & 0,234 & 0,164 & 0,144 & 0,056 & 0,105 & 0,139 & $-0,161$ & 0,554 & $-0,002$ & 0,279 & $-0,426$ & $-0,116$ \\
\hline FCS64 & CCS & 0,107 & $-0,098$ & 0,015 & $-0,163$ & $-0,245$ & 0,332 & $-0,208$ & 0,479 & $-0,002$ & 0,193 & $-0,503$ & $-0,145$ \\
\hline FCS65 & CCS & 0,221 & 0,301 & 0,674 & 0,120 & $-0,356$ & $-0,132$ & $-0,320$ & $-0,334$ & $-0,363$ & $-0,333$ & 0,181 & $-0,320$ \\
\hline FCS66 & CCS & 0,535 & 0,494 & 0,599 & 0,176 & $-0,111$ & $-0,095$ & $-0,394$ & 0,426 & 0,088 & $-0,044$ & $-0,012$ & $-0,431$ \\
\hline FCS67 & CCS & $-0,246$ & $-0,291$ & $-0,122$ & $-0,574$ & $-0,137$ & $-0,112$ & 0,156 & 0,410 & 0,196 & 0,272 & $-0,586$ & $-0,149$ \\
\hline FCS68 & $\mathrm{CCS}$ & 0,121 & $-0,017$ & 0,133 & $-0,025$ & 0,298 & 0,023 & 0,049 & 0,479 & 0,077 & 0,149 & $-0,434$ & $-0,627$ \\
\hline
\end{tabular}




\begin{tabular}{|c|c|c|c|c|c|c|c|c|c|c|c|c|c|}
\hline & & FCS25 & FCS26 & FCS27 & FCS28 & FCS29 & FCS30 & FCS31 & FCS32 & FCS33 & FCS34 & FCS35 & FCS36 \\
\hline FCS52 & $\mathrm{CCS}$ & 0,162 & 0,210 & $-0,091$ & 0,254 & 0,507 & $-0,051$ & $-0,337$ & 0,235 & $-0,007$ & 0,049 & 0,486 & $-0,260$ \\
\hline FCS53 & CCS & $-0,005$ & $-0,196$ & $-0,078$ & $-0,298$ & $-0,374$ & 0,208 & 0,354 & $-0,118$ & $-0,108$ & $-0,311$ & $-0,742$ & $-0,077$ \\
\hline FCS54 & $\mathrm{CCS}$ & $-0,194$ & $-0,110$ & $-0,463$ & $-0,300$ & $-0,098$ & $-0,133$ & $-0,375$ & $-0,140$ & 0,318 & 0,615 & 0,504 & 0,097 \\
\hline FCS55 & $\mathrm{CCS}$ & 0,045 & $-0,212$ & $-0,341$ & $-0,001$ & 0,322 & 0,334 & $-0,067$ & 0,267 & 0,404 & 0,146 & 0,172 & $-0,343$ \\
\hline FCS56 & $\mathrm{CCS}$ & $-0,297$ & 0,172 & $-0,073$ & $-0,451$ & $-0,116$ & $-0,176$ & $-0,485$ & $-0,363$ & 0,213 & 0,603 & 0,118 & 0,235 \\
\hline FCS57 & CCS & 0,137 & $-0,164$ & 0,345 & $-0,062$ & $-0,080$ & 0,068 & $-0,168$ & $-0,158$ & 0,345 & 0,268 & $-0,222$ & 0,354 \\
\hline FCS58 & CCS & 0,095 & 0,069 & 0,233 & $-0,352$ & 0,005 & $-0,286$ & $-0,491$ & $-0,363$ & 0,262 & 0,475 & $-0,066$ & 0,342 \\
\hline FCS59 & CCS & 0,154 & $-0,108$ & 0,431 & $-0,236$ & 0,056 & $-0,049$ & $-0,304$ & $-0,300$ & 0,380 & 0,368 & $-0,295$ & 0,360 \\
\hline FCS60 & CCS & $-0,062$ & $-0,228$ & $-0,145$ & $-0,026$ & $-0,187$ & $-0,038$ & $-0,363$ & $-0,001$ & 0,240 & 0,208 & 0,255 & 0,390 \\
\hline FCS61 & $\mathrm{CCS}$ & $-0,216$ & 0,646 & 0,516 & 0,245 & $-0,119$ & $-0,235$ & $-0,124$ & $-0,384$ & $-0,296$ & 0,144 & $-0,289$ & 0,266 \\
\hline FCS62 & CCS & $-0,289$ & 0,299 & $-0,236$ & 0,135 & 0,325 & $-0,151$ & $-0,278$ & $-0,186$ & 0,038 & 0,534 & 0,518 & $-0,225$ \\
\hline FCS63 & CCS & $-0,360$ & 0,155 & $-0,250$ & $-0,200$ & 0,242 & 0,377 & 0,160 & 0,462 & 0,320 & 0,392 & 0,127 & $-0,110$ \\
\hline FCS64 & CCS & $-0,415$ & 0,272 & $-0,442$ & $-0,090$ & 0,339 & 0,404 & 0,333 & 0,294 & $-0,005$ & 0,249 & 0,005 & $-0,538$ \\
\hline FCS65 & CCS & 0,601 & $-0,315$ & $-0,149$ & $-0,374$ & $-0,219$ & $-0,635$ & $-0,601$ & $-0,706$ & 0,318 & 0,370 & 0,254 & 0,033 \\
\hline FCS66 & $\mathrm{CCS}$ & 0,180 & 0,098 & $-0,036$ & 0,238 & 0,366 & $-0,060$ & $-0,383$ & 0,070 & 0,491 & 0,441 & 0,453 & $-0,099$ \\
\hline FCS67 & CCS & $-0,435$ & $-0,120$ & $-0,293$ & 0,276 & 0,601 & 0,690 & 0,427 & 0,517 & $-0,039$ & $-0,147$ & 0,049 & $-0,492$ \\
\hline FCS68 & CCS & $-0,324$ & $-0,117$ & $-0,338$ & 0,012 & 0,293 & 0,260 & $-0,105$ & 0,311 & 0,083 & 0,243 & 0,479 & $-0,042$ \\
\hline
\end{tabular}




\begin{tabular}{|c|c|c|c|c|c|c|c|c|c|c|c|c|c|}
\hline & & FCS37 & FCS38 & FCS39 & FCS40 & FCS41 & FCS42 & FCS43 & FCS44 & FCS45 & FCS46 & FCS47 & FCS48 \\
\hline FCS52 & CCS & 0,551 & 0,348 & $-0,396$ & 0,081 & 0,585 & 0,579 & 0,055 & $-0,287$ & 0,106 & 0,270 & 0,610 & 0,092 \\
\hline FCS53 & CCS & $-0,075$ & $-0,176$ & 0,389 & 0,126 & $-0,482$ & $-0,501$ & $-0,111$ & 0,123 & 0,086 & 0,068 & $-0,216$ & $-0,102$ \\
\hline FCS54 & $\mathrm{CCS}$ & $-0,023$ & $-0,153$ & 0,100 & 0,525 & 0,233 & 0,549 & 0,668 & 0,020 & $-0,015$ & 0,282 & 0,639 & 0,225 \\
\hline FCS55 & CCS & 0,162 & 0,004 & $-0,017$ & 0,484 & 0,037 & 0,484 & 0,484 & $-0,298$ & 0,098 & 0,107 & 0,759 & 0,094 \\
\hline FCS56 & $\mathrm{CCS}$ & $-0,071$ & 0,288 & 0,420 & 0,295 & 0,156 & 0,211 & 0,585 & 0,182 & $-0,032$ & $-0,076$ & 0,251 & 0,344 \\
\hline FCS57 & $\mathrm{CCS}$ & 0,271 & 0,058 & 0,577 & 0,617 & 0,046 & 0,227 & 0,633 & 0,432 & $-0,026$ & 0,532 & $-0,028$ & 0,143 \\
\hline FCS58 & CCS & 0,246 & 0,122 & 0,579 & 0,321 & 0,091 & 0,209 & 0,533 & 0,171 & $-0,089$ & $-0,034$ & 0,114 & 0,227 \\
\hline FCS59 & CCS & 0,159 & 0,095 & 0,670 & 0,343 & $-0,033$ & 0,132 & 0,599 & 0,221 & $-0,138$ & $-0,054$ & $-0,035$ & 0,144 \\
\hline FCS60 & $\mathrm{CCS}$ & 0,135 & $-0,156$ & 0,140 & 0,246 & 0,545 & 0,339 & 0,295 & 0,106 & 0,109 & 0,655 & 0,448 & $-0,099$ \\
\hline FCS61 & $\mathrm{CCS}$ & $-0,031$ & 0,286 & 0,221 & $-0,039$ & 0,085 & $-0,490$ & 0,000 & $-0,027$ & $-0,065$ & $-0,041$ & $-0,332$ & $-0,271$ \\
\hline FCS62 & $\mathrm{CCS}$ & $-0,033$ & 0,269 & $-0,122$ & 0,249 & 0,145 & 0,318 & 0,559 & $-0,143$ & $-0,047$ & 0,010 & 0,480 & 0,322 \\
\hline FCS63 & $\mathrm{CCS}$ & 0,179 & 0,084 & $-0,011$ & 0,447 & 0,151 & 0,515 & 0,312 & 0,209 & 0,408 & $-0,018$ & 0,593 & 0,413 \\
\hline FCS64 & $\mathrm{CCS}$ & 0,022 & 0,188 & $-0,329$ & 0,246 & 0,139 & 0,224 & 0,114 & $-0,199$ & 0,389 & $-0,099$ & 0,702 & 0,297 \\
\hline FCS65 & $\mathrm{CCS}$ & $-0,291$ & $-0,239$ & 0,231 & 0,213 & $-0,126$ & $-0,050$ & 0,321 & $-0,485$ & $-0,314$ & $-0,082$ & 0,009 & 0,086 \\
\hline FCS66 & CCS & 0,197 & 0,113 & 0,063 & 0,599 & 0,211 & 0,451 & 0,584 & $-0,289$ & 0,139 & 0,259 & 0,601 & 0,215 \\
\hline FCS67 & $\mathrm{CCS}$ & $-0,089$ & 0,199 & $-0,547$ & $-0,360$ & 0,287 & 0,260 & $-0,071$ & $-0,222$ & 0,194 & $-0,228$ & 0,610 & 0,037 \\
\hline FCS68 & $\mathrm{CCS}$ & 0,233 & 0,028 & $-0,335$ & 0,080 & 0,559 & 0,774 & 0,344 & 0,034 & $-0,020$ & 0,195 & 0,742 & 0,014 \\
\hline
\end{tabular}




\begin{tabular}{|c|c|c|c|c|c|c|c|c|c|c|c|}
\hline & & FCS49 & FCS50 & FCS51 & FCS52 & FCS53 & FCS54 & FCS55 & FCS56 & FCS57 & FCS58 \\
\hline FCS52 & CCS & $-0,544$ & 0,196 & 0,648 & 1,000 & $-0,549$ & 0,417 & 0,377 & 0,227 & 0,010 & 0,388 \\
\hline FCS53 & $\mathrm{CCS}$ & 0,553 & $-0,194$ & $-0,164$ & $-0,549$ & 1,000 & $-0,318$ & 0,009 & $-0,199$ & 0,300 & $-0,184$ \\
\hline FCS54 & CCS & $-0,244$ & 0,162 & 0,132 & 0,417 & $-0,318$ & 1,000 & 0,509 & 0,711 & 0,271 & 0,510 \\
\hline FCS55 & $\mathrm{CCS}$ & $-0,538$ & 0,241 & 0,176 & 0,377 & 0,009 & 0,509 & 1,000 & 0,195 & 0,272 & 0,254 \\
\hline FCS56 & $\mathrm{CCS}$ & $-0,133$ & 0,036 & $-0,032$ & 0,227 & $-0,199$ & 0,711 & 0,195 & 1,000 & 0,387 & 0,739 \\
\hline FCS57 & CCS & $-0,238$ & 0,208 & $-0,490$ & 0,010 & 0,300 & 0,271 & 0,272 & 0,387 & 1,000 & 0,535 \\
\hline FCS58 & CCS & $-0,431$ & $-0,092$ & $-0,014$ & 0,388 & $-0,184$ & 0,510 & 0,254 & 0,739 & 0,535 & 1,000 \\
\hline FCS59 & $\mathrm{CCS}$ & $-0,509$ & $-0,122$ & $-0,355$ & 0,065 & 0,016 & 0,220 & 0,339 & 0,506 & 0,684 & 0,838 \\
\hline FCS60 & CCS & $-0,245$ & $-0,040$ & 0,116 & 0,479 & $-0,103$ & 0,596 & 0,194 & 0,386 & 0,509 & 0,409 \\
\hline FCS61 & CCS & 0,312 & $-0,040$ & $-0,355$ & $-0,210$ & 0,113 & $-0,205$ & $-0,440$ & 0,103 & 0,075 & 0,129 \\
\hline FCS62 & $\mathrm{CCS}$ & $-0,159$ & 0,246 & 0,116 & 0,433 & $-0,478$ & 0,698 & 0,315 & 0,594 & $-0,008$ & 0,444 \\
\hline FCS63 & $\mathrm{CCS}$ & $-0,095$ & 0,193 & 0,372 & 0,369 & $-0,138$ & 0,622 & 0,566 & 0,462 & 0,110 & 0,232 \\
\hline FCS64 & CCS & 0,221 & $-0,036$ & 0,536 & 0,264 & 0,073 & 0,403 & 0,506 & 0,226 & $-0,257$ & $-0,062$ \\
\hline FCS65 & $\mathrm{CCS}$ & $-0,443$ & $-0,027$ & $-0,291$ & $-0,036$ & $-0,161$ & 0,235 & 0,184 & 0,219 & 0,060 & 0,352 \\
\hline FCS66 & $\mathrm{CCS}$ & $-0,675$ & 0,505 & $-0,046$ & 0,558 & $-0,331$ & 0,628 & 0,746 & 0,360 & 0,393 & 0,484 \\
\hline FCS67 & $\mathrm{CCS}$ & $-0,128$ & $-0,365$ & 0,506 & 0,250 & $-0,203$ & $-0,004$ & 0,423 & $-0,141$ & $-0,432$ & $-0,212$ \\
\hline FCS68 & CCS & $-0,397$ & $-0,108$ & 0,529 & 0,681 & $-0,581$ & 0,685 & 0,474 & 0,380 & $-0,034$ & 0,318 \\
\hline
\end{tabular}




\begin{tabular}{|c|c|c|c|c|c|c|c|c|c|c|c|}
\hline & & FCS59 & FCS60 & FCS61 & FCS62 & FCS63 & FCS64 & FCS65 & FCS66 & FCS67 & FCS68 \\
\hline FCS52 & CCS & 0,065 & 0,479 & $-0,210$ & 0,433 & 0,369 & 0,264 & $-0,036$ & 0,558 & 0,250 & 0,681 \\
\hline FCS53 & CCS & 0,016 & $-0,103$ & 0,113 & $-0,478$ & $-0,138$ & 0,073 & $-0,161$ & $-0,331$ & $-0,203$ & $-0,581$ \\
\hline FCS54 & CCS & 0,220 & 0,596 & $-0,205$ & 0,698 & 0,622 & 0,403 & 0,235 & 0,628 & $-0,004$ & 0,685 \\
\hline FCS55 & CCS & 0,339 & 0,194 & $-0,440$ & 0,315 & 0,566 & 0,506 & 0,184 & 0,746 & 0,423 & 0,474 \\
\hline FCS56 & CCS & 0,506 & 0,386 & 0,103 & 0,594 & 0,462 & 0,226 & 0,219 & 0,360 & $-0,141$ & 0,380 \\
\hline FCS57 & CCS & 0,684 & 0,509 & 0,075 & $-0,008$ & 0,110 & $-0,257$ & 0,060 & 0,393 & $-0,432$ & $-0,034$ \\
\hline FCS58 & CCS & 0,838 & 0,409 & 0,129 & 0,444 & 0,232 & $-0,062$ & 0,352 & 0,484 & $-0,212$ & 0,318 \\
\hline FCS59 & CCS & 1,000 & 0,203 & 0,098 & 0,150 & 0,034 & $-0,247$ & 0,405 & 0,409 & $-0,127$ & 0,093 \\
\hline FCS60 & CCS & 0,203 & 1,000 & $-0,025$ & 0,174 & 0,172 & $-0,074$ & $-0,018$ & 0,363 & $-0,148$ & 0,524 \\
\hline FCS61 & CCS & 0,098 & $-0,025$ & 1,000 & 0,203 & $-0,376$ & $-0,141$ & $-0,094$ & $-0,049$ & $-0,321$ & $-0,405$ \\
\hline FCS62 & $\mathrm{CCS}$ & 0,150 & 0,174 & 0,203 & 1,000 & 0,397 & 0,446 & 0,162 & 0,634 & 0,150 & 0,466 \\
\hline FCS63 & $\mathrm{CCS}$ & 0,034 & 0,172 & $-0,376$ & 0,397 & 1,000 & 0,744 & $-0,318$ & 0,456 & 0,249 & 0,552 \\
\hline FCS64 & $\mathrm{CCS}$ & $-0,247$ & $-0,074$ & $-0,141$ & 0,446 & 0,744 & 1,000 & $-0,257$ & 0,278 & 0,519 & 0,372 \\
\hline FCS65 & $\mathrm{CCS}$ & 0,405 & $-0,018$ & $-0,094$ & 0,162 & $-0,318$ & $-0,257$ & 1,000 & 0,274 & $-0,198$ & $-0,073$ \\
\hline FCS66 & $\mathrm{CCS}$ & 0,409 & 0,363 & $-0,049$ & 0,634 & 0,456 & 0,278 & 0,274 & 1,000 & 0,034 & 0,400 \\
\hline FCS67 & CCS & $-0,127$ & $-0,148$ & $-0,321$ & 0,150 & 0,249 & 0,519 & $-0,198$ & 0,034 & 1,000 & 0,528 \\
\hline FCS68 & CCS & 0,093 & 0,524 & $-0,405$ & 0,466 & 0,552 & 0,372 & $-0,073$ & 0,400 & 0,528 & 1,000 \\
\hline
\end{tabular}


APÊNDICE D - PRINCIPAIS TIPOS DE EMBARCAÇÕES DE APOIO MARÍTIMO

AHTS - Anchor Handling Tug Supply

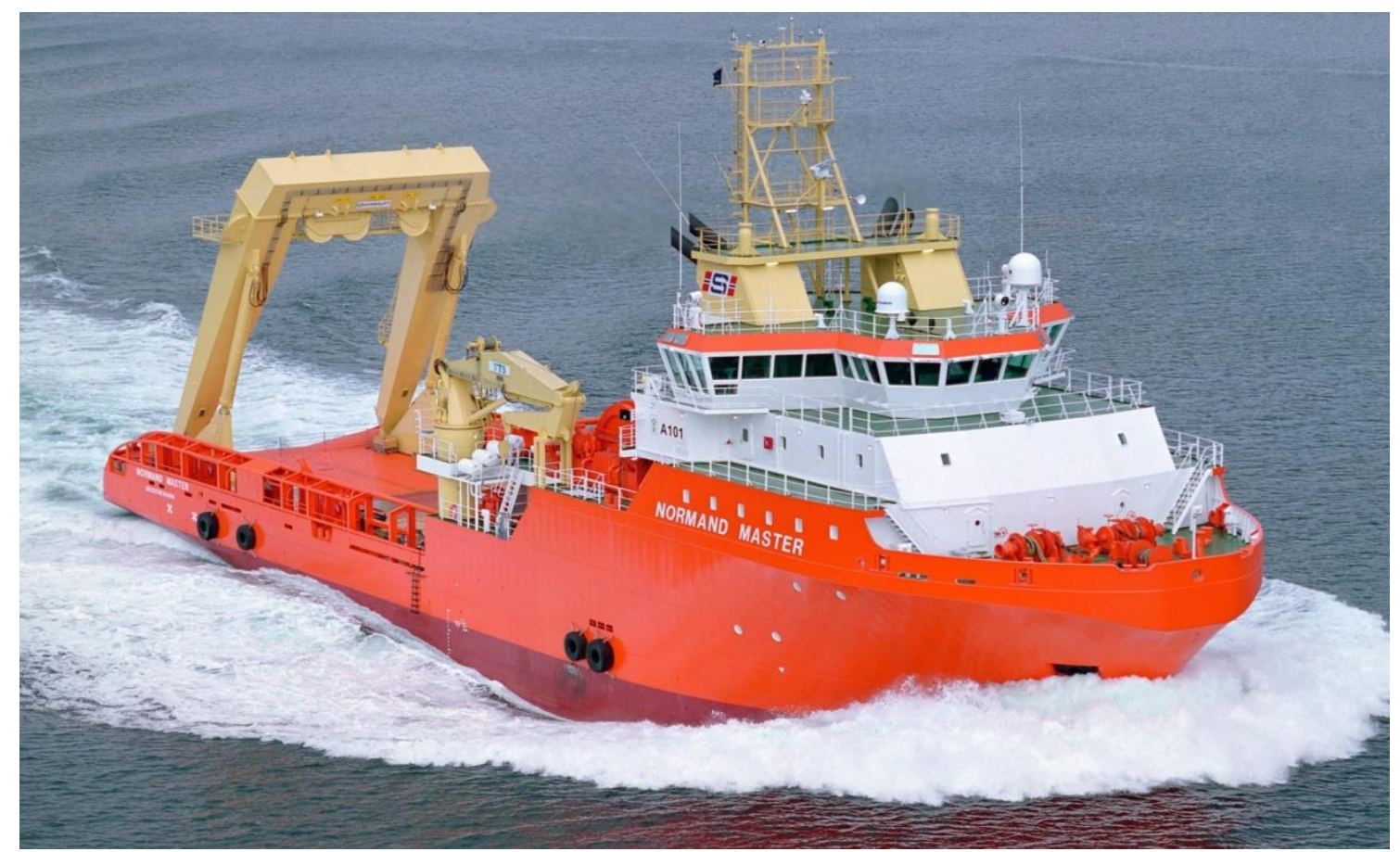

https://solstad.no/blog/fleet/normand-master/

\section{PSV - Platform Supply Vessel}

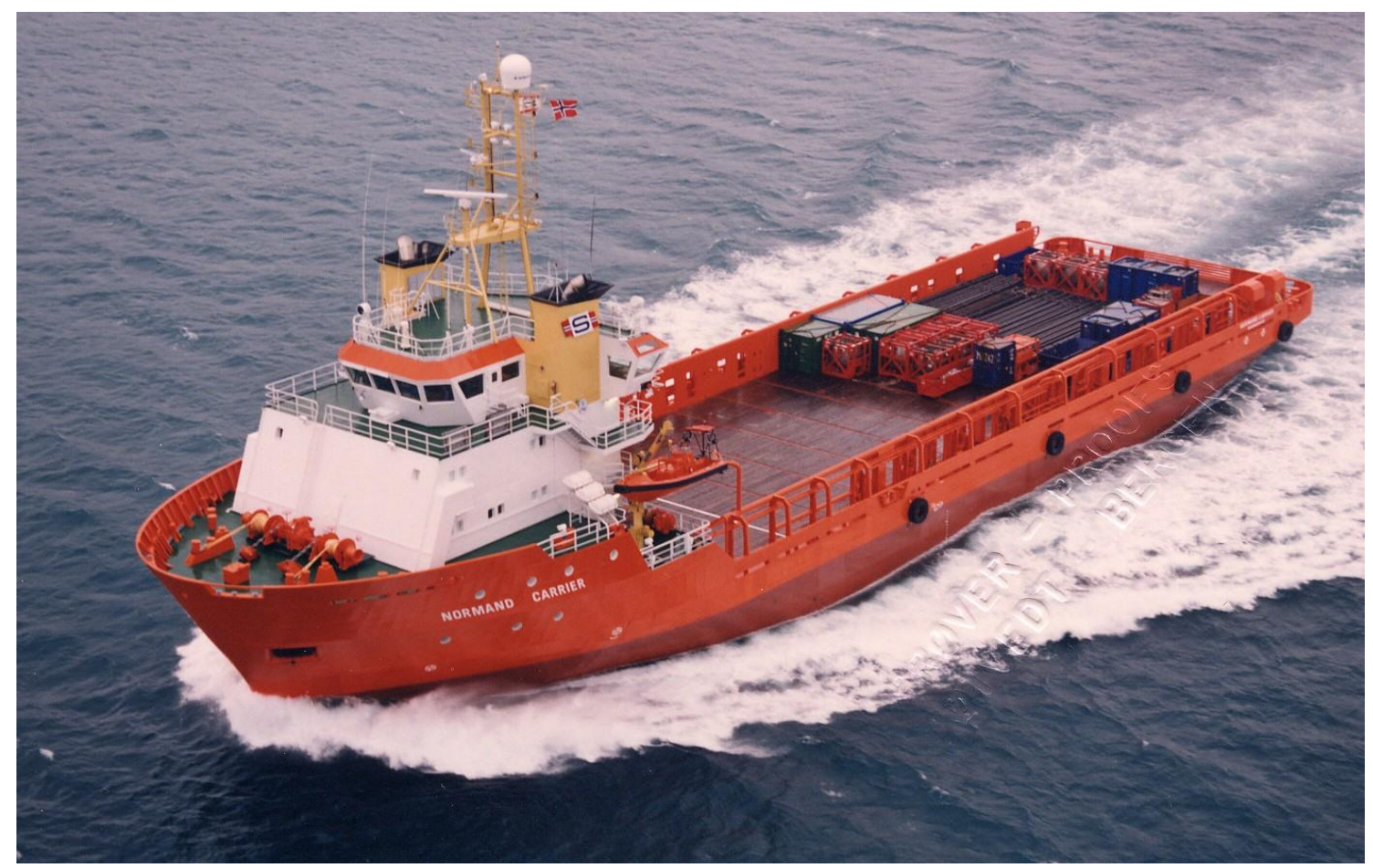

https://solstad.no/blog/fleet/normand-carrier/ 


\section{SV - Mini Supply Vessel}

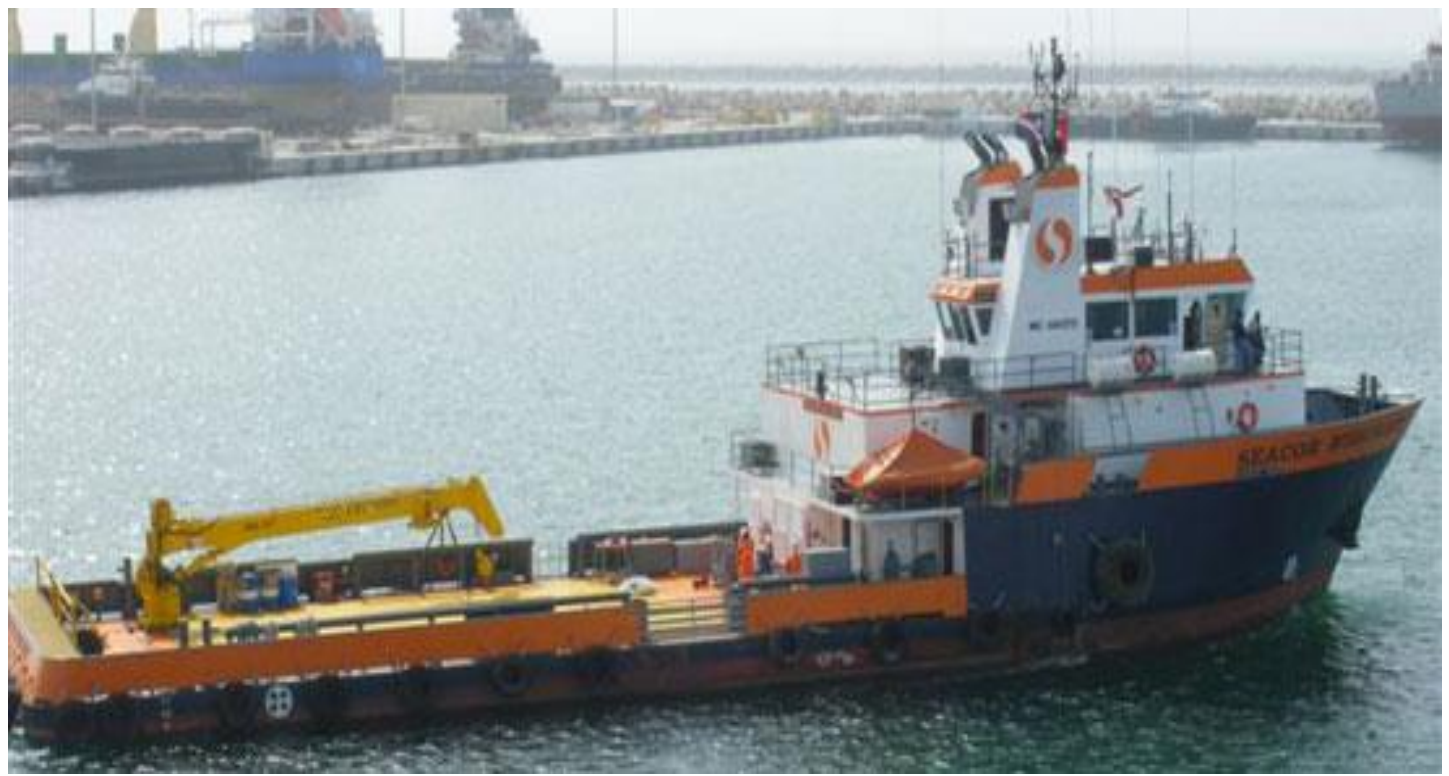

https://www.seacormarine.com/cgi-bin/ourfleet.cgi?type=ms

\section{FSV - Fast Supply Vessel}

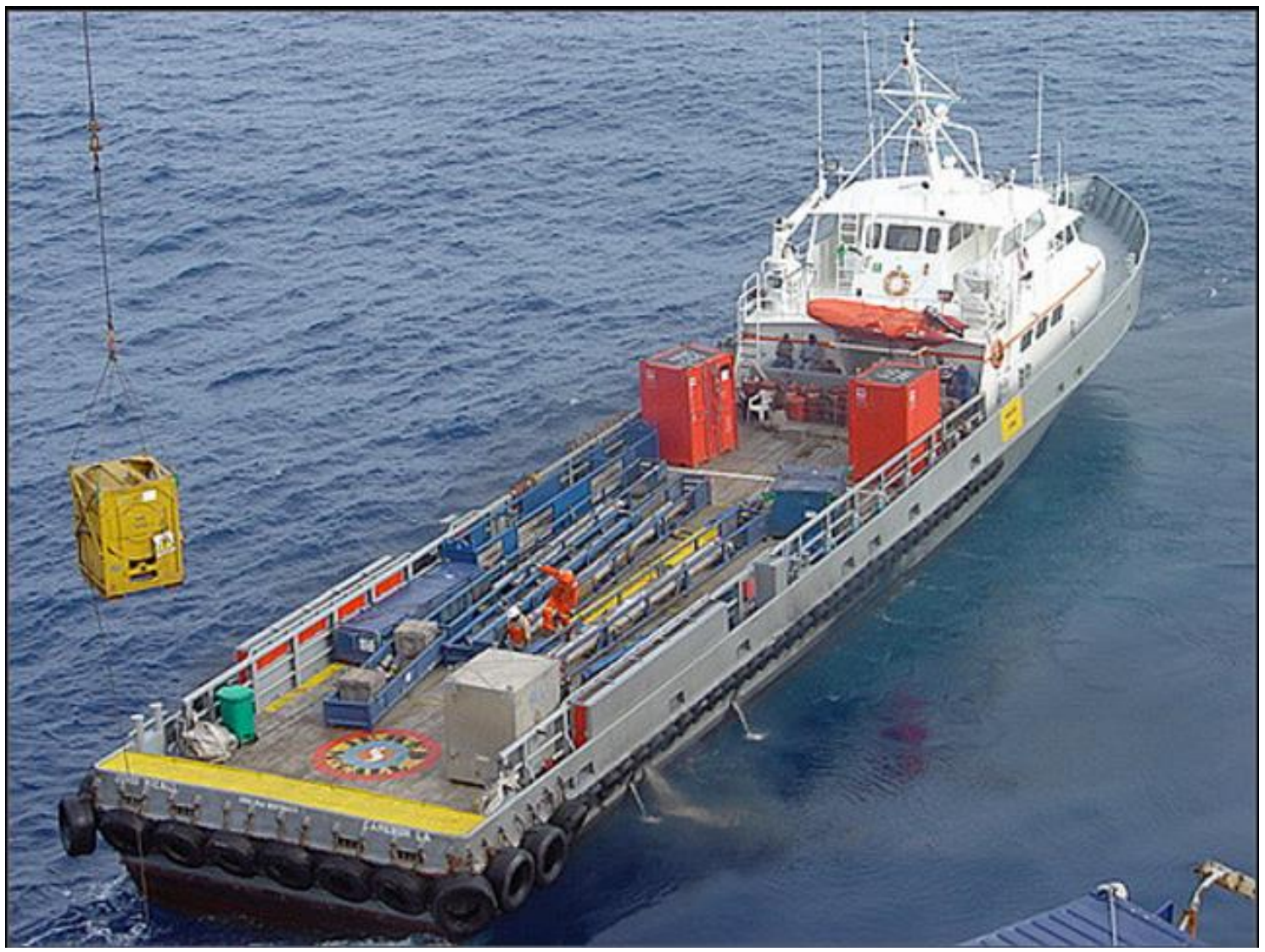

http://www.flickriver.com/photos/royluck/2203052865/ 


\section{Crewboat}

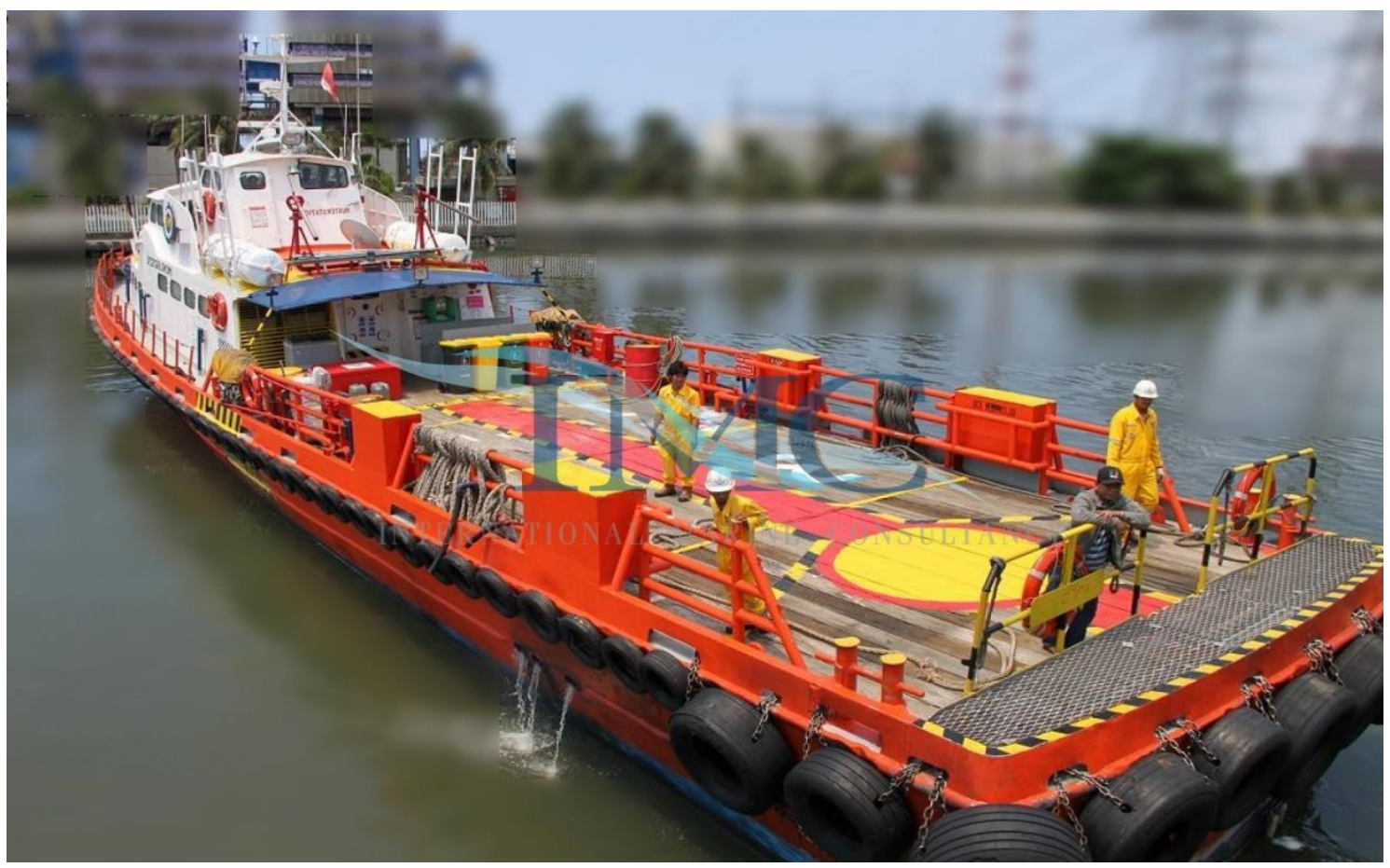

http://www.imcbrokers.com/vessels/search/detail/33m-60pax-offshore-crewboat

\section{LH - Line handling}

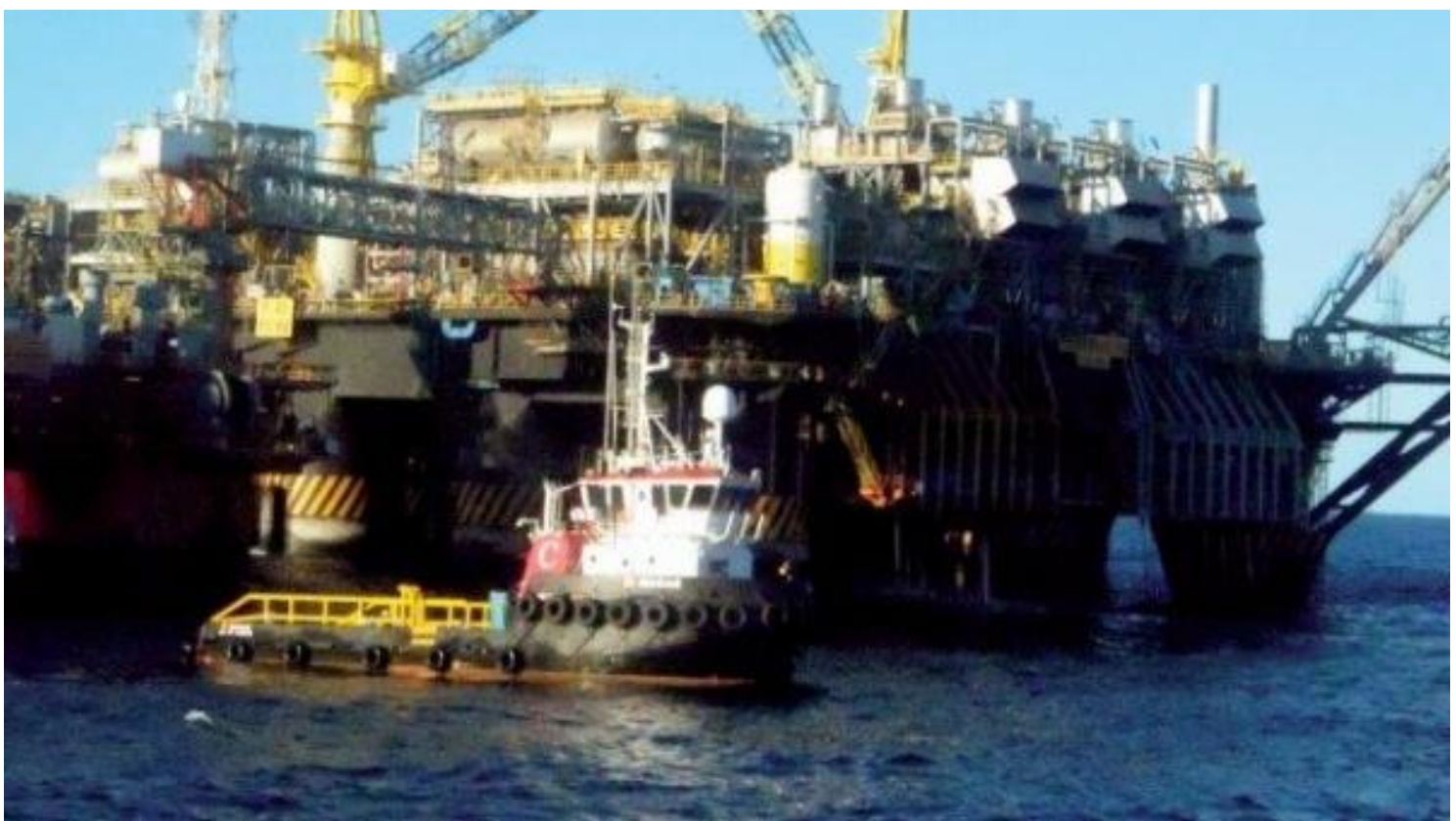

http://www.camorim.com.br/frota/index.php?option=com_k2\&view=item\&id=196\&itemid=3 25 


\section{OSRV - Oil Spill Recovery Vessel}

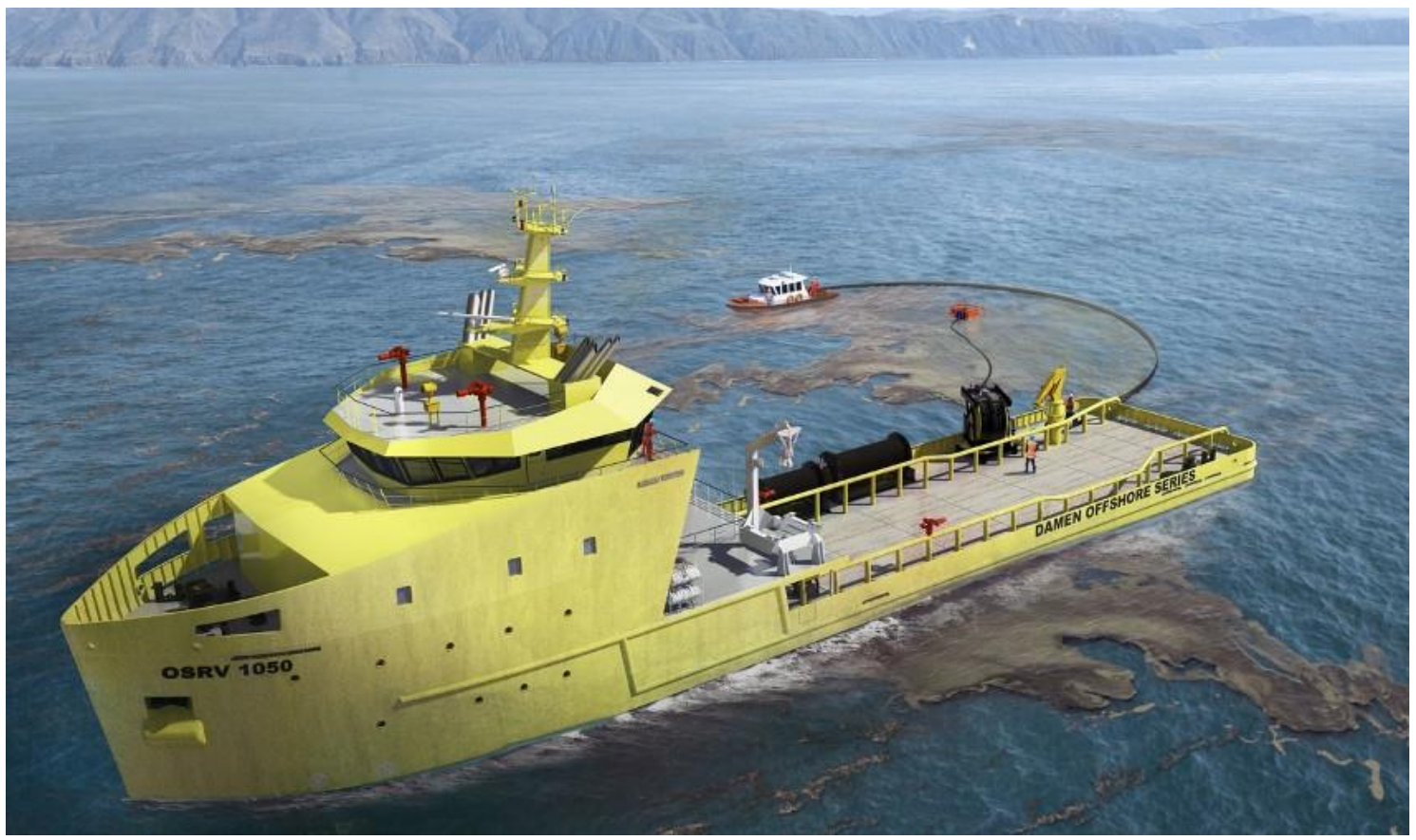

http://www.navioseportos.com.br/site/index.php/glossarios/glossarios/osrv

\section{RSV - Rov Support Vessel}

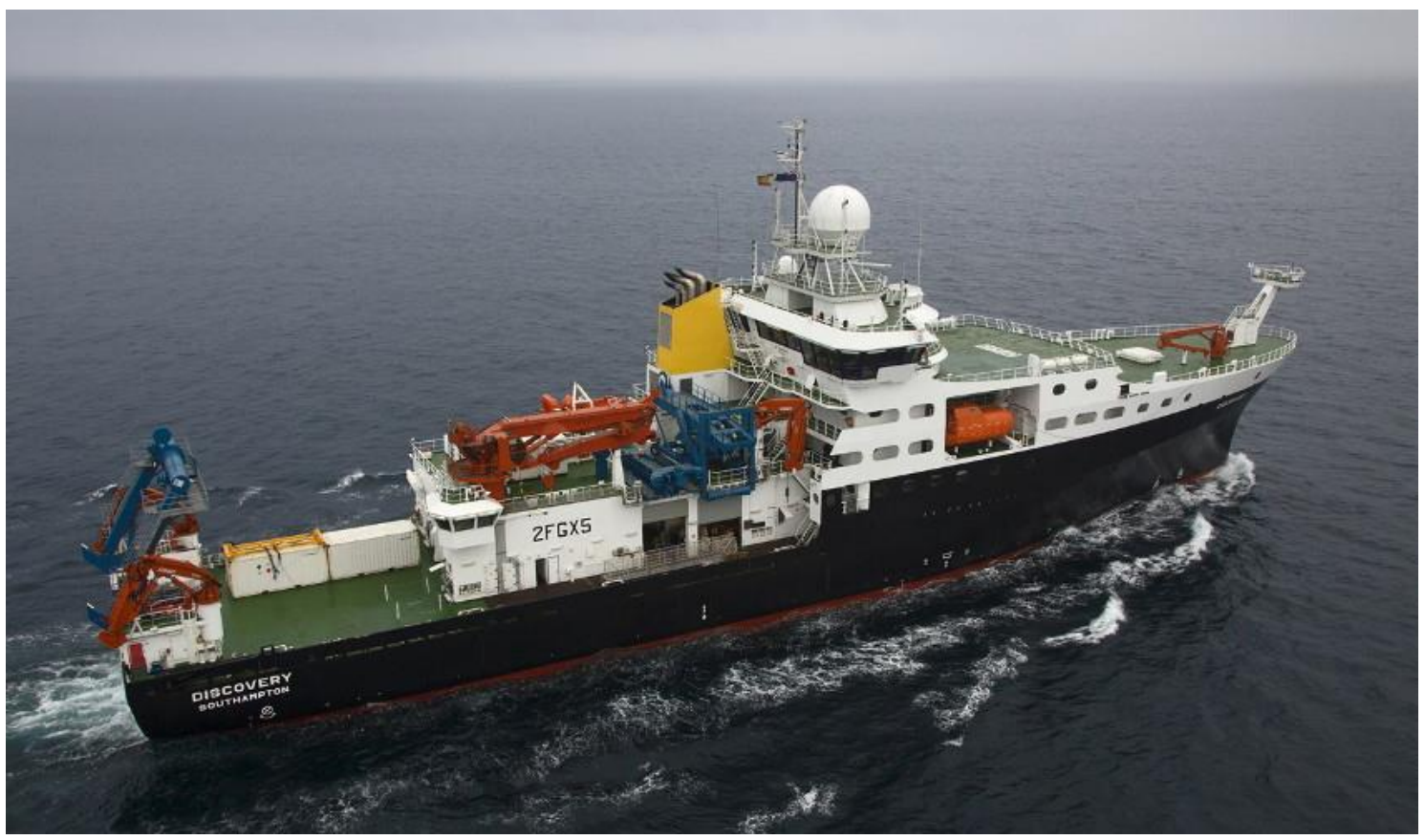

http://www.navioseportos.com.br/site/index.php/glossarios/glossarios/rsv 
DSV - Diving Support Vessel

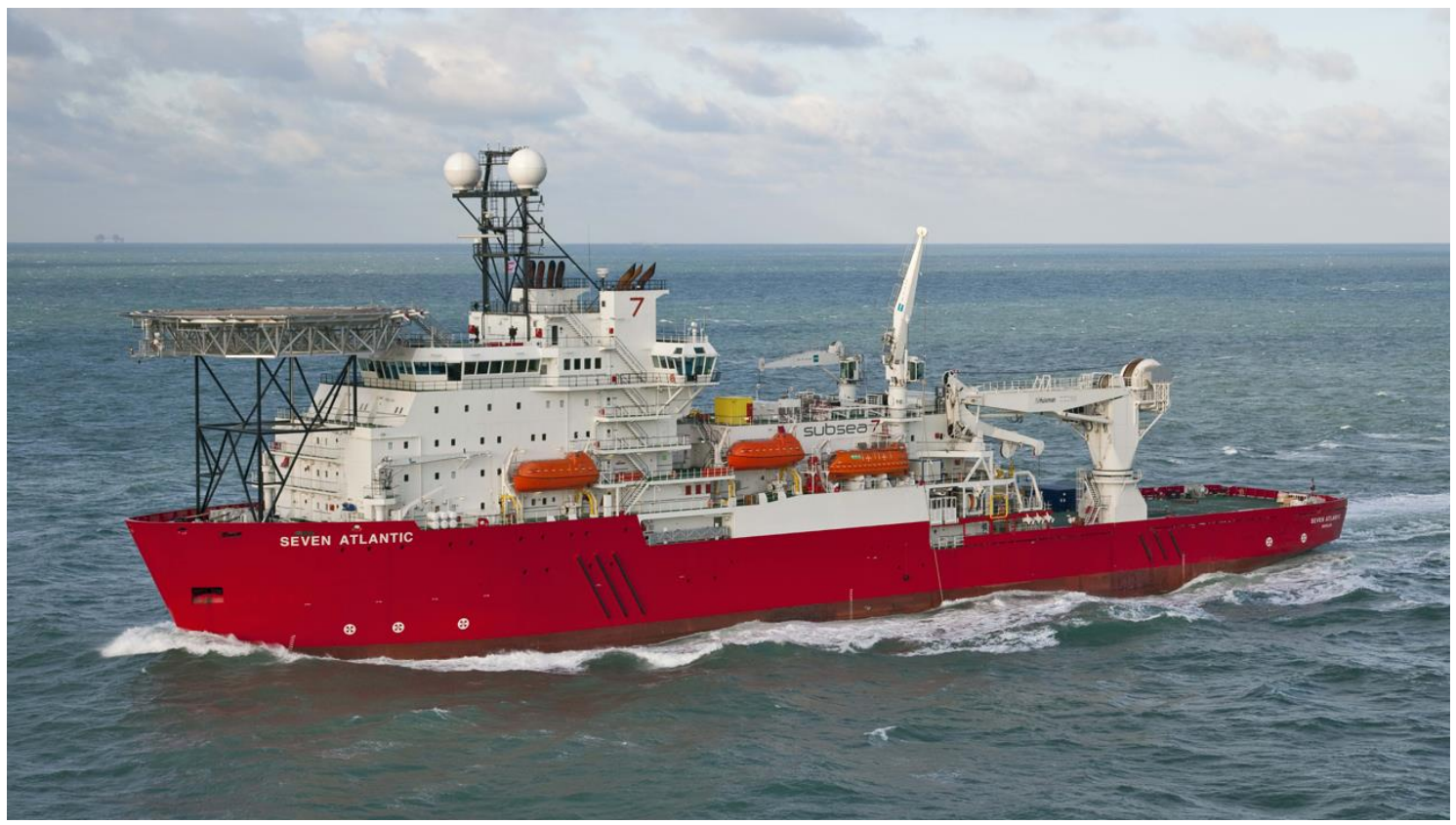

https://www.royalihc.com/en/products/offshore/offshore-support/diving-support-vessels

\section{WSV - Well Stimulation Vessel}

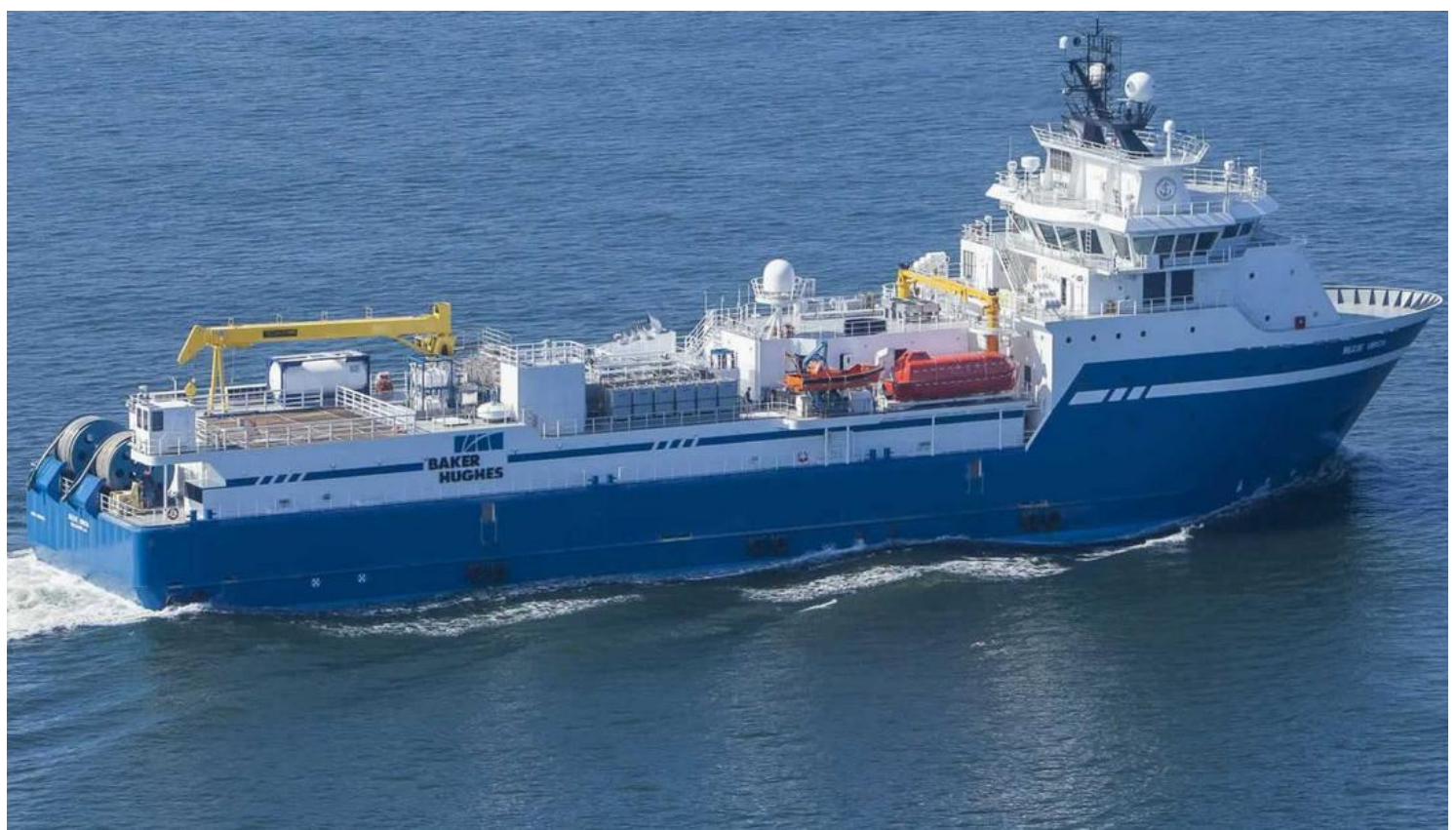

http://worldmaritimenews.com/wp-content/uploads/2013/10/Blue-Orca-stimulation-vessel.jpg 


\section{PLSV - Pipe Laying Support Vessel}

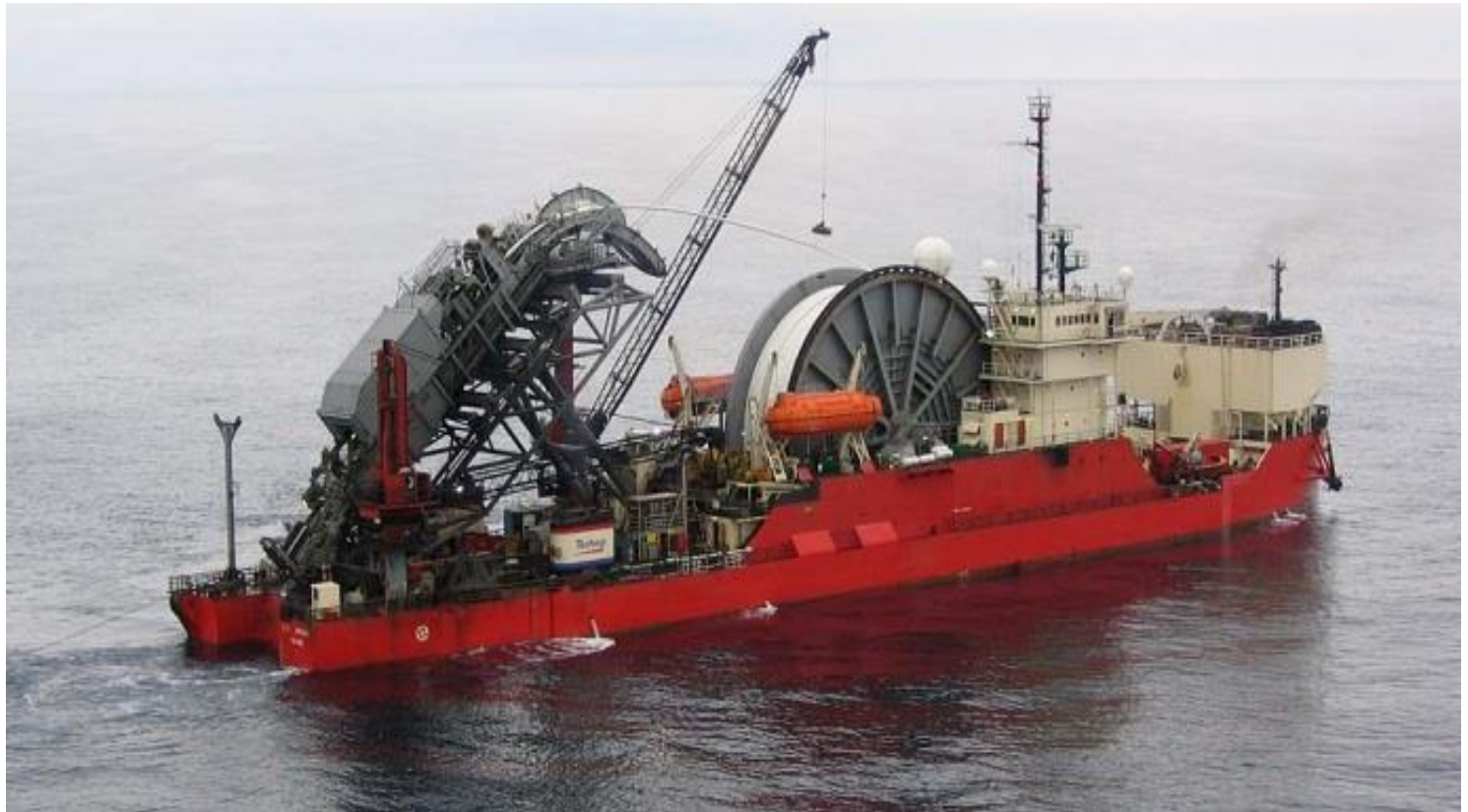

http://maritime-connector.com/wiki/Specialised-vessels/

\section{MPSV - Multi-Purpose Support Vessel}

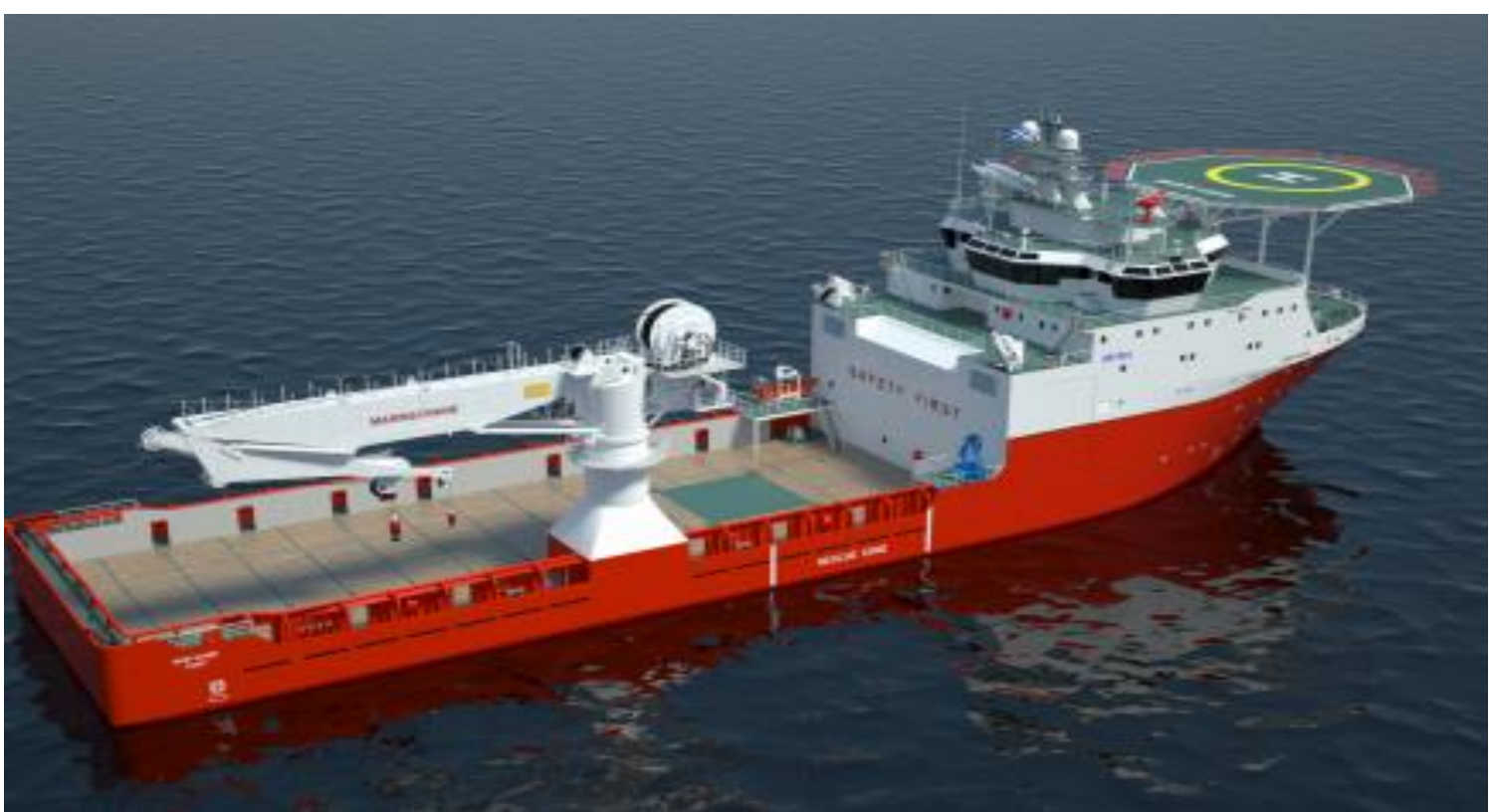

http://www.offshoreshipdesigners.com/offshore-vessel-design/special-offshorevessels/imt993-multi-purose-support-vessel/ 